\title{
Body Composition, Physical Activity and Quality of Life in end-stage renal disease patients
}

Citation for published version (APA):

Broers, N. J. H. (2016). Body Composition, Physical Activity and Quality of Life in end-stage renal disease patients: a phenotypical approach. [Doctoral Thesis, Maastricht University]. Proefschriftmaken.nl II Uitgeverij BOXPress. https://doi.org/10.26481/dis.20161103nb

Document status and date:

Published: 01/01/2016

DOI:

10.26481/dis.20161103nb

Document Version:

Publisher's PDF, also known as Version of record

\section{Please check the document version of this publication:}

- A submitted manuscript is the version of the article upon submission and before peer-review. There can be important differences between the submitted version and the official published version of record.

People interested in the research are advised to contact the author for the final version of the publication, or visit the DOI to the publisher's website.

- The final author version and the galley proof are versions of the publication after peer review.

- The final published version features the final layout of the paper including the volume, issue and page numbers.

Link to publication

\footnotetext{
General rights rights.

- You may freely distribute the URL identifying the publication in the public portal. please follow below link for the End User Agreement:

www.umlib.nl/taverne-license

Take down policy

If you believe that this document breaches copyright please contact us at:

repository@maastrichtuniversity.nl

providing details and we will investigate your claim.
}

Copyright and moral rights for the publications made accessible in the public portal are retained by the authors and/or other copyright owners and it is a condition of accessing publications that users recognise and abide by the legal requirements associated with these

- Users may download and print one copy of any publication from the public portal for the purpose of private study or research.

- You may not further distribute the material or use it for any profit-making activity or commercial gain

If the publication is distributed under the terms of Article $25 \mathrm{fa}$ of the Dutch Copyright Act, indicated by the "Taverne" license above, 


\section{Body Composition, Physical Activity and Quality of Life in end-stage renal disease patients: a phenotypical approach}

Natascha Juliana Hendrika Broers 
(C) Copyright Natascha JH Broers, Maastricht 2016

Layout: Natascha Broers / Proefschriftmaken.nl

Cover: Helo Birdie Art by Joanne Ho (Swimming Pool Series - 'kidney shaped pool')

Printed by: Proefschriftmaken.nl

ISBN: 978-94-6295-516-5

Printing of this thesis was financially supported by an unrestricted grant from Fresenius Medical Care 


\title{
Body Composition, Physical Activity and Quality of Life in end-stage renal disease patients: a phenotypical approach
}

\author{
PROEFSCHRIFT
}

Ter verkrijging van de graad van doctor aan de Universiteit van Maastricht, op gezag van de Rector Magnificus, Prof. dr. Rianne M. Letschert, volgens het besluit van het College van Decanen, in het openbaar te verdedigen op donderdag 3 november 2016, om 14.00 uur.

door

Natascha Juliana Hendrika Broers 


\section{Promotores}

Prof. dr. J.P. Kooman

Prof. dr. K.M.L. Leunissen

\section{Co-Promotores}

Dr. F.M. van der Sande

\section{Beoordelingscommissie}

Prof. dr. O. Bekers (voorzitter)

Prof. dr. C.A.J.M. Gaillard, Universitair Medisch Centrum Groningen

Prof. dr. L. van Loon

Dr. G. Plasqui

Prof. dr. P.M. ter Wee, VU Medisch Centrum Amsterdam 


\section{TABLE OF CONTENTS}

CHAPTER 1 General introduction and outline of the thesis

CHAPTER 2 The first year on haemodialysis: a critical transition

CHAPTER 3 Body composition in dialysis patients: a functional assessment of bioimpedance using different prediction models

CHAPTER 4 Physical activity in end-stage renal disease patients, a study in CKD-5 non-dialysis and dialysis patients including the transition period

CHAPTER 5 Season affects body composition and estimation of fluid overload in haemodialysis patients: variations in body composition; a survey from the European MONDO database

CHAPTER 6 Changes in health-related quality of life from in the transitional phase of stage 5 chronic kidney disease patients and associations with physical activity: a cross-sectional and longitudinal analysis

CHAPTER 7 Quality of life in dialysis patients: a retrospective cohort study

CHAPTER 8 General discussion and summary

Samenvatting

Valorisation addendum

Dankwoord

Curriculum vitae

List of publications 



\section{CHAPTER 1}

GENERAL INTRODUCTION AND OUTLINE OF THE THESIS 


\section{INTRODUCTION}

The kidneys are central organs in the homeostasis of the body. The kidney has regulatory, excretory, metabolic and endocrine functions. The first two are evidenced by the regulation of water, sodium, electrolyte and acid-base balance and the removal of uremic waste products of the body. Examples of the last two functions are the role of the kidney in vitamin D metabolism and erythropoietin production.

Chronic kidney disease (CKD) is very common in the population. It can result from a variety of mechanisms, the most frequent being generalized; atherosclerosis, diabetes mellitus, immunological and genetic disorders. CKD is subdivided into five stages, which are summarized in figure 1.1, where stages 1-3 are by far the most common, and are already associated with an increased risk of mortality. The burden of disease and health care costs per patient are by far the greatest in CKD stage 5 (CKD-5), also called end-stage renal disease (ESRD). During this stage, the patient is generally prepared for renal replacement therapy, which can be grossly divided into renal transplantation and dialysis therapy.

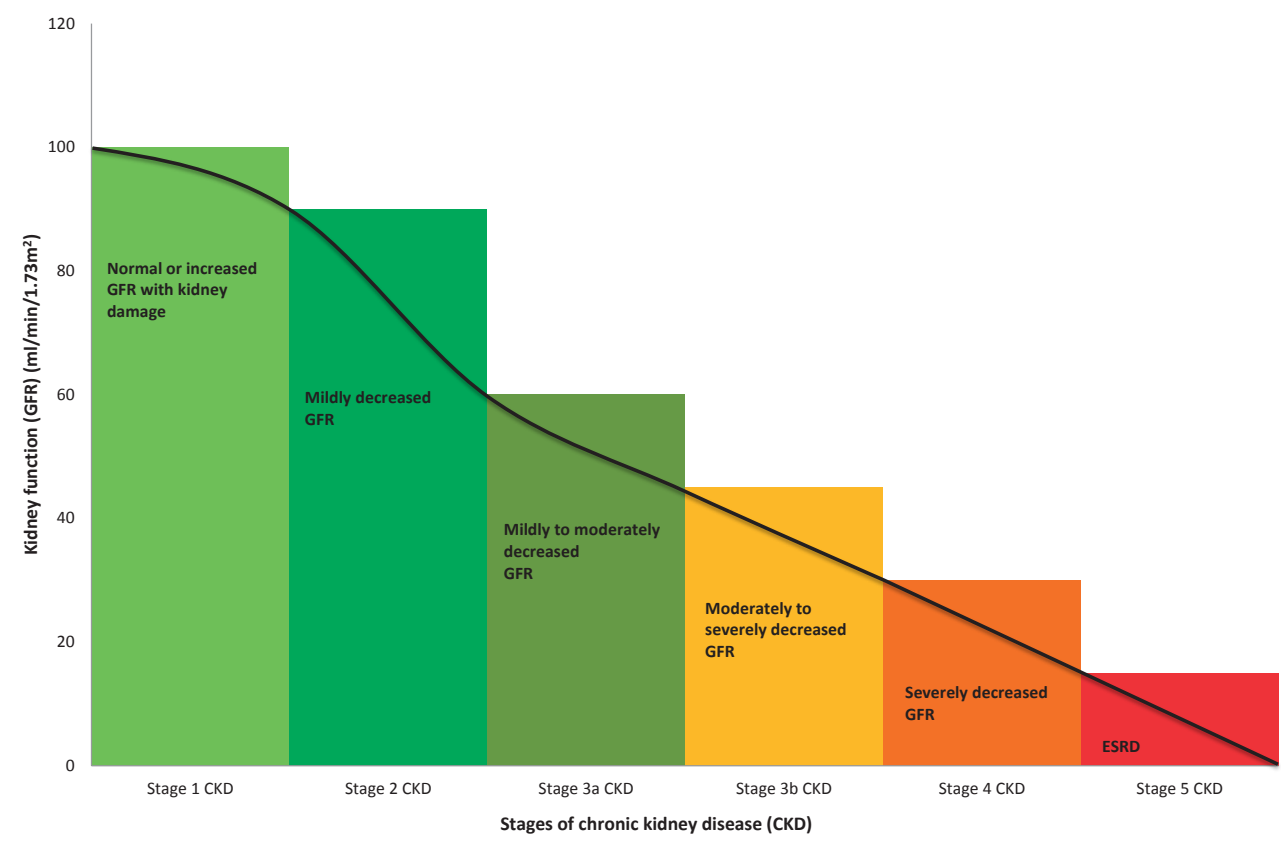

Figure 1.1 Stages of chronic kidney disease (CKD) following the Kidney Disease Outcomes Quality Initiative (KDOQI) Guidelines, from the National Kidney Foundation.

Dialysis is a life-saving treatment for patients with ESRD. In 2013, an estimated 2.522.000 patients were treated with chronic dialysis treatment ${ }^{1}$. The most commonly used chronic dialysis techniques are hemodialysis (HD) (figure 1.2) and peritoneal dialysis (PD) (figure 1.3). During HD, uremic toxins are removed and acid-base and electrolyte abnormalities are corrected by diffusion between blood and dialysis fluid, which are separated by a semipermeable membrane, whereas fluid is removed by convection by application of a 
trans-membranous pressure gradient between the blood and dialysate compartment. $\mathrm{HD}$ is performed intermittently. Although the most common treatment schedule is three times per week four hours, various observational and intervention studies have suggested beneficial effects of more prolonged and/or more frequent treatment schedules ${ }^{2}$.

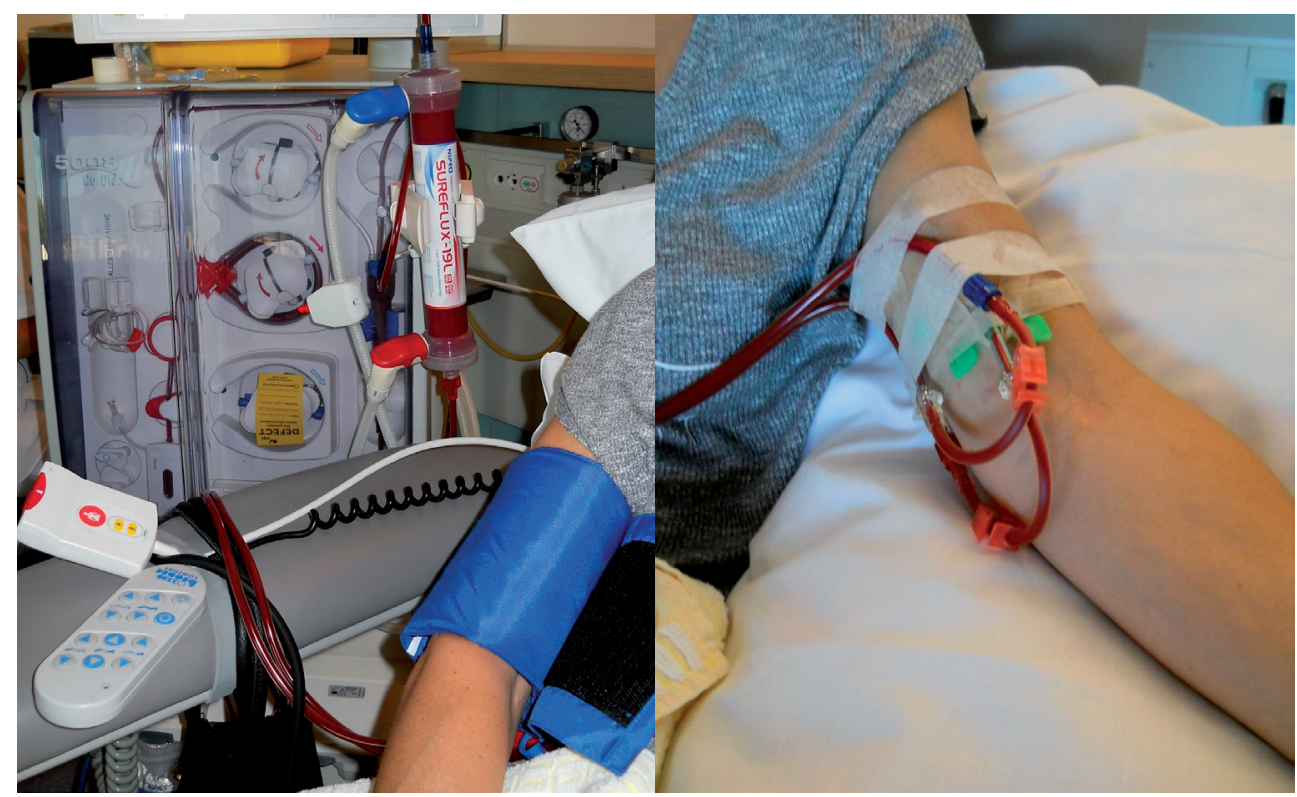

Figure 1.2 Hemodialysis.

PD is performed more continuously, in which the blood is cleaned by diffusion between the peritoneal capillaries and a sterile dialysis fluid which is installed and removed 4-5 times daily in the peritoneal cavity through a catheter, whereas excess fluid is removed by an osmotic gradient evoked by a hypertonic concentration in the dialysis fluid. 


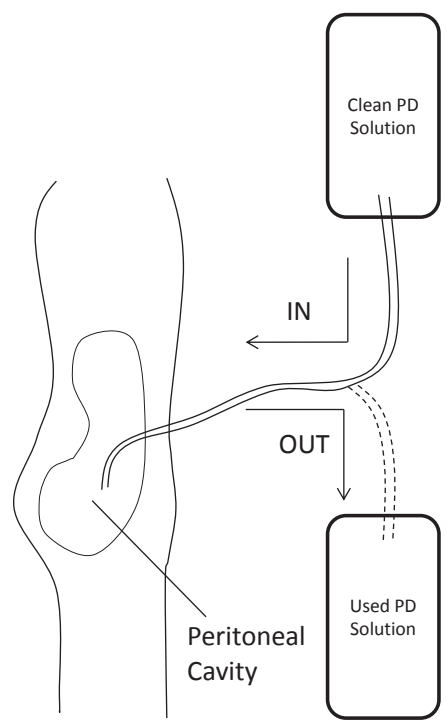

Figure 1.3 Peritoneal Dialysis.

Although dialysis is a life-saving treatment for ESRD patients, it has been shown that in the first 90-120 days after initiation of dialysis therapy the risk for mortality is high $\mathrm{h}^{3-5}$, and that approximately 35 percent of all deaths in the first year occur in the first 90 days after the start of dialysis ${ }^{3}$. In the critical period from the CKD-5 non-dialysis phase into the first year after the initiation of dialysis treatment many critical pathophysiological and psychological consequences can occur. Despite the pronounced effects on the physiology of the patient, relatively few studies have looked into detailed phenotypic changes following the start of dialysis. Of these, cardiovascular and nutritional parameters, which are strong predictors of outcome, appear to have specific relevance.

Chapter 2 provides a general literature overview on phenotypical changes, with special attention for cardiovascular and nutritional parameters during the first year of dialysis treatment.

Despite the benefits of dialysis, the morbidity and mortality of ESRD treated with HD and PD is still very high. The most common causes of death in this population are cardiovascular or infectious $s^{6,7}$. Whereas various risk factors for adverse outcome have been identified in dialysis patients, it has been consistently shown that nutritional parameters are one of the strongest predictors of mortality in this population ${ }^{8,9}$.

The prevalence of protein-energy wasting (PEW), which has a strong multifactorial cause, in patients with ESRD is high ${ }^{10}$. PEW is defined as a "simultaneous loss of systematic protein and energy stores, leading ultimately to loss of muscle and fat mass (FM) and cachexia"10,11. There are various diagnostic criteria for the diagnosis of PEW in dialysis patients such as 
biochemical markers (low serum albumin), reduced body mass (such as declining weight, and low dietary intake) and a reduction in muscle tissue ${ }^{11}$.

Also assessment of body composition (BC) is of relevance in the diagnosis of nutritional disorders in ESRD patients. An advantage of the assessment of $\mathrm{BC}$, next to body weight or body mass index (BMI), is that both lean tissue mass (LTM) (including muscle) and FM can be analyzed separately. This is of importance given the high prevalence of so-called sarcopenic obesity (combination of low muscle mass/LTM and high FM) in patients with CKD ${ }^{12}$, in which $\mathrm{BMI}$ does not give an adequate indication of $\mathrm{BC}^{13}$.

For the assessment of BC, different methodologies, from highly advanced ones, such as neutron activation analysis to anthropometric bedside methods are available. Methods such as computed tomography (CT), magnetic resonance imaging (MRI) and dual energy x-ray absorptiometry (DEXA) are useful, but not easy to implement routinely in clinical practice ${ }^{14}$. Bioimpedance analysis (BIA) is an operator independent and easily applicable technique, which can be used at bedside or during outpatient visits. In the European Best Practice Guidelines, BIA is endorsed as one of the techniques which can provide useful information on $\mathrm{BC}$ in dialysis patients ${ }^{15}$. Both single- and multi-frequency (MF) analyzers have been used in patients with ESRD. An important caveat for the use of BIA in patients with abnormalities in fluid state, such as renal disease, is that conventional BIA equations are not able to correctly address the impact of fluid overload on the assessment for $\mathrm{BC}^{16,17}$. With bioimpedance spectroscopy (BIS), body compartments are not assessed directly, but calculated from the resistivity at a range of frequencies, which reflect intracellular and extracellular fluid compartments. A previous study by Konings et al. showed an important effect of extracellular overhydration on the estimation of lean body mass (LBM) by MF-BIA techniques ${ }^{18}$. Using novel equations based on a physiological model, assuming a constant hydration ratio for FM and LTM, Chamney et al. were able to construct a three compartment (3-C) model for BIS, which included overhydration (fluid overload) as a separate compartment ${ }^{19}$. However, a direct comparison between two compartment (2-C) and 3-C models in the estimation of BC in dialysis patients has not been performed yet.

Therefore, in chapter 3, the agreement between the 2-C and 3-C bioimpedance models in the assessment of $B C$ was assessed.

The pathophysiology of abnormalities in nutritional state and $B C$ in patients with ESRD is multifactorial. Important factors are: reduced appetite due to accumulation of uremic toxins, dietary restrictions, metabolic acidosis, comorbidities, lifestyle, and reduced physical activity $(P A)^{10}$. Many of these factors, but not all, are positively influenced by dialysis treatment. Nevertheless, dialysis may lead to a loss of nutrients in the dialysate and induce inflammation ${ }^{20-22}$. Whereas the start of dialysis was accompanied with an increase in serum albumin and an increase in protein intake ${ }^{23-26}$, reports on the effects of starting dialysis 
treatment on BC, or comparative studies between CKD-5 non-dialysis and dialysis patients are scarce.

The least specific parameter reflecting $B C$ is body weight. Changes in body weight after the start of dialysis can either reflect changes in hydration, LTM or FM. A single-centre study from Tassin in 363 incident dialysis patients showed that mean target (dry) body weight decreased by $6.5 \%$ in the first eight weeks after the start of dialysis, followed by an increase of $1.9 \%$ during week $8-52^{26}$. Changes in target body weight after eight weeks were positively related to protein intake (reflected by protein nitrogen appearance) and serum albumin, but inversely to C-reactive protein (CRP) at twelve weeks after the start of dialysis. Moreover, an increase in body weight between week 8 and 52 after the start of dialysis was predictive of survival. However, after one year of treatment, mean target body weight in the cohort was still approximately four kg lower than the weight at the start of dialysis. The initial decline in body weight is suggested to reflect a decrease in extracellular volume due to the removal of excess fluid by ultrafiltration, whereas the later increase is suggested to reflect an improvement in nutritional state, which would be supported by the relation between changes in body weight and biochemical nutritional parameters. In a study of Sipahioglu et al. mean pre-dialytic body weight decreased from $80.7 \mathrm{~kg}$ at baseline to $79.4 \mathrm{~kg}$ after three months, followed by a gradual increase to $80.7 \mathrm{~kg}$ at the end of the first year ${ }^{27}$. In contrast, a study, in 142 incident HD patients (34 diabetics), which assessed BC in more detail by DEXA, showed a decline in LBM of $1.1 \mathrm{~kg}$ in non-diabetic patients, and of $3.4 \mathrm{~kg}$ in diabetic patients in the first year of dialysis ${ }^{28}$. Still, differences in hydration state following the start of dialysis might have affected LBM measurements ${ }^{18}$.

In a study using both DEXA as well as neutron activation analysis, Pellicano et al. did not observe significant changes in total protein stores as well as in LBM in a combined cohort of $46 \mathrm{HD}$ and PD patients, which was followed for twelve months from the start of dialysis ${ }^{29}$.

In chapter 4 differences in $B C$, using the 3-C model, were investigated between CKD-5 nondialysis patients and dialysis patients. Moreover, changes in BC during the first 6 months on dialysis were investigated.

Next to BC, also PA is a very important health parameter in renal disease. Physical inactivity in dialysis patients is associated with an increased risk of mortality and risk of hospitalization ${ }^{30,31}$. It is well known that dialysis patients have decreased levels of PA matching a sedentary lifestyle, recently defined as number of steps $<7500 /$ day $^{32}$. Indeed, in a cross-sectional multicentre study in HD patients the mean number of steps was 5660 . PA was lowest on non-dialysis days, but also compatible with a sedentary lifestyle on nondialysis days. Nevertheless, this study did not include comparison groups such as healthy controls or CKD-5 non-dialysis patients ${ }^{32}$. In a large cohort from France, the mean number of steps in dialysis patients was 3700 per day, whereas the advocated threshold is 10000 steps per day ${ }^{33}$. Also in earlier phases of CKD, a reduced PA has been observed ${ }^{34}$. However, 
there is limited literature regarding differences in PA between CKD-5 non-dialysis and dialysis patients, and there are no longitudinal data regarding the effects of starting chronic dialysis treatment. Whereas some literature suggests that PA is already severely decreased in the CKD-5 non-dialysis phase, due to fatigue related with advanced renal failure and the presence of comorbidity, but also to pre-existent lifestyle factors ${ }^{35}$, others conclude that PA was generally adequate; in a study in 24 CKD-5 non-dialysis patients with a mean eGFR of $17.7 \mathrm{ml} / \mathrm{min}$, the mean number of steps was 10423 . Also in this study, no comparison groups were included ${ }^{36}$.

The transition from the CKD-5 non-dialysis to the dialysis phase, as well as chronic dialysis treatment, can have a major physiological and psychological impact on patients with ESRD ${ }^{37}$. Although the partial reversal of the uremic state by dialysis might improve physical fitness, the travel times to and from the dialysis clinic as well as the treatment time itself, next to the fact that dialysis patients often complain of tiredness after a dialysis sessions, may impair PA and stimulate a sedentary lifestyle. For the assessment of PA often questionnaires (e.g. Baecke), or simple actometers are frequently used. Although questionnaires and objective measurements of PA are related, they are not necessarily synonymous ${ }^{38}$.

Recently, the Sensewear armband has become available. This accelerometer, which is a noninvasive device, is able to measure both PA as well as metabolic parameters, such as energy expenditure (EE), which is achieved by continuous recording of physiological signals from the body, such as skin temperature, dissipated heat from the body (heat flux), galvanic skin response and movement. Previously, the Sensewear armband has been validated for these purposes in different (patient) groups ${ }^{39}$, such as diabetics ${ }^{40}$ and CKD patients ${ }^{33}$. Despite the fact that in free-living adults some disagreement between Sensewear outcomes and gold standard methods, such as the doubly labelled water method (DLW), were observed ${ }^{39}$, objective measures, such as accelerometers, are still considered to be the most valid method to monitor PA regarding to frequency, duration and intensity of $P A^{41}$. Therefore, the Sensewear armband, which gives multidimensional feedback of PA parameters, provides important information about a patient's physical health status.

In chapter 4, also PA was compared between CKD-5 non-dialysis patients, dialysis patients, and healthy controls using the Sensewear armband. Moreover, the effects of starting dialysis on PA were investigated. Also, the relation between PA and BC was assessed.

In most of the studies assessing the relation between PA and outcome, self-reported questionnaires were used ${ }^{42}$. Relatively few studies have focused on clinical and phenotypical correlates of low PA, assessed by objective methodologies, in patients with ESRD ${ }^{32}$. However, such an analysis is of importance in order to identify potentially modifiable factors. In a previous study in dialysis and transplant patients, a relation between self-reported physical activity levels (PAL) and exercise capacity (assessed by VO2 peak) was observed, whereas 
the latter was related to age and muscle strength, and indirectly to LBM, assessed by DEXA ${ }^{43}$. In the study of Avesani et al. serum creatinine, as an indirect measure of LBM, was positively related to the number of steps and activity related $\mathrm{EE}$, whereas age and $\mathrm{BMI}$ were negatively related to parameters of $\mathrm{PA}^{32}$. In a study in 24 patients with CKD stage 4-5 (mean eGFR $17.7 \mathrm{ml} / \mathrm{min} / 1.73 \mathrm{~m}^{2}$ ), fat free mass (FFM) and FM, assessed using bioimpedance, were respectively positively and negatively related to $\mathrm{PA}^{36}$. Given the scarcity of literature, more data on potentially modifiable determinants of PA in patients with ESRD is necessary.

In chapter 4, also the relation between PA, estimated using the Sensewear armband, and muscle strength and $B C$ was assessed.

In the interpretation of changes in $\mathrm{BC}$, it is also of importance to take non modifiable determinants into account. One potentially important determinant is season, which plays a major role in human physiology and was also found to be related to various clinical parameters in dialysis patients, such as systolic blood pressure and inter-dialytic weight gain, and even survival ${ }^{44,45}$. In addition, biochemical parameters related to nutrition were also found to differ between summer and winter months. Yanai et al. observed higher levels of blood urea nitrogen (BUN) and phosphate in winter when compared with summer ${ }^{46}$. In a US cohort BUN and normalized protein catabolic rate ( $\mathrm{nPCR}$ ), a parameter related to protein intake, were increased during winter time ${ }^{47}$. Limited data are present on seasonal variations in $\mathrm{BC}$ in the general population ${ }^{48,49}$. However, seasonal differences in $\mathrm{BC}$ have not been assessed yet in dialysis patients.

In chapter 5, seasonal variations in BC, using the 3-C bioimpedance technique, were assessed in an international cohort of dialysis patients.

Another very important determinant of health is health-related quality of life (HRQOL). There is no univocal definition for HRQOL, but overall it is estimated by a multidimensional assessment consisting of physical, functional, psychological/emotional and social/ occupational components to measure an individual's well-being for these domains ${ }^{50}$. In dialysis patients, HRQOL was strongly associated with outcome ${ }^{51}$. Whereas various scales are available to assess HRQOL, the short form (SF)-36 scale is one of the most frequently used scales both in dialysis patients ${ }^{52}$, as well as in other populations with chronic diseases, such as COPD $^{53}$ and congestive heart failure ${ }^{54}$. The SF-36 is a multi-purpose, short-form health survey, which includes 36 items. These 36 items provide a measure of physical and mental health items. The 36 items can be subdivided in eight subscales: physical functioning, rolephysical, bodily pain, general health, vitality, social functioning, role-emotional, and mental health. These eight subscales can be summarized in two summary scores: the physical component summary score and the mental component summary score. Furthermore, the 
scales are normalized to make them comparable with the general population and other patient groups with specific disease states ${ }^{55,56}$.

Although HRQOL is reduced in both dialysis and CKD-5 non-dialysis patients, there are no data available which compared these two groups. Starting dialysis may have a profound effect on HRQOL. This can be either positive through an improvement in uremic symptoms, but also negative through the fact that the patient becomes dependent on medical technology in order to maintain life. To the best of our knowledge, changes in HRQOL during the transition period from the CKD-5 non-dialysis to the dialysis phase have not been investigated yet.

In the interpretation of $\mathrm{HRQOL}$, it is important to modify potentially reversible factors. One such factor is PA, which was related to HRQOL in a large international cohort (DOPPS) ${ }^{42}$. However, in this study PA was assessed by questionnaires and not by objective methods.

In chapter 6, HRQOL was compared between healthy controls, CKD-5 non-dialysis and dialysis patients. Moreover, the effect of starting dialysis on HRQOL was followed from the CKD5 non-dialysis phase until six months after starting dialysis. Furthermore, the association between HRQOL and PA was assessed.

Various cross-sectional studies showed that HRQOL was related to outcome in dialysis patients ${ }^{57-61}$. However, there are no studies assessing the relation between dynamic changes in HRQOL in dialysis patients. In addition, it is not well known whether potentially modifiable parameters are related to changes in $\mathrm{HRQOL}$ in dialysis patients or not, and if $\mathrm{HRQOL}$ retains prognostic significance after correction for these factors.

In chapter 7, the relation between changes in HRQOL and outcome, as well as the relation between potentially modifiable factors and changes in HRQOL, was investigated in a larger cohort of US dialysis patients.

In chapter 8 a general discussion of the findings of the study is presented.

In this thesis the following aims will be discussed:

- To review phenotypical changes during the first year of dialysis treatment (CHAPTER 2)

- To assess the agreement between the 2-C and 3-C bioimpedance models in the assessment of BC (CHAPTER 3)

- To study and compare differences in PA and BC between CKD-5 non-dialysis and dialysis patients as well as with healthy controls (CHAPTER 4)

- To investigate the effects of starting dialysis on PA and $B C$, and to study the relation between PA and BC and muscle strength in ESRD patients (CHAPTER 4)

- To explore seasonal variations in $B C$, using the 3-C bioimpedance technique, in an international cohort of dialysis patients (CHAPTER 5) 
- To compare HRQOL between healthy controls, CKD-5 non-dialysis and dialysis patients (CHAPTER 6)

- To study the effect of starting dialysis on HRQOL from the CKD-5 non-dialysis phase until six months after starting dialysis. Also, the assess the association between HRQOL and PA (CHAPTER 6)

- To study the relation between changes in HRQOL and outcome, and the relation between potentially modifiable factors and changes in HRQOL in a larger cohort of US dialysis patients (CHAPTER 7) 


\section{REFERENCES}

1. Fresenius Medical Care. ESRD Patients in 2013: A Global Perspective. 2013 [cited $201612-$ 04-2016]; Available from: http://www.vision-fmc.com/files/ESRD_Patients_in_2013.pdf.

2. Cornelis T, Kotanko P, Goffin E, Kooman JP, van der Sande FM, Chan CT. Can intensive hemodialysis prevent loss of functionality in the elderly ESRD patient? Semin Dial 2011;24:645-652.

3. Noordzij M,Jager KJ. Increased mortality early after dialysis initiation: a universal phenomenon. Kidney Int 2014;85:12-14.

4. Robinson BM, Zhang J, Morgenstern H, Bradbury BD, Ng LJ, McCullough KP, et al. Worldwide, mortality risk is high soon after initiation of hemodialysis. Kidney Int 2014;85:158-165.

5. de Jager DJ, Grootendorst DC, Jager KJ, van Dijk PC, Tomas LM, Ansell D, et al. Cardiovascular and noncardiovascular mortality among patients starting dialysis. Jama 2009;302:1782-1789.

6. Grooteman MP, van den Dorpel MA, Bots ML, Penne EL, van der Weerd NC, Mazairac AH, et al. Effect of online hemodiafiltration on all-cause mortality and cardiovascular outcomes. J Am Soc Nephrol 2012;23:1087-1096.

7. den Hoedt CH, Grooteman MP, Bots ML, Blankestijn PJ, van der Tweel I, van der Weerd NC, et al. The Effect of Online Hemodiafiltration on Infections: Results from the CONvective TRAnsport STudy. PLoS One 2015;10:e0135908.

8. Kopple JD, Greene T, Chumlea WC, Hollinger D, Maroni BJ, Merrill D, et al. Relationship between nutritional status and the glomerular filtration rate: results from the MDRD study. Kidney Int 2000;57:1688-1703.

9. Pupim LB, Evanson JA, Hakim RM, Ikizler TA. The extent of uremic malnutrition at the time of initiation of maintenance hemodialysis is associated with subsequent hospitalization. J Ren Nutr 2003;13:259-266.

10. Obi Y, Qader H, Kovesdy CP,Kalantar-Zadeh K. Latest consensus and update on proteinenergy wasting in chronic kidney disease. Curr Opin Clin Nutr Metab Care 2015;18:254-262.

11. Fouque D, Kalantar-Zadeh K, Kopple J, Cano N, Chauveau P, Cuppari L, et al. A proposed nomenclature and diagnostic criteria for protein-energy wasting in acute and chronic kidney disease. Kidney Int 2008;73:391-398.

12. Sharma D, Hawkins M,Abramowitz MK. Association of sarcopenia with eGFR and misclassification of obesity in adults with CKD in the United States. Clin J Am Soc Nephrol 2014;9:2079-2088.

13. Marcelli D, Brand K, Ponce P, Milkowski A, Marelli C, Ok E, et al. Longitudinal Changes in Body Composition in Patients After Initiation of Hemodialysis Therapy: Results From an International Cohort. J Ren Nutr 2015;

14. Fosbol MO,Zerahn B. Contemporary methods of body composition measurement. Clin Physiol Funct Imaging 2015;35:81-97.

15. Fouque D, Vennegoor M, ter Wee $P$, Wanner C, Basci A, Canaud B, et al. EBPG guideline on nutrition. Nephrol Dial Transplant 2007;22 Suppl 2:ii45-87. 
16. Moissl UM, Wabel P, Chamney PW, Bosaeus I, Levin NW, Bosy-Westphal A, et al. Body fluid volume determination via body composition spectroscopy in health and disease. Physiol Meas 2006;27:921-933.

17. Marcelli D, Wabel P, Wieskotten S, Ciotola A, Grassmann A, Di Benedetto A, et al. Physical methods for evaluating the nutrition status of hemodialysis patients. J Nephrol 2015;28:523-530.

18. Konings CJ, Kooman JP, Schonck M, van Kreel B, Heidendal GA, Cheriex EC, et al. Influence of fluid status on techniques used to assess body composition in peritoneal dialysis patients. Perit Dial Int 2003;23:184-190.

19. Chamney PW, Wabel P, MoissI UM, Muller MJ, Bosy-Westphal A, Korth O, et al. A whole-body model to distinguish excess fluid from the hydration of major body tissues. Am J Clin Nutr 2007;85:80-89.

20. Bergstrom J. Nutrition and mortality in hemodialysis. J Am Soc Nephrol 1995;6:1329-1341.

21. Rosansky S, Glassock RJ,Clark WF. Early start of dialysis: a critical review. Clin J Am Soc Nephrol 2011;6:1222-1228.

22. Ikizler TA, Pupim LB, Brouillette JR, Levenhagen DK, Farmer K, Hakim RM, et al. Hemodialysis stimulates muscle and whole body protein loss and alters substrate oxidation. Am J Physiol Endocrinol Metab 2002;282:E107-116.

23. Goldwasser P, Kaldas Al,Barth RH. Rise in serum albumin and creatinine in the first half year on hemodialysis. Kidney Int 1999;56:2260-2268.

24. Pupim LB, Kent P, Caglar K, Shyr Y, Hakim RM,lkizler TA. Improvement in nutritional parameters after initiation of chronic hemodialysis. Am J Kidney Dis 2002;40:143-151.

25. Mehrotra R, Berman N, Alistwani A,Kopple JD. Improvement of nutritional status after initiation of maintenance hemodialysis. Am J Kidney Dis 2002;40:133-142.

26. Chazot C, Deleaval P, Bernollin AL, Vo-Van C, Lorriaux C, Hurot JM, et al. Target weight gain during the first year of hemodialysis therapy is associated with patient survival. Nephron Clin Pract 2014;126:128-134.

27. Sipahioglu MH, Usvyat L, Liu L, Abbas SR, Raimann JG, Rosales L, et al. Early systolic blood pressure changes in incident hemodialysis patients are associated with mortality in the first year. Kidney Blood Press Res 2012;35:663-670.

28. Pupim LB, Heimburger O, Qureshi AR, Ikizler TA,Stenvinkel P. Accelerated lean body mass loss in incident chronic dialysis patients with diabetes mellitus. Kidney Int 2005;68:2368-2374.

29. Pellicano R, Strauss BJ, Polkinghorne KR,Kerr PG. Longitudinal body composition changes due to dialysis. Clin J Am Soc Nephrol 2011;6:1668-1675.

30. Stack AG, Molony DA, Rives T, Tyson J,Murthy BV. Association of physical activity with mortality in the US dialysis population. Am J Kidney Dis 2005;45:690-701.

31. Tentori F, Elder SJ, Thumma J, Pisoni RL, Bommer J, Fissell RB, et al. Physical exercise among participants in the Dialysis Outcomes and Practice Patterns Study (DOPPS): correlates and associated outcomes. Nephrol Dial Transplant 2010;25:3050-3062. 
32. Avesani CM, Trolonge S, Deleaval P, Baria F, Mafra D, Faxen-Irving G, et al. Physical activity and energy expenditure in haemodialysis patients: an international survey. Nephrol Dial Transplant 2012;27:2430-2434.

33. Mafra D, Deleaval P, Teta D, Cleaud C, Perrot MJ, Rognon S, et al. New measurements of energy expenditure and physical activity in chronic kidney disease. J Ren Nutr 2009;19:16-19.

34. Johansen KL,Painter P. Exercise in individuals with CKD. Am J Kidney Dis 2012;59:126-134.

35. Gould DW, Graham-Brown MP, Watson EL, Viana JL,Smith AC. Physiological benefits of exercise in pre-dialysis chronic kidney disease. Nephrology (Carlton) 2014;19:519-527.

36. Wlodarek D, Glabska D,Rojek-Trebicka J. Physical activity of predialysis patients with chronic kidney disease measured using SenseWear Armban. J Sports Med Phys Fitness 2011;51:639-646.

37. Broers NJ, Cuijpers AC, van der Sande FM, Leunissen KM,Kooman JP. The first year on haemodialysis: a critical transition. Clin Kidney J 2015;8:271-277.

38. Speck BJ,Looney SW. Self-reported physical activity validated by pedometer: A pilot study. Public Health Nurs 2006;23:88-94.

39. St-Onge $M$, Mignault $D$, Allison DB,Rabasa-Lhoret R. Evaluation of a portable device to measure daily energy expenditure in free-living adults. Am J Clin Nutr 2007;85:742-749.

40. Mignault D, St-Onge M, Karelis AD, Allison DB,Rabasa-Lhoret R. Evaluation of the Portable HealthWear Armband: a device to measure total daily energy expenditure in free-living type 2 diabetic individuals. Diabetes Care 2005;28:225-227.

41. Plasqui $G$, Joosen AM, Kester AD, Goris AH,Westerterp KR. Measuring free-living energy expenditure and physical activity with triaxial accelerometry. Obes Res 2005;13:1363-1369.

42. Lopes AA, Lantz B, Morgenstern H, Wang M, Bieber BA, Gillespie BW, et al. Associations of self-reported physical activity types and levels with quality of life, depression symptoms, and mortality in hemodialysis patients: the DOPPS. Clin J Am Soc Nephrol 2014;9:1702-1712.

43. van den Ham EC, Kooman JP, Schols AM, Nieman FH, Does JD, Franssen FM, et al. Similarities in skeletal muscle strength and exercise capacity between renal transplant and hemodialysis patients. Am J Transplant 2005;5:1957-1965.

44. Usvyat LA, Carter M, Thijssen S, Kooman JP, van der Sande FM, Zabetakis P, et al. Seasonal variations in mortality, clinical, and laboratory parameters in hemodialysis patients: a 5-year cohort study. Clin J Am Soc Nephrol 2012;7:108-115.

45. Cheung AK, Yan G, Greene T, Daugirdas JT, Dwyer JT, Levin NW, et al. Seasonal variations in clinical and laboratory variables among chronic hemodialysis patients. J Am Soc Nephrol 2002;13:2345-2352.

46. Yanai M, Satomura A, Uehara Y, Murakawa M, Takeuchi M,Kumasaka K. Circannual rhythm of laboratory test parameters among chronic haemodialysis patients. Blood Purif 2008;26:196-203.

47. Broers NJ, Usvyat LA, Marcelli D, Bayh I, Scatizzi L, Canaud B, et al. Season affects body composition and estimation of fluid overload in haemodialysis patients: variations in body composition; a survey from the European MONDO database. Nephrol Dial Transplant 2014;

48. Plasqui $\mathrm{G}$,Westerterp KR. Seasonal variation in total energy expenditure and physical activity in Dutch young adults. Obes Res 2004;12:688-694. 
49. Morinaka T, Wozniewicz M, Jeszka J, Bajerska J, Limtrakul PN, Makonkawkeyoon L, et al. Comparison of seasonal variation in the fasting respiratory quotient of young Japanese, Polish and Thai women in relation to seasonal change in their percent body fat. J Physiol Anthropol 2012;31:10.

50. Fallowfield L. What is quality of life? What is...? series 2009 [cited 2016 03-02-2016]; Available from: http://www.medicine.ox.ac.uk/bandolier/painres/download/whatis/WhatisQOL.pdf.

51. Broers NJ, Usvyat LA, Kooman JP, van der Sande FM, Lacson E, Jr., Kotanko P, et al. Quality of Life in Dialysis Patients: A Retrospective Cohort Study. Nephron 2015;130:105-112.

52. Wight JP, Edwards L, Brazier J, Walters S, Payne JN,Brown CB. The SF36 as an outcome measure of services for end stage renal failure. Qual Health Care 1998;7:209-221.

53. Wilke S, Janssen DJ, Wouters EF, Schols JM, Franssen FM,Spruit MA. Correlations between disease-specific and generic health status questionnaires in patients with advanced COPD: a one-year observational study. Health Qual Life Outcomes 2012;10:98.

54. Johansson P, Agnebrink M, Dahlstrom U,Brostrom A. Measurement of health-related quality of life in chronic heart failure, from a nursing perspective-a review of the literature. Eur J Cardiovasc Nurs 2004;3:7-20.

55. WARE JE SK, Kosinski M, Gandek B. SF-36 Health Survey Manual and Interpretation Guide, Boston, The Health Institute, New England Medical Center. 1993;

56. Ware JE KM, Keller SK. SF-36 Physical and Mental Health Summary Scales: A User's Manual, Boston, The Health Institute, New England Medical Center. 1994;

57. DeOreo PB. Hemodialysis patient-assessed functional health status predicts continued survival, hospitalization, and dialysis-attendance compliance. Am J Kidney Dis 1997;30:204-212.

58. Mapes DL, Bragg-Gresham JL, Bommer J, Fukuhara S, McKevitt P, Wikstrom B, et al. Healthrelated quality of life in the Dialysis Outcomes and Practice Patterns Study (DOPPS). Am J Kidney Dis 2004;44:54-60.

59. Lowrie EG, Curtin RB, LePain N,Schatell D. Medical outcomes study short form-36: a consistent and powerful predictor of morbidity and mortality in dialysis patients. Am J Kidney Dis 2003;41:1286-1292.

60. Lopes AA, Bragg-Gresham JL, Satayathum S, McCullough K, Pifer T, Goodkin DA, et al. Healthrelated quality of life and associated outcomes among hemodialysis patients of different ethnicities in the United States: the Dialysis Outcomes and Practice Patterns Study (DOPPS). Am J Kidney Dis 2003;41:605-615.

61. Kalantar-Zadeh K, Kopple JD, Block G,Humphreys MH. Association among SF36 quality of life measures and nutrition, hospitalization, and mortality in hemodialysis. J Am Soc Nephrol 2001;12:2797-2806. 



\section{CHAPTER 2}

THE FIRST YEAR ON HAEMODIALYSIS: A CRITICAL TRANSITION

Natascha J.H. Broers, Anne C.M. Cuijpers, Frank M. van der Sande, Karel M.L. Leunissen and Jeroen P. Kooman

Clin Kidney J. 2015;8(3):271-7 


\section{ABSTRACT}

The first year following the start of haemodialysis (HD) is associated with increased mortality, especially during the first 90-120 days after the start of dialysis. Whereas the start of dialysis has important effects on the internal environment of the patient, there are relatively few studies assessing changes in phenotype and underlying mechanisms during the transition period following pre-dialysis to dialysis care, although more insight into these parameters is of importance in unravelling the causes of this increased early mortality. In this review, changes in cardiovascular, nutritional and inflammatory parameters during the first year of HD, as well as changes in physical and functional performance are discussed. Treatment-related factors that might contribute to these changes include vascular access and pre-dialysis care, dialysate prescription and the insufficient correction of the internal environment by current dialysis techniques. Patient-related factors include the ongoing loss of residual renal function and the progression of comorbid disease. Identifying phenotypic changes and targeting risk patterns might improve outcome during the transition period. Given the scarcity of data on this subject, more research is needed.

\section{Keywords}

arterial stiffness, fluid overload, haemodialysis, pre-dialysis, vascular calcification 


\section{INTRODUCTION}

One of the most critical periods in the life of an end stage renal disease (ESRD) patient is the start of dialysis ${ }^{1,2}$. During this period, the patient becomes dependent upon medical technology, which can have critical pathophysiological and psychological consequences. Although the start of haemodialysis (HD) has pronounced effects on the physiology of the patient, relatively few studies have looked into detailed phenotypic changes following the start of dialysis. It is the aim of this review, which will be limited to HD patients, to discuss the time course of various clinically relevant parameters early after start of HD, attempting to provide a better understanding of the risk associated with the early transition period following initiation of dialysis. Given their relation with outcome, the main emphasis will lie on changes in cardiovascular, nutritional and inflammatory parameters, followed by a short discussion on physical and functional performance.

\section{Early mortality after dialysis and its predictors}

Several large-scale observational studies have shown that the first months on dialysis can be considered as a critical period. Especially the first 90-120 days are associated with an increased risk of mortality ${ }^{3-5}$. Previous registry data from Europe and North America showed that $\sim 35 \%$ of the mortality during the first year after start of dialysis occurred in the first 90 days ${ }^{3}$. In addition, despite regional differences, recent data from the Dialysis Outcomes and Practice Patterns Study (DOPPS) in 86886 patients showed that the increased risk of death early after the start of dialysis can be considered as a global phenomenon ${ }^{4}$.

Two large studies have looked into the detailed causes of death in the early period following the start of dialysis. In a DOPPS study in incident US patients, causes of mortality after the start of dialysis were predominantly classified as cardiovascular, followed by withdrawal, with a relatively low percentage of infection-related mortality ${ }^{6}$. In the European Dialysis and Transplant Association registry, the relative contribution of non-cardiovascular death to early mortality was higher, specifically infectious-related disease ( $14 \%$ of all deaths) ${ }^{5}$.

Given the strong mortality risk associated with central venous catheters (CVC) in this and other studies, the relatively low contribution of infection to early death in the US DOPPS cohort appears surprising, given the large percentage of patients treated with catheters in USA 4 . However, part of this discrepancy might be explained by the observation that cardiovascular mortality was greatly increased following infection-related hospitalization in dialysis patients ${ }^{7}$. With regard to cardiovascular mortality, both a high incidence of cardiac as well as vascularrelated mortality was observed in the early period following the start of dialysis ${ }^{6}$. Few studies looked into overall or specific morbidity or mortality during the transition period of starting dialysis, with inclusion of the pre-dialysis period. A recent study in elderly patients showed a high incidence of stroke following the start of dialysis with a peak in the first month of dialysis, although the incidence started to increase from 2 months before the start of dialysis ${ }^{8}$. The risk of stroke was increased by the presence of hypertension, atherosclerotic disease and diabetes. 
Both patient- and treatment-related factors (especially the use of CVC and the quality of predialysis care) are important risk factors for early mortality. Important treatment-related risk factors in the transition period include the use of CVC and the quality of pre-dialysis care ${ }^{4,9,10}$. Consistent care in the transition period [defined as visits in 3 or more of the 6 months prior to renal replacement therapy (RRT) start] was received by only a minority (29.1\%) of patients in a large cohort study (12.143 patients), and even in only $38.1 \%$ of patients which were known at the outpatient nephrology clinic for more than 6 months ${ }^{11}$. These are important modifiable factors, as several observational studies found an increase in modality selection and timely creation of a permanent access, and even an improvement in short-term mortality by adequate pre-dialysis care and education ${ }^{12}$. Patient-related risk factors include age, factors related to cardiovascular disease (such as congestive heart failure) as well as to malnutrition (low serum phosphorus) and/or inflammation (decreased serum albumin) and haemoglobin ${ }^{6,13,14}$. Other studies also showed an important mortality risk associated with frailty at the start of dialysis ${ }^{15}$. Notably, in a recent report from Taiwan, dialysis was even associated with an increased mortality risk when compared with conservative care in patients above 70 years of age ${ }^{14}$, although this finding, which is in contrast to previous literature ${ }^{16}$, needs to be confirmed. Also, it is likely that many other (potentially modifiable) factors are predictive of outcome after dialysis. However, at present, there are only a limited amount of studies covering the transition period of the pre-dialysis to the dialysis period.

\section{Cardiovascular parameters}

\section{Fluid overload}

Fluid overload (FO) is an important risk factor for hypertension, left ventricular hypertrophy (LVH) and mortality in dialysis patients ${ }^{17,18}$. Limited evidence is available on the changes in fluid state after the start of RRT, or regarding comparisons between incident and prevalent dialysis patients. Given the removal of salt and water by dialysis, fluid state can be expected to improve, but this effect might be offset by the continuing loss of residual renal function ${ }^{19}$. Most of the evidence on fluid state in chronic kidney disease (CKD) patients has been obtained using bioimpedance methodology. One observational study in 269 prevalent HD patients, using bioimpedance spectroscopy (Body Composition Monitor ${ }^{\circledR}$ ) showed that $\sim 25 \%$ of prevalent HD patients were classified as severely overhydrated, defined as an FO relative to $15 \%$ of extracellular volume $(\sim 2.5 \mathrm{~L})$, which was an independent risk factor for mortality ${ }^{18}$. In a multicenter study in prevalent dialysis patients, the mean level of FO in HD patients, assessed by the same methodology, was $1.7 \mathrm{~L}^{20}$. A smaller study of Yilmaz et al. has also shown that abnormalities in indicators of FO already are observed before the start of dialysis, which appears to be related to the severity of the CKD stage ${ }^{21}$. This study of Yilmaz et al. observed a mean level of FO, assessed by the same methodology, of $3.9 \mathrm{~L}$ in 68 non-dialysed CKD stage 5 patients [mean estimated glomerular filtration rate (eGFR) $8.8 \mathrm{~mL} / \mathrm{min} / 1.73 \mathrm{~m}^{2}$ ], when compared with $2.3 \mathrm{~L}$ in 62 CKD stage 3-4 (mean GFR 28.9 
$\left.\mathrm{mL} / \mathrm{min} / 1.73 \mathrm{~m}^{2}\right)^{21}$, both higher when compared with the levels in the dialysis population studied by van Biesen et al. ${ }^{20}$. Other markers related to FO, such as $\mathrm{N}$-terminal prohormone brain natriuretic peptide (NTpro-BNP) and vena cava diameter, were higher in CKD stage 5 when compared with CKD stage 3-4 patients ${ }^{17}$. These findings corroborate earlier studies showing evidence of FO in patients with mild-to-moderate CKD 22,23 . Hung et al. observed a high prevalence $(52 \%)$ of FO (defined as FO above $1.1 \mathrm{~L}$, i.e. above the 90th percentile of a matchedpopulation) in patients with stages 3-5 CKD, 52\% were hypervolaemic. Strikingly, whereas FO was strongly associated with all of the components of malnutritioninflammation-atherosclerosis syndrome, measures of kidney function (estimated GFR) and proteinuria were not ${ }^{24}$.

However, these findings were not confirmed in a recent single-centre study in 175 patients with a mean eGFR of $15.6 \mathrm{~mL} / \mathrm{min} / 1.73 \mathrm{~m}^{2}$, given the fact that the mean level of FO in these patients was only $0.21 \mathrm{~L}^{25}$. No studies directly compared FO between pre-dialysis and dialysis patients. However, in the single prospective study which has, to the best of our knowledge, been published on this subject, the extracellular water:total body water (ECW:TBW) ratio, assessed by multi-frequency bioimpedance, declined from 53 to $42 \%$. The study cohort included 46 patients [65\% HD and 35\% peritoneal dialysis (PD)], no significant differences in the ECW:TBW trends were observed between PD and HD patients ${ }^{26}$. Regardless of the dialysis vintage, interventions based on the Body Composition Monitor aiming for normovolaemia have resulted in an improvement in blood pressure (BP) regulation, arterial stiffness, LVH and even a reduction in all-cause mortality ${ }^{27,28}$.

Summarizing, FO appears to be already present before the start of dialysis, at least according to several studies, and appears to increase in relation to the severity of the CKD. Scarce available data suggests that FO improves after the start of dialysis therapy. However, more detailed studies are needed to assess the determinants and effects of different treatment policies on changes in fluid state following the start of dialysis.

\section{Hypertension}

There have been few studies assessing BP trends after the start of dialysis. A single-centre study from Tassin in France in 308 incident patients showed that BP in general decreased after the start of dialysis ${ }^{29}$. In this cohort, mean systolic BP decreased from 142 to 131 $\mathrm{mmHg}$, and mean diastolic BP from 75 to $69 \mathrm{mmHg}$ in the first year of dialysis. However, this centre is unique, especially in terms of dialysis duration, and it is therefore not known to what extent these data can be extrapolated to the general dialysis population. Low BP at the start of dialysis was associated with a higher mortality, in agreement with the 'reversed epidemiology concept' which is in line with previous studies ${ }^{30,31}$. However, BP at 3, 6 and 12 months was not associated with adverse outcome. In contrast, the tertile of patients which experienced the largest decline in BP during the first year on dialysis had better combination with the excellent survival reported in this centre, the decline in BP after the start of dialysis was interpreted as beneficial ${ }^{29}$. 
In contrast, a study comprising 3446 incident dialysis patients of a US provider ${ }^{32}$ showed an initial decrease in systolic BP within the first week after the start of dialysis, followed by a steady increase and a plateau phase after 12 weeks. No major differences in mean predialytic systolic BP levels in the overall cohort were observed between the start of dialysis and a 1-year follow-up period ${ }^{32}$. Also in this study, low pre-dialytic BP (defined as systolic $\mathrm{BP}<120 \mathrm{mmHg}$ ) at the start of dialysis was associated with increased early (6-12 weeks) mortality. In addition, the authors identified different BP slopes. Intriguingly, in contrast to the Tassin study, patients with a declining BP during the first year of dialysis had higher mortality when comparing with an increasing BP slope during dialysis. As will be discussed later, body weight initially declined in the first 12 weeks of dialysis, followed by an increase during the remainder of the first year period. Although data on treatment policies in the study by Sipahioglu et al. are not available, the differences between both studies might among others be due to differences in dialysis prescription (minimum $5 \mathrm{~h}$ in Tassin; dialysate sodium $138 \mathrm{mmol} / \mathrm{L}$ ), diet (strict sodium restriction in Tassin) and case-mix. Whereas an improvement in BP control achieved by gradual reduction in dry weight and a salt-restricted diet may be beneficial, a decline in systolic BP due to deterioration in cardiac function is associated with an adverse prognosis.

Therefore, changes in BP during the first year on dialysis are quite variable between patients. The complex relation between BP trends and outcome is likely dependent on the context.

\section{Cardiac structure and function}

Patients with CKD stage 5 often already have many abnormalities in cardiac structure and function before they start on dialysis, which carry important prognostic significance. The prevalence of LVH is high. One report in 213 non-dialysis CKD patients showed a prevalence of LVH of $76 \%$ in patients with CKD stage 5 when compared with $52 \%$ in patients with CKD stage $3^{33}$. Hypertension is an important risk factor for progression of $\mathrm{LVH}$ in pre-dialysis $\mathrm{CKD}^{34}$. In a study of 433 incident dialysis patients, $15 \%$ had systolic dysfunction, 32\% left ventricular dilatation and $74 \% \mathrm{LVH}$ at the start of dialysis, all associated with an adverse prognosis ${ }^{35}$. In another study by the same group, $31 \%$ had congestive heart failure at the start of dialysis, whereas $25 \%$ of patients without signs of congestive heart failure at the start of dialysis developed this complication during a mean follow-up period of 42 months. Important risk factors for the development of congestive heart failure were hypoalbuminaemia, anaemia and hypertension ${ }^{36}$. In a smaller study in 30 non-diabetic dialysis patients, mean left ventricular mass (LVM) did not change significantly from baseline (the start of dialysis) in 12 and 24 months after the start of dialysis, although changes in LVM in individual patients were related to changes in BP and inversely to haemoglobin ${ }^{37}$.

Indeed, changes in cardiac function after the start of dialysis appear to be quite variable between patients. In a multicentre incident cohort of 227 dialysis patients (54\% HD), 30\% had a history of cardiac failure before the start of dialysis, whereas $6 \%$ developed new-onset cardiac failure during the first year after the start of dialysis and $15 \%$ developed cardiac 
failure after the first year on dialysis. On the other hand, systolic function and LVM improved in respectively 48 and $46 \%$ of patients ${ }^{38}$.

The question is how these differences in changes in cardiac structure and/or function following the start of dialysis can be explained. It is not unreasonable to assume that an improvement in fluid status could be involved in the improved cardiac function observed in a subgroup of patients, although no data on this subject are available. On the other hand, both patient- and treatment- related factors could play a role in the deterioration in cardiac function after the start of HD treatment. With regard to patient related factors, LVM index at baseline was related to the emergence of cardiac failure following the start of dialysis ${ }^{38}$. A study in prevalent dialysis patients showed an inverse relation between LVM and residual renal function ${ }^{39}$. With regard to treatment-related factors, several studies have shown disturbances in regional wall contractility during the dialysis procedure, attributed to cardiac stunning (impaired but reversible myocardial contractility due to ischaemia) ${ }^{40}$, which were not present before dialysis ${ }^{41,42}$. Reversible intradialytic changes in regional LV wall contractility were predictive of persistently impaired systolic function during later follow-up, as well as for increased mortality ${ }^{43,44}$. Given these data, it is suggestive that the dialysis procedure itself plays a role in the loss of myocardial contractile tissue, although patient susceptibility also plays a role, given the fact that intra-dialytic regional wall abnormalities followed by a persistent loss of systolic function are primarily observed in a subset of dialysis patients, notably in those with pre-existent higher LVM and higher interleukin-6 (IL-6) levels ${ }^{43,45}$.

Summarizing, the effect of starting dialysis on cardiac function appears to be variable, with a subgroup showing an improvement, and the other subgroup showing deterioration. To what degree underlying cardiac pathology, or the effects of dialysis treatment are responsible for the changes observed in the latter group, further research is needed.

\section{Arterial stiffness and vascular calcification}

An increase in vascular stiffness increases the systolic burden to the heart and is an important risk factor for mortality both in dialysis patients as well as in patients with CKD. Various studies have shown that arterial stiffness, assessed by different parameters, is increased in both CKD as well as dialysis patients when compared with controls ${ }^{46-50}$. The processes leading to arterial stiffness likely start early in the course of renal failure $\mathrm{e}^{46,50}$. Also, the age-related progression in arterial stiffness may be more rapid in patients with ESRD when compared with subjects without renal impairment. In a study in 80 prevalent dialysis patients and 60 controls, the mean change in pulse-wave velocity (PWV), as a marker of arterial stiffness over a 3-year time period was larger in dialysis patients $(64 \mathrm{~cm} / \mathrm{s})$ when compared with the $27 \mathrm{~cm} / \mathrm{s}$ observed in controls ${ }^{51}$. However, in a sub-study of the Convective Transport Study, no change in PWV was observed in 189 prevalent patients during a maximal followup period of 3 years ${ }^{52}$. One cross-sectional study found an increase in vascular stiffness in both pre-dialysis patients as well as maintenance dialysis patients when compared with controls, without significant differences between both patient groups ${ }^{49}$. To the best of our 
knowledge, longitudinal studies following changes in arterial stiffness from the transition phase of pre-dialysis ESRD to the dialysis period are yet lacking.

With regard to vascular calcifications, there is ample evidence that these progress during time on dialysis ${ }^{53}$. However, as holds true for arterial stiffness, vascular calcification is also prevalent in earlier stages of $\mathrm{CKD}^{54}$. Whereas pharmacological treatment can, to some degree, influence the calcification process, this is not yet clear for dialysis therapy, as no long-term studies concerning the effect of different dialysate calcium levels on vascular calcification are available. Thus, until now, the question whether the progression in vascular calcification observed during dialysis treatment is (partly) due to a detrimental effect of the dialysis treatment itself or only to insufficient correction of the abnormalities in mineral metabolism remains to be answered.

Summarizing, available evidence suggests that arterial wall parameters, both with regard to stiffness as well as calcifications, deteriorate during dialysis, but also show a high prevalence of arterial disease before the start of dialysis. The extent to which dialysis treatment itself can influence arterial wall properties in the long term needs further study.

\section{Nutritional state and body composition}

Protein-energy wasting is an important risk factor for mortality in dialysis patients, certainly when accompanied by inflammation ${ }^{55}$. Abnormalities in nutritional state already occur in the pre-dialysis stage, associated with a spontaneous decline in protein intake ${ }^{56}$. Both in prevalent dialysis patients but also at the onset of dialysis, malnutrition is an important risk factor for mortality ${ }^{57,58}$.

The start of dialysis could theoretically have both positive and negative effects on nutritional state $^{58,59}$. Positive effects include the increased removal of uraemic toxins, which might be involved in anorexia, the correction of acidosis and the possibility for a more liberal diet when compared with the pre-dialysis stage. Negative effects include the loss of (micro) nutrients, as well as the inflammatory process which may accompany dialysis treatment ${ }^{58-61}$. Whereas studies in prevalent patients suggest a decline in nutritional parameters over time ${ }^{62,63}$, studies in incident patients suggested an improvement in (especially biochemical) parameters reflecting malnutrition, such as pre-albumin and albumin, as well as an increase in protein intake (reflected by protein nitrogen appearance) in the first year following the start of dialysis ${ }^{64,65}$. These findings were confirmed by later studies ${ }^{66}$. However, it is uncertain whether these biochemical changes are also reflected in improvements in body composition. The least specific parameter reflecting body composition is body weight. Changes in body weight after the start of dialysis can either reflect changes in hydration, lean tissue mass (LTM) or fat mass. A single-centre study from Tassin in 363 incident dialysis patients showed that mean target (dry) body weight decreased by $6.5 \%$ in the first 8 weeks after the start of dialysis, followed by an increase of $1.9 \%$ during week $8-52^{66}$. Changes in target body weight after 8 weeks were positively related to protein intake (reflected by protein nitrogen appearance) and serum albumin, but inversely to C-reactive protein (CRP) at 12 weeks 
after the start of dialysis. Moreover, an increase in body weight between week 8 and 52 after the start of dialysis was predictive of survival. However, this subsequent increase in body weight occurred only in $60 \%$ of patients. After 1 year of treatment, mean target body weight in the cohort was still $\sim 4 \mathrm{~kg}$ lower than the weight at the start of dialysis. The initial decline in body weight is suggested to reflect a decrease in extracellular volume due to the removal of excess fluid by ultrafiltration, whereas the later increase is suggested to reflect an improvement in nutritional state, which would be supported by the relation between changes in body weight and biochemical nutritional parameters. In the earlier mentioned study of Sipahioglu et al., mean pre-dialytic body weight decreased from $80.7 \mathrm{~kg}$ at baseline to $79.4 \mathrm{~kg}$ after 3 months, followed by a gradual increase to $80.7 \mathrm{~kg}$ at the end of the first year ${ }^{32}$. In contrast, a study, in 142 incident HD patients (34 diabetics), which assessed body composition in more detail by dual-energy X-ray absorptiometry (DEXA) showed a decline in lean body mass of $1.1 \mathrm{~kg}$ in non-diabetic patients and of $3.4 \mathrm{~kg}$ in diabetic patients in the first year of dialysis ${ }^{67}$. Still, studies in which body composition is assessed by DEXA or bioimpedance using a two-compartment model likely cannot differentiate well between ECW and LTM in patients with $\mathrm{FO}^{68}$.

In a study using both DEXA as well as neutron activation analysis, Pellicano et al. did not observe significant changes in total protein stores as well as lean body mass in a combined cohort of $46 \mathrm{HD}$ and PD patients which was followed for 12 months fromthe start of dialysis ${ }^{26}$. Summarizing, although there is evidence for a beneficial effect of starting dialysis regarding protein intake and laboratory parameters, the relation between the start of dialysis and changes in body composition deserve further study. Changes in nutritional state appear to have prognostic significance.

\section{Systemic inflammation}

The presence of systemic inflammation is an important characteristic of CKD. Also in nondialysed CKD patients, inflammation likely plays a very important role in the pathogenesis of various systemic complications associated with ESRD such as cardiovascular disease and malnutrition ${ }^{69}$, whereas markers of systemic inflammation, such as CRP, are consistently related to mortality $55,69,70$. The pathogenesis of systemic inflammation in patients with ESRD is multifactorial. Next to the uraemic state itself, systemic inflammation can also occur as a result of comorbidity related to CKD, such as e.g. systemic atherosclerosis, heart failure or (occult) infections ${ }^{69,71-73}$. Dialysis-related factors, such as bioincompatible membranes may play a role in its pathogenesis ${ }^{74}$ although, also with the use of synthetic membranes was an inflammatory response observed during dialysis ${ }^{75,76}$. Also dialysate impurity may play a role, given the fact that markers of inflammation and oxidative stress were significantly lower in patients treated with ultrapure versus standard dialysate ${ }^{77}$.

Moreover, also the vascular access is likely involved in the pathogenesis of systemic inflammation. Recently, in a study in 583 incident HD patients, the use of CVC and arteriovenous (AV) grafts was associated with a respectively 62 and $30 \%$ higher increase in CRP 
levels during a follow-up period of 3 years when compared with patients with AV fistula ${ }^{78}$. Given the multifactorial pathogenesis of inflammation in ESRD patients, the uraemia- or dialysisspecific role in the pathogenesis of systemic inflammation may be difficult to unravel from those of comorbid factors in clinical research, although in patients with an unexplained increase in CRP levels, a search for underlying pathology is warranted ${ }^{72,73}$.

Few other studies assessed the effects of starting dialysis on inflammatory parameters. Mclntyre et al. found in a cross-sectional analysis higher endotoxin levels endotoxin levels in patients on dialysis when compared with patients with pre-dialysis CKD, which was associated with systemic inflammation. Endotoxin levels in HD patients were related to intra-dialytic haemodynamic stress, which led to authors to suggest that recurrent gut ischaemia due to intra-dialytic hypotension may play a role in its pathogenesis ${ }^{79}$. In contrast, despite the fact that in a study in prevalent dialysis patients IL-6 levels increased during a 3-year follow-up period $^{62}$, Pupim et al. did not observe a change in inflammatory parameters or parameters related to oxidative stress in the year following the start of dialysis ${ }^{80}$. Summarizing, despite evidence for an acute effect of dialysis treatment on the inflammatory response, it is uncertain whether HD treatment itself, when performed with biocompatible membranes and ultrapure dialysate, is an important contributor to chronic systemic inflammation. However, HD access may be an important determinant for systemic inflammation. Still, the relative effects of treatment-related factors, the uraemic state and comorbidity are likely complex and not easy to unravel.

\section{Physical activity and functional performance}

It is well known that both physical activity and performance in dialysis patients is low. Many HD patients lead a sedentary lifestyle ${ }^{81,82}$. In a recent international survey, physical activity was classified as low (defined by a number of steps $<7500 /$ day) in $64 \%$ of 134 dialysis patients with a mean age of 54.9 years ${ }^{82}$. The mean number of steps in their population was 5660 . Both a sedentary lifestyle and low physical performance important risk factors for mortality ${ }^{83,84}$. Physical activity was related to serum albumin, lean body mass and haemoglobin levels showing an important correlate between potentially reversible factors $^{85}$. Some reports suggest that physical activity is also already low in the predialysis phase, possibly due to the fatigue associated with advanced renal failure and the presence of comorbid disease, but possibly also to pre-existent lifestyle factors ${ }^{86}$. However, using the same methodology (Sensewear ${ }^{\circledR}$ ) as in the Avesani study ${ }^{82}$, in a study of 24 patients with CKD stage 4-5 not on dialysis (mean age 60.9 years), a mean daily physical activity duration of $74 \mathrm{~min}$ and a mean number of steps of 10423/day was observed, which lead the authors to conclude that physical activity was generally satisfactory in their cohort ${ }^{87}$.

To the best of our knowledge, there are no prospective studies looking at the effects of starting dialysis. However, two studies showed that physical activity was lower on dialysis when compared with non-dialysis days ${ }^{82,88}$. 
With regard to the effects of the start of dialysis on functional performance, especially in relation to activities of daily living (ADL), recent studies have shown concerning results. In a study in nursing home patients on dialysis, Kurella Tamura et al. not only observed an excess mortality early after the start of dialysis, but also a significant decline in ADL functional capacity in survivors ${ }^{89}$. To the best of our knowledge, no studies have been performed on functional performance in younger patients starting dialysis. Summarizing, there is limited evidence on the relation between the start of dialysis and changes in physical performance. Observational studies in elderly and frail patients showed a sharp decline in functional status following dialysis. Given the observational nature of these data, it is difficult to distinguish between cause and effect. Possibly, the additional stressor of starting dialysis put further stress in these very frail patients at high risk of homeostatic breakdown. Alternatively, dialysis may have been started within a course of an already irreversible decline in physical functioning ${ }^{90,91}$.

\section{CONCLUSION}

The start of dialysis is associated with pronounced phenotypic and pathophysiologic changes. Causes of these changes are multifactorial and may include the dialysis treatment itself, the progressive loss of renal function, next to the insufficient correction of the internal milieu by current dialysis modalities, as well as ongoing and progressive comorbid disease. The relative role of these different mechanisms is not easy to unravel in clinical studies, and clinical studies performed during the transition period from pre-dialysis ESRD to the dialysis period are surprisingly scarce. Although the focus of this review is not on therapeutic implications, the positive effects of early intervention programs suggest that multidimensional approach might improve outcome in the transition period of the start of dialysis $^{92}$. Next to adequate preparation of the patient for dialysis therapy including access care, individualized and targeted prescription of dialysis treatment, attention for diet and physical rehabilitation, 'just in time' starting of dialysis and adequate treatment of comorbid disease are all likely important in improving outcome during this critical period ${ }^{59,93,94}$.

\section{FUNDING}

Jeroen P. Kooman, Frank M. van der Sande and Natascha J.H. Broers are supported by an unrestricted grant from Fresenius Medical Care Europe.

\section{CONFLICT OF INTEREST STATEMENT}

The authors declare that they have no conflict of interest. 


\section{REFERENCES}

1. Mclntyre CW, Rosansky SJ. Starting dialysis is dangerous: how do we balance the risk? Kidney Int 2012;82:382-387.

2. Kooman JP, Usvyat L, van der Sande FM, Thijssen S, Levin N, Leunissen KM, et al. 'Time and time again': oscillatory and longitudinal time patterns in dialysis patients. Kidney Blood Press Res 2012;35:534-548.

3. Noordzij M,Jager KJ. Increased mortality early after dialysis initiation: a universal phenomenon. Kidney Int 2014;85:12-14.

4. Robinson BM, Zhang J, Morgenstern H, Bradbury BD, Ng LJ, McCullough KP, et al. Worldwide, mortality risk is high soon after initiation of hemodialysis. Kidney Int 2014;85:158-165.

5. de Jager DJ, Grootendorst DC, Jager KJ, van Dijk PC, Tomas LM, Ansell D, et al. Cardiovascular and noncardiovascular mortality among patients starting dialysis. Jama 2009;302:1782-1789.

6. Bradbury BD, Fissell RB, Albert JM, Anthony MS, Critchlow CW, Pisoni RL, et al. Predictors of early mortality among incident US hemodialysis patients in the Dialysis Outcomes and Practice Patterns Study (DOPPS). Clin J Am Soc Nephrol 2007;2:89-99.

7. Dalrymple LS, Mohammed SM, Mu Y, Johansen KL, Chertow GM, Grimes B, et al. Risk of cardiovascular events after infection-related hospitalizations in older patients on dialysis. Clin J Am Soc Nephrol 2011;6:1708-1713.

8. Murray AM, Seliger S, Lakshminarayan K, Herzog CA,Solid CA. Incidence of stroke before and after dialysis initiation in older patients. J Am Soc Nephrol 2013;24:1166-1173.

9. Hasegawa T, Bragg-Gresham JL, Yamazaki S, Fukuhara S, Akizawa T, Kleophas W, et al. Greater first-year survival on hemodialysis in facilities in which patients are provided earlier and more frequent pre-nephrology visits. Clin J Am Soc Nephrol 2009;4:595-602.

10. de Jager DJ, Voormolen N, Krediet RT, Dekker FW, Boeschoten EW,Grootendorst DC. Association between time of referral and survival in the first year of dialysis in diabetics and the elderly. Nephrol Dial Transplant 2011;26:652-658.

11. Singhal R, Hux JE, Alibhai SM,Oliver MJ. Inadequate predialysis care and mortality after initiation of renal replacement therapy. Kidney Int 2014;86:399-406.

12. Lacson E, Jr., Wang W, DeVries C, Leste K, Hakim RM, Lazarus M, et al. Effects of a nationwide predialysis educational program on modality choice, vascular access, and patient outcomes. Am J Kidney Dis 2011;58:235-242.

13. van Diepen M, Schroijen MA, Dekkers OM, Rotmans JI, Krediet RT, Boeschoten EW, et al. Predicting mortality in patients with diabetes starting dialysis. PLoS One 2014;9:e89744.

14. Shih CJ, Chen YT, Ou SM, Yang WC, Kuo SC,Tarng DC. The impact of dialysis therapy on older patients with advanced chronic kidney disease: a nationwide population-based study. BMC Med 2014;12:169.

15. Johansen KL, Delgado C, Bao Y,Kurella Tamura M. Frailty and dialysis initiation. Semin Dial 2013;26:690-696. 
16. Murtagh FE, Marsh JE, Donohoe P, Ekbal NJ, Sheerin NS,Harris FE. Dialysis or not? A comparative survival study of patients over 75 years with chronic kidney disease stage 5 . Nephrol Dial Transplant 2007;22:1955-1962.

17. Konings CJ, Kooman JP, Schonck M, Dammers R, Cheriex E, Palmans Meulemans AP, et al. Fluid status, blood pressure, and cardiovascular abnormalities in patients on peritoneal dialysis. Perit Dial Int 2002;22:477-487.

18. Wizemann V, Wabel P, Chamney P, Zaluska W, MoissI U, Rode C, et al. The mortality risk of overhydration in haemodialysis patients. Nephrol Dial Transplant 2009;24:1574-1579.

19. de Jager DJ, Halbesma N, Krediet RT, Boeschoten EW, le Cessie S, Dekker FW, et al. Is the decline of renal function different before and after the start of dialysis? Nephrol Dial Transplant 2013;28:698-705.

20. van Biesen W, Claes K, Covic A, Fan S, Lichodziejewska-Niemierko M, Schoder V, et al. A multicentric, international matched pair analysis of body composition in peritoneal dialysis versus haemodialysis patients. Nephrol Dial Transplant 2013;28:2620-2628.

21. Yilmaz Z, Yildirim Y, Oto F, Aydin FY, Aydin E, Kadiroglu AK, et al. Evaluation of volume overload by bioelectrical impedance analysis, NT-proBNP and inferior vena cava diameter in patients with stage 3\&4 and 5 chronic kidney disease. Ren Fail 2014;36:495-501.

22. Essig M, Escoubet B, de Zuttere D, Blanchet F, Arnoult F, Dupuis E, et al. Cardiovascular remodelling and extracellular fluid excess in early stages of chronic kidney disease. Nephrol Dial Transplant 2008;23:239-248.

23. Dumler F,Kilates C. Prospective nutritional surveillance using bioelectrical impedance in chronic kidney disease patients. J Ren Nutr 2005;15:148-151.

24. Hung SC, Kuo KL, Peng CH, Wu CH, Lien YC, Wang YC, et al. Volume overload correlates with cardiovascular risk factors in patients with chronic kidney disease. Kidney Int 2014;85:703-709.

25. Caravaca F, Martinez del Viejo C, Villa J, Martinez Gallardo R,Ferreira F. Hydration status assessment by multi-frequency bioimpedance in patients with advanced chronic kidney disease. Nefrologia 2011;31:537-544.

26. Pellicano R, Strauss BJ, Polkinghorne KR,Kerr PG. Longitudinal body composition changes due to dialysis. Clin J Am Soc Nephrol 2011;6:1668-1675.

27. Hur E, Usta M, Toz H, Asci G, Wabel P, Kahvecioglu S, et al. Effect of fluid management guided by bioimpedance spectroscopy on cardiovascular parameters in hemodialysis patients: a randomized controlled trial. Am J Kidney Dis 2013;61:957-965.

28. Onofriescu M, Hogas S, Voroneanu L, Apetrii M, Nistor I, Kanbay M, et al. Bioimpedanceguided fluid management in maintenance hemodialysis: a pilot randomized controlled trial. Am J Kidney Dis 2014;64:111-118.

29. Chazot C, Vo-Van C, Deleaval P, Lorriaux C, Hurot JM, Mayor B, et al. Predialysis systolic blood pressure evolution in incident hemodialysis patients: effects of the dry weight method and prognostic value. Blood Purif 2012;33:275-283. 
30. Li Z, Lacson E, Jr., Lowrie EG, Ofsthun NJ, Kuhlmann MK, Lazarus JM, et al. The epidemiology of systolic blood pressure and death risk in hemodialysis patients. Am J Kidney Dis 2006;48:606-615.

31. Kalantar-Zadeh K, Block G, Humphreys MH,Kopple JD. Reverse epidemiology of cardiovascular risk factors in maintenance dialysis patients. Kidney Int 2003;63:793-808.

32. Sipahioglu MH, Usvyat L, Liu L, Abbas SR, Raimann JG, Rosales L, et al. Early systolic blood pressure changes in incident hemodialysis patients are associated with mortality in the first year. Kidney Blood Press Res 2012;35:663-670.

33. Vickery S, Price CP, John RI, Abbas NA, Webb MC, Kempson ME, et al. B-type natriuretic peptide (BNP) and amino-terminal proBNP in patients with CKD: relationship to renal function and left ventricular hypertrophy. Am J Kidney Dis 2005;46:610-620.

34. Okumura K, lo H, Matsumoto M, Seto T, Takagi M, Masuda A, et al. Predictive factors associated with change rates of LV hypertrophy and renal dysfunction in CKD patients. Clin Nephrol 2013;79:7-14.

35. Foley RN, Parfrey PS, Harnett JD, Kent GM, Martin CJ, Murray DC, et al. Clinical and echocardiographic disease in patients starting end-stage renal disease therapy. Kidney Int 1995;47:186-192.

36. Harnett JD, Foley RN, Kent GM, Barre PE, Murray D,Parfrey PS. Congestive heart failure in dialysis patients: prevalence, incidence, prognosis and risk factors. Kidney Int 1995;47:884-890.

37. Io H, Matsumoto M, Okumura K, Sato M, Masuda A, Furukawa M, et al. Predictive factors associated with left ventricular hypertrophy at baseline and in the follow-up period in nondiabetic hemodialysis patients. Semin Dial 2011;24:349-354.

38. Foley RN, Parfrey PS, Kent GM, Harnett JD, Murray DC,Barre PE. Serial change in echocardiographic parameters and cardiac failure in end-stage renal disease. J Am Soc Nephrol 2000;11:912-916.

39. Mostovaya IM, Bots ML, van den Dorpel MA, Goldschmeding R, den Hoedt CH, Kamp O, et al. Left ventricular mass in dialysis patients, determinants and relation with outcome. Results from the COnvective TRansport STudy (CONTRAST). PLoS One 2014;9:e84587.

40. Camici PG, Prasad SK,Rimoldi OE. Stunning, hibernation, and assessment of myocardial viability. Circulation 2008;117:103-114.

41. Assa S, Hummel YM, Voors AA, Kuipers J, Groen H, de Jong PE, et al. Changes in left ventricular diastolic function during hemodialysis sessions. Am J Kidney Dis 2013;62:549-556.

42. Burton JO, Jefferies HJ, Selby NM,McIntyre CW. Hemodialysis-induced cardiac injury: determinants and associated outcomes. Clin J Am Soc Nephrol 2009;4:914-920.

43. Assa S, Hummel YM, Voors AA, Kuipers J, Westerhuis R, de Jong PE, et al. Hemodialysisinduced regional left ventricular systolic dysfunction: prevalence, patient and dialysis treatment-related factors, and prognostic significance. Clin J Am Soc Nephrol 2012;7:1615-1623.

44. Burton JO, Jefferies $\mathrm{HJ}$, Selby NM,McIntyre CW. Hemodialysis-induced repetitive myocardial injury results in global and segmental reduction in systolic cardiac function. Clin J Am Soc Nephrol 2009;4:1925-1931. 
45. Assa S, Hummel YM, Voors AA, Kuipers J, Westerhuis R, Groen H, et al. Hemodialysis-induced regional left ventricular systolic dysfunction and inflammation: a cross-sectional study. Am J Kidney Dis 2014;64:265-273.

46. Briet $M$, Boutouyrie $P$, Laurent $S$, London $G M$. Arterial stiffness and pulse pressure in $C K D$ and ESRD. Kidney Int 2012;82:388-400.

47. Verbeke F, Van Biesen W, Honkanen E, Wikstrom B, Jensen PB, Krzesinski JM, et al. Prognostic value of aortic stiffness and calcification for cardiovascular events and mortality in dialysis patients: outcome of the calcification outcome in renal disease (CORD) study. Clin J Am Soc Nephrol 2011;6:153-159.

48. Karras A, Haymann JP, Bozec E, Metzger M, Jacquot C, Maruani G, et al. Large artery stiffening and remodeling are independently associated with all-cause mortality and cardiovascular events in chronic kidney disease. Hypertension 2012;60:1451-1457.

49. Porazko T, Kuzniar J, Kusztal M, Kuzniar TJ, Weyde W, Kuriata-Kordek M, et al. Increased aortic wall stiffness associated with low circulating fetuin $\mathrm{A}$ and high C-reactive protein in predialysis patients. Nephron Clin Pract 2009;113:c81-87.

50. Hermans MM, Henry R, Dekker JM, Kooman JP, Kostense PJ, Nijpels G, et al. Estimated glomerular filtration rate and urinary albumin excretion are independently associated with greater arterial stiffness: the Hoorn Study. J Am Soc Nephrol 2007;18:1942-1952.

51. Avramovski P, Janakievska P, Sotiroski K,Sikole A. Accelerated progression of arterial stiffness in dialysis patients compared with the general population. Korean J Intern Med 2013;28:464-474.

52. Mostovaya IM, Bots ML, van den Dorpel MA, Grooteman MP, Kamp O, Levesque R, et al. A randomized trial of hemodiafiltration and change in cardiovascular parameters. Clin J Am Soc Nephrol 2014;9:520-526.

53. Noordzij M, Cranenburg EM, Engelsman LF, Hermans MM, Boeschoten EW, Brandenburg VM, et al. Progression of aortic calcification is associated with disorders of mineral metabolism and mortality in chronic dialysis patients. Nephrol Dial Transplant 2011;26:1662-1669.

54. Garcia-Canton C, Bosch E, Ramirez A, Gonzalez Y, Auyanet I, Guerra R, et al. Vascular calcification and 25-hydroxyvitamin $\mathrm{D}$ levels in non-dialysis patients with chronic kidney disease stages 4 and 5. Nephrol Dial Transplant 2011;26:2250-2256.

55. Carrero JJ,Stenvinkel P. Inflammation in end-stage renal disease--what have we learned in 10 years? Semin Dial 2010;23:498-509.

56. Kopple JD, Greene T, Chumlea WC, Hollinger D, Maroni BJ, Merrill D, et al. Relationship between nutritional status and the glomerular filtration rate: results from the MDRD study. Kidney Int 2000;57:1688-1703.

57. Pupim LB, Evanson JA, Hakim RM, Ikizler TA. The extent of uremic malnutrition at the time of initiation of maintenance hemodialysis is associated with subsequent hospitalization. J Ren Nutr 2003;13:259-266.

58. Bergstrom J. Nutrition and mortality in hemodialysis. J Am Soc Nephrol 1995;6:1329-1341.

59. Rosansky S, Glassock RJ,Clark WF. Early start of dialysis: a critical review. Clin J Am Soc Nephrol 2011;6:1222-1228. 
60. Anderstam B, Mamoun AH, Sodersten P,Bergstrom J. Middle-sized molecule fractions isolated from uremic ultrafiltrate and normal urine inhibit ingestive behavior in the rat. J Am Soc Nephrol 1996;7:2453-2460.

61. Ikizler TA, Pupim LB, Brouillette JR, Levenhagen DK, Farmer K, Hakim RM, et al. Hemodialysis stimulates muscle and whole body protein loss and alters substrate oxidation. Am J Physiol Endocrinol Metab 2002;282:E107-116.

62. den Hoedt CH, Bots ML, Grooteman MP, van der Weerd NC, Penne EL, Mazairac AH, et al. Clinical predictors of decline in nutritional parameters over time in ESRD. Clin J Am Soc Nephrol 2014;9:318-325.

63. Kaysen GA. Progressive inflammation and wasting in patients with ESRD. Clin J Am Soc Nephrol 2014;9:225-226.

64. Pupim LB, Kent P, Caglar K, Shyr Y, Hakim RM, Ikizler TA. Improvement in nutritional parameters after initiation of chronic hemodialysis. Am J Kidney Dis 2002;40:143-151.

65. Mehrotra R, Berman N, Alistwani A,Kopple JD. Improvement of nutritional status after initiation of maintenance hemodialysis. Am J Kidney Dis 2002;40:133-142.

66. Chazot C, Deleaval P, Bernollin AL, Vo-Van C, Lorriaux C, Hurot JM, et al. Target weight gain during the first year of hemodialysis therapy is associated with patient survival. Nephron Clin Pract 2014;126:128-134.

67. Pupim LB, Heimburger O, Qureshi AR, Ikizler TA,Stenvinkel P. Accelerated lean body mass loss in incident chronic dialysis patients with diabetes mellitus. Kidney Int 2005;68:2368-2374.

68. Konings CJ, Kooman JP, Schonck M, van Kreel B, Heidendal GA, Cheriex EC, et al. Influence of fluid status on techniques used to assess body composition in peritoneal dialysis patients. Perit Dial Int 2003;23:184-190.

69. Peev V, Nayer A,Contreras G. Dyslipidemia, malnutrition, inflammation, cardiovascular disease and mortality in chronic kidney disease. Curr Opin Lipidol 2014;25:54-60.

70. Stenvinkel P, Heimburger O, Paultre F, Diczfalusy U, Wang T, Berglund L, et al. Strong association between malnutrition, inflammation, and atherosclerosis in chronic renal failure. Kidney Int 1999;55:1899-1911.

71. Sandek A, Bauditz J, Swidsinski A, Buhner S, Weber-Eibel J, von Haehling S, et al. Altered intestinal function in patients with chronic heart failure. J Am Coll Cardiol 2007;50:1561-1569.

72. Beerenhout $\mathrm{CH}$, Kooman JP, van der Sande FM, Hackeng C,Leunissen KM. C-reactive protein levels in dialysis patients are highly variable and strongly related to co-morbidity. Nephrol Dial Transplant 2003;18:221.

73. Snaedal S, Heimburger O, Qureshi AR, Danielsson A, Wikstrom B, Fellstrom B, et al. Comorbidity and acute clinical events as determinants of C-reactive protein variation in hemodialysis patients: implications for patient survival. Am J Kidney Dis 2009;53:1024-1033.

74. Bingel M, Lonnemann G, Koch KM, Dinarello CA,Shaldon S. Plasma interleukin-1 activity during hemodialysis: the influence of dialysis membranes. Nephron 1988;50:273-276.

75. Caglar K, Peng Y, Pupim LB, Flakoll PJ, Levenhagen D, Hakim RM, et al. Inflammatory signals associated with hemodialysis. Kidney Int 2002;62:1408-1416. 
76. Tarakcioglu M, Erbagci AB, Usalan C, Deveci R,Kocabas R. Acute effect of hemodialysis on serum levels of the proinflammatory cytokines. Mediators Inflamm 2003;12:15-19.

77. Susantitaphong P, Riella C,Jaber BL. Effect of ultrapure dialysate on markers of inflammation, oxidative stress, nutrition and anemia parameters: a meta-analysis. Nephrol Dial Transplant 2013;28:438-446.

78. Banerjee T, Kim SJ, Astor B, Shafi T, Coresh J,Powe NR. Vascular Access Type, Inflammatory Markers, and Mortality in Incident Hemodialysis Patients: The Choices for Healthy Outcomes in Caring for End-Stage Renal Disease (CHOICE) Study. Am J Kidney Dis 2014;

79. Mclntyre CW, Harrison LE, Eldehni MT, Jefferies HJ, Szeto CC, John SG, et al. Circulating endotoxemia: a novel factor in systemic inflammation and cardiovascular disease in chronic kidney disease. Clin J Am Soc Nephrol 2011;6:133-141.

80. Pupim LB, Himmelfarb J, McMonagle E, Shyr Y, Ikizler TA. Influence of initiation of maintenance hemodialysis on biomarkers of inflammation and oxidative stress. Kidney Int 2004;65:23712379.

81. Painter P. Physical functioning in end-stage renal disease patients: update 2005. Hemodial Int 2005;9:218-235.

82. Avesani CM, Trolonge S, Deleaval P, Baria F, Mafra D, Faxen-Irving G, et al. Physical activity and energy expenditure in haemodialysis patients: an international survey. Nephrol Dial Transplant 2012;27:2430-2434.

83. Stack AG, Molony DA, Rives T, Tyson J,Murthy BV. Association of physical activity with mortality in the US dialysis population. Am J Kidney Dis 2005;45:690-701.

84. Tentori F, Elder SJ, Thumma J, Pisoni RL, Bommer J, Fissell RB, et al. Physical exercise among participants in the Dialysis Outcomes and Practice Patterns Study (DOPPS): correlates and associated outcomes. Nephrol Dial Transplant 2010;25:3050-3062.

85. Zamojska S, Szklarek M, Niewodniczy M,Nowicki M. Correlates of habitual physical activity in chronic haemodialysis patients. Nephrol Dial Transplant 2006;21:1323-1327.

86. Gould DW, Graham-Brown MP, Watson EL, Viana JL,Smith AC. Physiological benefits of exercise in pre-dialysis chronic kidney disease. Nephrology (Carlton) 2014;19:519-527.

87. Wlodarek D, Glabska D,Rojek-Trebicka J. Physical activity of predialysis patients with chronic kidney disease measured using SenseWear Armban. J Sports Med Phys Fitness 2011;51:639-646.

88. Majchrzak KM, Pupim LB, Chen K, Martin CJ, Gaffney S, Greene JH, et al. Physical activity patterns in chronic hemodialysis patients: comparison of dialysis and nondialysis days. J Ren Nutr 2005;15:217-224.

89. Kurella Tamura M, Covinsky KE, Chertow GM, Yaffe K, Landefeld CS,McCulloch CE. Functional status of elderly adults before and after initiation of dialysis. N Engl J Med 2009;361:1539-1547.

90. Kotanko P, Kooman J, van der Sande F, Kappel F, Usvyat L. Accelerated or Out of Control: The Final Months on Dialysis. J Ren Nutr 2014;

91. Murray SA, Kendall M, Boyd K,Sheikh A. Illness trajectories and palliative care. Bmj 2005;330:1007-1011. 
92. Wingard RL, Pupim LB, Krishnan M, Shintani A, Ikizler TA,Hakim RM. Early intervention improves mortality and hospitalization rates in incident hemodialysis patients: RightStart program. Clin J Am Soc Nephrol 2007;2:1170-1175.

93. Intiso D. The rehabilitation role in chronic kidney and end stage renal disease. Kidney Blood Press Res 2014;39:180-188.

94. Mehrotra R, Rivara M,Himmelfarb J. Initiation of dialysis should be timely: neither early nor late. Semin Dial 2013;26:644-649. 



\section{CHAPTER 3}

BODY COMPOSITION IN DIALYSIS PATIENTS: A FUNCTIONAL ASSESSMENT OF BIOIMPEDANCE USING DIFFERENT PREDICTION MODELS

Natascha J.H. Broers, Remy J.H. Martens, Tom Cornelis, Nanda M.P. Diederen, Peter Wabel, Frank M. van der Sande, Karel M.L. Leunissen and Jeroen P. Kooman

J Ren Nutr. 2015;25(2):121-8 


\section{ABSTRACT \\ Objectives}

The assessment of body composition (BC) in dialysis patients is of clinical importance given its role in the diagnosis of malnutrition and sarcopenia. Bioimpedance techniques routinely express $\mathrm{BC}$ as a 2-compartment (2-C) model distinguishing fat mass (FM) and fat-free mass (FFM), which may be influenced by the hydration of adipose tissue and fluid overload $(\mathrm{OH})$. Recently, the BC monitor was introduced which applies a 3-compartment (3-C) model, distinguishing $\mathrm{OH}$, adipose tissue mass, and lean tissue mass. The aim of this study was to compare $\mathrm{BC}$ between the 2-C and 3-C models and assess their relation with markers of functional performance (handgrip strength [HGS] and 4-m walking test), as well as with biochemical markers of nutrition.

\section{Methods}

Forty-seven dialysis patients ( 30 males and 17 females) (35 hemodialysis, 12 peritoneal dialysis) with a mean age of 64.8616 .5 years were studied. 3-C BC was assessed by BC monitor, whereas the obtained resistivity values were used to calculate FM and FFM according to the Xitron Hydra 4200 formulas, which are based on a 2-C model.

\section{Results}

FFM (3-C) was $0.99 \mathrm{~kg}$ (95\% confidence interval [Cl], 0.27 to $1.71, \mathrm{P}=0.008)$ higher than FFM (2-C). FM (3-C) was $2.43 \mathrm{~kg}(95 \% \mathrm{Cl}, 1.70-3.15, \mathrm{P}=0.001)$ lower than $\mathrm{FM} \mathrm{(2-C).} \mathrm{OH} \mathrm{was}$ $1.4 \pm 1.8 \mathrm{~L}$. OH correlated significantly with $\triangle F F M(F F M ~ 3-C-F F M ~ 2-C)(r=0.361 ; P=0.05)$ and $\triangle F M(F M ~ 3-C-F M ~ 2-C)(r=0.387 ; P=0.009)$. HGS correlated significantly with FFM (2-C) $(r=0.713 ; P=0.001)$, FFM (3-C) $(r=0.711 ; P=0.001)$, body cell mass $(2-C)(r=0.733 ; P=0.001)$, and body cell mass $(3-C)(r=0.767 ; P=0.001)$. Both physical activity $(r=0.456 ; P=0.004)$ and HGS ( $r=0.488 ; P=0.002)$, but not $B C$, were significantly related to walking speed.

\section{Conclusions}

Significant differences between 2-C and 3-C models were observed, which are partly explained by the presence of $\mathrm{OH} . \mathrm{OH}$, which was related to $\triangle \mathrm{FFM}$ and $\triangle \mathrm{FM}$ of the 2-C and 3-C models, is therefore an important parameter for the differences in estimation of $\mathrm{BC}$ parameters of the 2-C and 3-C models. Both FFM (3-C) and FFM (2-C) were significantly related to HGS. Bioimpedance, HGS, and the 4-m walking test may all be valuable tools in the multidimensional nutritional assessment of both hemodialysis and peritoneal dialysis patients. 


\section{INTRODUCTION}

Protein-energy wasting (PEW) is common in dialysis patients and strongly related to morbidity and mortality ${ }^{1}$. Dialysis patients suffering from PEW syndrome are often characterized by low body weight, low protein and energy levels, and loss of muscle mass (sarcopenia) and have an increased risk of frailty, which is also common in dialysis patients besides an increased risk of mortality ${ }^{2}$. Given the fact that PEW and sarcopenia in dialysis patients may be partly amendable to interventions such as optimal nutrition and exercise training, optimal diagnosis of changes in body composition (BC) is of great clinical importance ${ }^{3}$. Various methods are available to estimate $B C$ in renal failure. For example, dual-energy X-ray absorptiometry (DEXA) and computed tomography or magnetic resonance imaging have a high reliability and precision in determining lipid mass and fat mass (FM) and thus estimating lean body mass (LBM) ${ }^{4-6}$. Nevertheless, these methods are not applicable on a bedside basis. Other techniques like anthropometric measurements are operator dependent and may therefore be imprecise. Recently, the value of serum creatinine as a marker of muscle mass was shown $n^{7,8}$. However, this approach is only reliable in stable dialysis patients due to the variability of serum creatinine levels, influenced by, for example, dietary intake ${ }^{8}$. Bioimpedance techniques are easily applicable as a bedside tool for nutritional assessment and have been widely used in studies for the assessment of $\mathrm{BC}$ in dialysis patients ${ }^{9}$. Multifrequency bioimpedance analysis is theoretically able to distinguish between extracellular (ECW) and intracellular water (ICW) and estimates BC as a 2-compartment (2-C) model by evaluating fat-freemass (FFM) and $\mathrm{FM}^{10}$, whereas appendicular mass by DEXA is used for the traditional diagnosis of sarcopenia. However, in a 2-C model, variations in hydration state may have a strong effect on the prediction of $\mathrm{FFM}^{11,12}$.

Recently, a novel prediction model was validated, in which $\mathrm{BC}$ is estimated as a 3-compartment (3-C) model, by which also fluid overload $(\mathrm{OH})$ is estimated. The model uses a correction factor for body mass index (BMI) and was introduced into the body composition monitor (BCM). The BCM is based on earlier versions of the XiTRON Bioimpedance spectroscopy device (Hydra 4200; XiTRON Technologies Inc., San Diego, CA), and estimates BC as a 3-C model by which $\mathrm{OH}$, lean tissue mass (LTM), and adipose tissue mass (ATM) are calculated from ECW and total body water estimations. In this model, constant hydration ratios of the normohydrated lean tissue and adipose tissue are assumed ${ }^{11}$. Various interventional and observational studies have shown the value of the $\mathrm{BCM}$ assessing $\mathrm{OH}$ in dialysis patients ${ }^{13-15}$. However, to the best of our knowledge, no direct comparison has been performed between 2-C and 3-C models in the assessment of $\mathrm{BC}$ in dialysis patients. Still, given the fact that both 2-C and 3-C models are presently used in clinical practice as well as for research purposes, it is of importance to identify potential differences in the assessment of $B C$ between both diagnostic approaches.

Whereas appendicular skeletal muscle, as measured by DEXA, is traditionally used as a gold standard in the diagnosis of sarcopenia, also FFM, assessed by BIA has been suggested as an 
alternative tool in the diagnosis of sarcopenia ${ }^{16}$. However, for a valid method in the diagnosis of sarcopenia, a strong relation between $\mathrm{BC}$ and functional performance is to be expected. Recently, functional definitions of sarcopenia, based on handgrip strength (HGS) and walking speed were introduced ${ }^{17}$. There is limited evidence on the relation between bioimpedance with functional parameters of physical performance. For clinical application, it is also of importance to identify to which degree there are different or overlapping dimensions between $\mathrm{BC}$ and different markers of physical performance.

The first aim of this study was to compare BC estimated by a 2-C and 3-C whole-body bioimpedance model. The second aim was to assess the relation between $\mathrm{BC}$, assessed by the two different models with parameters of functional performance, in comparison with biochemical and clinical nutritional parameters in dialysis patients.

\section{METHODS}

\section{Study population}

Forty-seven dialysis patients ( 35 hemodialysis [HD] and 12 peritoneal dialysis [PD] patients) were included in this study. Age ranged from 23 to 88 years. All participating patients were in a stable clinical condition. Patients were treated with HD or PD treatment for at least 1 month. Patients were not in a fasting state during the measurements. Exclusion criteria were an implantable cardioverter defibrillator or pacemaker (interference with BCM), acute intercurrent disease, and physical disability (walk test measurements). Written informed consent was obtained from each patient before participation. The study was approved by the Ethical Committee and the Hospital Board.

\section{Body composition monitor measurements}

Bioimpedance spectroscopy was used to determine BC by the 3-C model (ATM, LTM, and $\mathrm{OH}$ ) by the $\mathrm{BCM}^{\circledast}$ (Fresenius Medical Care, Bad Homburg). ATM consists of the lipid part and the fluid part. The hydration of FM is accounted for by a standardized hydration ratio $(0.2)$. Also FM is expressed by the BCM, which is adipose tissue corrected for this hydration factor. This parameter is referred to as FM (3-C). LTM (3-C) represents the muscle, organs, blood, bones, and fluid overload using fixed rations for the hydration of the LTM. The BCM model is described by Chamney et $\mathrm{al}^{11}$.

Measurements were taken as described in the manufacturer's manual ${ }^{18}$. Patients were in supine position. For all HD patients, measurements were taken before dialysis treatment, in agreement with earlier studies ${ }^{15,19}$. For all PD patients, measurements were taken during a visit at the out-patient clinic. Measurements were taken with a full abdomen for practical reasons, also because sequestered fluid in the trunk only has a minor influence on wholebody bioimpedance measurements ${ }^{20-22}$. In addition, body weight was corrected for PD fluid. The methodology to assess resistance of ECW and ICW in BCM is derived from the Xitron Hydra $4200^{\circledR}$. The original Hanai mixture theory equations were adjusted by Moissl ${ }^{23}$. 
Equations available from the user manual of the Xitron Hydra 4200 were used to calculate FFM and FM in a 2-C model (http://www.xitrontech.com/assets/002/5854.pdf).

\section{Handgrip strength}

HGS was measured twice with a hand held dynamometer (Jamar ${ }^{\circledR}$, Sammons Preston Inc, Bolingbrook, IL) in standing position with the arm in a flexed position of $90^{\circ}$. Measurements in HD patients took place on the contralateral arm of the shunt arm and in PD patients in the dominant hand.

\section{Four meter walking test}

Four meter walking test was conducted to determine walking speed. Patients covered a distance of $4 \mathrm{~m}$ to measure walking speed. The validity and sensitivity of the 4-m walking test have been confirmed in epidemiologic studies, and the test is widely used in other studies to determine walking speed ${ }^{24-27}$ among other parameters to assess sarcopenia in geriatric patients ${ }^{17}$ and physical function in end-stage renal disease patients ${ }^{28}$.

\section{Physical activity}

Physical activity was assessed by questioning the patient about their activity levels during leisure time. Patients were asked to answer the following question: "How often do you exercise (do physical activity during your leisure time)? For example, walking, running, swimming, biking?" The following answer possibilities were given: (1) (almost) never, (2) once a week, (3) 2-3 times a week, (4) 4-5 times a week, (5) (almost) daily. Patients answering "(almost) never" were classified as inactive, according to the US Renal Data System Dialysis Morbidity and Mortality Study Wave $2^{29}$.

\section{Laboratory parameters}

Blood samples were collected in all patients to determine creatinine and albumin levels. In HD patients, blood samples were collected before the start of dialysis via vascular access (shunt or central venous catheter). In PD patients, blood samples were collected when all other measurements took place.

\section{Statistical analysis}

Differences between body compartments using the 2-C and 3-C models were assessed by paired-samples t-tests. Bivariate correlation tests were used to assess relations.

Data are expressed as mean \pm standard deviation, unless indicated otherwise. Statistical analyses were performed by IBM (Armonk, NY) SPSS Statistics for Windows, version 20. P-values $<0.05$ were considered to be statistically significant. 


\section{RESULTS}

\section{Patient characteristics}

Patient demographics are shown in Table 3.1. Of the 47 patients, $8.5 \%$ had a BMI $<20 \mathrm{~kg} / \mathrm{m}^{2}$, $21.3 \%$ had a BMI between 20 and $24.9 \mathrm{~kg} / \mathrm{m}^{2}, 38.3 \%$ had a BMI between 25 and $29.9 \mathrm{~kg} / \mathrm{m}^{2}$, and $31.9 \%$ had a $\mathrm{BMI} \geq 30 \mathrm{~kg} / \mathrm{m}^{2}$.

In $87.2 \%$ of the patients, mean walking speed $(1.32 \pm 0.46 \mathrm{~m} / \mathrm{second})$ was above the reference value for the general population, where poor mobility was defined as walking speed $<0.8 \mathrm{~m} /$ second $^{17}$. In Table 3.2 gender distribution is shown for different dialysis modalities.

Table 3.1 Patient Demographics.

\begin{tabular}{|c|c|}
\hline Patient Demographics & \\
\hline Number of Patients & 47 \\
\hline Male/Female & $30 / 17$ \\
\hline $\mathrm{HD} / \mathrm{PD}$ & $35 / 12$ \\
\hline Oliguric/Nonoliguric & $17 / 30$ \\
\hline Age (years) & $64.8 \pm 16.5$ \\
\hline Height (cm) & $170.7 \pm 9.0$ \\
\hline Weight Predialysis (kg) & $78.8 \pm 18.1$ \\
\hline BMI $\left(\mathrm{kg} / \mathrm{m}^{2}\right) \mathrm{m} / \mathrm{f}$ & $28.1 \pm 4.2 / 25.2 \pm 5.6$ \\
\hline LTI* $\left(\mathrm{kg} / \mathrm{m}^{2}\right) \mathrm{m} / \mathrm{f}$ & $13.8 \pm 2.5 / 11.3 \pm 1.6$ \\
\hline $\mathrm{FTI} *\left(\mathrm{~kg} / \mathrm{m}^{2}\right) \mathrm{m} / \mathrm{f}$ & $13.1 \pm 4.4 / 13.5 \pm 5.3$ \\
\hline Body Cell Mass* (kg) m/f & $23.0 \pm 5.3 / 15.8 \pm 3.5$ \\
\hline Fluid overload* (L) & $1.4 \pm 1.8$ \\
\hline SBP Predialysis (mmHg) & $148.0 \pm 24.6$ \\
\hline DBP Predialysis (mmHg) & $77.6 \pm 16.3$ \\
\hline Heart rate Predialysis (bpm) & $73 \pm 10$ \\
\hline Grip strength (kg) m/f & $29.6 \pm 10.2 / 17.9 \pm 7.1$ \\
\hline Walk speed (m/sec) & $1.32 \pm 0.46$ \\
\hline Serum Creatinine $(\mu \mathrm{mol} / \mathrm{L}) \mathrm{m} / \mathrm{f}$ & $768 \pm 204 / 678 \pm 346$ \\
\hline Serum Albumin (g/L) & $40.6 \pm 3.4$ \\
\hline
\end{tabular}

Data given as frequency and mean \pm SD. HD: hemodialysis; PD: peritoneal dialysis; BMI: body mass index; LTI: lean tissue index; FTI: fat tissue index: SBP: systolic blood pressure; DBP: diastolic blood pressure. * Derived from the 3-C model by body composition monitor.

Table 3.2 Gender distribution per dialysis modality.

\begin{tabular}{lll}
\hline Parameter & Hemodialysis & Peritoneal Dialysis \\
\hline Male/Female & $22 / 13$ & $8 / 4$ \\
\hline
\end{tabular}

\section{Comparison of body composition between the 2-C and 3-C models}

Outcome parameters of the Xitron hydra 4200 (2-C) were significantly different from BCM outcomes (3-C). Results are shown in table 3.3. FFM (3-C) was on average (differences calculated per patient) $0.99 \mathrm{~kg}(95 \%$ confidence interval $[\mathrm{Cl}], 0.27$ to $1.71, \mathrm{P}=0.008)$ higher than FFM (2-C). The same held true for the different dialysis modalities, where the mean 
difference of FFM (3-C vs. 2-C) was $0.97 \pm 2.55 \mathrm{~kg}$ for $\mathrm{HD}$ and $1.04 \pm 1.90 \mathrm{~kg}$ for PD. FM (3-C) was on average (differences calculated per patient) $2.43 \mathrm{~kg}(95 \% \mathrm{Cl}, 1.70$ to $3.15, \mathrm{P}<0.001)$ lower than FM (2-C). The same held true for the different dialysis modalities, where the mean difference of FM (3-C vs. $2-C$ ) was $-2.45 \pm 2.60 \mathrm{~kg}$ for HD and $-2.36 \pm 1.81 \mathrm{~kg}$ for PD. Figure 3.1 showed a significant correlation between $\mathrm{OH}$ and both $\triangle F F M$ (FFM 3-C - FFM 2-C) $(r=0.361 ; P<0.05)$ and $\triangle F M(F M ~ 3-C-F M ~ 2-C)(r=0.387 ; P=0.009)$.

Table 3.3 Parameter outcomes 2-C model (Xitron hydra 4200) vs. 3-C model (BCM).

\begin{tabular}{lllr}
\hline Parameter & BCM $(\mathbf{n}=\mathbf{4 5})$ & Xitron hydra $\mathbf{4 2 0 0} \mathbf{( n = 4 5 )}$ & p-value \\
& 3-C & 2-C & 0.008 \\
\hline FFM (kg) & $48.70 \pm 10.02$ & $47.71 \pm 11.86$ & $<0.001$ \\
FM (kg) & $28.65 \pm 10.93$ & $31.08 \pm 9.28$ & $<0.001$ \\
Body Cell Mass (kg) & $20.28 \pm 5.84$ & $26.12 \pm 7.79$ & 0.019 \\
TBW (L) & $37.07 \pm 7.49$ & $36.44 \pm 8.68$ & 0.001 \\
ECW (L) & $18.05 \pm 3.84$ & $18.26 \pm 3.99$ & 0.001 \\
ICW (L) & $19.03 \pm 4.02$ & $18.18 \pm 5.25$ & \\
\hline
\end{tabular}

Data given as mean \pm SD. FFM: fat free mass; FM: fat mass; TBW: total body water; ECW: extracellular water; ICW: intracellular water.

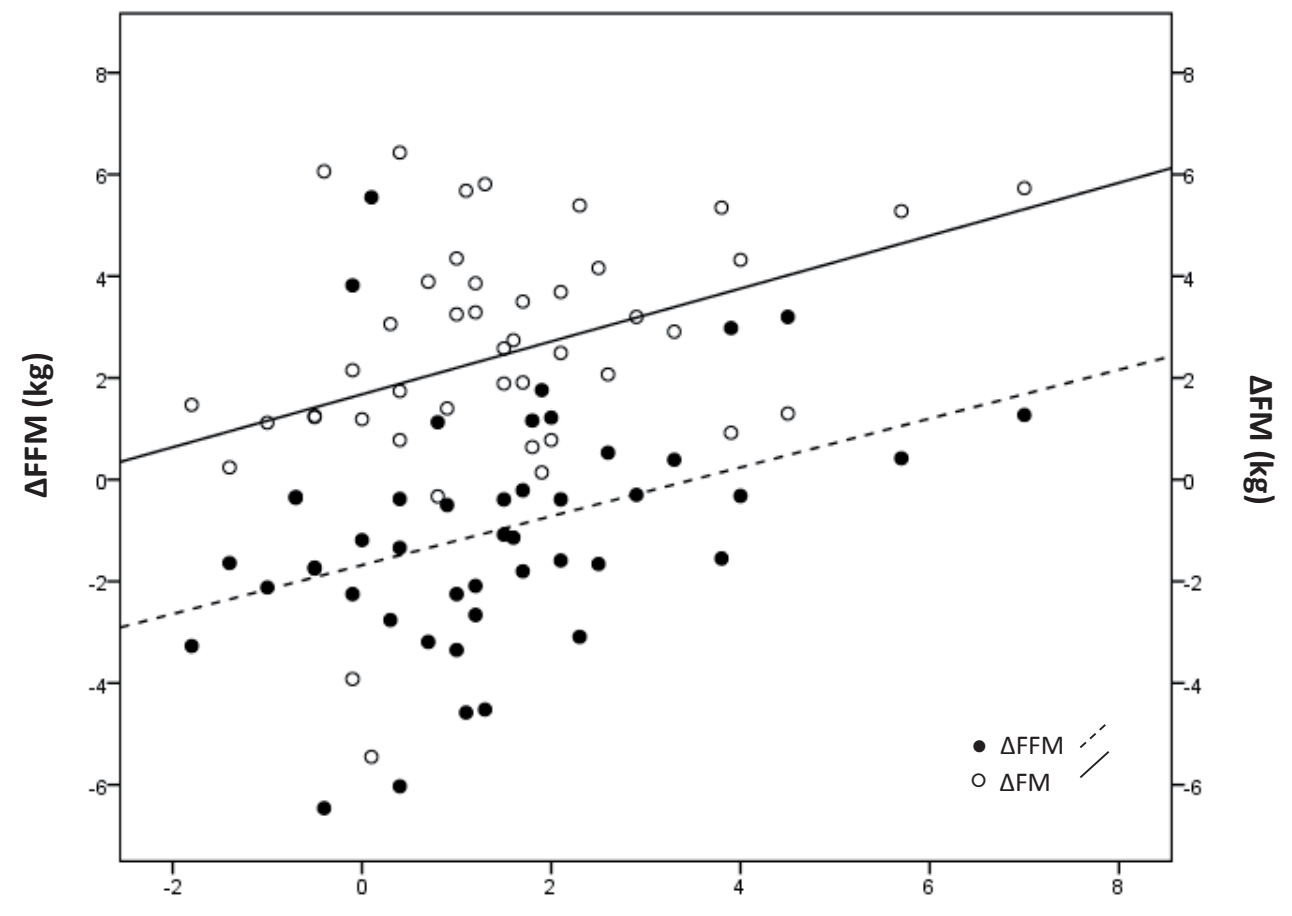

Fluid overload $(\mathrm{OH})(\mathrm{L})$

Figure 3.1 Relationship between fluid overload $(\mathrm{OH})$ and both $\Delta$ fat free mass $(\Delta \mathrm{FFM})$ and $\Delta$ fat mass $(\Delta \mathrm{FM})$. There was a significant positive correlation between $\mathrm{OH}$ and $\triangle F F M$ (black dots; scattered line) $(r=0.361 ; P<0.05) ;$ and there was a significant positive correlation between $\mathrm{OH}$ and $\Delta \mathrm{FM}$ (white dots; black line) $(r=0.387 ; \mathrm{P}=0.009)$. 


\section{Comparison of body composition between dialysis patients and healthy age-matched individuals}

For comparison with age-matched controls, LTM and ATM were corrected for height ${ }^{2}$ and expressed as lean tissue index (LTI) and fat tissue index (FTI), respectively. Reference values as reported by Wieskotten et al. ${ }^{30}$ were used.

Figure 3.2 showed that in $52.9 \%$ of the females and $32.1 \%$ of the males LTI (kilogram per square meter) was below reference ranges for healthy individuals. Whereas in $88.2 \%$ of the females and $96.4 \%$ of the males FTI (kilogram per square meter) was in general either normal or even above the age-matched reference ranges (Fig. 3.3).
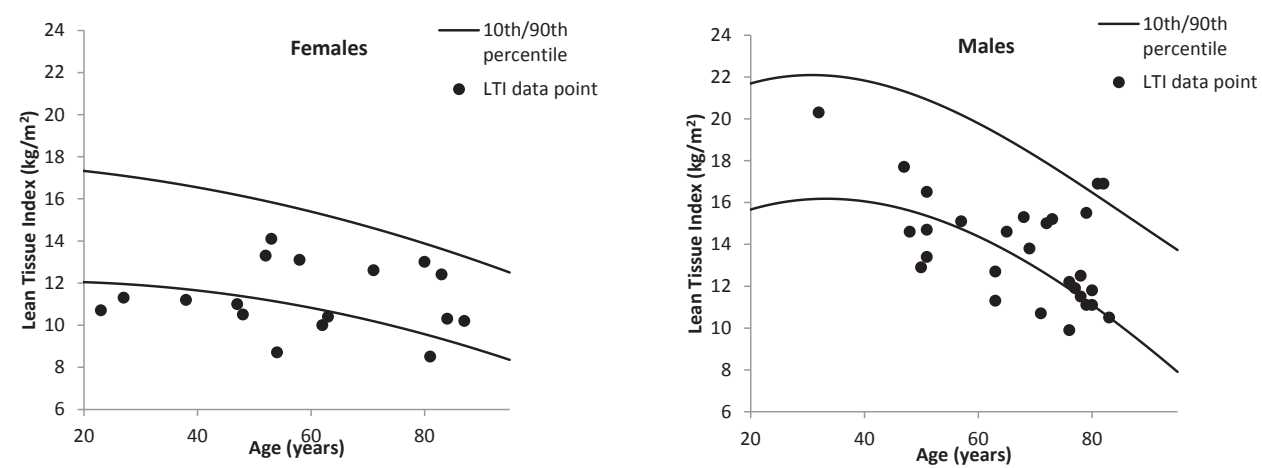

Figure 3.2 Lean tissue index (kilogram per square meter) in females and males. Females (52.9\%) and males $(32.1 \%)$ were under the reference ranges for age-matched controls ( $10^{\text {th }}$ percentile).
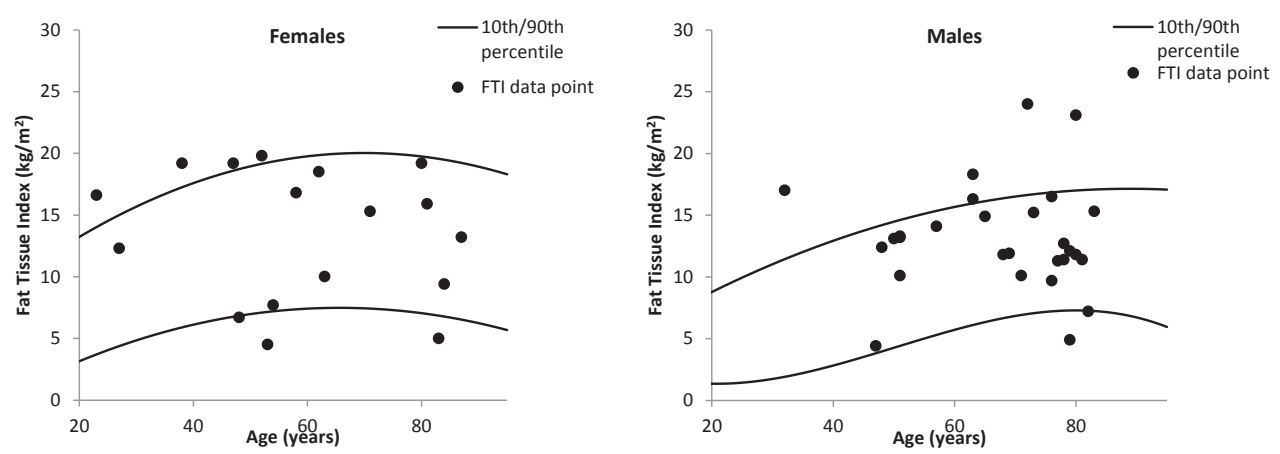

Figure 3.3 Fat tissue index (kilogram per square meter) in females and males. 88.2 percent of the females and 96.4 percent of the males were within or above the reference ranges for age-matched controls ( $10^{\text {th }}$ and $90^{\text {th }}$ percentile).

\section{Relation between functional parameters and bioimpedance}

Despite statistically significant differences between parameters of the 2-C and 3-C models, HGS was highly significantly related to FFM $(2-C)(r=0.713 ; P<0.001)$ and FFM $(3-C)(r=0.711$; $P<0.001 ;$ Fig. 3.4). HGS also significantly related to body cell mass $(2-C)(r=0.733 ; P<0.001)$ and body cell mass $(3-C)(r=0.767 ; P<0.001)$. No significant relations were found between 
4-m walking test and $B C$ parameters. Additional analyses showed that even when subdivided for dialysis modality, body cell mass was still highly related to HGS (Fig. 3.5). Again, no significant relations were found between 4-m walking test and BC.

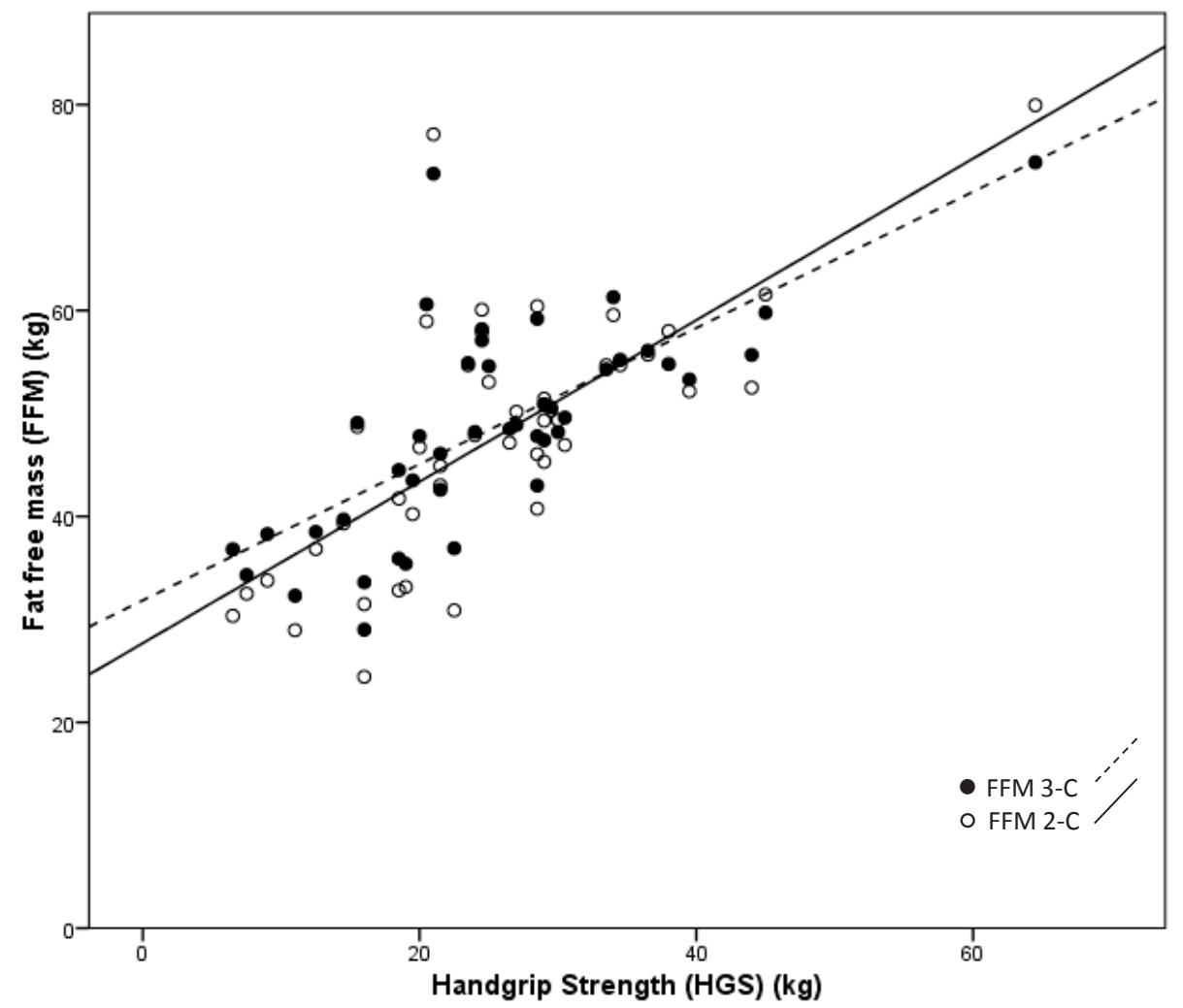

Figure 3.4 Relationship between handgrip strength and fat free mass. There was a significant positive correlation between handgrip strength and fat free mass $(3-C)$ (black dots; scattered line) $(r=0.713 ; P<0.001)$, and there was a significant positive correlation between handgrip strength and fat free mass (2-C) (white dots; black line) $(r=0.711 ; P<0.001)$.
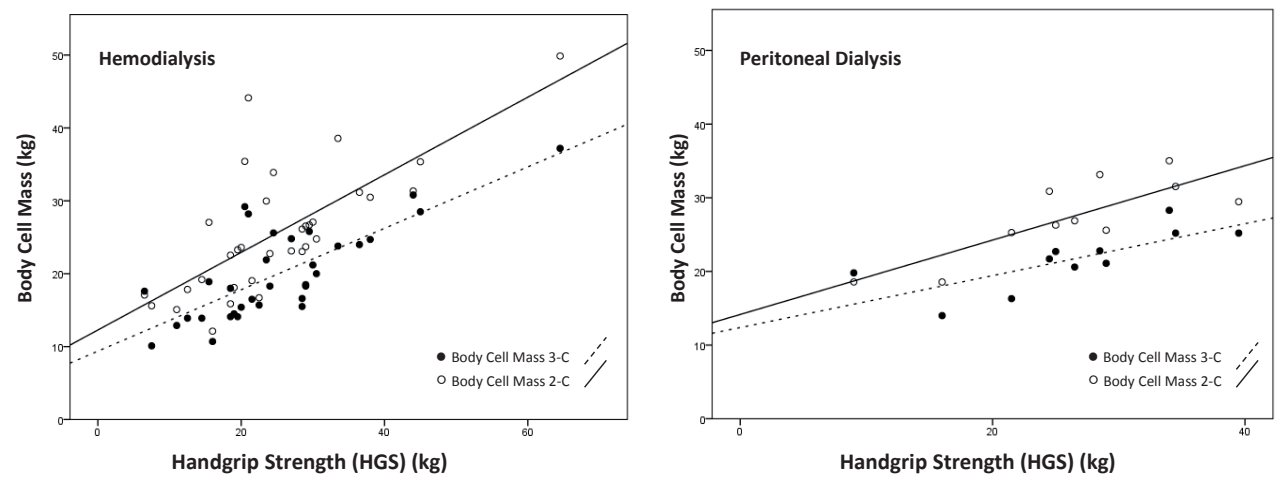

Figure 3.5. Relationship between handgrip strength (HGS) and body cell mass in hemodialysis (HD) and peritoneal dialysis (PD) patients. There was a significant positive correlation in HD patients between HGS and body cell mass (3C) (black dots; scattered line) ( $r=0.772 ; P<0.001)$; and HGS vs. body cell mass (2-C) (white dots; black line) ( $r=0.723$; $\mathrm{P}<0.001)$. Also a significant positive correlation in $\mathrm{PD}$ patients between $\mathrm{HGS}$ and body cell mass (3-C) was found (black dots; scattered line) ( $r=0.752 ; \mathrm{P}=0.008)$; and HGS vs. body cell mass (2-C) (white dots; black line) $(r=0.810 ; P=0.003)$. 


\section{Relation between bioimpedance and biochemical parameters}

The relationship between FFM $(2-C)$ and creatinine was significant $(r=0.317 ; P<0.05)$, the same held true for the relationship between FFM $(2-C)$ and albumin $(r=0.319 ; P<0.05)$. Comparable correlations were found for FFM $(3-C)$ and creatinine $(r=0.300 ; P<0.05)$ and albumin ( $r=0.319 ; \mathrm{P}<0.05)$. The relationship between body cell mass $(2-\mathrm{C})$ and creatinine was significant $(r=0.321 ; \mathrm{P}<0.05)$. The same held true for body cell mass $(2-\mathrm{C})$ and albumin $(r=0.378 ; P<0.05)$. For the body cell mass $(3-C)$, comparable correlations were found. $A$ significant relationship was found for both body cell mass $(3-C)$ and creatinine $(r=0.313$; $P<0.05)$ as well as for body cell mass $(3-C)$ and albumin $(r=0.388 ; P<0.05)$. No significant relations were found between FM (for both $2-\mathrm{C}$ and $3-\mathrm{C}$ ) and creatinine and albumin.

\section{Relation between different functional parameters}

The relationship between physical activity assessed by questionnaires, and HGS was not significant ( $r=0.230 ; P=0.124)$. However, both physical activity $(r=0.456 ; P=0.004)$ and HGS ( $r=0.488 ; P=0.002$ ) were significantly related to the walking speed (Fig. 3.6).

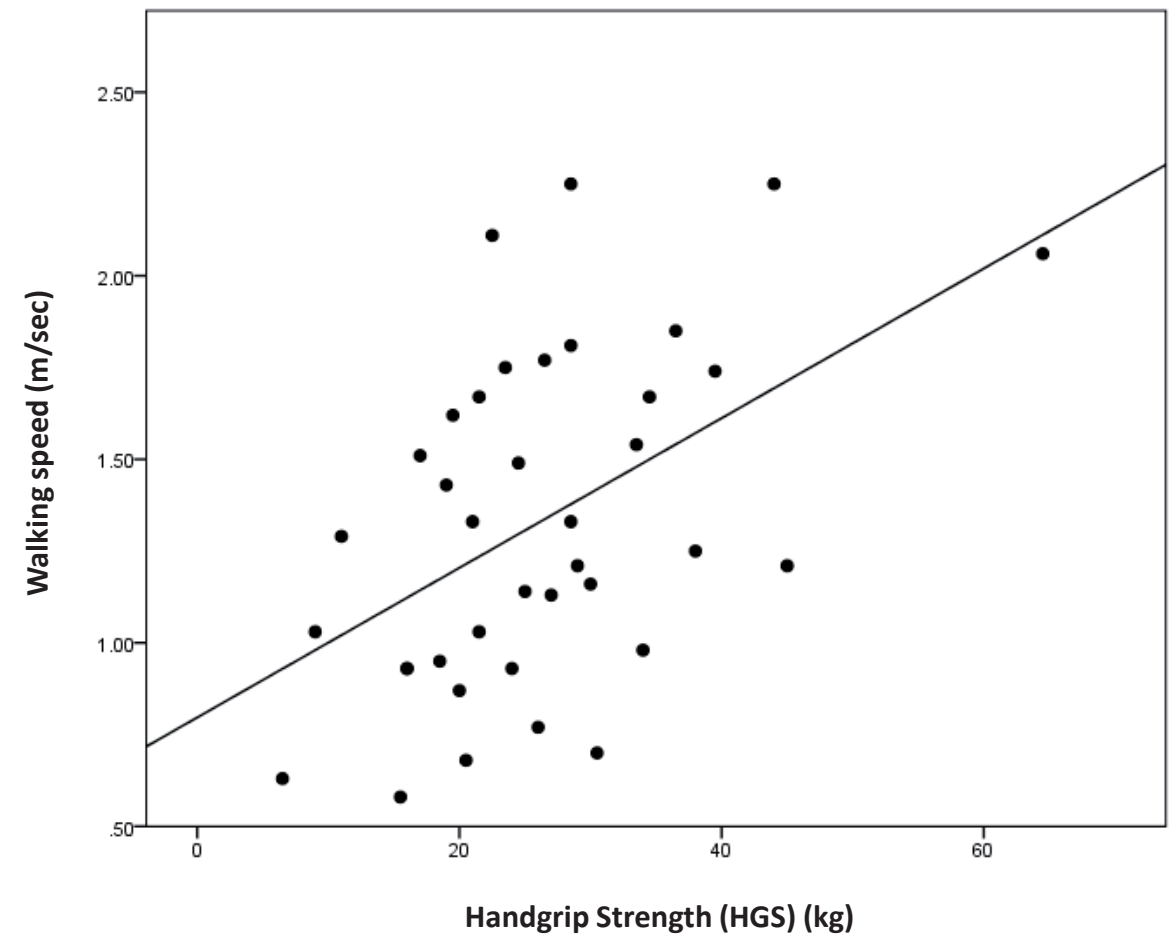

Figure 3.6 Relationship between handgrip strength and walking speed $(\mathrm{m} / \mathrm{sec})$. There was a significant positive correlation between handgrip strength and walking speed $(r=0.488 ; P=0.002)$. 


\section{DISCUSSION}

This study showed significant differences between the 2-C bioimpedance model and the 3-C model. However, both FFM (3-C) and FFM (2-C) were strongly related to HGS and therefore an important functional parameter of sarcopenia. Although a strong relation between bioimpedance parameters and HGS was observed, the results of the 4-m walking test were also significantly related to HGS but not directly to BC. This suggests that these 3 techniques, which are easily applicable in clinical practice, assess different but partly overlapping dimensions in both HD as well as in PD patients.

Differences between the 2-C and the 3-C models can be explained by different arrangements of $\mathrm{BC}$ parts (Fig. $3.7^{31}$ ). Were the $2-\mathrm{C}$ model divides $\mathrm{BC}$ in an FFM compartment and a FM compartment, the 3-C model identifies an LTM compartment, an ATM compartment, from which FM is derived, and a separate $\mathrm{OH}$ compartment. This 3-C model gives a more detailed view of $\mathrm{BC}$ compared with the $2-\mathrm{C}$ model. The separate $\mathrm{OH}$ component in the $3-\mathrm{C}$ model is likely of importance in the observed differences, as mean predialysis $\mathrm{OH}$ in our study was $1.4 \mathrm{~L}$, in agreement with results of others ${ }^{14}$. The fact that measurements were performed before dialysis, when the amount of $\mathrm{OH}$ is at its largest, may therefore have contributed to the difference between the $2-\mathrm{C}$ and $3-\mathrm{C}$ models.

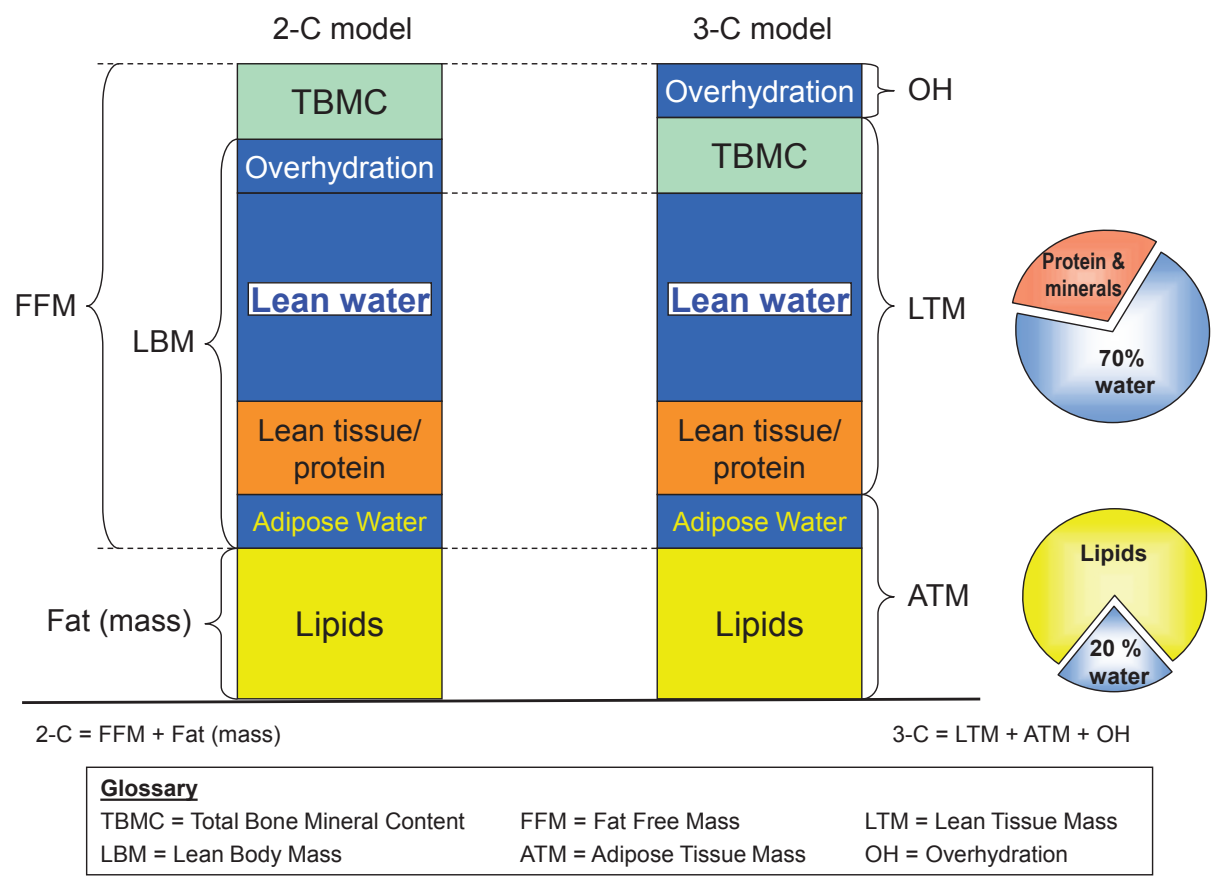

Figure 3.7 Distribution of body composition compartments ${ }^{31}$. 
The relation between $\mathrm{OH}$ and both $\triangle \mathrm{FFM}$ and $\triangle \mathrm{FM}$ (Fig. 2.1) was in line with this assumption and therefore showed the importance of $\mathrm{OH}$ in the estimation of $\mathrm{BC}$ parameters. Moreover, whereas the ECW component in the adipose compartment is in the 2-C model considered as a sole component of FFM, in the 3-C model, it is also included as a component of ATM. The difference between body cell mass estimated by $2-\mathrm{C}$ and the 3-C models is explained by the difference in calculations. Whereas the $2-\mathrm{C}$ model calculates body cell mass by dividing ICW by 0.7 , the $3-C$ model defines body cell mass as intracellular lean soft tissue mass, which is calculated by subtracting ECW and bone cell mass from FFM. The estimation of bone cell mass is based on DEXA-derived calculations with correction for height (U. Moissl, personal communication). Next to these factors, also the consideration of BMI in the estimation of body compartments might account for some remaining difference between the 2-C and 3-C models ${ }^{23}$.

In the general population, bioimpedance techniques are an accepted tool in the assessment of $\mathrm{BC}^{32}$. The fact that FFM (2-C) and FFM (3-C) are different stresses the need for populationbased reference values for the 3-C model. Using reference values for the 3-C model, which are available in abstract form (http://www.bcm-fresenius.com/mediafiles/information_ on_reference_ranges.pdf) ${ }^{30}$, a relatively large percentage of patients had an LTI below age-matched reference values despite the fact that BMI was in general not decreased in the studied population. In contrast, FTI was above the reference values in a substantial percentage of patients, suggesting the presence of sarcopenic obesity ${ }^{33}$ in a significant percentage of patients.

Next to identifying alterations in BC, it is also of importance to include functional tests in the assessment of dialysis patients, as these provide both important information for clinical decision making and because of their relation to outcome ${ }^{34}$. There are various techniques that can be applied to diagnose the functional status and functional limitations in patients at risk for sarcopenia and frailty. HGS and determining walking speed by the 4-m walking test are commonly used techniques in previous studies ${ }^{11,17}$. In this study, these parameters were applied because they are easy to implement in clinical practice and have been extensively validated $^{16-21}$. In previous studies in dialysis patients, HGS was found to be strongly related to LBM by reference techniques ${ }^{12,35}$. Also in the present study, both FFM (3-C) and FFM (2C) were strongly related to HGS, confirming the relation between $\mathrm{BC}$ and muscle strength for both models. As the difference in the strength of the correlations between the HGS and the 2-C and 3-C models estimates were small, the potential superiority of one of both models cannot be derived from the present study. BC (FFM and body cell mass [2-C and 3-C]) assessed by bioimpedance also correlated to important biochemical parameters of nutritional status, serum albumin, and serum creatinine. However, this correlation appeared less strong.

In the present study, significant relations between HGS and results of the 4-m walking test were observed. In contrast, no significant relation was observed between $\mathrm{BC}$ with the performance on the 4-m walking test. These results are in agreement with an earlier study 
by our group ${ }^{36}$, which also showed a relation between LBM, assessed by DEXA, and muscle strength by isokinetic dynamometry, whereas physical capacity assessed by cycle ergometry was only directly related to muscle strength and not to BC. The results of these studies ${ }^{36}$ suggest that in dialysis patients, the relation between $B C$ and functional performance may vary between parameters related to strength and mobility and as such represent different dimensions. Most likely, also other factors such as postural imbalance, visual acuity, postural hypotension, and cardiovascular function also are strong determinants of mobility in dialysis patients. Admittedly, the number of patients in which this relation was assessed was relatively small. In the general population, a relation between $\mathrm{BC}$ and mobility was observed in a far larger number of participants ${ }^{5}$.

Several limitations of the study need to be addressed. First, only a relatively small number of patients were studied, including HD and PD. Second, no comparison techniques, such as DEXA or anthropometry, were included to compare $\mathrm{BC}$ with that of the 2-C and 3-C models. However, in view of previous experience ${ }^{12}$, we pose that DEXA is not an adequate gold standard method in the assessment of LBM in patients with abnormalities in hydration state, as it cannot take a potential excess of ECW into account. Third, our study does not possess prognostic information.

We conclude that this study first shows the discrepancy in the estimation of FFM when assessed by either 2-C or 3-C compartment models in both HD patients as well as in PD patients, which needs to be taken into account when studies using different bioimpedance techniques are compared in the assessment of BC. BC, assessed by bioimpedance for both 2-C and 3-C models, is strongly related to HGS in patients of both dialysis modalities. Next, it shows that bioimpedance, HGS, and the 4-m walking test, each easily applicable technique in clinical parameters assess different but partly overlapping dimensions. These simple, noninvasive, and non-time consuming tests may be of value in the early diagnosis of PEW syndrome and/or sarcopenia inHD and PD patients facilitating interventions at an earlier point in time before the development of clinical symptoms.

\section{PRACTICAL APPLICATION}

Noninvasive techniques for $\mathrm{BC}$ assessment by bioimpedance, HGS measurements, and the 4-m walking test may all be valuable tools to assess nutritional status in dialysis patients. Implementing these tools on a bedside basis could facilitate interventions at an earlier point in time before the development of clinical symptoms. 


\section{REFERENCES}

1. Shinaberger CS, Kilpatrick RD, Regidor DL, McAllister CJ, Greenland S, Kopple JD, et al.: Longitudinal associations between dietary protein intake and survival in hemodialysis patients. Am J Kidney Dis 2006;48:37-49.

2. Fouque D, Kalantar-Zadeh K, Kopple J, Cano N, Chauveau P, Cuppari L, et al.: A proposed nomenclature and diagnostic criteria for protein-energy wasting in acute and chronic kidney disease. Kidney Int 2008;73:391-398.

3. Kalantar-Zadeh K, Cano NJ, Budde K, Chazot C, Kovesdy CP, Mak RH, et al.: Diets and enteral supplements for improving outcomes in chronic kidney disease. Nat Rev Nephrol 2011;7:369384.

4. Mazess RB, Barden HS, Bisek JP,Hanson J: Dual-energy x-ray absorptiometry for total-body and regional bone-mineral and soft-tissue composition. Am J Clin Nutr 1990;51:1106-1112.

5. Dufour AB, Hannan MT, Murabito JM, Kiel DP,McLean RR: Sarcopenia definitions considering body size and fat mass are associated with mobility limitations: the Framingham Study. J Gerontol A Biol Sci Med Sci 2013;68:168-174.

6. Ellis KJ: Human body composition: in vivo methods. Physiol Rev 2000;80:649-680.

7. Noori N, Kovesdy CP, Bross R, Lee M, Oreopoulos A, Benner D, et al.: Novel equations to estimate lean body mass in maintenance hemodialysis patients. Am J Kidney Dis 2011;57:130-139.

8. Patel SS, Molnar MZ, Tayek JA, Ix JH, Noori N, Benner D, et al.: Serum creatinine as a marker of muscle mass in chronic kidney disease: results of a cross-sectional study and review of literature. J Cachexia Sarcopenia Muscle 2013;4:19-29.

9. Yuste C, Abad S, Vega A, Barraca D, Bucalo L, Perez-de Jose A, et al.: Assessment of nutritional status in haemodialysis patients. Nefrologia 2013;33:243-249.

10. Kyle UG, Bosaeus I, De Lorenzo AD, Deurenberg P, Elia M, Gomez JM, et al.: Bioelectrical impedance analysis--part I: review of principles and methods. Clin Nutr 2004;23:1226-1243.

11. Chamney PW, Wabel P, MoissI UM, Muller MJ, Bosy-Westphal A, Korth O, et al.: A wholebody model to distinguish excess fluid from the hydration of major body tissues. Am J Clin Nutr 2007;85:80-89.

12. Konings CJ, Kooman JP, Schonck M, van Kreel B, Heidendal GA, Cheriex EC, et al.: Influence of fluid status on techniques used to assess body composition in peritoneal dialysis patients. Perit Dial Int 2003;23:184-190.

13. Moissl U, Arias-Guillen M, Wabel P, Fontsere N, Carrera M, Campistol JM, et al.: BioimpedanceGuided Fluid Management in Hemodialysis Patients. Clin J Am Soc Nephrol 2013;8:1575-1582.

14. Hur E, Usta M, Toz H, Asci G, Wabel P, Kahvecioglu S, et al.: Effect of fluid management guided by bioimpedance spectroscopy on cardiovascular parameters in hemodialysis patients: a randomized controlled trial. Am J Kidney Dis 2013;61:957-965.

15. Wizemann V, Wabel P, Chamney P, Zaluska W, MoissI U, Rode C, et al.: The mortality risk of overhydration in haemodialysis patients. Nephrol Dial Transplant 2009;24:1574-1579. 
16. Zamboni M, Mazzali G, Fantin F, Rossi A,Di Francesco V: Sarcopenic obesity: a new category of obesity in the elderly. Nutr Metab Cardiovasc Dis 2008;18:388-395.

17. Lauretani F, Russo CR, Bandinelli S, Bartali B, Cavazzini C, Di lorio A, et al.: Age-associated changes in skeletal muscles and their effect on mobility: an operational diagnosis of sarcopenia. J Appl Physiol 2003;95:1851-1860.

18. Fresenius Medical Care. Body Composition Monitor Manual Operation Procedure. Fresenius Medical Care D GmbH, Bad Homburg, Germany; 2007.

19. Wabel P, Rode C, Moissl U, Chamney PW, Wizemann V: Accuracy of bioimpedance spectroscopy (BIS) to detect fluid status changes in hemodialysis patients (abstract). Nephrol Dial Transplant 2007;22(suppl 6)VI129.

20. Van Biesen W, Williams JD, Covic AC, Fan S, Claes K, Lichodziejewska-Niemierko M, et al.: Fluid status in peritoneal dialysis patients: the European Body Composition Monitoring (EuroBCM) study cohort. PLoS One 2011;6:e17148.

21. Davison SN, Jhangri GS, Jindal K,Pannu N: Comparison of volume overload with cyclerassisted versus continuous ambulatory peritoneal dialysis. Clin J Am Soc Nephrol 2009;4:1044-1050.

22. Cooper BA, Aslani A, Ryan M, Zhu FY, Ibels LS, Allen BJ, et al.: Comparing different methods of assessing body composition in end-stage renal failure. Kidney Int 2000;58:408-416.

23. Moissl UM, Wabel P, Chamney PW, Bosaeus I, Levin NW, Bosy-Westphal A, et al.: Body fluid volume determination via body composition spectroscopy in health and disease. Physiol Meas 2006;27:921-933.

24. Ostir GV, Volpato S, Fried LP, Chaves P,Guralnik JM: Reliability and sensitivity to change assessed for a summary measure of lower body function: results from the Women's Health and Aging Study. J Clin Epidemiol 2002;55:916-921.

25. Penninx BW, Ferrucci L, Leveille SG, Rantanen T, Pahor M,Guralnik JM: Lower extremity performance in nondisabled older persons as a predictor of subsequent hospitalization. J Gerontol A Biol Sci Med Sci 2000;55:M691-697.

26. Guralnik JM, Ferrucci L, Simonsick EM, Salive ME,Wallace RB: Lower-extremity function in persons over the age of 70 years as a predictor of subsequent disability. N Engl J Med 1995;332:556-561.

27. Guralnik JM, Ferrucci L, Pieper CF, Leveille SG, Markides KS, Ostir GV, et al.: Lower extremity function and subsequent disability: consistency across studies, predictive models, and value of gait speed alone compared with the short physical performance battery. J Gerontol A Biol Sci Med Sci 2000;55:M221-231.

28. Hartmann EL, Kitzman D, Rocco M, Leng X, Klepin H, Gordon M, et al.: Physical function in older candidates for renal transplantation: an impaired population. Clin J Am Soc Nephrol 2009;4:588-594.

29. US Renal Data System: Researcher's Guide to the USRDS Database Bethesda, National Institutes of Health, National Insitute of Diabetes and Digestive and Kidney Diseases, 2004: 
30. Wieskotten S, MoissI U, Chamney P, Wabel P. Reference Ranges for Human Body Composition and Fluid Overload. Fresenius Medical Care D GmbH, Bad Homburg, Germany. 2013; Available from: http://www.bcm-fresenius.com/mediafiles/information_on_reference_ ranges.pdf. Accessed March 19, 2014.

31. Wabel P: Fresenius Medical Care D GmbH, Bad Homburg, Germany.

32. Mijnarends DM, Meijers JM, Halfens RJ, ter Borg S, Luiking YC, Verlaan S, et al.: Validity and reliability of tools to measure muscle mass, strength, and physical performance in communitydwelling older people: a systematic review. J Am Med Dir Assoc 2013;14:170-178.

33. Cruz-Jentoft AJ, Baeyens JP, Bauer JM, Boirie Y, Cederholm T, Landi F, et al.: Sarcopenia: European consensus on definition and diagnosis: Report of the European Working Group on Sarcopenia in Older People. Age Ageing 2010;39:412-423.

34. Johansen KL, Chertow GM, Jin C,Kutner NG: Significance of frailty among dialysis patients. J Am Soc Nephrol 2007;18:2960-2967.

35. Piitulainen E, Areberg J, Linden M, Eriksson S, Mattsson S,Wollmer P: Nutritional status and muscle strength in patients with emphysema and severe alpha(1)-antitrypsin deficiency. Chest 2002;122:1240-1246.

36. van den Ham EC, Kooman JP, Schols AM, Nieman FH, Does JD, Franssen FM, et al.: Similarities in skeletal muscle strength and exercise capacity between renal transplant and hemodialysis patients. Am J Transplant 2005;5:1957-1965. 



\section{CHAPTER 4}

PhYSICAL ACTIVITY IN END-STAGE RENAL DISEASE PATIENTS, A STUDY

IN CKD-5 NON-DIALYSIS AND DIALYSIS PATIENTS INCLUDING THE

TRANSITION PERIOD

Natascha J.H. Broers, Remy J.H. Martens, Tom Cornelis, Nanda M.P.

Diederen, Frank M. van der Sande, Marc M.H. Hermans, Joris J.J.M Wirtz, F. Stifft, Constantijn J.A.M. Konings, Tom Dejagere, Peter Wabel, Bernard Canaud, Karel M.L. Leunissen and Jeroen P. Kooman

Submitted 


\section{ABSTRACT}

\section{Background}

Physical inactivity in end-stage renal disease (ESRD) patients is associated with increased mortality, which might be related to abnormalities in body composition (BC) and physical performance. It is uncertain to what extent the start of dialysis influences the effects of ESRD on physical activity (PA) and physical performance. This study aimed to (1) compare parameters of PA and physical performance between stage 5 chronic kidney disease (CKD5) non-dialysis patients and dialysis patients, and healthy controls, (2) to assess alterations in PA during the transition phase from CKD-5 non-dialysis to dialysis, and (3) to relate PA parameters to $\mathrm{BC}$ in CKD-5 non-dialysis and dialysis patients.

\section{Methods}

For the cross-sectional analyses 67 CKD-5 patients (38 CKD-5 non-dialysis patients and 29 dialysis patients (dialysis vintage $3.60 \pm 3.21$ years)), and 20 healthy controls were included. PA parameters (number of steps and activity related energy expenditure (AEE)) were measured by a SenseWear ${ }^{\mathrm{TM}}$ pro3 armband. Also, walking speed ( $4 \mathrm{~m}$ walking test) and handgrip strength (HGS) were measured. Lean tissue index (LTI) and fat tissue index (FTI) were measured by the Body Composition Monitor (C). In the longitudinal part, these parameters were assessed in 30 CKD-5 non-dialysis patients (who were also part of the cross-sectional analysis), before the start of dialysis and then five to six months later after starting dialysis.

\section{Results}

PA parameters were significantly lower in CKD-5 non-dialysis patients as compared with healthy controls (median number of steps [interquartile range]: 5009.0 [3187.5-7031.5] vs. 11062.0 [7687.0-13839.0], $p<0.001$; median AEE: 122.0 [63.5-280.0] vs. 623.5 [497.75-952.5] kcal, $\mathrm{p}<0.001$ ), but not as compared with dialysis patients (median number of steps [interquartile range]: 3994.5 [1993.5-6712.75]; median AEE: 160.5 [80.25-450.25] kcal). HGS was significantly lower in both CKD-5 non-dialysis and dialysis patients as compared with healthy controls after adjustment for age and sex. Walking speed was significantly lower in CKD-5 non-dialysis patients as compared with healthy controls, but not as compared with dialysis patients.

In the combined group of CKD patients, a negative association was found between number of steps and FTI (Beta -204.78 steps per $1 \mathrm{~kg} / \mathrm{m}^{2}$ higher $\mathrm{FTI} ; 95 \% \mathrm{Cl}$ : -386.54 to -23.01 ) after adjustment for age, sex, patient group, diabetes and LTI, whereas LTI was not statistically significantly associated with number of steps. After starting dialysis, PA parameters and walking speed significantly $(p<0.05)$ increased over a six month period of time.

\section{Conclusions}

PA is already lower in CKD-5 non-dialysis patients as compared with healthy controls, and does not differ from dialysis patients. However, the transition phase from CKD-5 non-dialysis to dialysis is associated with a modest improvement in PA. Physical inactivity may be related to the increase in fat mass, which is commonly observed in the dialysis population. 


\section{INTRODUCTION}

It is well known that dialysis patients have decreased levels of physical activity (PA), matching a sedentary lifestyle, which was recently defined as number of steps $<7500 /$ day $^{1}$. Physical inactivity in dialysis patients is associated with an increased hospitalization and mortality risk $^{2,3}$, and is also associated with alterations in body composition (BC) and decreased muscle strength ${ }^{4}$. Also, in earlier phases of chronic kidney disease (CKD), a reduced PA has been observed ${ }^{5}$.

The transition phase from CKD-5 non-dialysis to dialysis, as well as the chronic dialysis treatment can have a major physiological and psychological impact on patients with endstage renal disease (ESRD) ${ }^{6}$. It is not well known whether PA is affected by chronic dialysis treatment or whether low PA is an inherent characteristic of ESRD. Whereas some literature suggests that PA is already decreased in the CKD-5 non-dialysis phase due to fatigue related to uremic disorders, the presence of comorbidity, and pre-existent lifestyle factors ${ }^{7}$, others indicate that PA is adequately preserved in a cohort of CKD stage 4-5 patients ${ }^{8}$. Additionally, in theory dialysis treatment may improve PA on non-dialysis days due to the partial correction of the uremic state. Nevertheless, the treatment itself may induce fatigue and stimulate a sedentary lifestyle on dialysis days itself ${ }^{9}$.

PA may also be associated with BC changes. This may be of prognostic importance, as lower a lean tissue index (LTI) (lean tissue mass (LTM) corrected for height) is related to higher mortality, although the relation between fat tissue index (FTI) (adipose tissue mass (ATM) corrected for height) and survival in dialysis patients is not straightforward ${ }^{10}$. However, to the best of our knowledge there is only limited data available assessing the association between PA and BC in a cohort including CKD-5 non-dialysis and dialysis patients ${ }^{11-13}$.This study firstly aimed to compare PA and physical performance cross-sectionally between CKD-5 non-dialysis and dialysis patients, and healthy controls. Secondly, we aimed to assess longitudinally any alterations in PA and physical performance during the transition from the CKD-5 non-dialysis to the dialysis phase, and thirdly, to assess the associations between PA and $\mathrm{BC}$ parameters in ESRD patients.

\section{MATERIALS AND METHODS}

This study consisted of a cross-sectional part and a longitudinal part. The cross-sectional analyses included 67 patients, 38 CKD-5 non-dialysis patients and 29 dialysis patients (dialysis vintage $3.60 \pm 3.21$ years) and 20 healthy controls. Patients were recruited from the following dialysis centers in the South East of the Netherlands and the North East of Belgium: University Hospital Maastricht, Catharina Hospital Eindhoven, Viecuri Hospital Venlo, Zuyderland Medical Centre Sittard, St Laurentius Hospital Roermond and Virga Jesse Hospital Hasselt. CKD-5 non-dialysis patients were ESRD patients starting with dialysis within one month (measurements were performed maximum 4 weeks prior to the first dialysis session). Prevalent dialysis patients had been treated with hemodialysis (HD) or peritoneal dialysis (PD) treatment for at least twelve months. 
The longitudinal analysis is part of an ongoing prospective study and included 30 CKD-5 nondialysis patients (who were also part of the cross-sectional analysis) for whom six months follow up data were available. Measurements were performed before the start of dialysis treatment (within one month before the first dialysis session) and five to six months after starting dialysis by the same methods as used for the cross-sectional part.

Exclusion criteria for patients were: an acute start of dialysis treatment, active symptomatic coronary artery disease or cardiac failure New York Heart Association (NYHA) classification III or IV, active malignancies, active infections, and inability to provide informed consent. For bioimpedance measurements: no implantable cardioverter defibrillator (ICD) or pacemaker (interference with body composition monitor (BCM)). For walking test measurements: physical disability (patients had to be able to walk without help), There were no restrictions for other measurements in patients with an ICD or pacemaker or physical disability.

Healthy controls were non-diabetic, non-smokers, and not hypertensive, and were recruited via advertisements.

Exclusion criteria for healthy controls were: hypertension during the screening; systolic blood pressure higher than $170 \mathrm{mmHg}$ and/or diastolic blood pressure larger than 100 $\mathrm{mmHg}$, diabetes mellitus, and inability to provide informed consent.

Patients as well as healthy controls were in a fasting state during the measurements, except for the PA measurements.

Written informed consent was obtained from each patient prior to participation. The study was approved by the Ethical Committee (NL33129.068.10, NL35039.068.10) and the Hospital Board of the Maastricht University Medical Center+.

\section{Physical Activity Measurements}

Participants were requested to wear a SenseWear ${ }^{\mathrm{TM}}$ pro 3 armband (Bodymedia ${ }^{\circledR}$, Pittsburg, PA) to measure different PA parameters (total energy expenditure (TEE), activity related energy expenditure (AEE), number of steps) for 2 days (CKD-5 non-dialysis patients: $1.99 \pm 0.44$ days, mean on-body time: $93.6 \%$; dialysis patients: $2.30 \pm 0.73$ days, mean on-body time: 96.7\%; controls: $2.07 \pm 0.54$ days, mean on-body time: $96.1 \%)$. For the primary analyses, the mean of the total on-body time was calculated (expressed as TEE, AEE and number of steps per 24 hours) to include both the dialysis and non-dialysis day. Data collected on both week days as well as weekend days were included in the analysis.

In an additional analysis, a 24 hours measurement cycle was analyzed for the dialysis patient group to exclude the dialysis session. For the longitudinal analysis in the CKD-5 non-dialysis group the available data were not sufficient to exclude dialysis session.

\section{Body Composition Measurements}

$\mathrm{BC}$ was determined by bioimpedance spectroscopy with the Body Composition Monitor $\left(\mathrm{BCM}^{\circledR}\right.$, Fresenius Medical Care, Bad Homburg, Germany) which uses a 3-C model (ATM, 
LTM, and fluid overload (FO)) described by the model of Chamney et al. ${ }^{14}$. ATM and LTM were corrected for height to derive FTI and LTI. Measurements were taken as described in the manufacturer's manual ${ }^{15}$. Patients were in supine position. In HD patients, measurements were taken before the dialysis treatment, in agreement with previous studies ${ }^{16-18}$. In PD patients, measurements were taken during a visit at the out-patient clinic. Measurements in PD patients were taken with a full abdomen for practical reasons, and because sequestered fluid in the trunk only has a minor influence on whole-body bioimpedance measurements ${ }^{19-21}$. Body weight was corrected for PD fluid. Not all patients were in fasting state as requested before measurements, most cases due to diabetes $(n=6)$ or for practical reasons $(n=12)$.

\section{Muscle Strength}

Muscle strength was determined by measuring handgrip strength (HGS) twice with a hand held dynamometer (Jamar ${ }^{\circledR}$, Sammons Preston Inc, Bolingbrook, IL) in standing position with the arm in a flexed position of 90 degrees. Measurements in HD patients took place on the contralateral arm of the shunt arm and in PD patients and healthy controls in the dominant hand.

\section{Four meter walking test}

A four meter walking test was conducted to determine walking speed $(\mathrm{m} / \mathrm{sec}$ ) by covering a distance of four meter. Several studies confirmed the validity and sensitivity of this widely used test for determining walking speed ${ }^{22-25}$ and physical performance in ESRD patients ${ }^{26}$.

\section{Comorbidity Score}

Comorbidity index was determined for each patient based on the comorbidity checklist by the Davies comorbidity index scoring system ${ }^{27}$. Patients were divided into three risk groups; low, medium and high risk of mortality. The Davies comorbidity index is commonly used in ESRD patients ${ }^{27-29}$.

\section{Nutritional and Biochemical parameters}

Biomarkers such as albumin, hemoglobin ( $\mathrm{HB})$, dialysis adequacy (Kt/V), and the estimated glomerular filtration rate (eGFR) were measured or determined during routine patient laboratory measurements. GFR was estimated with the four-variable modification of diet in renal disease (MDRD) equation ${ }^{30}$.

\section{Statistical Analysis}

Data are expressed as mean \pm SD or median [interquartile range] unless indicated otherwise. For the cross-sectional analyses, differences in the categorical variables were assessed by the Chi-square test. Differences in the continuous variables PA, physical performance, and $\mathrm{BC}$ between groups were assessed by independent-samples t-tests or the Mann-Whitney U test, as appropriate. In addition, multivariable linear regression analyses were conducted 
to adjust for age and sex differences between groups and for diabetes. Multivariable linear regression analyses were performed to evaluate the association between BC (LTI and FTI) and PA (number of steps and AEE) in CKD-5 non-dialysis and dialysis patients. AEE had to be transformed with the natural logarithm to fulfill the normality assumptions. Regression coefficients were back-transformed (exponentiated) to obtain the ratio of the geometric means of AEE per $1 \mathrm{~kg} / \mathrm{m} 2$ higher LTI and FTI, respectively. We adjusted for potential confounders as follows: model 1) unadjusted model; model 2) age, sex, patient group and diabetes; model 3) model $2+$ FTI or LTI. In addition, we tested for statistical interaction between BC and patient group.

For the longitudinal analysis; comparison of changes over time within the CKD-5 non-dialysis patient group was done using dependent-samples t-tests or Wilcoxon matched pairs signed rank sum test as appropriate. Differences in change between dialysis modalities were conducted with independent sample t-tests.

Statistical analyses were performed by IBM SPSS Statistics for Windows, version 23 (IBM Corp. Armonk, NY, USA). For the interaction analyses, a $\mathrm{P}_{\text {interaction }}<0.10$ was considered statistically significant. For all other analyses, $p$-values $<0.05$ were considered to be statistically significant.

\section{RESULTS}

Table 4.1a Patient Demographics.

\begin{tabular}{|c|c|c|c|}
\hline & CKD-5 non-dialysis patients & Dialysis patients & Healthy controls \\
\hline Number of Patients & 38 & 29 & 20 \\
\hline Male (\%) & 73.7 & 69.0 & 65.0 \\
\hline $\mathrm{HD} / \mathrm{PD}$ & - & $21 * / 8$ & - \\
\hline Age (years) & $61.11 \pm 12.25$ & $58.17 \pm 14.65$ & $59.65 \pm 14.10$ \\
\hline Height $(\mathrm{cm})$ & $173.68 \pm 9.67$ & $171.59 \pm 9.57$ & $174.75 \pm 11.36$ \\
\hline Weight (kg) & $77.67 \pm 16.76$ & $82.75 \pm 15.31$ & $76.68 \pm 15.80$ \\
\hline BMI $\left(\mathrm{kg} / \mathrm{m}^{2}\right)$ & $25.48 \pm 3.76$ & $28.06 \pm 4.45$ & $24.86 \pm 3.41$ \\
\hline Albumin $(\mathrm{g} / \mathrm{L})$ & $35.34 \pm 5.18$ & $40.24 \pm 3.55$ & $40.24 \pm 2.30$ \\
\hline Hemoglobin (mmol/L / g/dL) & $6.69 \pm 0.90 / 10.78 \pm 1.45$ & $6.93 \pm 0.71 / 11.17 \pm 1.15$ & - \\
\hline eGFR $\left(\mathrm{ml} / \mathrm{min} / 1.73 \mathrm{~m}^{2}\right)$ & $8.40 \pm 2.79$ & - & $72.59 \pm 11.07$ \\
\hline \multicolumn{4}{|l|}{ Origin of end-stage renal disease } \\
\hline Diabetic nephropathy (\%) & 5.3 & 20.7 & - \\
\hline Polycystic kidney disease (\%) & 26.3 & 17.2 & \\
\hline Nephrosclerosis(\%) & 15.8 & 6.9 & \\
\hline Hypertensive nephropathy (\%) & 5.3 & 10.3 & \\
\hline Nephrotic syndrome (\%) & 13.2 & 3.4 & \\
\hline E.c.i. (\%) & 13.2 & 13.8 & \\
\hline Other (\%) & 21.1 & 27.6 & \\
\hline Diabetes Mellitus (\%) & 13.2 & 41.4 & - \\
\hline Cardiovascular Disease (\%) & 36.8 & 37.9 & - \\
\hline \multicolumn{4}{|l|}{ Risk of mortality by Davies index } \\
\hline Low risk (\%) & 47.4 & 41.4 & - \\
\hline Medium risk (\%) & 39.5 & 37.9 & \\
\hline High risk (\%) & 13.2 & 20.7 & \\
\hline History of prior KTx (\%) & 23.7 & 31.0 & 0.0 \\
\hline SBP $(\mathrm{mmHg})$ & $146.29 \pm 22.14$ & $152.43 \pm 26.47$ & $137.98 \pm 13.39$ \\
\hline $\mathrm{DBP}(\mathrm{mmHg})$ & $81.95 \pm 13.05$ & $80.84 \pm 12.44$ & $82.30 \pm 6.90$ \\
\hline
\end{tabular}

Data are given in mean $\pm \mathrm{SD}$. $\mathrm{HD}=$ hemodialysis, $\mathrm{PD}=$ peritoneal dialysis, $\mathrm{BMI}=$ body mass index, eGFR = estimated glomerular filtration rate, E.c.i. = e causa ignota, $\mathrm{KTx}=$ kidney transplantation, $\mathrm{SBP}=$ systolic blood pressure, $\mathrm{DBP}=$ diastolic blood pressure * All HD patients have arteriovenous (AV) fistulas, Laboratory parameters were available in: $n=37$ in the CKD-5 non-dialysis group, $n=28$ for hemoglobin and $n=25$ for albumin in the dialysis group, $\mathrm{n}=20$ in the healthy control group. 


\section{Patient characteristics}

Patient characteristics for the cross-sectional are summarized in table 4.1a. Patient characteristics for the patients participating in the longitudinal part are summarized in table $4.1 \mathrm{~b}$.

Table 4.1b Baseline patient demographics longitudinal analyses.

\begin{tabular}{|c|c|}
\hline Patient Demographics & Before start of dialysis \\
\hline Number of Patients & 30 \\
\hline Male (\%) & 66.7 \\
\hline $\mathrm{HD} * / \mathrm{PD}^{\#}$ & $15 / 15$ \\
\hline Age (years) & $60.67 \pm 13.03$ \\
\hline Height $(\mathrm{cm})$ & $172.27 \pm 9.85$ \\
\hline Weight (kg) & $76.35 \pm 16.82$ \\
\hline BMI $\left(\mathrm{kg} / \mathrm{m}^{2}\right)$ & $25.44 \pm 3.78$ \\
\hline Albumin $(\mathrm{g} / \mathrm{L})$ & $36.16 \pm 3.59$ \\
\hline Hemoglobin (mmol/L / g/dL) & $6.66 \pm 0.84 / 10.73 \pm 1.36$ \\
\hline eGFR $\left(\mathrm{ml} / \mathrm{min} / 1.73 \mathrm{~m}^{2}\right)$ & $8.66 \pm 2.94$ \\
\hline \multicolumn{2}{|l|}{ Origin of end-stage renal disease } \\
\hline Diabetic nephropathy (\%) & 6.7 \\
\hline Polycystic kidney disease (\%) & 30.0 \\
\hline Nephrosclerosis(\%) & 16.7 \\
\hline Hypertensive nephropathy (\%) & 3.3 \\
\hline Nephrotic syndrome (\%) & 13.3 \\
\hline E.c.i. $(\%)$ & 13.3 \\
\hline Other (\%) & 16.7 \\
\hline Diabetes Mellitus (\%) & 10.0 \\
\hline Cardiovascular Disease (\%) & 33.3 \\
\hline \multicolumn{2}{|l|}{ Risk of mortality by Davies index } \\
\hline Low risk (\%) & 46.7 \\
\hline Medium risk (\%) & 43.3 \\
\hline High risk (\%) & 10.0 \\
\hline History of prior KTx (\%) & 23.3 \\
\hline SBP (mmHg) & $144.83 \pm 22.55$ \\
\hline \multirow[t]{2}{*}{$\mathrm{DBP}(\mathrm{mmHg})$} & $81.93 \pm 13.37$ \\
\hline & Six months after the start of dialysis \\
\hline Albumin $(\mathrm{g} / \mathrm{L})$ & $34.25 \pm 2.88$ \\
\hline Hemoglobin (mmol/L / g/dL) & $7.21 \pm 0.79 / 11.62 \pm 1.27$ \\
\hline $\mathrm{Kt} / \mathrm{V}$ (HD/PD) & $1.28 \pm 0.16 / 2.59 \pm 1.03$ \\
\hline
\end{tabular}

Data are given in mean $\pm S D$. $\mathrm{HD}=$ hemodialysis, $\mathrm{PD}=$ peritoneal dialysis, $\mathrm{BMI}=$ body mass index, eGFR = estimated glomerular filtration rate, E.c.i. $=$ e causa ignota, $\mathrm{KTx}=$ kidney transplantation, $\mathrm{SBP}=$ systolic blood pressure, $\mathrm{DBP}$ = diastolic blood pressure * 1 HD patient had a central venous catheter (CVC) \# 1 PD patient switched from PD to HD via CVC 3 months after the start of dialysis, Laboratory parameters were available in $n=29$.

\section{Physical activity parameters}

PA parameters, number of steps and AEE were significantly lower in both CKD-5 non-dialysis patients and dialysis patients as compared with healthy controls (table 4.2a, figure 4.1). No significant differences were found between CKD-5 non-dialysis and dialysis patients (table 4.2a, figure 4.1). TEE was significantly lower in CKD-5 non-dialysis patients as compared with healthy controls, but not as compared with dialysis patients (table 4.2a, figure 4.1). 
Furthermore, TEE in dialysis patients was not significantly lower when compared with healthy controls (table 4.2a, figure 4.1). Additionally, after exclusion of the dialysis day from the analyses, results were similar, except for the difference in TEE between dialysis patients and healthy controls which became statistically significant (table 4.2b). After adjustment for age, sex and diabetes outcomes were not materially changed.
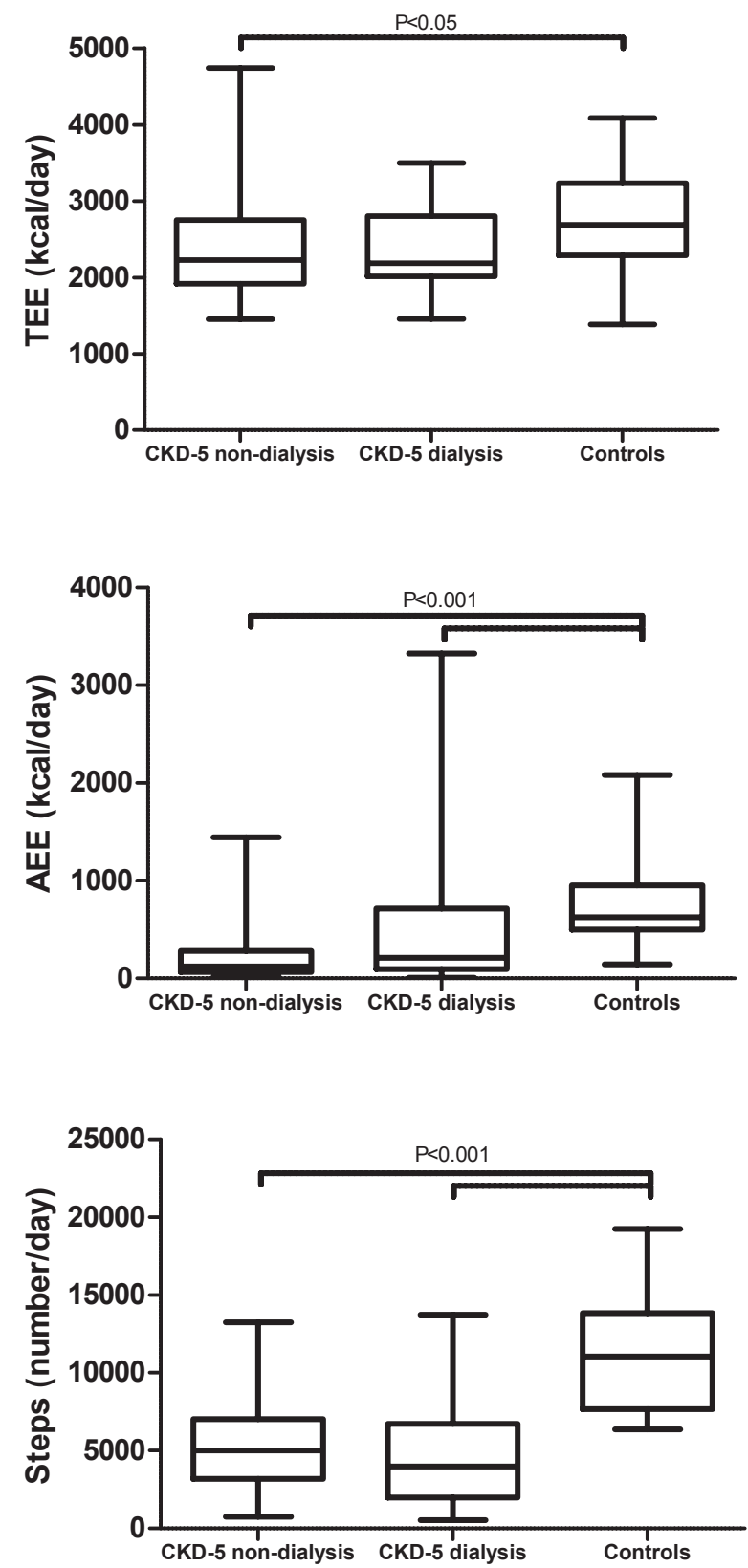

Figure 4.1 PA parameters between groups. TEE = total energy expenditure; $\mathrm{AEE}$ = activity induced energy expenditure, $\mathrm{CKD}=$ chronic kidney disease. 

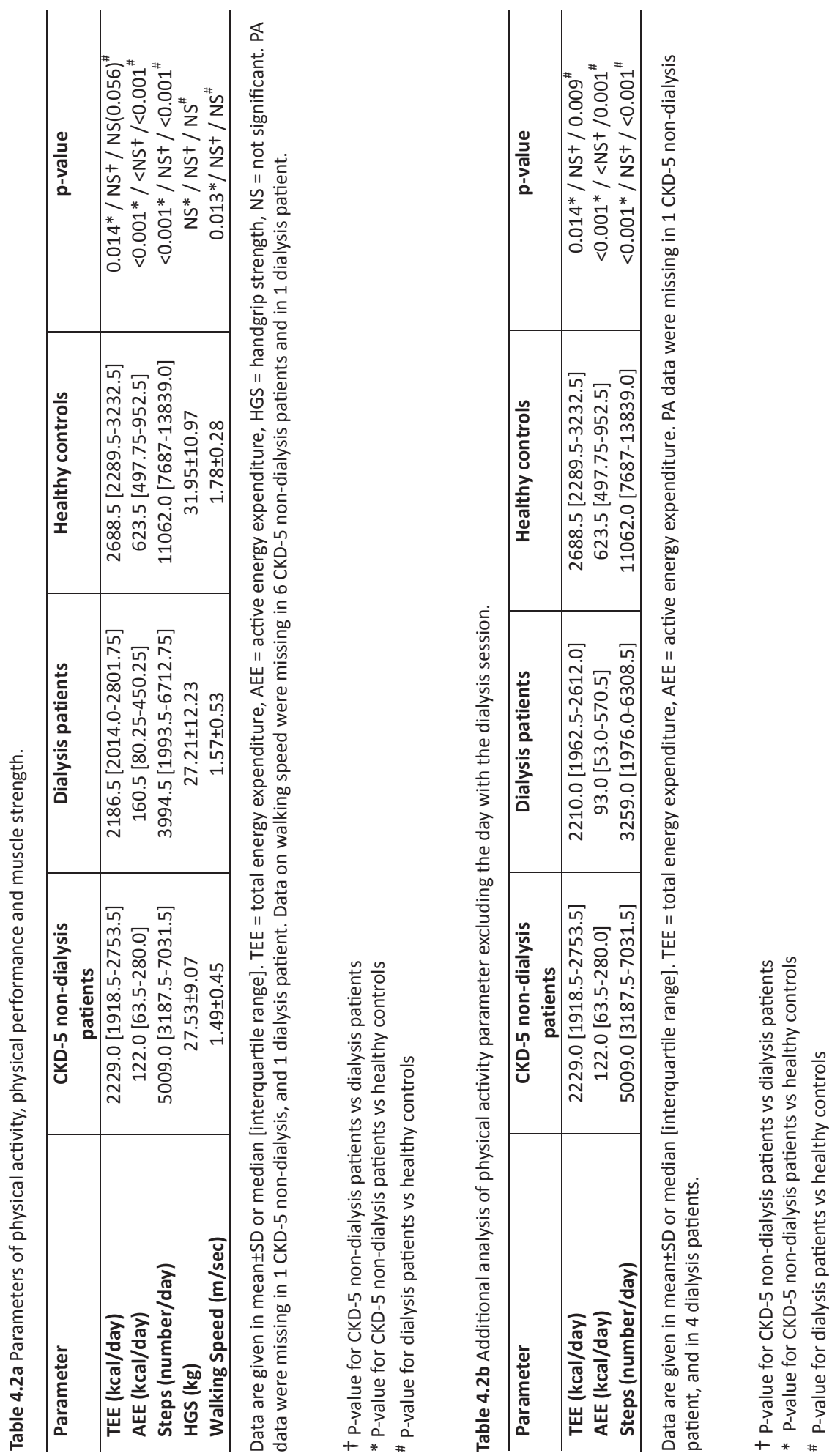


\section{Muscle strength and walking speed}

No significant differences were found for HGS between CKD-5 non-dialysis patients and dialysis patients as well as for healthy controls (table 4.2a). However, after adjustment for age and sex differences between groups and for diabetes, both CKD-5 non-dialysis (-4.59 kg, $95 \% \mathrm{Cl}[-8.89,-0.29])$ and dialysis patients $(-4.46 \mathrm{~kg}, 95 \% \mathrm{Cl}[-9.36,-0.43])$ had significantly lower HGS as compared with healthy controls. Walking speed was significantly lower in CKD5 non-dialysis patients as compared with healthy controls, but not as compared with dialysis patients (table 4.2a). After adjustment for age and sex differences and diabetes between groups, CKD-5 non-dialysis patients $(-0.22 \mathrm{~m} / \mathrm{s}, 95 \% \mathrm{Cl}[-0.42,-0.02])$ had a statistically significantly lower walking speed as compared with healthy controls.

\section{Body Composition}

LTI $\left(\mathrm{kg} / \mathrm{m}^{2}\right)$ was significantly lower in dialysis patients $(13.03 \pm 2.92 \mathrm{~kg})$ as compared with CKD-5 non-dialysis patients $(14.40 \pm 2.42 \mathrm{~kg})(\mathrm{p}=0.047)$ as well as with healthy controls $(14.63 \pm 1.90 \mathrm{~kg}) \quad(p=0.039)$. FTI $\quad\left(\mathrm{kg} / \mathrm{m}^{2}\right)$ was significantly higher in dialysis patients $(14.27 \pm 4.67 \mathrm{~kg})$ as compared with CKD-5 non-dialysis patients $(10.41 \pm 3.91 \mathrm{~kg})(p=0.001)$ as well as with healthy controls $(10.07 \pm 3.04 \mathrm{~kg})(p=0.001)$. For both LTI and FTI, no significant differences were found between CKD-5 non-dialysis patients when compared with healthy controls. When adjusted for age and sex differences and diabetes between groups, results showed no significant differences in LTI between groups anymore. For FTI only significant differences were found between CKD-5 non-dialysis and dialysis patients after adjustment for age, sex and diabetes.

\section{Comorbidity Score}

Risk class for mortality based on the Davies comorbidity index are summarized in table 4.1a. No significant differences were found between CKD-5 non-dialysis and dialysis patients regarding the distribution for each category (low, medium and high risk) ( $p=0.701)$.

\section{Associations between BC and PA-parameters}

Associations between BC and PA-parameters were evaluated in CKD-5 non-dialysis and dialysis patients. Both patient groups were combined as the regression analyses indicated no statistical interaction with patient group.

After adjustment for age, sex, patient group and diabetes, higher LTI was borderline significantly associated with higher number of steps (Beta $(95 \% \mathrm{Cl}) 300.89$ (-17.59-619.37) steps per $1 \mathrm{~kg} / \mathrm{m}^{2}$ higher LTI) and AEE (Ratio (95\%Cl) 1.106 (0.985-1.241) times higher AEE per $1 \mathrm{~kg} / \mathrm{m}^{2}$ higher LTI). However, this association was attenuated after adjustment for FTI (table 4.3).

After adjustment for age, sex, patient group and diabetes, higher FTI was associated with lower number of steps (Beta $(95 \% \mathrm{Cl})-235.71(-412.16$ to -59.24$)$ steps per $1 \mathrm{~kg} / \mathrm{m}^{2}$ higher 
FTI) and AEE (Ratio (95\% Cl) 0.930 (0.871-0.992) times higher AEE per $1 \mathrm{~kg} / \mathrm{m}^{2}$ higher FTI. These associations remained present after further adjustment for LTI (table 4.3).

Table 4.3 Association between body composition and physical activity parameters.

\begin{tabular}{|c|c|c|c|c|c|c|}
\hline & \multicolumn{3}{|c|}{ Number of Steps } & \multicolumn{3}{|l|}{ AEE } \\
\hline & & Beta $(95 \% \mathrm{Cl})$ & p-value & & Ratio $95 \% \mathrm{Cl}$ ) & p-value \\
\hline \multirow{3}{*}{ LTI } & Model 1 & $534.62[269.66 ; 99.59]$ & $<0.001$ & Model 1 & $1.157[1.055 ; 1.270]$ & 0.002 \\
\hline & Model 2 & $300.89[-17.59 ; 619.37]$ & 0.064 & Model 2 & $1.106[0.985 ; 1.241]$ & 0.085 \\
\hline & Model 3 & $206.93[-111.54 ; 525.40]$ & 0.198 & Model 3 & $1.075[0.956 ; 1.208]$ & 0.221 \\
\hline \multirow{3}{*}{ FTI } & Model 1 & $-292.17[-453.58 ;-130.76]$ & 0.001 & Model 1 & $0.938[0.886 ; 0.994]$ & 0.030 \\
\hline & Model 2 & $-235.71[-412.16 ;-59.24]$ & 0.010 & Model 2 & $0.930[0.871 ; 0.992]$ & 0.028 \\
\hline & Model 3 & $-204.78[-386.54 . ;-23.01]$ & 0.028 & Model 3 & $0.940[0.879 ; 1.004]$ & 0.067 \\
\hline
\end{tabular}

Betas represent the differences in number of steps per 24 hours per $1 \mathrm{~kg} / \mathrm{m}^{2}$ higher LTI and FTI, respectively. Ratios represent the ratio of the geometric means of AEE per $1 \mathrm{~kg} / \mathrm{m}^{2}$ higher LTI and $\mathrm{FTI}$, respectively. For example, each $1 \mathrm{~kg} / \mathrm{m}^{2}$ higher FTI was associated with a 0.943 times lower AEE (model 3). Model 1: unadjusted model; model 2: age, sex, group, diabetes; model 3: model 2 + FTI or LTI. AEE: active energy expenditure, $\mathrm{Cl}$ : confidence interval.

\section{Longitudinal analyses}

Changes over time in the first six months after starting dialysis were found for PA parameters, TEE, AEE and number of steps (table 4.4). Walking speed significantly increased over time by $+0.23 \mathrm{~m} / \mathrm{s}(p=0.010)$ (table 4.4). No changes were found for HGS during the six month follow-up period. Also no significant changes were observed in $\mathrm{BC}$ over the six month time period (data not shown). Hemoglobin levels significantly increased in the first six months after starting dialysis from $6.66 \pm 0.84 \mathrm{mmol} / \mathrm{L}(10.73 \pm 1.36 \mathrm{~g} / \mathrm{dl})$ to $7.21 \pm 0.79 \mathrm{mmol} / \mathrm{L}$ $(11.62 \pm 1.27 \mathrm{~g} / \mathrm{dl})(\mathrm{p}=0.008)$ (table $4.1 \mathrm{~b})$. No significant changes were found for albumin in the first six months after the start of dialysis ( $p=0.060$ ) (table $4.1 b$ ).

Additional analyses based on dialysis modality did not show significantly different outcomes for PA parameters, where the median change of TEE over six months was +55.0 [+147.0 -50.0] kcal/day for PD patients and $+371.0[+611.0-0] \mathrm{kcal} /$ day for HD patients $(p=0.135)$. For AEE the mean change over six months was $+87.60 \pm 211.97 \mathrm{kcal} /$ day for PD patients and $+202.6 \pm 261.75 \mathrm{kcal} /$ day for HD patients $(p=0.315)$, and mean change in number of steps over six months of time was $+1986.73 \pm 2689.64$ steps/day for PD patients and $+1810.13 \pm 3248.84$ steps/day for HD patients $(p=0.815)$. For HGS, the mean changes over six months were $-1.30 \pm 3.58 \mathrm{~kg}$ in PD patients and $+2.80 \pm 4.03 \mathrm{~kg}$ in HD patients $(p=0.006)$. No differences were found for walking speed between PD and HD patients over time, where change over time in walking speeds was $+0.16 \pm 0.36 \mathrm{~m} / \mathrm{s}$ in PD patients, and $+0.33 \pm 0.38 \mathrm{~m} / \mathrm{s}$ in HD patients $(p=0.292)$. 
Table 4.4 Longitudinal analyses for parameters of physical activity, physical performance, and muscle strength.

\begin{tabular}{|c|c|c|c|}
\hline Parameter & Visit & CKD-5 non-dialysis patients & p-value \\
\hline TEE (kcal/day) & $\begin{array}{l}\text { Before start dialysis } \\
\text { Six months after start dialysis }\end{array}$ & $\begin{array}{l}2186.5[1929.25-2575.75] \\
2385.0[2062.75-2628.25]\end{array}$ & 0.021 \\
\hline AEE (kcal/day) & $\begin{array}{l}\text { Before start } \\
\text { Six months after start dialysis }\end{array}$ & $\begin{array}{c}129.5[56.25-285.25] \\
273.50[93.77-482.25]\end{array}$ & 0.005 \\
\hline Steps (number/day) & $\begin{array}{l}\text { Before start } \\
\text { Six months after start dialysis }\end{array}$ & $\begin{array}{c}5378.0[2998.0-7092.25] \\
5576.0[3978.25-9357.25]\end{array}$ & 0.003 \\
\hline HGS (kg) & $\begin{array}{l}\text { Before start } \\
\text { Six months after start dialysis }\end{array}$ & $\begin{array}{c}27.97 \pm 9.29 \\
28.72 \pm 10.21\end{array}$ & NS \\
\hline Walking Speed (m/sec) & $\begin{array}{l}\text { Before start } \\
\text { Six months after start dialysis }\end{array}$ & $\begin{array}{l}1.50 \pm 0.45 \\
1.73 \pm 0.38\end{array}$ & 0.010 \\
\hline
\end{tabular}

Data are given in mean $\pm S D$ or median [interquartile range]. TEE = total energy expenditure, $\mathrm{AEE}=$ active energy expenditure, HGS = handgrip strength, NS = not significant, Walking speed data were missing in 7 patients.

\section{DISCUSSION}

This study focused on the differences in PA between CKD-5 non-dialysis patients, prevalent dialysis patients and healthy controls and on the alterations in PA from CKD-5 non-dialysis care to the first six months after starting dialysis. Furthermore, associations between PA and $\mathrm{BC}$ were assessed.

The cross-sectional analyses showed that PA parameters are already lower in the CKD-5 nondialysis phase (CKD-5) as compared with healthy controls, and are comparable with those of prevalent dialysis patients, consistent with a sedentary lifestyle as previously defined by Avesani et al. ${ }^{1}$. The very low number of steps, as a hallmark of physical inactivity, in both CKD-5 non-dialysis and prevalent dialysis patients, is of serious concern although not an entirely new finding in this field ${ }^{1}$. However, research on this topic has been controversial with other studies showing relatively preserved PA in patients with advanced CKD ${ }^{8}$.

The results of the longitudinal study suggested that the start of dialysis appeared to have a positive effect on PA parameters such as number of steps and AEE, which significantly increased after the start of dialysis, whether this is related to a beneficial effect of starting dialysis per se or to the slight increase in hemoglobin levels following the start of dialysis is not known.

Nonetheless, also after the start of dialysis PA parameters are still lower as compared with healthy controls. These results reemphasize the need for additional interventions, such as exercise training to increase PA parameters both before and after the start of dialysis, which has been shown to be beneficial in this patient group by several studies ${ }^{31,32}$. In line with that, results of our study showed that walking speed, as a parameter of physical performance, was already significantly decreased in the CKD-5 non-dialysis phase. Initiation of dialysis treatment was associated with a significant increase in walking speed during the first 6 months after starting dialysis.

Contrastingly, earlier research in elderly dialysis patients showed that the start of dialysis is related to an increased risk of disability, particularly to activities of daily living (ADL), next to an increased risk of mortality ${ }^{33}$. Nevertheless, that study population consisted mostly of 
frail elderly people in a nursing home environment, in which the start of dialysis could be an additional factor for further decline in physical functioning ${ }^{34,35}$. In contrast, we focused on a younger and possibly less frail patient group, and studied parameters of PA and physical performance, by field tests instead of self-reported tests. Additional analyses showed that dialysis modality did not present different outcomes for PA parameters and physical performance.

HGS, as a parameter of muscle strength, tended to be lower in the CKD-5 non-dialysis patients group, which is in line with earlier research in both older adults ${ }^{36}$, as well as in patients ESRD starting dialysis treatment ${ }^{37}$. A study of Isoyama et al. also showed that muscle strength is a strong predictor for mortality in dialysis patients, even more strongly than muscle mass itself $^{38}$. In line with this study, our findings showed that starting dialysis treatment does not seem to have a detrimental effect on HGS, however also no positive effect on HGS was observed either during the first six months of dialysis treatment.

Regarding to BC, the cross-sectional analysis showed that LTI was significantly lower in dialysis patients when compared with CKD-5 non-dialysis patients where LTI did not differ significantly from healthy controls. The decline in LTI in dialysis patients is in line with previous research ${ }^{4,39,40}$. However, after adjustment for age, sex and diabetes, no significant differences were found in LTI between patient groups.

In contrast, FTI was significantly higher in dialysis patients as compared with both CKD-5 non-dialysis patients and healthy controls. After adjustment for age, sex and diabetes the difference between CKD-5 non-dialysis and dialysis patients was similar, suggesting that only a part of high FTI levels was explained by the presence of diabetes, which was more prevalent in the dialysis patient group as compared with the CKD-5 non-dialysis group. These results are in line with a recent cohort study in 8227 patients, in which a mean increase in FTI of 0.95 $\mathrm{kg} / \mathrm{m}^{2}$ and a mean decrease in LTI of $0.4 \mathrm{~kg} / \mathrm{m}^{2}$ were observed within 2 years following the start of dialysis ${ }^{41}$. The higher FTI can possibly be explained by effects of dialysis treatment, differences in food intake in dialysis patients, which were not captured in the present study, to a survivor bias, or to prolonged physical inactivity. Indeed, FTI was inversely associated to PA after adjustment for age, sex, group, diabetes and LTI, whereas LTI was not significantly associated with parameters of PA when adjusted for age, sex, group, diabetes and FTI.

This study had some limitations; firstly the study population was relatively small and contained both HD and PD patients. However, in the longitudinal study no difference in changes in PA and physical performance were observed between patients who started with HD as compared with PD, with the exception of HGS, which increased in HD patients and decreased in PD patients. Secondly, due to the fact that we have included relatively young and possibly less frail controls and patients, there might be a possibility of selection bias. In addition, none of 30 CKD-5 non-dialysis patients in the longitudinally analyses died in the first six months of the transitional phase after starting dialysis treatment. Thirdly, PA was only measured for a relatively short period of time (48 hours), which might have biased outcome parameters. We chose to include an additional analysis of a non-dialysis day in 
order to exclude the effects of the time allocated to the dialysis treatment per se. Finally, in the cross-sectional part, there was an imbalance in diabetics between the CKD-5 nondialysis and dialysis patients. However, results did not materially change after adjustment for diabetes.

To conclude, PA parameters are already lower in the CKD-5 non-dialysis phase, consistent with a sedentary lifestyle, and were not different from prevalent dialysis patients. The transition from the CKD-5 non-dialysis to the dialysis phase was associated with a modest improvement in PA parameters in the first six months after the start of dialysis treatment. Additionally, FTI was inversely associated with PA, suggesting a role of physical inactivity in the increase in fat mass in both CKD-5 non-dialysis and dialysis patients. These results underscore the importance of physical activity programs which should also include the CKD5 non-dialysis phase.

\section{FUNDING}

Jeroen P. Kooman, Frank M. van der Sande and Natascha J.H. Broers are supported by an unrestricted grant from Fresenius Medical Care Europe. Peter Wabel and Bernard Canaud are employees of Fresenius Medical Care Europe. 


\section{REFERENCES}

1. Avesani CM, Trolonge S, Deleaval P, Baria F, Mafra D, Faxen-Irving G, et al. Physical activity and energy expenditure in haemodialysis patients: an international survey. Nephrol Dial Transplant 2012;27:2430-2434.

2. Stack AG, Molony DA, Rives T, Tyson J,Murthy BV. Association of physical activity with mortality in the US dialysis population. Am J Kidney Dis 2005;45:690-701.

3. Tentori F, Elder SJ, Thumma J, Pisoni RL, Bommer J, Fissell RB, et al. Physical exercise among participants in the Dialysis Outcomes and Practice Patterns Study (DOPPS): correlates and associated outcomes. Nephrol Dial Transplant 2010;25:3050-3062.

4. van den Ham EC, Kooman JP, Schols AM, Nieman FH, Does JD, Franssen FM, et al. Similarities in skeletal muscle strength and exercise capacity between renal transplant and hemodialysis patients. Am J Transplant 2005;5:1957-1965.

5. Johansen KL,Painter P. Exercise in individuals with CKD. Am J Kidney Dis 2012;59:126-134.

6. Broers NJ, Cuijpers AC, van der Sande FM, Leunissen KM,Kooman JP. The first year on haemodialysis: a critical transition. Clin Kidney J 2015;8:271-277.

7. Gould DW, Graham-Brown MP, Watson EL, Viana JL,Smith AC. Physiological benefits of exercise in pre-dialysis chronic kidney disease. Nephrology (Carlton) 2014;19:519-527.

8. Wlodarek D, Glabska D,Rojek-Trebicka J. Physical activity of predialysis patients with chronic kidney disease measured using SenseWear Armban. J Sports Med Phys Fitness 2011;51:639-646.

9. Fouque D, Pelletier S, Mafra D,Chauveau P. Nutrition and chronic kidney disease. Kidney Int 2011;80:348-357.

10. Marcelli D, Usvyat LA, Kotanko P, Bayh I, Canaud B, Etter M, et al. Body composition and survival in dialysis patients: results from an international cohort study. Clin J Am Soc Nephrol 2015;10:1192-1200.

11. Cupisti A, D’Alessandro C, Fumagalli G, Vigo V, Meola M, Cianchi C, et al. Nutrition and physical activity in CKD patients. Kidney Blood Press Res 2014;39:107-113.

12. Rhee $\mathrm{CM}$,Kalantar-Zadeh K. Resistance exercise: an effective strategy to reverse muscle wasting in hemodialysis patients? J Cachexia Sarcopenia Muscle 2014;5:177-180.

13. Kuo YT, Chiu KM, Tsang YM, Chiu CM,Chien MY. Influence of Chronic Kidney Disease on Physical Function and Quality of Life in Patients after Coronary Artery Bypass Grafting. Cardiorenal Med 2015;5:237-245.

14. Chamney PW, Wabel P, MoissI UM, Muller MJ, Bosy-Westphal A, Korth O, et al. A whole-body model to distinguish excess fluid from the hydration of major body tissues. Am J Clin Nutr 2007;85:80-89.

15. Fresenius Medical Care (2007) Body Composition Monitor Manual Operation Procedure. Fresenius Medical Care BH.

16. Wizemann V, Wabel P, Chamney P, Zaluska W, MoissI U, Rode C, et al. The mortality risk of overhydration in haemodialysis patients. Nephrol Dial Transplant 2009;24:1574-1579. 
17. Wabel P RC, MoissI U, Chamney PW, Wizemann V. Accuracy of bioimpedance spectroscopy (BIS) to detect fluid status changes in hemodialysis patients (abstract). Nephrol Dial Transplant 2007;22(suppl 26)VI129.

18. Broers NJ, Martens RJ, Cornelis T, Diederen NM, Wabel P, van der Sande FM, et al. Body composition in dialysis patients: a functional assessment of bioimpedance using different prediction models. J Ren Nutr 2015;25:121-128.

19. Van Biesen W, Williams JD, Covic AC, Fan S, Claes K, Lichodziejewska-Niemierko M, et al. Fluid status in peritoneal dialysis patients: the European Body Composition Monitoring (EuroBCM) study cohort. PLoS One 2011;6:e17148.

20. Davison SN, Jhangri GS, Jindal K,Pannu N. Comparison of volume overload with cyclerassisted versus continuous ambulatory peritoneal dialysis. Clin J Am Soc Nephrol 2009;4:1044-1050.

21. Cooper BA, Aslani A, Ryan M, Zhu FY, Ibels LS, Allen BJ, et al. Comparing different methods of assessing body composition in end-stage renal failure. Kidney Int 2000;58:408-416.

22. Ostir GV, Volpato S, Fried LP, Chaves P,Guralnik JM. Reliability and sensitivity to change assessed for a summary measure of lower body function: results from the Women's Health and Aging Study. J Clin Epidemiol 2002;55:916-921.

23. Penninx BW, Ferrucci L, Leveille SG, Rantanen T, Pahor M,Guralnik JM. Lower extremity performance in nondisabled older persons as a predictor of subsequent hospitalization. J Gerontol A Biol Sci Med Sci 2000;55:M691-697.

24. Guralnik JM, Ferrucci L, Simonsick EM, Salive ME,Wallace RB. Lower-extremity function in persons over the age of 70 years as a predictor of subsequent disability. $\mathrm{N}$ Engl J Med 1995;332:556-561.

25. Guralnik JM, Ferrucci L, Pieper CF, Leveille SG, Markides KS, Ostir GV, et al. Lower extremity function and subsequent disability: consistency across studies, predictive models, and value of gait speed alone compared with the short physical performance battery. J Gerontol A Biol Sci Med Sci 2000;55:M221-231.

26. Hartmann EL, Kitzman D, Rocco M, Leng X, Klepin H, Gordon M, et al. Physical function in older candidates for renal transplantation: an impaired population. Clin J Am Soc Nephrol 2009;4:588-594.

27. Davies SJ, Russell L, Bryan J, Phillips L,Russell Gl. Comorbidity, urea kinetics, and appetite in continuous ambulatory peritoneal dialysis patients: their interrelationship and prediction of survival. Am J Kidney Dis 1995;26:353-361.

28. Davies SJ, Phillips L, Naish PF,Russell GI. Quantifying comorbidity in peritoneal dialysis patients and its relationship to other predictors of survival. Nephrol Dial Transplant 2002;17:1085-1092.

29. Van Manen JG, Korevaar JC, Dekker FW, Boeschoten EW, Bossuyt PM, Krediet RT. Adjustment for comorbidity in studies on health status in ESRD patients: which comorbidity index to use? J Am Soc Nephrol 2003;14:478-485. 
30. Levey AS, Stevens LA, Schmid CH, Zhang YL, Castro AF, 3rd, Feldman HI, et al. A new equation to estimate glomerular filtration rate. Ann Intern Med 2009;150:604-612.

31. van den Ham EC, Kooman JP, Schols AM, Nieman FH, Does JD, Akkermans MA, et al. The functional, metabolic, and anabolic responses to exercise training in renal transplant and hemodialysis patients. Transplantation 2007;83:1059-1068.

32. Bae YH, Lee SM,Jo Jl. Aerobic training during hemodialysis improves body composition, muscle function, physical performance, and quality of life in chronic kidney disease patients. J Phys Ther Sci 2015;27:1445-1449.

33. Kurella Tamura M, Covinsky KE, Chertow GM, Yaffe K, Landefeld CS,McCulloch CE. Functional status of elderly adults before and after initiation of dialysis. N Engl J Med 2009;361:1539-1547.

34. Kotanko P, Kooman J, van der Sande F, Kappel F,Usvyat L. Accelerated or Out of Control: The Final Months on Dialysis. J Ren Nutr 2014;

35. Murray SA, Boyd K,Sheikh A. Palliative care in chronic illness. Bmj 2005;330:611-612.

36. Hughes VA, Frontera WR, Wood M, Evans WJ, Dallal GE, Roubenoff R, et al. Longitudinal muscle strength changes in older adults: influence of muscle mass, physical activity, and health. J Gerontol A Biol Sci Med Sci 2001;56:B209-217.

37. Heimburger O, Qureshi AR, Blaner WS, Berglund L,Stenvinkel P. Hand-grip muscle strength, lean body mass, and plasma proteins as markers of nutritional status in patients with chronic renal failure close to start of dialysis therapy. Am J Kidney Dis 2000;36:1213-1225.

38. Isoyama N, Qureshi AR, Avesani CM, Lindholm B, Barany P, Heimburger O, et al. Comparative associations of muscle mass and muscle strength with mortality in dialysis patients. Clin J Am Soc Nephrol 2014;9:1720-1728.

39. Foley RN, Wang C, Ishani A, Collins AJ,Murray AM. Kidney function and sarcopenia in the United States general population: NHANES III. Am J Nephrol 2007;27:279-286.

40. Mak RH,Cheung W. Cachexia in chronic kidney disease: role of inflammation and neuropeptide signaling. Curr Opin Nephrol Hypertens 2007;16:27-31.

41. Marcelli D, Brand K, Ponce P, Milkowski A, Marelli C, Ok E, et al. Longitudinal Changes in Body Composition in Patients After Initiation of Hemodialysis Therapy: Results From an International Cohort. J Ren Nutr 2015; 



\section{CHAPTER 5}

SEASON AFFECTS BODY COMPOSITION AND ESTIMATION OF FLUID

OVERLOAD IN HAEMODIALYSIS PATIENTS: VARIATIONS IN BODY COMPO-

SITION; A SURVEY FROM THE EUROPEAN MONDO DATABASE

Natascha J.H. Broers, Len A. Usvyat, Daniele Marcelli, Inga Bayh, Laura Scatizzi, Bernard Canaud, Frank M. van der Sande, Peter Kotanko, Ulrich Moissl and Jeroen P. Kooman on behalf the MONitoring Dialysis Outcomes (MONDO) Consortium

Nephrol Dial Transplant. 2015; 30: 676-681 


\section{ABSTRACT \\ Background}

Seasonal variations in blood pressure (BP) and inter-dialytic weight gain (IDWG) are well established in dialysis patients. However, no study has assessed changes in body composition (BC) in this population.

\section{Methods}

In this survey, seasonal variations in fat mass (FM), lean tissue mass (LTM), extracellular water (ECW) and fluid overload (FO) were assessed in 42099 dialysis patients (mean age 61.2 years, $58 \%$ males) from the Fresenius Medical Care Europe database, as part of the MONitoring Dialysis Outcomes (MONDO) consortium, in relation to other nutritional parameters, IDWG and $\mathrm{BP}$. $\mathrm{BC}$ was assessed by a body composition monitor $\left(\mathrm{BCM}^{\circledR}\right.$, Fresenius Medical Care, Bad Homburg, Germany).

\section{Results}

FM was highest in winter and lowest in summer ( $\triangle \mathrm{FM}-1.17 \mathrm{~kg} ; \mathrm{P}<0.001)$, whereas LTM was lowest during winter and highest in summer ( $\triangle \mathrm{LTM} 0.86 \mathrm{~kg}$; $\mathrm{P}<0.0001)$. ECW and FO were lowest in winter, and highest in spring ( $\triangle \mathrm{ECW}$ : $0.13 \mathrm{~L} ; \mathrm{P}<0.0001, \Delta \mathrm{FO}: 0.31 \mathrm{~L} ; \mathrm{P}<0.0001)$ and summer ( $\triangle \mathrm{ECW}$ : $0.15 \mathrm{~L} ; \mathrm{P}<0.0001$ and $\triangle \mathrm{FO}: 0.2 \mathrm{~L} ; \mathrm{P}<0.0001$ ), despite a higher systolic blood pressure (SBP; $136.7 \pm 17.4 \mathrm{mmHg}$ ) and IDWG $(3.0 \pm 1.1 \mathrm{~kg})$ during winter. C-reactive protein (CRP), serum sodium and haemoglobin levels were highest in winter, whereas serum albumin was lowest in fall. Normalized protein catabolic rate (nPCR) was lowest in winter and matched variations in $\mathrm{BC}$ only to a minor degree.

\section{Conclusions}

$\mathrm{BC}$ and hydration state, assessed by bioimpedance spectroscopy, follows a seasonal pattern which may be of relevance for the estimation of target weight, and for the interpretation of longitudinal studies including estimates of BC. Whether these changes should lead to therapeutic interventions could be the focus of future studies.

\section{Keywords}

bio-impedance spectroscopy, body composition, body composition monitor, fluid status 


\section{INTRODUCTION}

Biological rhythms play an important role in human physiology. While the significance of ultradian (cycle time <20 h; e.g. heart rate variability) and circadian rhythms [e.g. blood pressure (BP)] in dialysis patients is well established in numerous clinical studies (for review see ${ }^{1}$ ), we and others have also shown the significance of seasonal variations in dialysis patients ${ }^{2,3}$. In a recent study in 15056 patients from the Renal Research Institute, NY, USA ${ }^{4}$, significant seasonal variations in important clinical and laboratory parameters and mortality were shown. Mortality, as well as systolic blood pressure (SBP) and inter-dialytic weight gain (IDWG), were higher in winter compared with the summer months. The same held true for inflammatory parameters.

Body composition (BC) has been shown to be an important parameter related to outcome in dialysis patients. Alterations in BC are very common in dialysis patients, in particular loss of lean tissue mass (LTM) which is induced by protein-energy wasting and highly associated to morbidity and mortality ${ }^{5}$. Since in both the general population and in dialysis patients, cardiovascular mortality follows a seasonal pattern ${ }^{4,6}$ and, since dietary intake, BC, physical activity and immune function vary by seasons in healthy subjects ${ }^{7}$, we felt a need to study seasonal variations of $\mathrm{BC}$ in dialysis patients to close that knowledge gap. The primary aim of this study was to test for seasonal variations of $B C$ in dialysis patients. Our secondary aim was to study the relation of variations in $\mathrm{BC}$ with those of relevant clinical parameters.

\section{MATERIALS AND METHODS}

The MONitoring Dialysis Outcomes (MONDO) consortium consists of haemodialysis (HD) databases from Renal Research Institute clinics in the USA; Fresenius Medical Care (FMC) clinics in Europe, Asia Pacific and Latin America; KfH Clinics in Germany; Imperial College, London, UK; Hadassah Medical Center, Jerusalem, Israel, and Maastricht University Medical Centre, Netherlands. Electronic medical records were used to document patient care. From there, information is made available in a primary database after obtaining informed consent and in accordance with local privacy and data protection regulations. For this analysis, we enrolled chronic HD patients treated in FMC facilities in 17 European countries between January 2006 and December 2012 in this retrospective cohort study. BC was assessed by whole body multi-frequency bio-impedance spectroscopy with the body composition monitor (BCM ${ }^{\circledR}, \mathrm{FMC}$, Bad Homburg, Germany). The BCM determines fat mass (FM), LTM, extracellular water (ECW) and fluid overload (FO). The model on which the BCM operates is described by Chamney et al. ${ }^{8}$. BCM measurements are performed in Fresenius Europe clinics as part of routine clinical care since 1 July 2011 when FO became a part of the balance score card. Prior to that date, BCM availability was limited being based on the requests of individual clinics.

Pre-dialysis SBP, IDWG, normalized protein catabolic rate (nPCR) and biochemical parameters [serum creatinine, albumin and C-reactive protein (CRP)] were included in the analysis. These parameters were available for the majority of patients in the database. Most data 
were missing for CRP, which was available in 32799 patients. Patients were included if at least one BCM measurement was available for analysis. There were no exclusion criteria. A sensitivity analysis was performed in patients in whom measurements were available for all seasons.

Data analysis was performed by linear mixed model (LMM) analysis with season as fixed effect, and patient as random effect. Analysis was only adjusted for the year of measurement. Winter was used as the reference season. Effect sizes as obtained in the LMM model represent therefore differences between the various seasons and winter. These differences, as well as their significance and $95 \%$ confidence intervals in the season, are reported in the different tables. Additional analyses were performed after dividing patients into tertiles for body mass index (BMI) and for different geographical areas of Europe, i.e. eastern Europe, north/west Europe, southern Europe and western Asia (Turkey). In addition, cosinor analysis was performed to construct figures per month. SAS version 9.3 (Cary, NC, USA) software was used for statistical analysis.

\section{RESULTS}

\section{Patient characteristics}

We studied 42099 patients with a mean age of 61.2 years, $58 \%$ males, $19.3 \%$ with diabetes and $26.7 \%$ with a history of cardiovascular disease. Further patient characteristics are displayed in Table 5.1. The mean BMI was $26.1 \pm 6.7 \mathrm{~kg} / \mathrm{m}^{2}$. Mean FM was $26.4 \pm 11.5 \mathrm{~kg}$ and mean LTM was $34.2 \pm 10.0 \mathrm{~kg}$. Mean ECW was $16.9 \pm 3.4 \mathrm{~L}$ and mean FO was $2.0 \pm 2.6 \mathrm{~L}$.

Table 5.1 Patient demographics.

\begin{tabular}{ll}
\hline Patient demographics & \\
\hline Number of patients & 42099 \\
Age (years) & $61.2 \pm 15.2$ \\
Male (\%) & 57.6 \\
Vintage (4 years) & $2.6 \pm 4.1$ \\
BMI (kg/m ${ }^{2}$ ) & $26.1 \pm 6.7$ \\
(Pre) Systolic Blood Pressure (mm/Hg) & $136.7 \pm 17.4$ \\
Albumin (g/dL) & $3.9 \pm 0.4$ \\
Creatinine ( $\mu \mathrm{mol} / \mathrm{L})$ & $7.8 \pm 2.4$ \\
CRP (mg/L) & $12.9 \pm 15.5$ \\
Serum Sodium (mmol/L) & $138.3 \pm 3.8$ \\
Hemoglobin (g/dL) & $11.3 \pm 1.5$ \\
nPCR (g/kg/day) & $1.05 \pm 0.27$ \\
LTM (kg) & $34.2 \pm 10.0$ \\
FM (kg) & $26.4 \pm 11.5$ \\
ECW (L) & $16.9 \pm 3.4$ \\
FO (L) & $2.0 \pm 2.6$ \\
\hline
\end{tabular}

BMI: body mass index; SBP: systolic blood pressure; CRP: C-reactive protein; nPCR: normalized protein catabolic rate; LTM: lean tissue mass; FM: fat mass; ECW: extracellular water; FO: fluid overload. 


\section{Variations in body composition}

FM was significantly lower in spring $(-0.5 \mathrm{~kg} ; \mathrm{P}<0.0001)$, summer $(-1.2 \mathrm{~kg} ; \mathrm{P}<0.0001)$ and fall $(-0.4 \mathrm{~kg} ; \mathrm{P}<0.0001)$, when compared with winter (Table 5.2, Figure 5.1). LTM was significantly higher in the spring $(0.4 \mathrm{~kg} ; \mathrm{P}<0.0001)$, summer $(0.9 \mathrm{~kg} ; \mathrm{P}<0.0001)$ and fall $(0.1$ $\mathrm{kg}$; $\mathrm{P}<0.0001$ ) when compared with winter (Table 5.2, Figure 5.2). Sub-analyses for eastern Europe, north/west Europe, southern Europe and western Asia showed similar findings for both FM as well as LTM when compared with the analysis for whole Europe (data not shown).

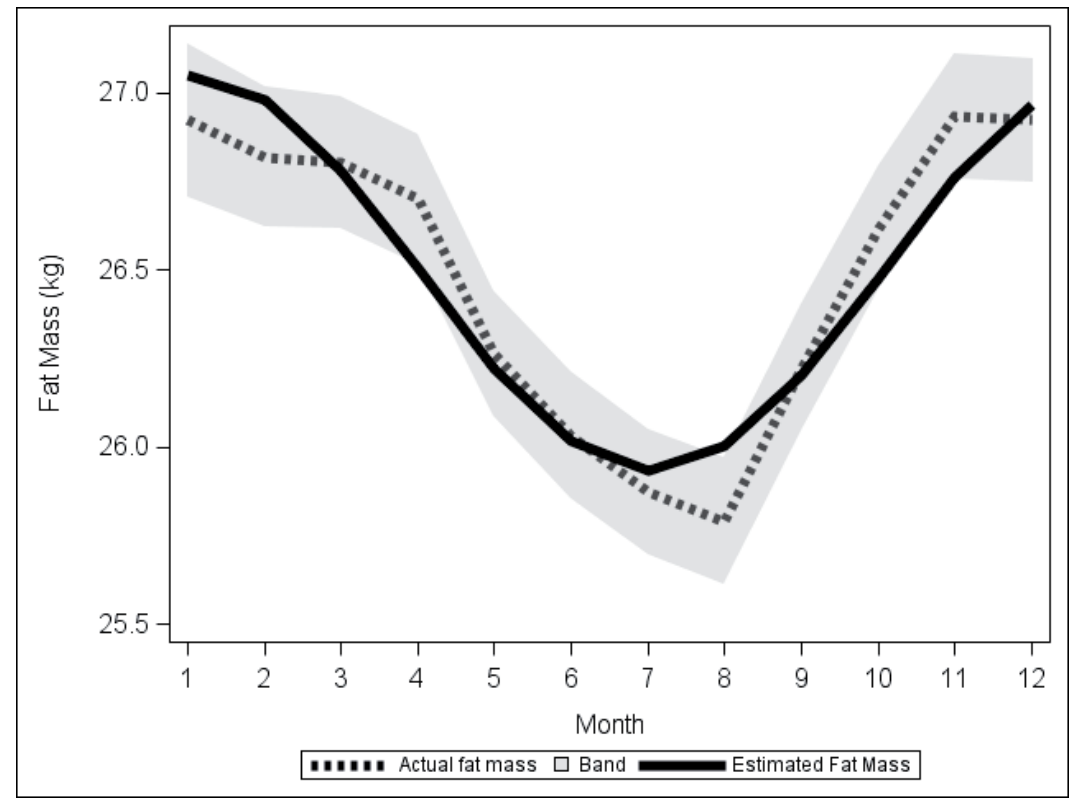

Figure 5.1 Seasonal variations in fat mass. 


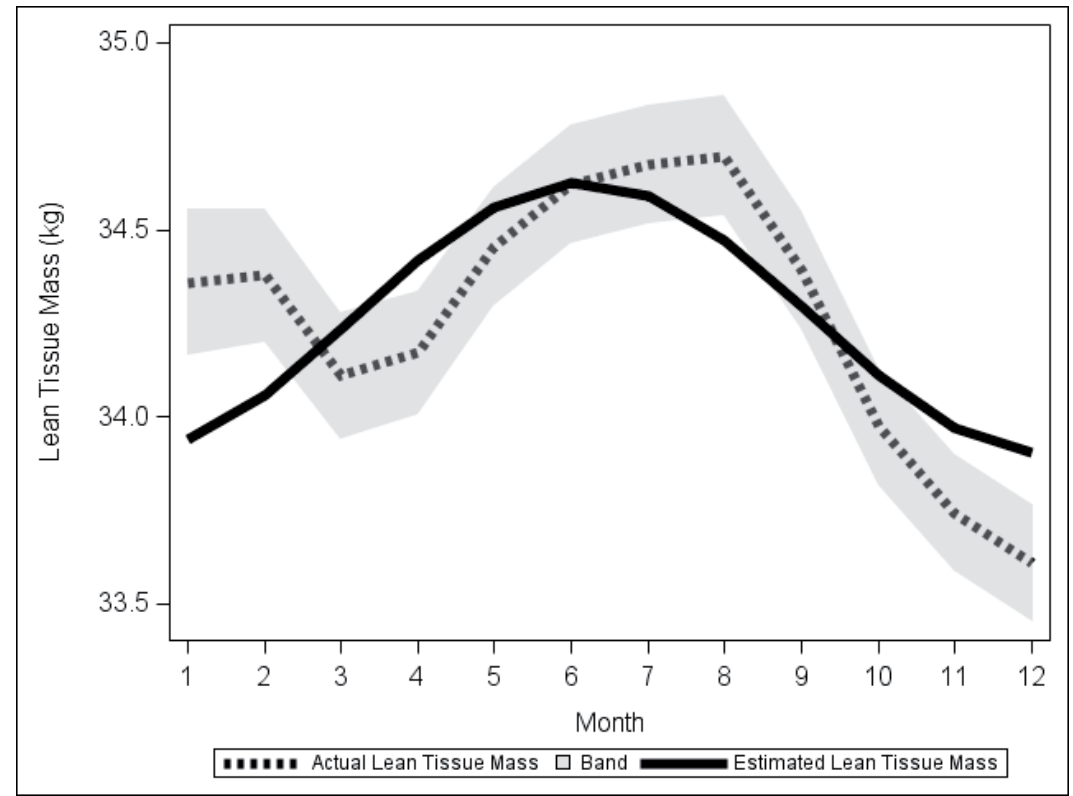

Figure $\mathbf{5 . 2}$ Seasonal variations in lean tissue mass. 
Table 5.2 Differences between seasons with winter as reference month.

\begin{tabular}{|c|c|c|c|c|c|}
\hline Parameter & Season & $\begin{array}{l}\text { Difference } \\
\text { to Winter }\end{array}$ & $95 \% \mathrm{LCL}$ & $95 \%$ UCL & p-value \\
\hline \multirow[t]{3}{*}{ LTM (kg) } & Spring & 0.41 & 0.37 & 0.46 & $<.0001$ \\
\hline & Summer & 0.86 & 0.82 & 0.90 & $<.0001$ \\
\hline & Fall & 0.13 & 0.09 & 0.17 & $<.0001$ \\
\hline \multirow[t]{3}{*}{ FM (kg) } & Spring & -0.47 & -0.59 & -0.35 & $<.0001$ \\
\hline & Summer & -1.17 & -1.28 & -1.06 & $<.0001$ \\
\hline & Fall & -0.37 & -0.48 & -0.26 & $<.0001$ \\
\hline \multirow[t]{3}{*}{ ECW (L) } & Spring & 0.13 & 0.09 & 0.16 & $<.0001$ \\
\hline & Summer & 0.15 & 0.12 & 0.18 & $<.0001$ \\
\hline & Fall & -0.01 & -0.04 & 0.02 & 0.472 \\
\hline \multirow[t]{3}{*}{ FO (L) } & Spring & 0.31 & 0.27 & 0.35 & $<.0001$ \\
\hline & Summer & 0.20 & 0.16 & 0.24 & $<.0001$ \\
\hline & Fall & 0.04 & 0.00 & 0.08 & 0.046 \\
\hline \multirow[t]{3}{*}{ SBP (mmHg) } & Spring & -0.71 & -0.74 & -0.67 & $<.0001$ \\
\hline & Summer & -2.50 & -2.54 & -2.47 & $<.0001$ \\
\hline & Fall & -0.77 & -0.80 & -0.73 & $<.0001$ \\
\hline \multirow[t]{3}{*}{ Albumin (g/dL) } & Spring & 0.008 & 0.004 & 0.011 & $<.0001$ \\
\hline & Summer & -0.004 & -0.007 & -0.000 & 0.033 \\
\hline & Fall & -0.016 & -0.019 & -0.013 & $<.0001$ \\
\hline \multirow[t]{3}{*}{ Creatinine ( $\mu \mathrm{mol} / \mathrm{L})$} & Spring & -0.039 & -0.056 & -0.022 & $<.0001$ \\
\hline & Summer & 0.003 & -0.013 & 0.020 & 0.682 \\
\hline & Fall & -0.100 & -0.116 & -0.083 & $<.0001$ \\
\hline \multirow[t]{3}{*}{ CRP (mg/L) } & Spring & -0.407 & -0.584 & -0.230 & $<.0001$ \\
\hline & Summer & -0.946 & -1.121 & -0.771 & $<.0001$ \\
\hline & Fall & -0.516 & -0.685 & -0.347 & $<.0001$ \\
\hline \multirow{3}{*}{$\begin{array}{l}\text { Serum Sodium } \\
\text { (mmol/L) }\end{array}$} & Spring & -0.005 & -0.136 & 0.126 & 0.942 \\
\hline & Summer & -0.345 & -0.470 & -0.220 & $<.0001$ \\
\hline & Fall & -0.700 & -0.821 & -0.580 & $<.0001$ \\
\hline \multirow[t]{3}{*}{ Hemoglobin (g/dL) } & Spring & -0.117 & -0.165 & -0.068 & $<.0001$ \\
\hline & Summer & -0.107 & -0.153 & -0.061 & $<.0001$ \\
\hline & Fall & -0.040 & -0.085 & 0.004 & 0.074 \\
\hline \multirow[t]{3}{*}{ nPCR (g/kg/day) } & Spring & 0.001 & -0.003 & 0.004 & 0.756 \\
\hline & Summer & 0.002 & -0.002 & 0.005 & 0.338 \\
\hline & Fall & 0.015 & 0.011 & 0.018 & $<.0001$ \\
\hline \multirow[t]{3}{*}{ IDWG\% } & Spring & -0.003 & -0.005 & 0.000 & 0.060 \\
\hline & Summer & -0.120 & -0.122 & -0.117 & $<.0001$ \\
\hline & Fall & 0.012 & 0.009 & 0.014 & $<.0001$ \\
\hline \multirow[t]{3}{*}{ Post weight (kg) } & Spring & -0.075 & -0.099 & -0.051 & $<.0001$ \\
\hline & Summer & -0.172 & -0.196 & -0.148 & $<.0001$ \\
\hline & Fall & 0.008 & -0.0156 & 0.0311 & 0.514 \\
\hline
\end{tabular}

LCL: lower control limit; UCL: upper control limit; LTM: lean tissue mass; FM: fat mass; ECW: extracellular water; FO: fluid overload; SBP:, systolic blood pressure; CRP: C-reactive protein; nPCR: normalized protein catabolic rate; IDWG: interdialytic weight gain.

\section{Seasonality of fluid status}

ECW was significantly higher during spring $(0.1 \mathrm{~L} ; \mathrm{P}<0.0001)$ and summer $(0.2 \mathrm{~L} ; \mathrm{P}<0.0001)$ when compared with winter, but not different during fall (-0.01 L; $P=0.472$ ) (Table 5.2, Figure 5.3). FO was significantly higher during spring ( $0.31 \mathrm{~L} ; \mathrm{P}<0.0001)$, summer $(0.2 \mathrm{~L} ; \mathrm{P}<0.0001)$ and fall (0.04 L; $\mathrm{P}=0.046)$ when compared with winter (Table 5.2, Figure 5.4). Sub-analyses for eastern Europe, north/west Europe, southern Europe and western Asia showed similar findings for FO as compared with the analysis for whole Europe (data not shown). 


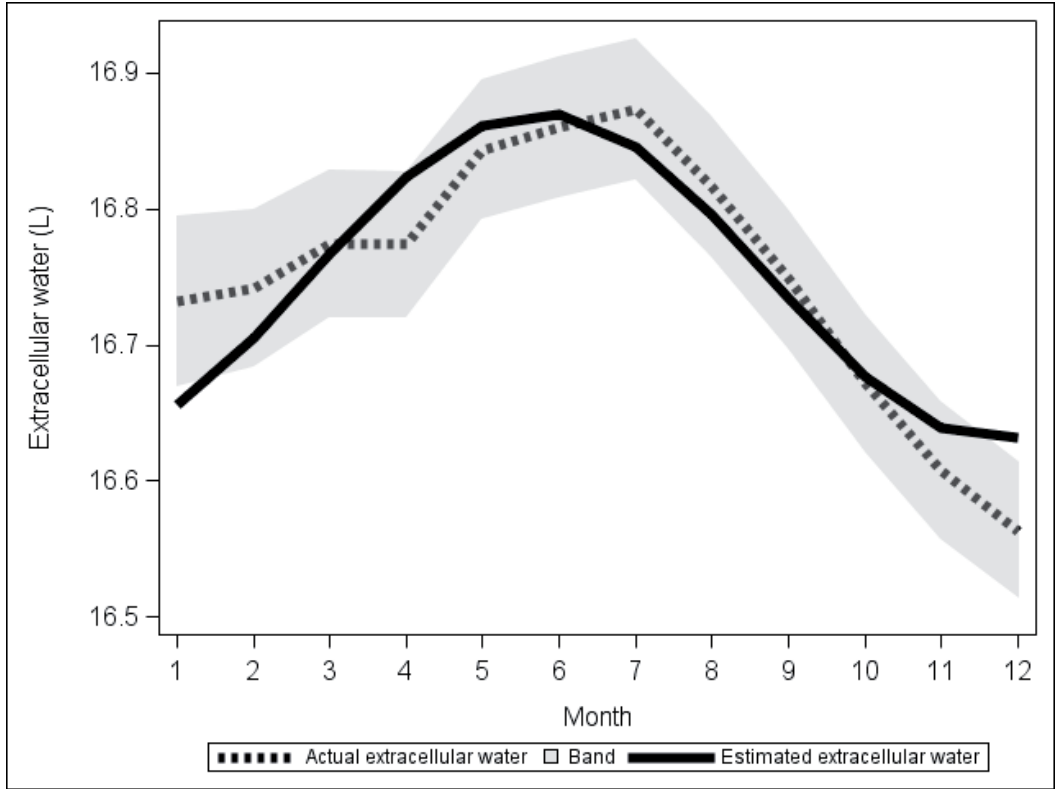

Figure 5.3 Seasonal variations in extracellular water.

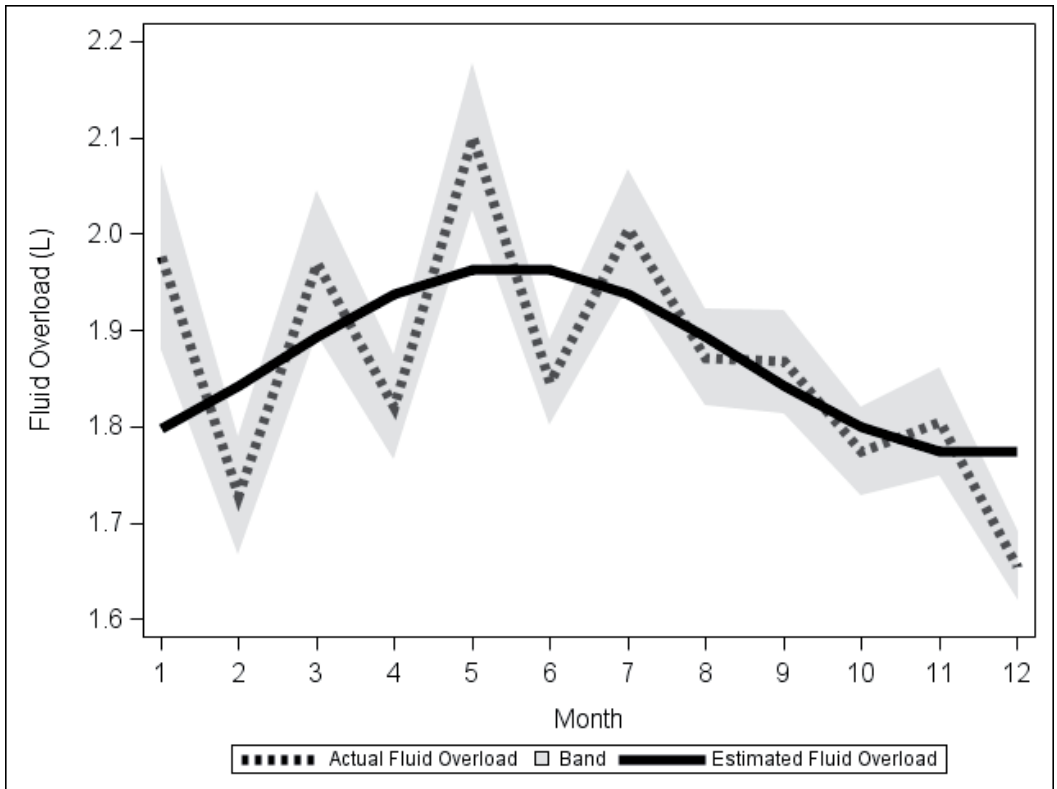

Figure 5.4 Seasonal variations in fluid overload. 
When adjusted for tertiles of BMI, FO remained significantly different in the spring and summer when compared with winter (Table 5.3). SBP was significantly lower in spring (-0.7 $\mathrm{mmHg}$; $\mathrm{P}<0.0001)$, summer $(-2.5 \mathrm{mmHg} ; \mathrm{P}<0.0001)$ and fall $(-0.8 \mathrm{mmHg} ; \mathrm{P}<0.0001)$ when compared with winter (Table 5.2).

Table 5.3 Fluid overload (FO) adjusted for BMI tertiles.

\begin{tabular}{|c|c|c|c|c|c|}
\hline Parameter & Season & $\begin{array}{l}\text { Difference } \\
\text { to Winter }\end{array}$ & $95 \%$ LCL & $95 \%$ UCL & p-value \\
\hline \multirow[t]{3}{*}{ BMI $1^{\text {st }}$ tertile } & Spring & 0.18 & 0.12 & 0.23 & $<.0001$ \\
\hline & Summer & 0.17 & 0.12 & 0.22 & $<.0001$ \\
\hline & Fall & -0.03 & -0.08 & 0.02 & 0.213 \\
\hline \multirow[t]{3}{*}{ BMI $2^{\text {nd }}$ tertile } & Spring & 0.16 & 0.11 & 0.22 & $<.0001$ \\
\hline & Summer & 0.21 & 0.16 & 0.26 & $<.0001$ \\
\hline & Fall & 0.04 & -0.01 & 0.09 & 0.120 \\
\hline \multirow[t]{3}{*}{ BMI $3^{\text {th }}$ tertile } & Spring & 0.12 & 0.06 & 0.18 & 0.000 \\
\hline & Summer & 0.15 & 0.09 & 0.21 & $<.0001$ \\
\hline & Fall & 0.01 & -0.04 & 0.07 & 0.669 \\
\hline
\end{tabular}

LCL: lower control limit; UCL: upper control limit; BMI: body mass index.

\section{Sensitivity analysis for body composition}

For 18658 patients, measurements were available for all seasons. Results with regard to seasonal variations in $\mathrm{BC}$ were not materially different from the overall analysis, except for the fact that differences for ECW between autumn and winter months became significant, whereas the difference between fall and winter for FO lost significance (Table 5.4).

Table 5.4 Differences between seasons with winter as reference month (only patients for whom measurements were available for all seasons included).

\begin{tabular}{llllll}
\hline Parameter & Season & $\begin{array}{l}\text { Difference } \\
\text { to Winter }\end{array}$ & 95\% LCL & 95\% UCL & p-value \\
\hline LTM (kg) & Spring & 0.39 & 0.35 & 0.44 & $<.0001$ \\
& Summer & 0.82 & 0.77 & 0.87 & 0.18 \\
& Fall & 0.13 & 0.09 & -0.29 & $<.0001$ \\
\hline FM (kg) & Spring & -0.33 & -0.37 & -0.91 & $<.0001$ \\
& Summer & -0.95 & -0.99 & -0.28 & $<.0001$ \\
& Fall & -0.33 & -0.36 & 0.19 & $<.0001$ \\
\hline ECW (L) & Spring & 0.17 & 0.16 & 0.26 & $<.0001$ \\
& Summer & 0.25 & 0.24 & 0.07 & $<.0001$ \\
\hline FO (L) & Fall & 0.06 & 0.05 & 0.35 & $<.001$ \\
& Spring & 0.29 & 0.23 & 0.17 & 0.08 \\
\hline
\end{tabular}

LCL: lower control limit; UCL: upper control limit; LTM: lean tissue mass; FM: fat mass; ECW: extracellular water; FO: fluid overload.

\section{Seasonality of biochemical parameters and $\mathrm{nPCR}$}

Albumin was significantly higher in spring but not in summer and fall when compared with winter (Table 5.2). Creatinine was significantly lower in spring and fall, but not in summer when compared with winter (Table 5.2). CRP was significantly lower in spring, summer and fall when compared with winter (Table 5.2). Serum sodium was significantly lower in summer and fall when compared with winter, but not in spring (Table 5.2). Haemoglobin levels were 
significantly lower in spring and summer but not in fall, when compared with winter (Table 5.2). nPCR was only significantly higher during fall, but no significant differences were found in spring and summer when compared with winter (Table 5.2).

\section{DISCUSSION}

This study shows significant seasonal variations in BC, assessed by bio-impedance spectroscopy. FM was highest during winter, while LTM was highest during summer. Indicators of fluid state, ECW and FO, were higher during spring and summer. Also, serum albumin levels were higher during spring.

To our knowledge, this is the first study investigating seasonal variations in $B C$ in dialysis patients. There is also a paucity of related research in healthy subjects while, in the animal world, studies in seasonal variations in BC are well explored ${ }^{9}$. Most of the studies were conducted in healthy subjects ${ }^{10-12}$. A recent study by Morinaka et al. ${ }^{12}$ showed that per cent body fat is lower during summer months, which is in agreement to the findings of the present study. To the best of our knowledge, no data on seasonal variations in LTM in human studies are available for comparison. The reasons for the increased FM and lower LTM during winter are not completely clear yet. The differences in BC may not be clinically negligible, as mean FM was estimated to be $1.17 \mathrm{~kg}$ higher and LTM was estimated to be $0.86 \mathrm{~kg}$ lower in the winter period in this latter group. The increase in FM could partly be explained by a higher nutritional intake during winter months. A study by Yanai et al. ${ }^{13}$ showed seasonal effects on food intake in general and protein intake in particular, based on blood urea nitrogen (BUN) and phosphate levels which are higher in winter when compared with summer. Our findings corroborate a study by Cheung et al. ${ }^{14}$ where BUN concentrations and nPCR rates were increased during winter in dialysis patients from the USA. However, in the present study, seasonal differences in nPCR were not as pronounced as those of BC and did not fully match the variations in FM. Serum albumin levels were significantly lower in fall and in summer when compared with winter, but highest in spring. Serum creatinine levels were lower in spring and fall when compared with winter, and thus corroborate findings of Yanai et al. ${ }^{13}$. Therefore, biochemical parameters match the variations in $\mathrm{BC}$ to some degree, but not in full. Notably, dilutional effects, due to differences in FO, may also affect the different laboratory parameters to some degree.

Next to nutritional intake, it is also possible that physical activity plays a role in seasonal variations in BC. Earlier studies in healthy subjects showed a decrease in physical activity during the winter months ${ }^{10}$. Unfortunately, no physical activity data are available in our study, so this hypothesis remains conjectural. Another potential mechanism related to higher LTM in summer is a lower level of inflammation, as evidenced by decreased CRP levels during this season.

A somewhat unexpected finding of the study is the larger ECW and FO during summer and spring, which are in line with decreased haemoglobin levels, with an increase between 0.2 and $0.3 \mathrm{~L}$, which may not be negligible clinically and in the interpretation of longitudinal 
studies focusing on seasonal- sensitive parameters such as BP and BC. While increased fluid intake as a consequence of increased thirst with rising and higher ambient temperatures may be put forward to explain the increased ECW and FO during summer months, this is at variance to the relatively lower IDWG in these seasons.

Another possible mechanism might be that the decrease in FM during the summer period leads to a concomitant reduction in dry weight, which may pass unnoticed in clinical practice. This is supported by the fact that the decrease in FM during summer was not completely balanced by an increase in LTM, as judged from the effect sizes of these parameters. In other words, more FM is lost during summer than compensated for by the increase in LTM. Intriguingly, increased ECW and FO levels are contrary to the lower SBP during summer period observed in the present, but also in previous studies ${ }^{3,4}$ in summer. Relevant in this context is the relation between FO and mortality ${ }^{15}$. An earlier study by Usvyat et al. ${ }^{4}$ showed that mortality risk is highest during the winter season, which is contradictory regarding the findings in our study where ECW and FO were higher during the summer and spring season. In addition, decreased levels of serum sodium, which is also a known risk factor for mortality in dialysis patients, were observed in the summer months, in line with earlier data from Cheung et al. ${ }^{14}$. Whether the decline in serum sodium during summer is related to the increase in ECW and FO during the summer period cannot be stated. Also, in chronic heart failure patients lower serum sodium levels were observed during summer, which was associated with an increased hospitalization risk during this period ${ }^{16}$. The divergent trends between risk factors for mortality and seasonal changes in these parameters necessitates further analysis, because the time pad between changes in risk factors and the time of mortality in dialysis patients is a relatively novel field of research ${ }^{17}$.

One remaining question is in which compartment the excess FO is located. The fact that changes in BP and FO are dyssynchronous would suggest that the excess volume is located outside the blood compartment. It might be hypothesized that, given the fact that LTM is higher in summer time, the additional interstitial compartment could locate some of the excess volume. Wherever the location, the higher ECW and FO in summer suggest that lower SBP in summer is partly volume independent and caused by other factors such as reduced peripheral vasoconstriction during this season ${ }^{18}$.

In the only previous study which assessed this subject, no relation between seasonal variations in BP and extracellular volume was observed in 122 Chinese peritoneal dialysis patients ${ }^{19}$. Moreover, this study showed no seasonal variations in ECW, but differed from our study in terms of the size of the study population and in the climate zone.

Possible clinical implications of the present study are that additional attention for dry weight adjustment may be warranted during changes in seasons. Also the interpretation of longitudinal interventional studies will give more insight into pathophysiology. In addition, longitudinal studies assessing BC should take seasonal variations in BC into account. Whether nutritional- or physical activity-based interventions controlled for season could improve health status in dialysis patients might be a topic for future studies and possibly 
target interventions to prevent the loss of lean body mass in winter, the season associated with the highest complication rate.

While our study was performed in a large international cohort of dialysis patients, it has some limitations. BC was measured exclusively by the BCM and no reference methods were used. However, the BCM has been validated with Dual energy X-ray absorptiometry in previous studies ${ }^{20,21}$. ECW, which changed during the seasons, is distributed in fat and lean tissue. Changes in FM were inverse to changes in ECW. The BCM model assumes a constant hydration ratio of adipose and lean tissue, and calculates FO as the difference between total ECW, and the ECW assumed to be present in healthy LTM and $\mathrm{FM}^{8}$. Thus, this assumption would lead to incorrect estimation of FO if the hydration ratio of these tissues would vary by seasons, but there is no research suggesting this possibility. Previous research indicates that $\mathrm{BC}$ determined by the $\mathrm{BCM}$ may be influenced by $\mathrm{BMI}^{8}$. For this reason, we performed additional analysis in patients stratified in BMI tertiles; however, this sub-group analysis did not materially changes our results. Of note, LTM is derived from measured parameters, while FM is calculated as the difference between gravimetric body weight and LTM. An increase in clothing, as might occur during winter time theoretically, could affect body weight and thus the estimation of FM. In contrast, the measurements of LTM and extracellular volume are not affected by clothing. We cannot address this possibility in the context of our study, because we have no documentation of patient clothing. Our study population was predominantly Caucasian and limited to Europe, which may limit generalizability to other regions of the world. Nevertheless, additional analyses were done for eastern Europe, north/west Europe, southern Europe and western Asia. Results showed similar findings when compared with the analyses for whole Europe. Lastly, patients were included if they had at least a single $\mathrm{BCM}$ measurement, so measurements for all seasons were not available for every patient. However, this aspect was corrected for by including patient as random factor in the mixed linear model.

In conclusion, this study in a large cohort of European dialysis patients showed significant seasonal variations in BC, with higher FM during winter and higher LTM during the summer period, assessed by bio-impedance spectroscopy. ECW and FO were actually highest during summer, in contrast to lower IDWG and SBP during this season. The clinical relevance of the present biological findings, as well as the need for interventions should be addressed in future studies.

\section{FUNDING}

J.P.K., F.M.v.d.S. and N.J.H.B. are supported by an unrestricted grant from Fresenius Medical Care Europe. L.A.U., D.M., I.B., L.S., B.C. and U.M. are employees of Fresenius Medical Care.

\section{CONFLICT OF INTEREST STATEMENT}

None declared. The results presented in this paper have not been published previously in whole or part. 


\section{REFERENCES}

1. Kooman JP, Usvyat L, van der Sande FM, Thijssen S, Levin N, Leunissen KM, et al.: 'Time and time again': oscillatory and longitudinal time patterns in dialysis patients. Kidney Blood Press Res 2012;35:534-548.

2. Usvyat LA, Kotanko P, van der Sande FM, Kooman JP, Carter M, Leunissen KM, et al.: Circadian variations in body temperature during dialysis. Nephrol Dial Transplant 2012;27:1139-1144.

3. Argiles A, Lorho R, Servel MF, Chong G, Kerr PG,Mourad G: Seasonal modifications in blood pressure are mainly related to interdialytic body weight gain in dialysis patients. Kidney Int 2004;65:1795-1801.

4. Usvyat LA, Carter M, Thijssen S, Kooman JP, van der Sande FM, Zabetakis P, et al.: Seasonal variations in mortality, clinical, and laboratory parameters in hemodialysis patients: a 5-year cohort study. Clin J Am Soc Nephrol 2012;7:108-115.

5. Shinaberger CS, Kilpatrick RD, Regidor DL, McAllister CJ, Greenland S, Kopple JD, et al.: Longitudinal associations between dietary protein intake and survival in hemodialysis patients. Am J Kidney Dis 2006;48:37-49.

6. Cold exposure and winter mortality from ischaemic heart disease, cerebrovascular disease, respiratory disease, and all causes in warm and cold regions of Europe. The Eurowinter Group. Lancet 1997;349:1341-1346.

7. Shephard RJ,Aoyagi Y: Seasonal variations in physical activity and implications for human health. Eur J Appl Physiol 2009;107:251-271.

8. Chamney PW, Wabel P, MoissI UM, Muller MJ, Bosy-Westphal A, Korth O, et al.: A wholebody model to distinguish excess fluid from the hydration of major body tissues. Am J Clin Nutr 2007;85:80-89.

9. McGuire LP, Fenton MB,Guglielmo CG: Phenotypic flexibility in migrating bats: seasonal variation in body composition, organ sizes and fatty acid profiles. J Exp Biol 2013;216:800-808.

10. Plasqui $G$, Westerterp KR: Seasonal variation in total energy expenditure and physical activity in Dutch young adults. Obes Res 2004;12:688-694.

11. Westerterp KR, Plasqui G, Goris AH: Water loss as a function of energy intake, physical activity and season. Br J Nutr 2005;93:199-203.

12. Morinaka T, Wozniewicz M, Jeszka J, Bajerska J, Limtrakul PN, Makonkawkeyoon L, et al.: Comparison of seasonal variation in the fasting respiratory quotient of young Japanese, Polish and Thai women in relation to seasonal change in their percent body fat. J Physiol Anthropol 2012;31:10.

13. Yanai M, Satomura A, Uehara Y, Murakawa M, Takeuchi M,Kumasaka K: Circannual rhythm of laboratory test parameters among chronic haemodialysis patients. Blood Purif 2008;26:196-203.

14. Cheung AK, Yan G, Greene T, Daugirdas JT, Dwyer JT, Levin NW, et al.: Seasonal variations in clinical and laboratory variables among chronic hemodialysis patients. J Am Soc Nephrol 2002;13:2345-2352. 
15. Wizemann V, Wabel P, Chamney P, Zaluska W, Moissl U, Rode C, et al.: The mortality risk of overhydration in haemodialysis patients. Nephrol Dial Transplant 2009;24:1574-1579.

16. Zhao Q, Yu S, Huang H, Cui H, Qin M, Kong B, et al.: The seasonal variation in hospitalizations due to chronic systolic heart failure correlates with blood sodium levels and cardiac function. Exp Clin Cardiol 2013;18:77-80.

17. Usvyat LA, Barth C, Bayh I, Etter M, von Gersdorff GD, Grassmann A, et al.: Interdialytic weight gain, systolic blood pressure, serum albumin, and $\mathrm{C}$-reactive protein levels change in chronic dialysis patients prior to death. Kidney Int 2013;84:149-157.

18. Mercer JB: Cold--an underrated risk factor for health. Environ Res 2003;92:8-13.

19. MoissI $\cup \mathrm{BI}$, Lemmey $\mathrm{A}$ et al.: Validation of a $3 \mathrm{C}$ model for determination of body fat mass. J Am Soc Nephrol 2007;18 A: 257:

20. MoissI U WP, Chamney PW et al.: Validation of a bioimpedance spectroscopy; method for the assessment of fat free mass. NDT Plus;2008; 1(Suppl 2): ii215 



\section{CHAPTER 6}

CHANGES IN HEALTH-RELATED QUALITY OF LIFE FROM IN THE TRANSITIONAL PHASE OF STAGE 5 CHRONIC KIDNEY DISEASE PATIENTS AND ASSOCIATIONS WITH PHYSICAL ACTIVITY: A CROSS-SECTIONAL AND LONGITUDINAL ANALYSIS

Natascha J.H. Broers, Remy J.H. Martens, Tom Cornelis, Nanda M.P. Diederen, Frank M. van der Sande, Marc M.H. Hermans, Joris J.J.M Wirtz, F. Stifft, Constantijn J.A.M. Konings, Tom Dejagere, Bernard Canaud, Karel M.L. Leunissen and Jeroen P. Kooman

Manuscript in preparation 


\section{ABSTRACT}

\section{Background}

Dialysis patients have low scores of Health-related quality of life (HRQOL) which are associated with an increased risk of hospitalization and mortality. Also in stage 5 chronic kidney disease (CKD-5) non-dialysis patients HRQOL scores seem to be lower as compared with the general population. Few data exist on possible modifiable factors of low HRQOL in patients with advanced CKD. This study firstly aimed to compare HRQOL between CKD-5 non-dialysis and dialysis patients and to assess longitudinal changes from the CKD-5 nondialysis phase until six months after the start of dialysis. Secondly, the association between HRQOL and physical activity (PA) was studied.

\section{Methods}

For the cross-sectional analyses 67 patients ( 38 CKD-5 non-dialysis patients and 29 dialysis patients (dialysis vintage $3.60 \pm 3.21$ years)), and 20 healthy controls were included. HRQOL was measured by Short Form-36 (SF-36) questionnaires to measure physical and mental domains of health expressed by the physical component summary (PCS) and mental component summary (MCS) scores. PA (number of steps) was measured by a SenseWearTM pro3 armband. In the longitudinal part, these parameters were assessed in 30 CKD-5 nondialysis patients (who were also part of the cross-sectional analysis), before the start of dialysis and five to six months after starting dialysis.

\section{Results}

PCS scores were significantly lower both in CKD-5 non-dialysis patients (median [interquartile range] 35.60 [30.28-45.13]) and dialysis patients (40.4 [31.8-45.2]) as compared with healthy controls (56.9 [53.75-59.95]) $(p<0.001)$. MCS scores were significantly lower in CKD-5 non-dialysis patients (median [interquartile range]47.85 [41.7-54.85]) $(p<0.001)$, but not in dialysis patients (53.5 [42.8-59.85]) ( $p=0.099)$ as compared with healthy controls 56.9 [53.75-59.95]. Differences between CKD-5 non-dialysis and dialysis patients were not significantly different for both PCS scores $(p=0.544)$ and MCS scores $(p=0.149)$. PCS and MCS scores did not change significantly from the CKD-5 non-dialysis phase until 6 months after the start of dialysis. PA was significantly correlated with PCS in both CKD-5 non-dialysis patients $(r=0.571 ; p<0.001)$, and dialysis patients $(r=0.467 ; p=0.012)$, but not to MCS scores.

\section{Conclusions}

PCS and MCS scores are already low in the CKD-5 non-dialysis phase. In the first six months after the start of dialysis treatment HRQOL scores did not change significantly. Given the association between PCS score and PA, the importance of physical activity programs should be underscored in both CKD-5 non-dialysis patients and dialysis patients to improve HRQOL already in earlier stages of CKD. 


\section{INTRODUCTION}

Numerous studies already showed lower health-related quality of life (HRQOL) scores in dialysis patients as compared with the general population ${ }^{1-3}$. Low HRQOL scores were shown to be predictive of hospitalization and mortality in this patient group ${ }^{4-6}$. Nevertheless, in most studies, general trends at different time periods with a varying patient cohort were compared $^{1,7}$, and only a limited amount of studies followed HRQOL in dialysis patients over time in the same patients ${ }^{8,9}$. A previous study of our group showed the prognostic values of changes in HRQOL over time in maintenance hemodialysis (HD) patients, but did not include the stage 5 chronic kidney disease (CKD-5) non-dialysis phase ${ }^{4}$. Few prospective studies have focused on the effects of starting dialysis treatment on $\mathrm{HRQOL}^{9,10}$, despite the fact that in patients with end-stage renal disease (ESRD) the transition from the CKD-5 non-dialysis phase to the start of dialysis is a major life event ${ }^{11-13}$. Theoretically, HRQOL may decrease following the start of dialysis due to the invasiveness of the therapy, or might be improved due to the partial resolution of uremic symptoms. Previous studies showed a reduction in HRQOL in patients with CKD-5 in the non-dialysis phase as compared with the general population ${ }^{10,14,15}$, but a comparative study between CKD-5 non-dialysis and prevalent dialysis patients, or a longitudinal study following the start of dialysis before dialysis initiation have not yet been performed.

In interpreting alterations in $\mathrm{HRQOL}$, it is important to identify potentially modifiable factors. Previously, we observed a relation between nutritional parameters and changes in $\mathrm{HRQOL}^{4}$. Recently, a larger international cohort study observed a significant relation between physical activity (PA) and HRQOL in maintenance dialysis patients ${ }^{16}$. However, in this study, PA was assessed by self-reported scales and not by objective measurements. In a previous study of our group, we observed a significant increase in walking speed six months after the start of dialysis as compared with the CKD-5 non-dialysis phase. Associations between changes in HRQOL and changes in PA following the start of dialysis have not been studied yet.

Aims of the present study were firstly to compare HRQOL between healthy controls, CKD- 5 non-dialysis and prevalent dialysis patients. Secondly, to assess changes from the CKD-5 nondialysis phase until six months after the start of dialysis, and thirdly, to asses associations between HRQOL and PA parameters, both in a cross-sectional and longitudinal design.

\section{PATIENTS AND METHODS}

This study consisted of a cross-sectional part and a longitudinal part. The cross-sectional analyses included 67 patients, 38 CKD-5 non-dialysis and 29 dialysis patients (dialysis vintage $3.60 \pm 3.21$ years) and 20 healthy controls. Patients were recruited from the following dialysis centers in the South East of the Netherlands and North East of Belgium: University Hospital Maastricht, Catharina Hospital Eindhoven, Viecuri Hospital Venlo, Zuyderland Medical Centre Sittard, St Laurentius Hospital Roermond and Virga Jesse Hospital Hasselt. CKD-5 non-dialysis patients were ESRD patients starting with dialysis within one month (measurements were performed maximum four weeks prior to the first dialysis session). 
Prevalent dialysis patients had been treated with hemodialysis (HD) or pertinoneal dialysis (PD) treatment for at least twelve months.

The longitudinal analysis is part of an ongoing prospective study and included 30 CKD-5 nondialysis patients (who were also part of the cross-sectional analysis) in the transition phase for whom six-months follow up data were available. Measurements were performed before the start of dialysis treatment (within one month before the first dialysis session) and five to six months after starting dialysis by the same methods as used for the cross-sectional part.

Exclusion criteria for patients were: an acute start of dialysis treatment, active symptomatic coronary artery disease or cardiac failure New York Heart Association (NYHA) class III or IV, active malignancies, active infections, and inability to provide informed consent. For bioimpedance measurements: no implantable cardioverter defibrillator (ICD) or pacemaker (interference with body composition monitor (BCM)). For walking test measurements: physical disability (patients had to be able to walk without help), There were no restrictions for other measurements in patients with an ICD or pacemaker or physical disability.

Healthy controls were non-diabetic, non-smokers, and not hypertensive, and were recruited via advertisements.

Exclusion criteria for healthy controls were: hypertension during the screening; systolic blood pressure higher than $170 \mathrm{mmHg}$ and/or diastolic blood pressure larger than 100 $\mathrm{mmHg}$, diabetes mellitus, and inability to provide informed consent.

Patients as well as healthy controls were in a fasting state during the measurements, except for the PA measurements.

Written informed consent was obtained from each patient prior to participation. The study was approved by the Ethical Committee (NL33129.068.10, NL35039.068.10) and the Hospital Board of the Maastricht University Medical Center+.

\section{Quality of Life measurements}

Short Form-36 (SF-36) questionnaires were filled out to measure physical component summary (PCS) scores for the physical domains of health, and mental component summary (MCS) for the mental domains of health. The SF-36 questionnaire is the most used tool to measure HRQOL in the field of nephrology worldwide ${ }^{17}$. The SF-36 is a multi-purpose, short-form health survey which includes 36 items. These 36 items provide a measure of physical and mental health items ranging from 0 ("worst possible health") to 100 ("best possible health"). The 36 items can be subdivided in 8 subscales known as: physical functioning (PF), role-physical (RP), bodily pain (BP), general health (GH), vitality (VT), social functioning (SF), role-emotional (RE) and mental health (MH). These 8 subscales were summarized in 2 summary scores known as: PCS score and a MCS score. For scoring of the questionnaires RAND-recommended scoring was used. In addition, all scales were normalized to make it comparable to the general population and other patient groups with specific disease states ${ }^{18,19}$. 


\section{Physical Activity measurements}

Participants were requested to wear a SenseWear ${ }^{\mathrm{TM}}$ pro 3 armband (Bodymedia ${ }^{\circledR}$, Pittsburg, PA) to measure PA parameter number of steps for 2 days (CKD-5 non-dialysis patients: $1.99 \pm 0.44$ days, mean on-body time: $93.6 \%$; dialysis patients: $2.30 \pm 0.73$ days, mean onbody time: $96.7 \%$; controls: $2.07 \pm 0.54$ days, mean on-body time: $96.1 \%)$. For the analyses, the mean of the total on-body time was calculated (expressed as number of steps per 24 hours) to include both the dialysis and non-dialysis day in the dialysis population. Data collected on both week days as well as weekend days were included in the analysis.

\section{Four meter walking test}

A four meter walking test was conducted to determine walking speed $(\mathrm{m} / \mathrm{sec})$ by covering a distance of four meter. Several studies confirmed the validity and sensitivity of this widely used test for determining walking speed ${ }^{20-23}$ and physical performance in ESRD patients ${ }^{24}$.

\section{Nutritional and Biochemical parameters}

Biomarkers such as albumin, hemoglobin (HB), dialysis adequacy (Kt/V), and the estimated glomerular filtration rate (eGFR) were measured or determined during routine patient laboratory measurements. GFR was estimated with the four-variable modification of diet in renal disease (MDRD) equation ${ }^{25}$.

\section{Comorbidity Score}

Comorbidity index was determined for each patient based on the comorbidity checklist by the Davies comorbidity index scoring system ${ }^{26}$. Patients were divided into three risk groups; low, medium and high risk of mortality. The Davies comorbidity index is commonly used in ESRD patients ${ }^{26-28}$.

\section{Longitudinal Analysis}

Changes in PA and BC parameters, HGS, walking speed and PCS scores were measured in 30 CKD-5 non-dialysis patients before the start of dialysis (within one month before start) and five to six months after starting dialysis by the same methods as for the cross-sectional part as described previously.

\section{Statistical Analysis}

Data are expressed as mean \pm SD or median [interquartile range], unless indicated otherwise. Differences in PCS scores and MCS scores between groups were assessed with the MannWhitney U test.

For the longitudinal analysis, changes over time within the CKD-5 non-dialysis patient group were evaluated with the Wilcoxon matched pairs signed rank sum test.

Differences in change between dialysis modalities were evaluated with the Wilcoxon matched pairs signed rank sum test. In addition, for the PA parameters, multivariable linear 
regression analyses were conducted to adjust for age and sex differences between groups and for diabetes.

Associations were assessed with Spearman's rank correlation coefficients.

Statistical analyses were performed by IBM SPSS Statistics for Windows, version 23 (IBM Corp. Armonk, NY, USA). P-values $<0.05$ were considered to be statistically significant.

\section{RESULTS}

\section{Patient characteristics}

Patient characteristics for the cross-sectional are summarized in table 6.1a. Patient characteristics for the patients participating in the longitudinal part are summarized in table 6.1b.

Table 6.1a Patient Demographics.

\begin{tabular}{|c|c|c|c|}
\hline & $\begin{array}{c}\text { CKD-5 non-dialysis } \\
\text { patients }\end{array}$ & Dialysis patients & $\begin{array}{l}\text { Healthy } \\
\text { controls }\end{array}$ \\
\hline Number of Patients & 38 & 29 & 20 \\
\hline Male (\%) & 73.7 & 69.0 & 65.0 \\
\hline HD/PD & - & $21 * / 8$ & - \\
\hline Age (years) & $61.11 \pm 12.25$ & $58.17 \pm 14.65$ & $59.65 \pm 14.10$ \\
\hline Height $(\mathrm{cm})$ & $173.68 \pm 9.67$ & $171.59 \pm 9.57$ & $174.75 \pm 11.36$ \\
\hline Weight (kg) & $77.67 \pm 16.76$ & $82.75 \pm 15.31$ & $76.68 \pm 15.80$ \\
\hline BMI $\left(\mathrm{kg} / \mathrm{m}^{2}\right)$ & $25.48 \pm 3.76$ & $28.06 \pm 4.45$ & $24.86 \pm 3.41$ \\
\hline Albumin $(\mathrm{g} / \mathrm{L})$ & $35.34 \pm 5.18$ & $40.24 \pm 3.55$ & $40.24 \pm 2.30$ \\
\hline Hemoglobin (mmol/L / g/dL) & $6.69 \pm 0.90 / 10.78 \pm 1.45$ & $6.93 \pm 0.71 / 11.17 \pm 1.15$ & - \\
\hline $\mathrm{Kt} / \mathrm{V}$ (HD/PD) & - & $1.54 \pm 0.39 / 2.17 \pm 0.74$ & - \\
\hline eGFR $\left(\mathrm{ml} / \mathrm{min} / 1.73 \mathrm{~m}^{2}\right)$ & $8.40 \pm 2.79$ & - & $72.59 \pm 11.07$ \\
\hline \multicolumn{4}{|l|}{ Origin of end-stage renal disease } \\
\hline Diabetic nephropathy (\%) & 5.3 & 20.7 & - \\
\hline Polycystic kidney disease (\%) & 26.3 & 17.2 & \\
\hline Nephrosclerosis(\%) & 15.8 & 6.9 & \\
\hline Hypertensive nephropathy (\%) & 5.3 & 10.3 & \\
\hline Nephrotic syndrome (\%) & 13.2 & 3.4 & \\
\hline E.c.i. (\%) & 13.2 & 13.8 & \\
\hline Other (\%) & 21.1 & 27.6 & \\
\hline Diabetes Mellitus (\%) & 13.2 & 41.4 & - \\
\hline Cardiovascular Disease (\%) & 36.8 & 37.9 & - \\
\hline \multicolumn{4}{|l|}{ Risk of mortality by Davies index } \\
\hline Low risk (\%) & 47.4 & 41.4 & - \\
\hline Medium risk (\%) & 39.5 & 37.9 & \\
\hline High risk (\%) & 13.2 & 20.7 & \\
\hline History of prior KTx (\%) & 23.7 & 31.0 & 0.0 \\
\hline SBP (mm Hg) & $146.29 \pm 22.14$ & $152.43 \pm 26.47$ & $137.98 \pm 13.39$ \\
\hline $\mathrm{DBP}(\mathrm{mmHg})$ & $81.95 \pm 13.05$ & $80.84 \pm 12.44$ & $82.30 \pm 6.90$ \\
\hline
\end{tabular}

Data are given in mean $\pm \mathrm{SD}$. $\mathrm{HD}=$ hemodialysis, $\mathrm{PD}=$ peritoneal dialysis, $\mathrm{BMI}=$ body mass index, eGFR = estimated glomerular filtration rate, E.c.i. = e causa ignota, $\mathrm{KTx}=$ kidney transplantation, $\mathrm{SBP}=$ systolic blood pressure, $\mathrm{DBP}=$ diastolic blood pressure ${ }^{*}$ All HD patients have arteriovenous (AV) fistulas, Laboratory parameters were available in: $n=37$ in the CKD-5 non-dialysis group, $n=28$ for hemoglobin and $n=25$ for albumin in the dialysis group, $\mathrm{n}=20$ in the healthy control group. 
Table 6.1b Patient demographics longitudinal analyses.

\begin{tabular}{|c|c|}
\hline Patient Demographics & Before start of dialysis \\
\hline Number of Patients & 30 \\
\hline Male (\%) & 66.7 \\
\hline $\mathrm{HD}^{*} / \mathrm{PD}^{\#}$ & $15 / 15$ \\
\hline Age (years) & $60.67 \pm 13.03$ \\
\hline Height (cm) & $172.27 \pm 9.85$ \\
\hline Weight (kg) & $76.35 \pm 16.82$ \\
\hline BMI $\left(\mathrm{kg} / \mathrm{m}^{2}\right)$ & $25.44 \pm 3.78$ \\
\hline Albumin $(g / L)$ & $36.12 \pm 3.65$ \\
\hline Hemoglobin (mmol/L / g/dL) & $6.66 \pm 0.84 / 10.73 \pm 1.36$ \\
\hline eGFR $\left(\mathrm{ml} / \mathrm{min} / 1.73 \mathrm{~m}^{2}\right)$ & $8.66 \pm 2.94$ \\
\hline \multicolumn{2}{|l|}{ Origin of end-stage renal disease } \\
\hline Diabetic nephropathy (\%) & 6.7 \\
\hline Polycystic kidney disease (\%) & 30.0 \\
\hline Nephrosclerosis(\%) & 16.7 \\
\hline Hypertensive nephropathy (\%) & 3.3 \\
\hline Nephrotic syndrome (\%) & 13.3 \\
\hline E.c.i. (\%) & 13.3 \\
\hline Other (\%) & 16.7 \\
\hline Diabetes Mellitus (\%) & 10.0 \\
\hline Cardiovascular Disease (\%) & 33.3 \\
\hline \multicolumn{2}{|l|}{ Risk of mortality by Davies index } \\
\hline Low risk (\%) & 46.7 \\
\hline Medium risk (\%) & 43.3 \\
\hline High risk (\%) & 10.0 \\
\hline History of prior KTx (\%) & 23.3 \\
\hline SBP $(\mathrm{mmHg})$ & $144.83 \pm 22.55$ \\
\hline \multirow[t]{2}{*}{ DBP (mmHg) } & $81.93 \pm 13.37$ \\
\hline & Six months after the start of dialysis \\
\hline Albumin (g/L) & $34.25 \pm 2.88$ \\
\hline Hemoglobin (mmol/L / g/dL) & $7.21 \pm 0.79 / 11.62 \pm 1.27$ \\
\hline $\mathrm{Kt} / \mathrm{V}$ (HD/PD) & $1.28 \pm 0.16 / 2.59 \pm 1.03$ \\
\hline
\end{tabular}

Data are given in mean $\pm \mathrm{SD}$. $\mathrm{HD}=$ hemodialysis, $\mathrm{PD}=$ peritoneal dialysis, $\mathrm{BMI}=$ body mass index, eGFR = estimated glomerular filtration rate, E.c.i. = e causa ignota, $\mathrm{KTx}=$ kidney transplantation, $\mathrm{SBP}=$ systolic blood pressure, $\mathrm{DBP}$ = diastolic blood pressure * 1 HD patient had a central venous catheter (CVC) \# 1 PD patient switched from PD to HD via CVC 3 months after the start of dialysis, Laboratory parameters were available in $n=29$.

\section{Quality of Life outcomes}

PCS scores were significantly lower in both CKD-5 non-dialysis patients (35.60 [30.2845.13]) and dialysis patients (40.4 [31.8-45.2]) as compared with healthy controls (56.9 [53.75-59.95]) $(p<0.001)$. For CKD-5 non-dialysis and dialysis patients PCS scores did not significantly differ ( $p=0.544$ ) (figure 6.1).

The same held true for the subscales, which correlate with PCS scores; PF, RP, BP, GH and VT, except for BP differences in dialysis patients as compared with healthy controls, which were not significantly different (figure 6.2).

MCS scores were significantly lower in CKD-5 non-dialysis patients (47.85 [41.7-54.85]) $(p<0.001)$, but not in dialysis patients $53.5[42.8-59.85](p=0.099)$ as compared with healthy 
controls (56.9 [53.75-59.95]). Here also, no significant differences were found for MCS scores between CKD-5 non-dialysis and dialysis patients ( $p=0.149$ ) (figure 6.3).

The same held true for the subscales which correlate with MCS scores; MH, RE, SF, VT and $\mathrm{GH}$, except for $\mathrm{MH}$ differences between dialysis patients and healthy controls, which were not significant (figure 6.2).

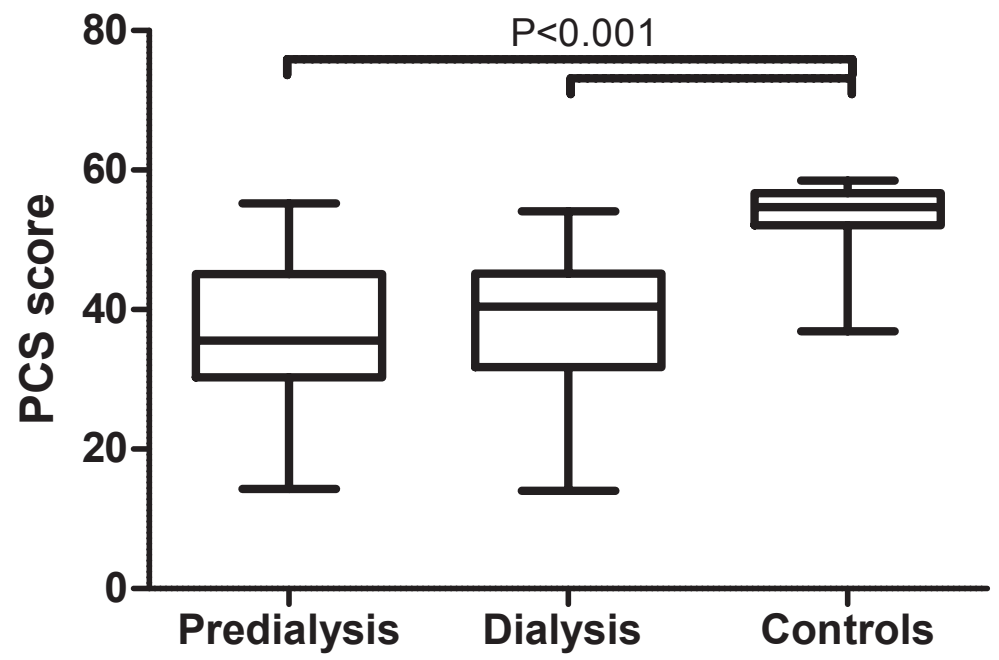

Figure 6.1 Physical component summary (PCS) scores.

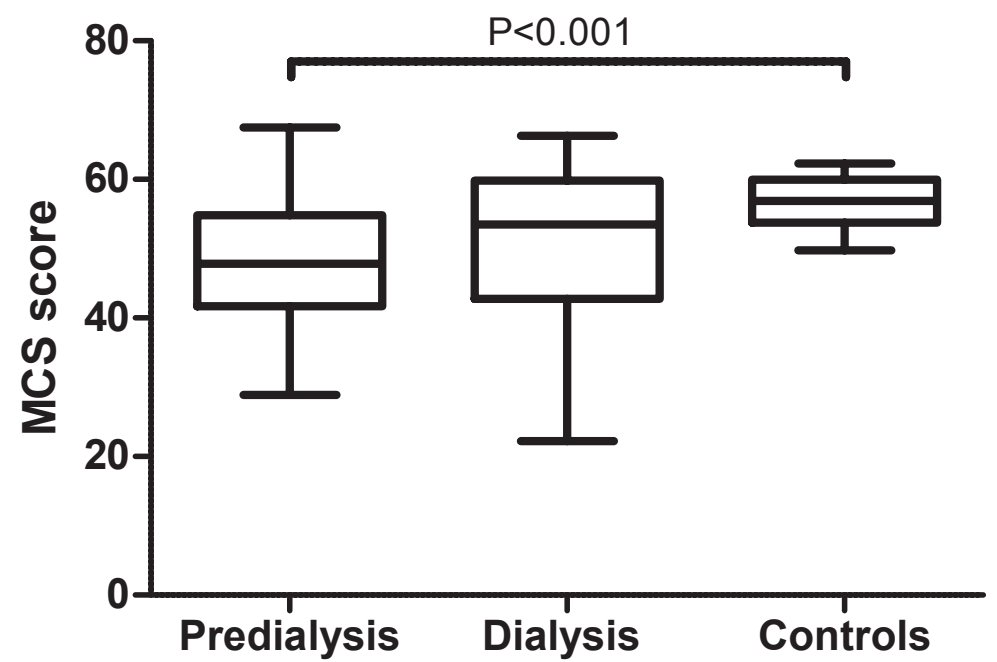

Figure 6.3 Mental component summary (MCS) scores. 

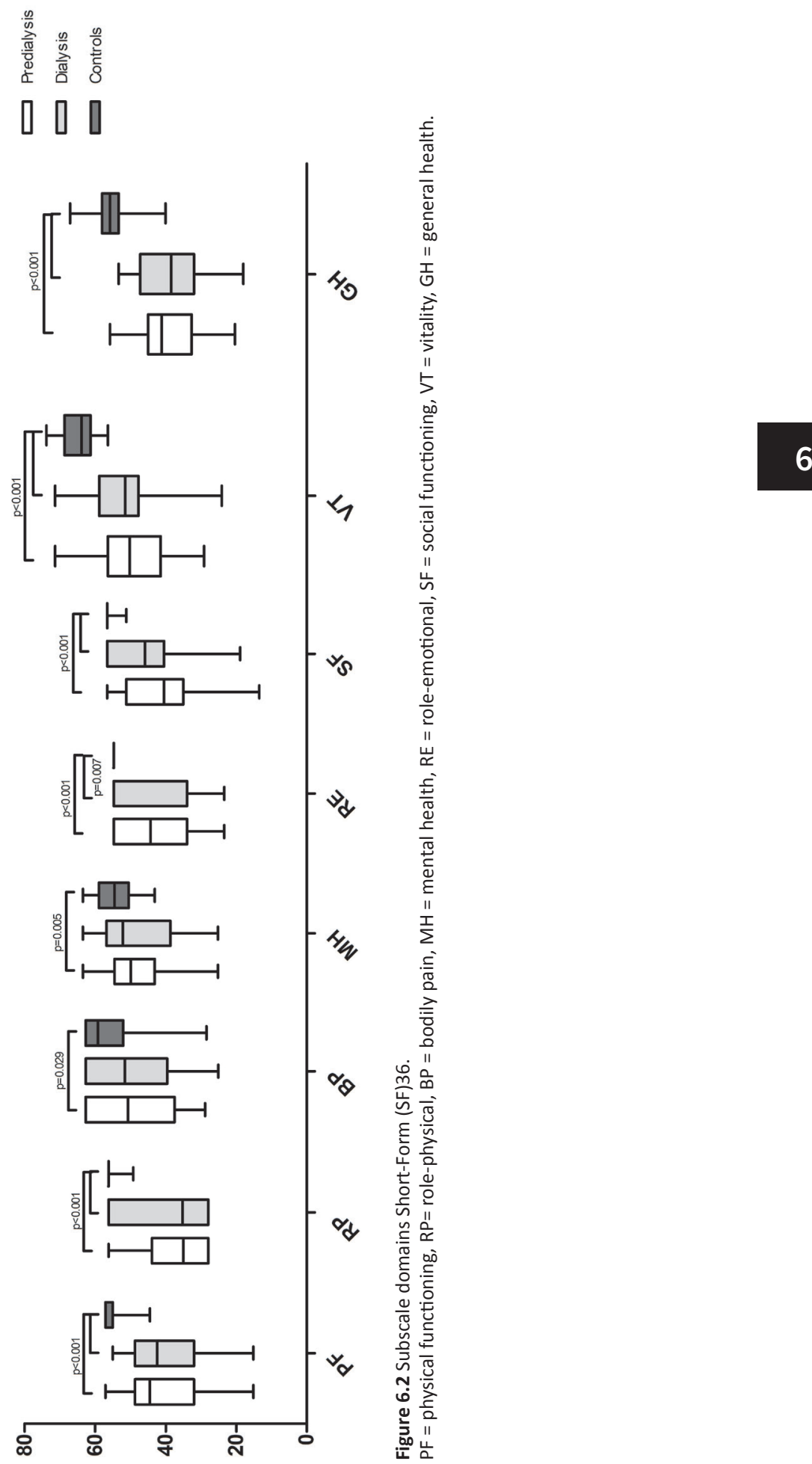


\section{Physical activity outcomes}

As described in our previous study (chapter 4), number of steps was significantly lower in both CKD-5 non-dialysis patients (5009.0 [3187.5-7031.5]) $(p<0.001)$ and dialysis patients (3994.5 [1993.5-6712.75]) $(p<0.001)$ as compared with healthy controls (11062.0 [768713839.0]).

Walking speed was significantly lower in CKD-5 non-dialysis patients $(1.49 \pm 0.45 \mathrm{~m} / \mathrm{s})$ as compared with healthy controls $(1.78 \pm 0.28 \mathrm{~m} / \mathrm{s})(\mathrm{p}=0.013)$, but not as compared with dialysis patients $(1.57 \pm 0.53)(p=0.567)$. After adjustment for differences in age, sex and diabetes between groups, results were not materially changed.

\section{Longitudinal outcomes HRQOL}

Over a six month period of time PCS scores did not significantly change after the start of dialysis (35.6 [30.83-44.35] to 38.8 [32.6-50.0]; $p=0.233$ ). Also, additional analyses of the subscales for PCS score; PF, RP, BP, GH and VT did not show significant changes over time. Also, MCS scores did not significantly change over a six month time period after the start of dialysis (50.15 [42.5-55.23] to 51.05 [39.7-57.63] $p=0.975)$. The same held true for the additional analyses of the subscales for MCS score; MH, RE, SF and again VT and GH did not significantly change over a six month time period after the start of dialysis.

When separated by dialysis modality, no significant changes over time were found for different dialysis modalities. For patients who started with HD, PCS scores remained similar (37.9 [30.2-48.5] to 37.9 [32.3-51.5]) ( $p=0.776)$ and MCS scores changed from (51.0 [45.554.7] to 54.6 [39.9-57.7]) ( $p=0.955$ ) over time. For patients who started with PD similar findings were observed were PCS scores changed from (35.2 [31.0-40.8] to 40.0 [33.2-45.7]) $(p=0.256)$ and MCS scores changed from (47.1 [42.2-58.0] to $46.7[37.5-55.6])(p=0.865)$ over time.

\section{Longitudinal outcomes of Physical Activity}

As also described in our previous study (chapter 4), significant changes over time in the first six months after starting dialysis were found for number of steps from 5378.0 [2998.07092.25] to 5576.0 [3978-9357.25] ( $p=0.003)$. Walking speed significantly increased over time from $1.50 \pm 0.45 \mathrm{~m} / \mathrm{s}$ to $1.73 \pm 0.38(\mathrm{p}=0.010)$.

\section{Associations between PA and HR-QOL scores}

Associations were found between number of steps and PCS scores in both CKD-5 non-dialysis $\left(r_{s}=0.571 ; p<0.001\right)$ and dialysis patients $\left(r_{s}=0.467 ; p=0.012\right)$ (figure 6.4). No associations were found between PA and MCS scores (CKD-5 non-dialysis patients $\left(r_{s}=-0.090 ; p=0.596\right)$, dialysis patients $\left.\left(r_{s}=-0.031 ; p=0.875\right)\right)$. The subscales PF, RP and VT, which correlate with the PCS score, were associated with number of steps in CKD-5 non-dialysis patients (PF $\left(r_{s}=0.550 ; p<0.001\right), R P\left(r_{s}=0.379 ; p=0.021\right)$ and $\left.V T\left(r_{s}=0.386 ; p=0.018\right)\right)$. In dialysis patients only an association between number of steps and subscale PF was found $\left(r_{s}=0.548 ; p=0.003\right)$. 


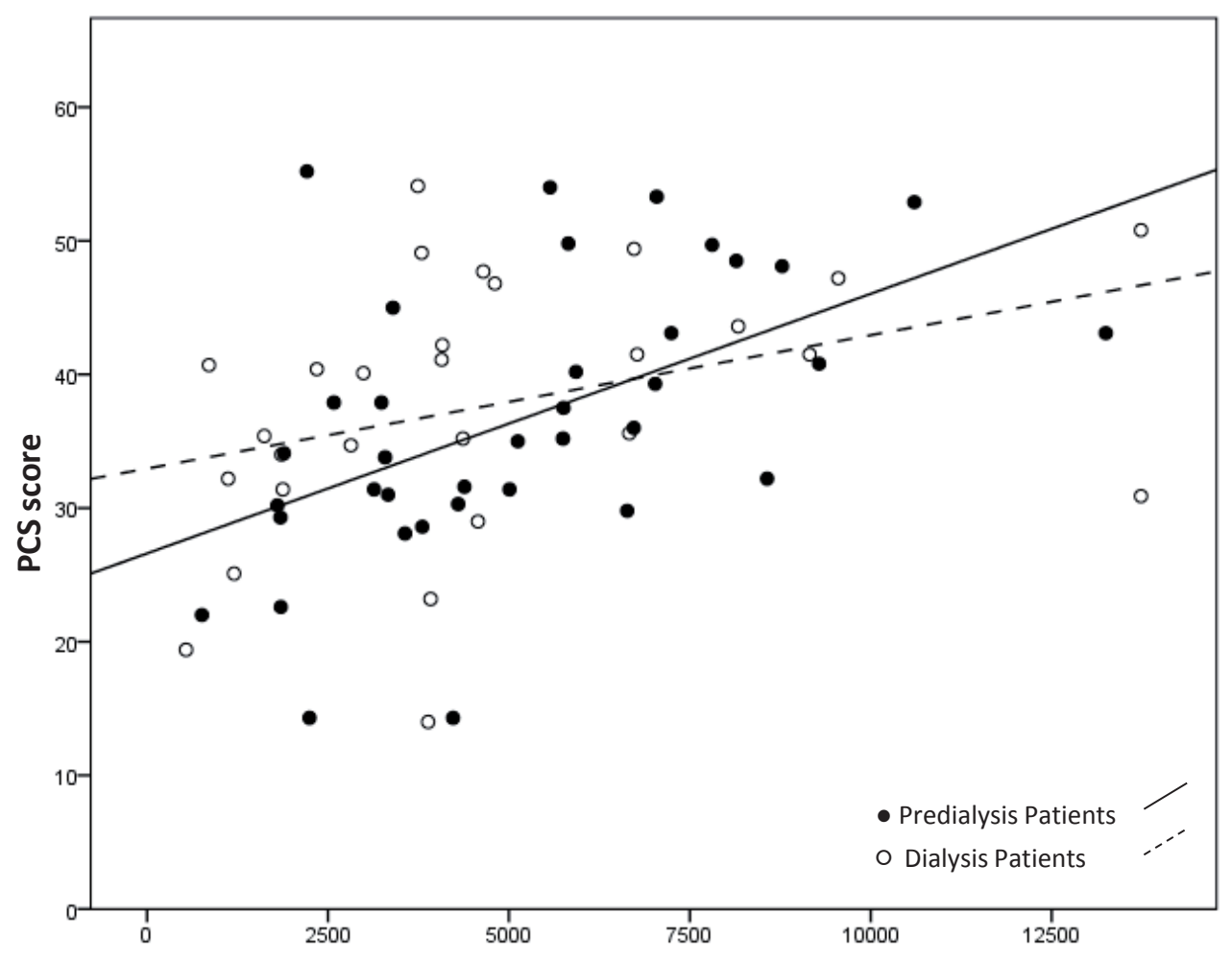

\section{Number of Steps}

Figure 6.4 Association between physical component summary (PCS) score and number of steps in both CKD-5 non-dialysis and dialysis patients.

Also, associations were found between walking speed and PCS scores in CKD-5 non-dialysis patients $\left(r_{s}=0.530 ; p=0.002\right)$, but not in dialysis patients $\left(r_{s}=0.103 ; p=0.608\right)$ (figure 6.5). No associations were found between walking speed and MCS scores (CKD-5 non-dialysis patients $\left(r_{s}=-0.124 ; p=0.500\right)$, dialysis patients $\left.\left(r_{s}=0.054 ; p=0.788\right)\right)$. The subscales PF, VT and SF, which correlate with the PCS score, were associated with walking speed in CKD-5 nondialysis patients (PF $\left(r_{s}=0.646 ; p<0.001\right), V T\left(r_{s}=0.428 ; p=0.015\right)$ and $S F\left(r_{s}=0.384 ; p=0.030\right)$ ). In dialysis patients no associations between walking speed and any of the subscales were found.

Furthermore, no associations were found between the change in the number of steps from the CKD-5 non-dialysis phase to the dialysis phase and both the change in PCS scores and the change in MCS scores. Similarly, no associations were found between the change in walking speed and both the change in PCS scores and the change in MCS scores. 


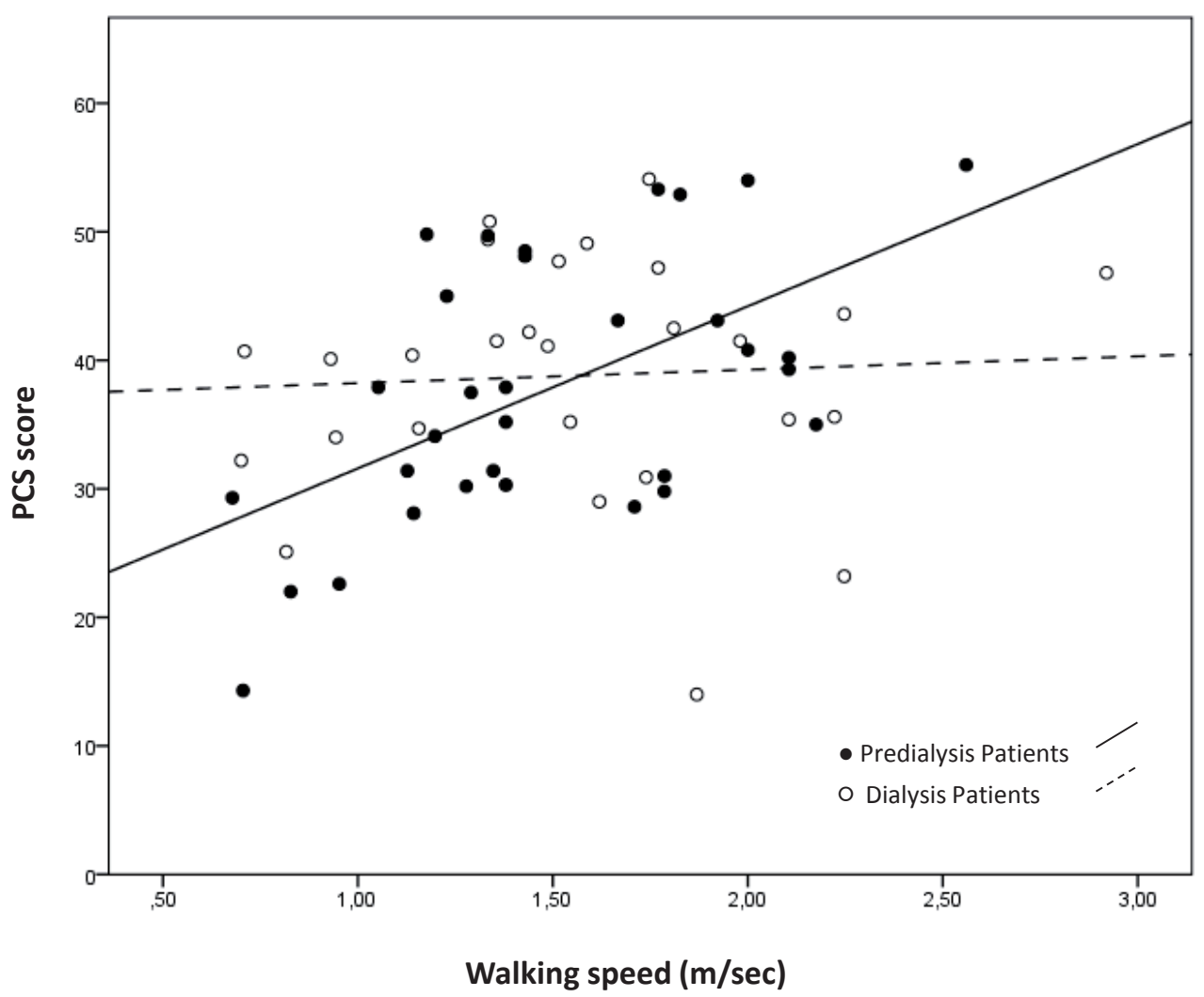

Figure 6.5 Association between physical component summary (PCS) score and walking speed in both CKD-5 nondialysis and dialysis patients.

\section{DISCUSSION}

This study firstly showed a reduction in the physical domains of the SF-36 HRQOL scores in both CKD-5 non-dialysis and prevalent dialysis patients, compared with age matched healthy controls, without significant differences between both patient groups. The mental domain of the SF-36 scale (MCS) was significantly lower in CKD-5 non-dialysis patients as compared with controls, without significant differences between CKD-5 non-dialysis and prevalent dialysis patients. Secondly, in the longitudinal analysis, no significant changes in HRQOL were observed in one of the critical periods for ESRD patients, i.e. the phase from CKD-5 non-dialysis phase until 6 months after the start of dialysis ${ }^{11-13}$, neither in the physical, nor as in the mental components. Lastly, PA parameters were significantly associated with PCS scores and components of the PCS scale of the SF-36, which was most pronounced for the PF component. No associations were found for changes in PA (delta number of steps/ delta walking speed) and changes in both PCS and MCS scores (delta PCS/delta MCS). The cross-sectional analysis showed PCS score values below norm-based scores in CKD5 non-dialysis patients as well as in dialysis patients, which were significantly lower as 
compared with healthy controls, suggesting reduced HRQOL in this patient group. Especially subscales physical functioning, role physical and general health, which are highly associated with the physical component ${ }^{18}$, were low as compared with norm-based values. Previous research in a large US dialysis cohort showed incomparable reduction in PCS and MCS scores of the SF-36 in both incident as well as prevalent dialysis patients ${ }^{4}$. Our findings are also in line with other literature, which showed lower HRQOL scores in incident dialysis patients $^{29}$, and in both CKD (stage $2-5$ ) patients as well as in HD patients ${ }^{2,30}$. However, to the best of our knowledge, no comparative study has been performed between CKD- 5 nondialysis and prevalent dialysis patients. Interestingly, these findings are not only common in ESRD patients, as also in other populations with chronic organ diseases, such as chronic obstructive pulmonary disease (COPD) ${ }^{31,32}$ and heart failure (HF) ${ }^{33}$, low HRQOL scores are observed.

In the longitudinal analysis no significant changes in PCS or MCS scores were observed in the first six months after starting dialysis. This is remarkable given the fact that the start of dialysis is a critical phase in ESRD patients ${ }^{11,12}$ with both phenotypic and pathophysiologic changes $^{13}$, an increased risk of mortality ${ }^{34,35}$, and in nursing home patients, a significantly decreased functional status ${ }^{36}$. We should acknowledge that our patient group may consist of a selected group, as all patients were recruited from the CKD-5 non-dialysis out-patient clinic. The severely impaired HRQOL in the CKD-5 non-dialysis phase underscores the need for strategies to improve HRQOL already in earlier stages of CKD ${ }^{37}$.

One of these potentially modifiable factors includes PA. We observed a significant relation between objectively measured PA parameters and physical domains of the PCS. A study of Painter et al. showed increased self-reported physical scale and PCS scores in patients receiving exercise training ${ }^{38}$. Also, a more recent study of Lopes et al. showed that higher self-reported aerobic physical activity level was associated with better physical HRQOL (higher PCS scores) in HD patients ${ }^{16}$. The results of our study thus confirm findings from previous research, although in our study objective measures were used to assess PA by the Sensewear Pro3 ${ }^{\mathrm{TM}}$. Next to that, the association between changes in HRQOL and changes in PA was longitudinally assessed over a six month time period. Despite the association between PA and PCS scores in the cross-sectional analysis, contrastingly no associations were found for changes in PA parameters and changes in PCS scores over a six month period of time. This might be due to the fact that changes in PA following the start of dialysis were not significant in the overall group and relatively small in individual patients.

Several limitations of the study deserve consideration: Firstly, both PD and HD patients were included, with apparently little differences between both groups. It is, however, important to realize that this study focused on the effects of starting dialysis treatment per se and not on differences in dialysis modalities, for which a larger sample size would be required. However, a previous study also did not conclude notable differences in HRQOL between HD and PD treatment ${ }^{9}$. Secondly, only the SF-36 questionnaire was used to measure HRQOL instead of the Kidney Disease Quality of Life-36 (KDQOL-36) which is especially designed 
for patients with ESRD. Nevertheless, the SF-36 is the most widely used tool to measure $\mathrm{HRQOL}$ in the field of nephrology worldwide ${ }^{17}$, and scores were normalized which made scores comparable to the general population (healthy controls) ${ }^{18,19}$. Thirdly, we cannot exclude selection bias as we have included relatively young and possibly less frail controls and patients. This is supported by the fact that, none of the 30 CKD- 5 non-dialysis patients in the longitudinal analyses died in the first six months of the transitional phase after starting dialysis treatment.

In conclusion, HRQOL (as measured by PCS and MCS scores in the SF-36) is already decreased in the CKD-5 non-dialysis phase. Additionally, in the first six months after the start of dialysis treatment HRQOL scores did not change significantly, suggesting no major effect of the start of dialysis in our ESRD patients, in whom the reduced quality of life appears to be primarily related to the renal disease per se. Next to HRQOL also PA is low in both CKD-5 non-dialysis as well as dialysis patients. Given the association between the physical domain of health (PCS) and PA, the importance of physical activity programs should be underscored and strongly encouraged in both CKD-5 non-dialysis as well as dialysis patients in order to increase the physical domains of HRQOL in these patients groups.

\section{FUNDING}

Jeroen P. Kooman, Frank M. van der Sande and Natascha J.H. Broers are supported by an unrestricted grant from Fresenius Medical Care Europe. Peter Wabel and Bernard Canaud are employees of Fresenius Medical Care Europe. 


\section{REFERENCES}

1. Mazairac AH, de Wit GA, Penne EL, van der Weerd NC, de Jong B, Grooteman MP, et al. Changes in quality of life over time--Dutch haemodialysis patients and general population compared. Nephrol Dial Transplant 2011;26:1984-1989.

2. Walters BA, Hays RD, Spritzer KL, Fridman M,Carter WB. Health-related quality of life, depressive symptoms, anemia, and malnutrition at hemodialysis initiation. Am J Kidney Dis 2002;40:1185-1194.

3. DeOreo PB. Hemodialysis patient-assessed functional health status predicts continued survival, hospitalization, and dialysis-attendance compliance. Am J Kidney Dis 1997;30:204-212.

4. Broers NJ, Usvyat LA, Kooman JP, van der Sande FM, Lacson E, Jr., Kotanko P, et al. Quality of Life in Dialysis Patients: A Retrospective Cohort Study. Nephron 2015;130:105-112.

5. Mapes DL, Lopes AA, Satayathum S, McCullough KP, Goodkin DA, Locatelli F, et al. Healthrelated quality of life as a predictor of mortality and hospitalization: the Dialysis Outcomes and Practice Patterns Study (DOPPS). Kidney Int 2003;64:339-349.

6. Mapes DL, Bragg-Gresham JL, Bommer J, Fukuhara S, McKevitt P, Wikstrom B, et al. Healthrelated quality of life in the Dialysis Outcomes and Practice Patterns Study (DOPPS). Am J Kidney Dis 2004;44:54-60.

7. Gabbay E, Meyer KB, Griffith JL, Richardson MM,Miskulin DC. Temporal trends in healthrelated quality of life among hemodialysis patients in the United States. Clin J Am Soc Nephrol 2010;5:261-267.

8. Merkus MP, Jager KJ, Dekker FW, De Haan RJ, Boeschoten EW,Krediet RT. Quality of life over time in dialysis: the Netherlands Cooperative Study on the Adequacy of Dialysis. NECOSAD Study Group. Kidney Int 1999;56:720-728.

9. Wu AW, Fink NE, Marsh-Manzi JV, Meyer KB, Finkelstein FO, Chapman MM, et al. Changes in quality of life during hemodialysis and peritoneal dialysis treatment: generic and disease specific measures. J Am Soc Nephrol 2004;15:743-753.

10. Korevaar JC, Jansen MA, Merkus MP, Dekker FW, Boeschoten EW,Krediet RT. Quality of life in predialysis end-stage renal disease patients at the initiation of dialysis therapy. The NECOSAD Study Group. Perit Dial Int 2000;20:69-75.

11. Mclntyre CW, Rosansky SJ. Starting dialysis is dangerous: how do we balance the risk? Kidney Int 2012;82:382-387.

12. Kooman JP, Usvyat L, van der Sande FM, Thijssen S, Levin N, Leunissen KM, et al. 'Time and time again': oscillatory and longitudinal time patterns in dialysis patients. Kidney Blood Press Res 2012;35:534-548.

13. Broers NJ, Cuijpers AC, van der Sande FM, Leunissen KM,Kooman JP. The first year on haemodialysis: a critical transition. Clin Kidney J 2015;8:271-277.

14. Loos C, Briancon S, Frimat L, Hanesse B,Kessler M. Effect of end-stage renal disease on the quality of life of older patients. J Am Geriatr Soc 2003;51:229-233. 
15. Gorodetskaya I, Zenios S, McCulloch CE, Bostrom A, Hsu CY, Bindman AB, et al. Healthrelated quality of life and estimates of utility in chronic kidney disease. Kidney Int 2005;68:2801-2808.

16. Lopes AA, Lantz B, Morgenstern H, Wang M, Bieber BA, Gillespie BW, et al. Associations of self-reported physical activity types and levels with quality of life, depression symptoms, and mortality in hemodialysis patients: the DOPPS. Clin J Am Soc Nephrol 2014;9:1702-1712.

17. Wight JP, Edwards L, Brazier J, Walters S, Payne JN,Brown CB. The SF36 as an outcome measure of services for end stage renal failure. Qual Health Care 1998;7:209-221.

18. Ware JE, Snow KK, Kosinski M, Gandek B. SF-36 Health Survey Manual and Interpretation Guide, Boston, The Health Institute, New England Medical Center. 1993;

19. Ware JE, Kosinski M, Keller SD. SF-36 Physical and Mental Health Summary Scales: A User's Manual, ed 2. Boston, The Health Institute, New England Medical Center. 1994;

20. Ostir GV, Volpato S, Fried LP, Chaves P,Guralnik JM. Reliability and sensitivity to change assessed for a summary measure of lower body function: results from the Women's Health and Aging Study. J Clin Epidemiol 2002;55:916-921.

21. Penninx BW, Ferrucci L, Leveille SG, Rantanen T, Pahor M,Guralnik JM. Lower extremity performance in nondisabled older persons as a predictor of subsequent hospitalization. J Gerontol A Biol Sci Med Sci 2000;55:M691-697.

22. Guralnik JM, Ferrucci L, Simonsick EM, Salive ME,Wallace RB. Lower-extremity function in persons over the age of 70 years as a predictor of subsequent disability. N Engl J Med 1995;332:556-561.

23. Guralnik JM, Ferrucci L, Pieper CF, Leveille SG, Markides KS, Ostir GV, et al. Lower extremity function and subsequent disability: consistency across studies, predictive models, and value of gait speed alone compared with the short physical performance battery. J Gerontol A Biol Sci Med Sci 2000;55:M221-231.

24. Hartmann EL, Kitzman D, Rocco M, Leng X, Klepin H, Gordon M, et al. Physical function in older candidates for renal transplantation: an impaired population. Clin J Am Soc Nephrol 2009;4:588-594.

25. Levey AS, Stevens LA, Schmid CH, Zhang YL, Castro AF, 3rd, Feldman HI, et al. A new equation to estimate glomerular filtration rate. Ann Intern Med 2009;150:604-612.

26. Davies SJ, Russell L, Bryan J, Phillips L,Russell Gl. Comorbidity, urea kinetics, and appetite in continuous ambulatory peritoneal dialysis patients: their interrelationship and prediction of survival. Am J Kidney Dis 1995;26:353-361.

27. Davies SJ, Phillips L, Naish PF,Russell Gl. Quantifying comorbidity in peritoneal dialysis patients and its relationship to other predictors of survival. Nephrol Dial Transplant 2002;17:1085-1092.

28. Van Manen JG, Korevaar JC, Dekker FW, Boeschoten EW, Bossuyt PM, Krediet RT. Adjustment for comorbidity in studies on health status in ESRD patients: which comorbidity index to use? J Am Soc Nephrol 2003;14:478-485. 
29. Merkus MP, Jager KJ, Dekker FW, Boeschoten EW, Stevens P,Krediet RT. Quality of life in patients on chronic dialysis: self-assessment 3 months after the start of treatment. The Necosad Study Group. Am J Kidney Dis 1997;29:584-592.

30. Perlman RL, Finkelstein FO, Liu L, Roys E, Kiser M, Eisele G, et al. Quality of life in chronic kidney disease (CKD): a cross-sectional analysis in the Renal Research Institute-CKD study. Am J Kidney Dis 2005;45:658-666.

31. HabrakenJM, van derWalWM, TerRietG, WeersinkEJ, TobenF,Bindels PJ. Health-related quality of life and functional status in end-stage COPD: a longitudinal study. Eur Respir J 2011;37:280288.

32. Wilke S, Janssen DJ, Wouters EF, Schols JM, Franssen FM,Spruit MA. Correlations between disease-specific and generic health status questionnaires in patients with advanced COPD: a one-year observational study. Health Qual Life Outcomes 2012;10:98.

33. Lesman-Leegte I, Jaarsma T, Coyne JC, Hillege HL, Van Veldhuisen DJ,Sanderman R. Quality of life and depressive symptoms in the elderly: a comparison between patients with heart failure and age- and gender-matched community controls. J Card Fail 2009;15:17-23.

34. Noordzij M,Jager KJ. Increased mortality early after dialysis initiation: a universal phenomenon. Kidney Int 2014;85:12-14.

35. Robinson BM, Zhang J, Morgenstern H, Bradbury BD, Ng LJ, McCullough KP, et al. Worldwide, mortality risk is high soon after initiation of hemodialysis. Kidney Int 2014;85:158-165.

36. Kurella Tamura M, Covinsky KE, Chertow GM, Yaffe K, Landefeld CS,McCulloch CE. Functional status of elderly adults before and after initiation of dialysis. N Engl J Med 2009;361:1539-1547.

37. Fassbinder TR, Winkelmann ER, Schneider J, Wendland J,Oliveira OB. Functional Capacity and Quality of Life in Patients with Chronic Kidney Disease In Pre-Dialytic Treatment and on Hemodialysis--A Cross sectional study. J Bras Nefrol 2015;37:47-54.

38. Painter P, Carlson L, Carey S, Paul SM,Myll J. Physical functioning and health-related qualityof-life changes with exercise training in hemodialysis patients. Am J Kidney Dis 2000;35:482-492. 



\section{CHAPTER 7}

QUALITY OF LIFE IN DIALYSIS PATIENTS: A RETROSPECTIVE COHORT STUDY

Natascha J.H. Broers, Len A. Usvyat, Jeroen P. Kooman, Frank M. van der Sande, Eduardo Lacson Jr., Peter Kotanko and Franklin W. Maddux

Nephron 2015;130:105-112 


\section{ABSTRACT}

\section{Background/Aim}

Physical component summary (PCS) and mental component summary (MCS) scores are associated with hospitalization and mortality in patients with end-stage renal disease. Most studies in these patients are cross-sectional in nature. This study aimed to assess the dynamics of health-related quality of life (HRQOL) over time, as well as determinants of changes in HRQOL. Also, the relation between changes in HRQOL with respect to both hospitalization and mortality was assessed.

\section{Methods}

A cross-sectional analysis was performed in 77,848 hemodialysis (HD) patients whereas changes in HRQOL were assessed in 8,339 patients over a 1-year time period. HRQOL measurements were assessed with Kidney Disease Quality of Life-36 questionnaires. Also, relevant biomarkers (albumin, creatinine, hemoglobin, sodium) and equilibrated normalized protein catabolic rate (enPCR) were measured.

\section{Results}

HRQOL were found to be decreased in HD patients. Nutritional indices like creatinine $(r=0.23$; $\mathrm{P}<0.0001)$ and serum albumin $(r=0.21 ; \mathrm{P}<0.0001)$ positively correlated with $\mathrm{PCS}$ scores. An increase in levels of albumin, creatinine, hemoglobin, enPCR and serum sodium over time are significantly $(P<0.0001)$ associated with positive changes in PCS scores. Changes in PCS scores were found to be predictive for hospitalization and mortality. The correlates of predictors for MCS scores were less strong compared to that of PCS scores. The strongest positive predictors of MCS scores were age $(r=0.08 ; P<0.0001)$, albumin $(r=0.05 ; P<0.0001)$ and sodium $(r=0.05 ; \mathrm{P}<0.0001)$.

\section{Conclusions}

Nutritional factors are strongly associated with changes in HRQOL, especially with regard to PCS scores (change over time in HRQOL was an independent predictor of hospitalization and mortality). Increased scores of HRQOL over time are positively associated with survival. 


\section{INTRODUCTION}

Over the years, numerous studies consistently showed that health-related quality of life (HRQOL) in patients with end-stage renal disease (ESRD) was lower compared to that in the general population, despite the technical developments in dialysis therapies ${ }^{1-3}$. Moreover, $\mathrm{HRQOL}$ is an important predictor of mortality in ESRD patients ${ }^{3-7}$. HRQOL of ESRD patients seemed to be the most affected in terms of physical functioning and vitality, whereas mental HRQOL appeared somewhat less impaired as compared to that of the general population ${ }^{8}$. Various patient-related factors were shown to be related to HRQOL, such as age and comorbidity 9 .

It is important to identify potentially modifiable determinants of HRQOL. Whereas the relation between hemoglobin levels and $\mathrm{HRQOL}$ is still controversial in many studies ${ }^{10-13}$, a systematic review of Spiegel et al. showed that HRQOL was strongly related to nutritional biomarkers like albumin and creatinine, while in contrast the correlation with dialysis adequacy (Kt/V) and inflammatory markers appeared to be less strong ${ }^{8}$. In addition, a study of Lacson et al. showed significant associations between both physical component summary (PCS) scores and mental component summary (MCS) scores, and various quality-of-care indicators such as albumin and Kt/V, and mortality ${ }^{14}$.

Earlier studies, however, have either focused on crosssectional relationships between HRQOL and its determinants ${ }^{15}$, or studied the relation between mortality and HRQOL using an assessment at a single point in time ${ }^{5,7}$. However, a recent study showed the additional value of following the dynamics of important outcome parameters in dialysis patients as compared to single measurements ${ }^{16}$. Therefore, additional information regarding potentially modifiable determinants of $\mathrm{HRQOL}$, as well as on the predictive value of HRQOL may be obtained when studying dynamics in HRQOL.

Most studies that have addressed dynamics in HRQOL have done so by comparing general trends at different time periods with a varying patient cohort ${ }^{1,17}$. Nevertheless, few studies followed HRQOL in hemodialysis (HD) patients over time in the same patients ${ }^{18,19}$.

Given the inclusion of a large number of patients, and the availability of repeated measurements utilizing the Kidney Disease Quality of Life-36 (KDQOL-36 TM), the Fresenius North America Database provided an excellent opportunity to study not only cross-sectional correlates but also the determinants and prognostic value of changes in KDQOL-36 TM component summary scores for maintenance dialysis patients, as was the goal of this paper.

\section{PATIENTS AND METHODS}

In order to evaluate HRQOL of the patients, the KDQOL-36 TM survey was used ${ }^{20}$. The KDQOL-36 TM is a self-reported measure developed for individuals with ESRD, which consists of the SF-12 PCS and MCS scores along with the Burden of Kidney Disease (BHR) and Effects of Kidney Disease (EHR) subscales ${ }^{21}$. The PCS and MCS scores obtained from the SF-12 component of the KDQOL-36 TM are comparable to the PCS and MCS scores directly obtained from the Short Form-36 questionnaire ${ }^{22}$. A baseline survey was obtained beginning in 2008, and ever 
since, this survey was routinely offered within the first 120 days of initiating dialysis and, for all patients, annually thereafter, providing the patients consent. All measures of the different subscales were scored on a 0 to 100 point scale were higher values representing better HRQOL. RAND-recommended scoring was used that was derived using normalized (t-score) scoring algorithms for this too ${ }^{23,24}$. PCS/MCS scores are used this way to make it comparable to the general population and other patient groups with specific disease states. There are no RAND PCS/MCS norms specific to ESRD. However, data showing PCS/MCS scores for ESRD patients measured in large patient groups ${ }^{22,25}$ are available. It is a known fact that ESRD patients' MCS/ PCS scores are lower than those in the general population.

The study was divided into two parts: a cross-sectional evaluation and a longitudinal assessment. Initially, all KDQOL-36 TM surveys between January 1, 2008 and December 31, $2011(n=112,315)$ were screened (table 7.1).

Table 7.1 Patient Demographics.

\begin{tabular}{ll}
\hline Patient Demographics & \\
\hline Number of Patients & 77848 \\
Number of Surveys & 112315 \\
Age (years) & $61.92 \pm 14.59$ \\
Vintage (years) & $3.45 \pm 3.62$ \\
Male (\%) & 55 \\
Ethnicity: White (\%) & 60 \\
Ethnicity: Black (\%) & 36 \\
Ethnicity: Hispanic (\%) & 16 \\
Access: Catheter (\%) & 19 \\
BMI (kg/m ${ }^{2}$ & $28.75 \pm 7.89$ \\
Albumin (g/dL) & $3.87 \pm 0.39$ \\
Creatinine (mg/dL) & $8.22 \pm 3.03$ \\
enPCR (g/kg/day) & $0.90 \pm 0.26$ \\
Hemoglobin (g/dL) & $11.51 \pm 1.11$ \\
Predialysis Systolic Blood Pressure (mm/Hg) & $149.36 \pm 20.77$ \\
Physical Component Score (0-100) & $36.52 \pm 10.47$ \\
Mental Component Score (0-100) & $50.12 \pm 10.70$ \\
Symptom Problem Score (0-100) & $77.79 \pm 16.35$ \\
Burden of Kidney Disease Score (0-100) & $50.26 \pm 29.31$ \\
Effects of Kidney Disease Score (0-100) & $71.94 \pm 22.50$ \\
\hline
\end{tabular}

Data given as mean \pm SD. BMI: body mass index; enPCR: equilibrated normalized protein catabolic rate.

The cross-sectional analysis focused on determining the differences between incident and prevalent patients, different age categories, as well as to determine the associations between both PCS and MCS scores and nutritional and biochemical indices. Next, the longitudinal analysis focused on differences in PCS and MCS scores over time, which are highly related to care and mortality. Other variables were not taken into account.

For the cross-sectional part, all clinical and demographical information was assessed at the same month as the HRQOL survey. Patients were also separately analyzed according to age $(<50,50-65,65-75$ and $>75$ years of age), and incident or prevalent status; incident patients were defined as those with vintage at the time of the survey as $<120$ days, the remaining patients were considered prevalent. 
In order to study the determinants of changes in $\mathrm{HRQOL}$, as well as the effects of changes in HRQOL on outcome, only patients who had $\geq 2$ surveys 12 months apart (i.e. survey 2 was done in the month 365 days after survey 1 ) were included. Clinical and demographic information was collected in the month of the first and second surveys. In these patients, the determinants of changes in HRQOL domains were assessed using paired t-test, as well as the predictive value of change in HRQOL on outcome using the Cox proportional hazards model. Biomarkers (albumin, creatinine, hemoglobin, sodium) and equilibrated normalized protein catabolic rate (enPCR) were measured. Only predictors with a correlation coefficient higher than 0.05 were reported. Analysis was conducted in accordance with privacy regulations of Fresenius Medical Care North America (FMCNA) and approved by New England IRB.

\section{RESULTS}

\section{Cross-sectional analysis}

For the cross-sectional part, 77,848 HD patients and 113,315 surveys were included in the analysis (some patients had more than one survey filled out) between September 2009 and December 2010. The mean vintage was 3.45 years and $6 \%$ of patients were incident. The cross-sectional analysis showed that the PCS scores of the overall patient group were found to be decreased in dialysis patients (table 7.1).

PCS scores, MCS scores, as well as BHR were lower in incidence as compared to those in prevalent patients. Yet, symptom problem score and EHR scores were higher in incident patients as compared to the scores in prevalent patients (fig. 7.1). However, differences, although significant, were small on an absolute scale.

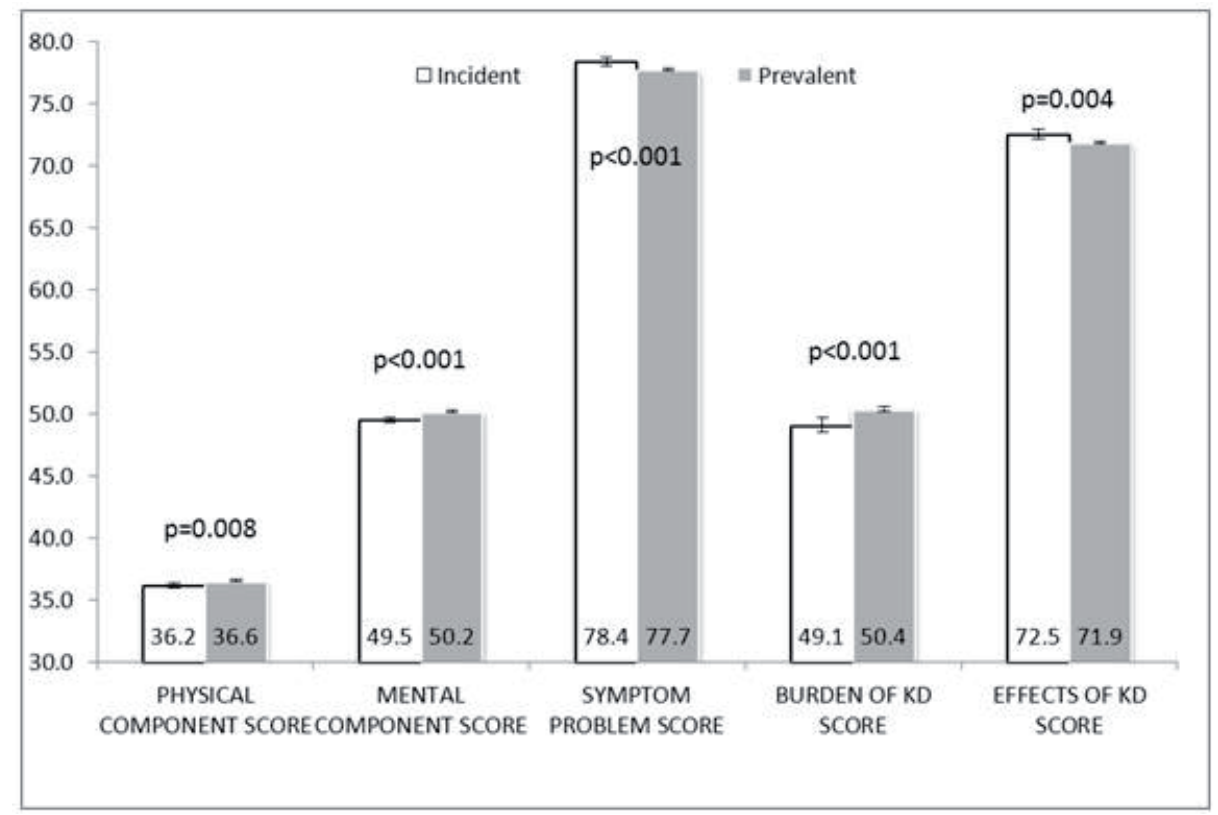

Figure 7.1 Comparison of incident and prevalent patients. 
As for age, patients were subdivided in four age categories; patients below 50, between 50 and 65 , between 65 and 75, and above 75 years of age. In general, PCS were higher in younger patients, whereas mental and especially EHR scores were lower in younger subjects (fig. 7.2).

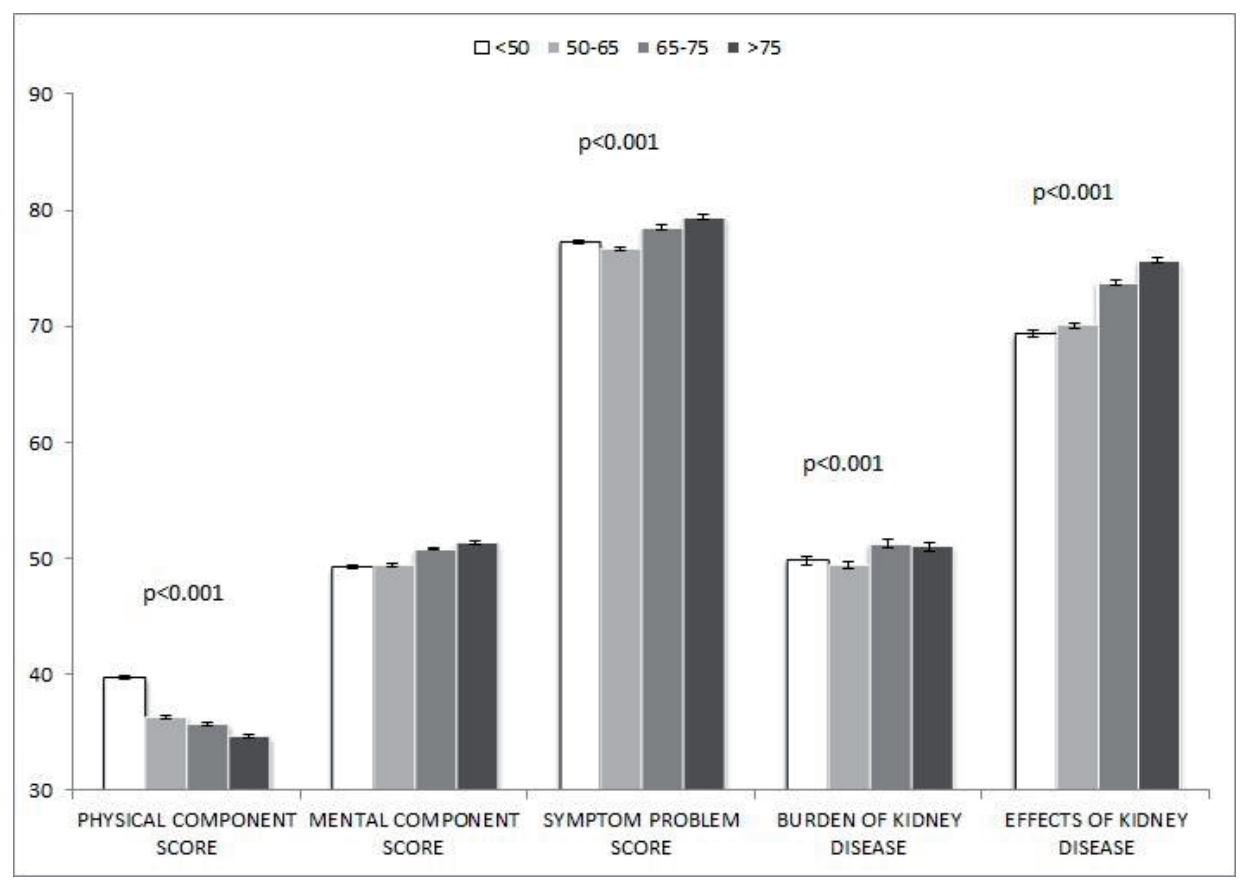

Figure 7.2 Comparison of patients by age group; below and above 50 years of age.

\section{Associations of HRQOL: cross-sectional analysis}

Determinants for HRQOL domains were most pronounced for PCS scores (table 7.2) and to a somewhat lesser degree for MCS scores (table 7.3). The largest positive correlates with PCS scores were nutritional indices, such as creatinine $(r=0.23 ; P<0.0001)$ and albumin $(r=0.21$; $P<0.0001$ ) (table 7.2). Important negative correlates were observed for age $(r=-0.17$; $P<0.0001)$, and to a somewhat lesser degree for neutrophil-to-lymphocyte ratio (NLR) $(r=$ $-0.11 ; \mathrm{P}<0.0001$ ) (table 7.2).

Table 7.2 Correlations of Physical Component Scores: cross-sectional data.

\begin{tabular}{lrl}
\hline Parameter & $\mathrm{r}$ & $\mathrm{p}$ - value \\
\hline Creatinine (mg/dl) & 0.23 & $<0.0001$ \\
Albumin (g/dl) & 0.21 & $<0.0001$ \\
Age (years) & -0.17 & $<0.0001$ \\
Predialysis Diastolic Blood Pressure (mm/Hg) & 0.15 & $<0.0001$ \\
EPO-dose & -0.12 & $<0.0001$ \\
NLR & -0.11 & $<0.0001$ \\
\hline
\end{tabular}

$E P O=$ erythropoietin; NLR = neutrophil lymphocyte ratio. 
Table 7.3 Correlations of Mental Component Scores: cross-sectional data.

\begin{tabular}{lll}
\hline Parameter & $r$ & $p$ - value \\
\hline Age (years) & 0.08 & $<0.0001$ \\
Albumin (g/dl) & 0.05 & $<0.0001$ \\
Serum Sodium (mmol/L) & 0.05 & $<0.0001$ \\
Predialysis Diastolic Blood Pressure (mm/Hg) & -0.05 & $<0.0001$ \\
EPO-dose & -0.05 & $<0.0001$ \\
\hline
\end{tabular}

EPO $=$ erythropoietin

The correlates of predictors for MCS scores were less pronounced as compared to the PCS scores. Age $(r=0.08 ; P<0.0001)$ and albumin $(r=0.05 ; P<0.0001)$, followed by serum sodium $(r=0.05 ; P<0.0001)$, were the strongest positive predictors of MCS (table 7.3). Biochemical correlates for other components/domains of the HRQOL score were less pronounced (data not shown).

\section{Longitudinal changes in HRQOL}

Table 4 shows the differences over time (12 months) in outcomes of the different HRQOL scores in 8,339 patients. In the overall patient group no statistically as well as clinically significant changes were found for PCS and MCS scores and for symptom problem scores. BHR and EHR scores significantly increased over time (table 7.4).

However, 78.7 percent of the patients showed changes in PCS scores larger than 2 points $(<-2$ or $>2$ ) (table 7.5). The same held true for MCS scores; 77.1 percent of the patients had changes larger than 2 points $(<-2$ or $>2$ ) (table 7.6$)$.

\section{Associations of changes in HRQOL}

The most significant positive associations for an increase in PCS scores were increases in nutritional parameters, hemoglobin and serum sodium (table 7.7). For changes in MCS scores, the only parameter was the change in serum albumin. For changes in other domains, no correlations above 0.05 were observed.

\section{Relation of changes in HRQOL with mortality}

Both cross-sectional values of PCS scores (1 point higher starting PCS score) as well as changes in PCS scores (1 point increase in 12 months) were predictive of mortality, after adjustments for clinical and demographic parameters, which were selected based on clinical plausibility (table 7.8).

\section{Relation of changes in HRQOL with hospitalization}

Both cross-sectional values of PCS scores (1 point higher starting PCS score) as well as changes in PCS scores (1 point increase in 12 months) were predictive of hospitalization, after adjustments for clinical and demographic parameters, which were selected based on clinical plausibility. Time to first hospitalization significantly prolonged with increased PCS scores (table 7.9). 
Table 7.4 Patient Demographics of patients with $\geq 2$ surveys.

\begin{tabular}{|c|c|c|c|c|}
\hline \multicolumn{5}{|l|}{ Patient Demographics } \\
\hline Number of patients & 8339 & & & \\
\hline Age (years) & $61.53 \pm 14.48$ & & & \\
\hline Vintage (years) & $3.31 \pm 3.62$ & & & \\
\hline Male (\%) & $54 \%$ & & & \\
\hline Ethnicity: White (\%) & $57 \%$ & & & \\
\hline Ethnicity: Black (\%) & $40 \%$ & & & \\
\hline Ethnicity: Hispanic (\%) & $16 \%$ & & & \\
\hline \multirow[t]{2}{*}{ BMI $\left(\mathrm{kg} / \mathrm{m}^{2}\right)$} & $28.89 \pm 7.40$ & & & \\
\hline & First Survey & $\begin{array}{l}95 \% \mathrm{Cl} \\
{[\mathrm{LCL}, \mathrm{UCL}]}\end{array}$ & $\begin{array}{l}\text { Change* } \\
\text { between } \\
\text { First and } \\
\text { Second } \\
\text { Survey (12 } \\
\text { months) }\end{array}$ & $\begin{array}{l}95 \% \mathrm{Cl} \\
{[\mathrm{LCL}, \mathrm{UCL}]}\end{array}$ \\
\hline Access: Catheter (\%) & 17 & & -6 & \\
\hline Albumin $(\mathrm{g} / \mathrm{dL})$ & 3.89 & {$[3.88,3.90]$} & 0.04 & {$[0.03,0.05]$} \\
\hline Creatinine $(\mathrm{mg} / \mathrm{dL})$ & 8.51 & {$[8.44,8.58]$} & 0.23 & {$[0.19,0.27]$} \\
\hline enPCR (g/kg/day) & 0.92 & {$[0.91,0.93]$} & -0.01 & {$[-0.02,0]$} \\
\hline Hemoglobin (g/dL) & 11.65 & {$[11.63,11.67]$} & -0.18 & {$[-0.21,-0.15]$} \\
\hline Predialysis Systolic Blood Pressure (mm/Hg) & 150.57 & {$[150.14,151]$} & -1.04 & {$[-1.42,-0.66]$} \\
\hline Physical Component Score $(0-100)$ & 37.59 & {$[37.37,37.81]$} & -0.05 & {$[-0.25,0.15]$} \\
\hline Mental Component Score $(0-100)$ & 51.10 & {$[50.88,51.32]$} & 0.14 & {$[-0.08,0.36]$} \\
\hline Symptom Problem Score $(0-100)$ & 79.20 & {$[78.86,79.54]$} & 0.24 & {$[-0.07,0.55]$} \\
\hline Burden of Kidney Disease Score $(0-100)$ & 52.42 & {$[51.80,53.04]$} & 1.32 & {$[0.75,1.89]$} \\
\hline Effects of Kidney Disease Score $(0-100)$ & 73.73 & {$[73.26,74.20]$} & 0.96 & {$[0.53,1.39]$} \\
\hline
\end{tabular}

Data given as mean \pm SD or mean and $95 \% \mathrm{Cl}$; BMI: body mass index; enPCR: equilibrated normalized protein catabolic rate; $\mathrm{Cl}$ : confidence interval; LCL: lower control limit; UCL:upper control limit.

*Change between first and second survey was calculated as last survey - first survey. 


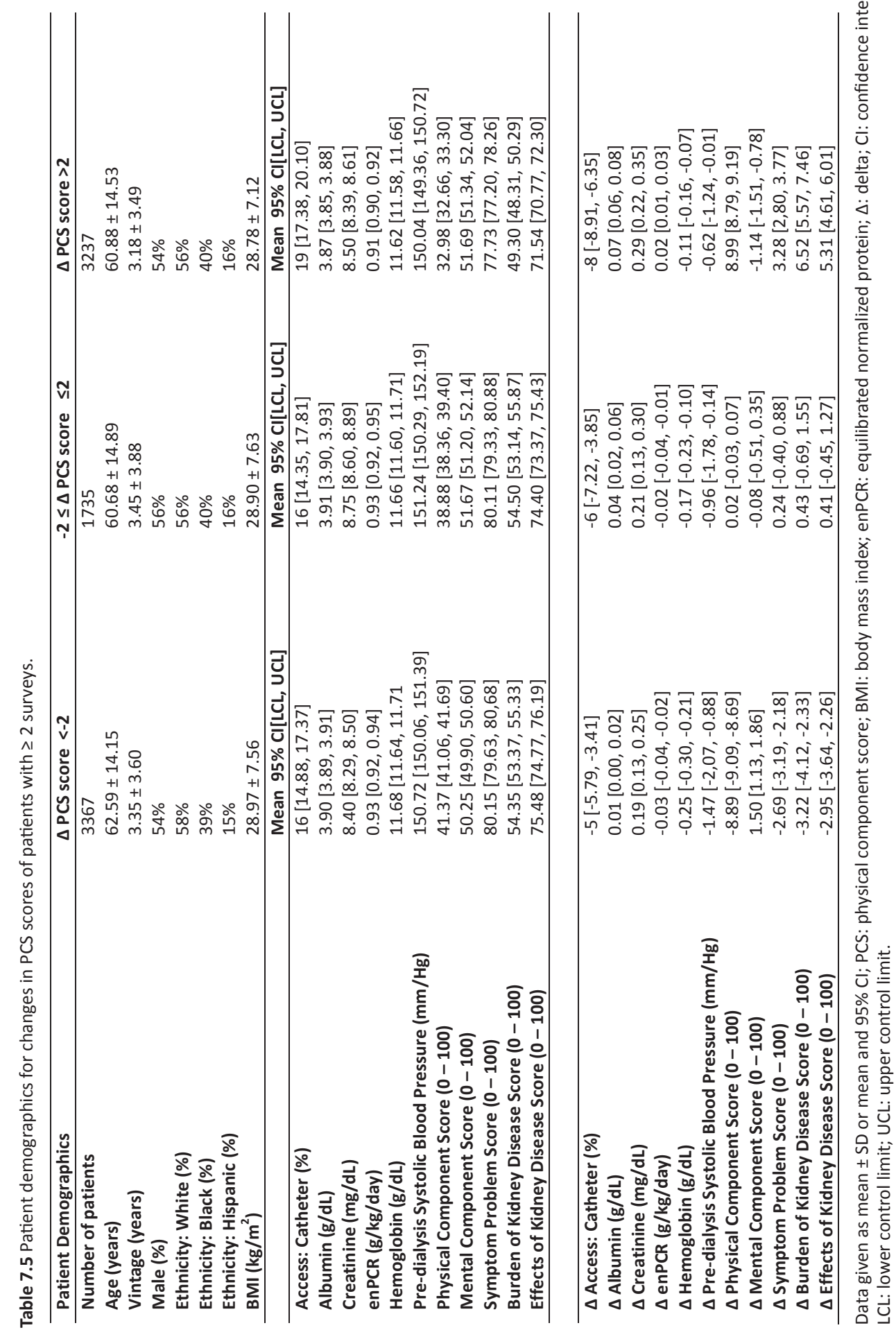




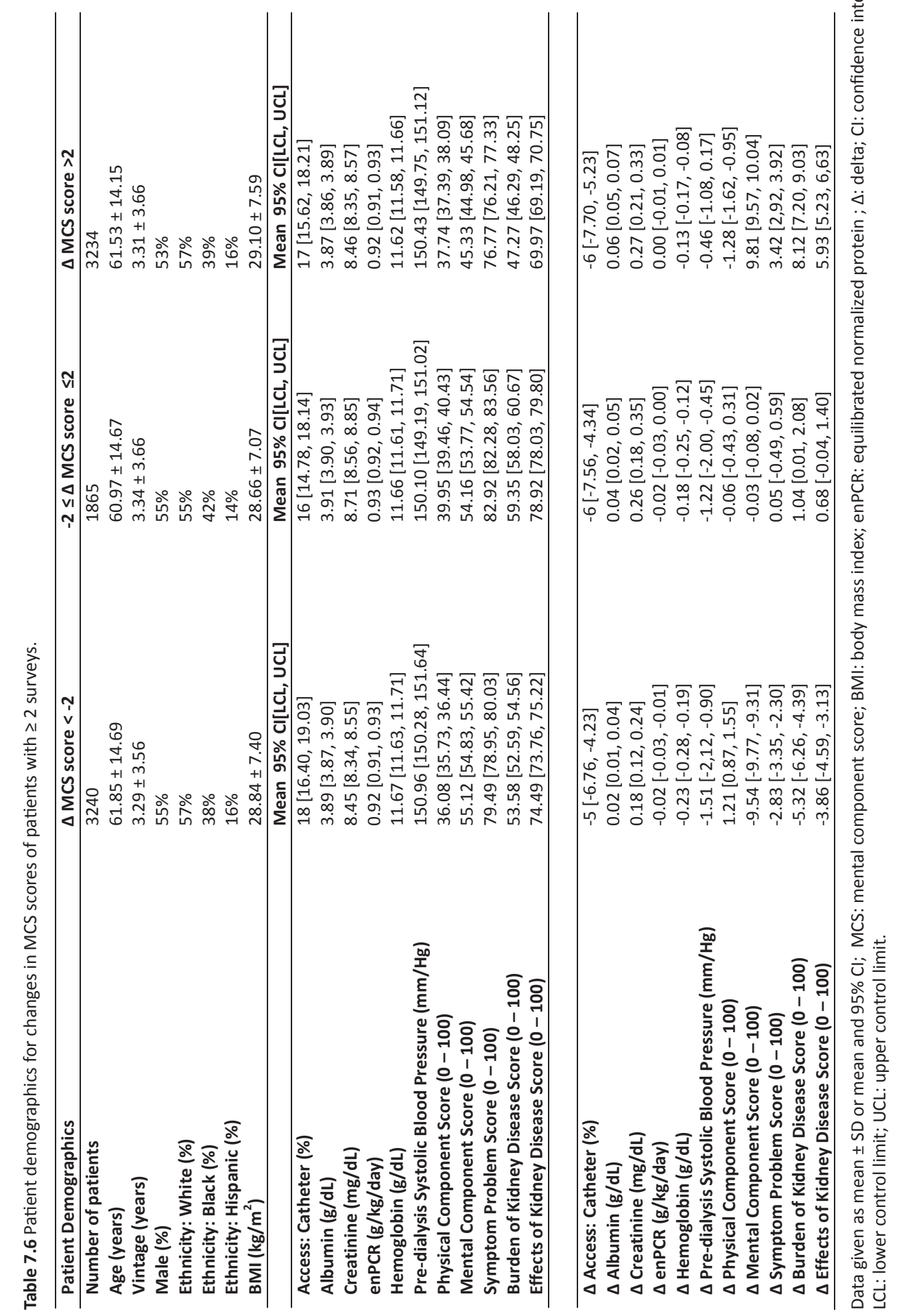


Table 7.7 Correlations of changes over time in Physical Component Scores: cross-sectional data.

\begin{tabular}{lll}
\hline Parameter & $\mathbf{r}$ & p - value \\
\hline Albumin (g/dl) & 0.10 & $<0.0001$ \\
enPCR (g/kg/day) & 0.08 & $<0.0001$ \\
Hemoglobin (g/dL) & 0.05 & $<0.0001$ \\
Serum Sodium (mmol/L) & 0.05 & $<0.0001$ \\
Creatinine (mg/dl) & 0.05 & $<0.0001$ \\
\hline
\end{tabular}

enPCR = equilibrated normalized protein catabolic rate.

Table 7.8 Hazard Ratios for mortality in patients with $\geq 2$ surveys.

\begin{tabular}{llll}
\hline Parameter & Hazard Ratio & $\mathbf{9 5 \% ~ C l ~ [ L C L , ~ U C L ] ~}$ & p - value \\
\hline Age (years) & 1.02 & {$[1.02,1.03]$} & $<.0001$ \\
Male & 1.07 & {$[0.92,1.25]$} & 0.361 \\
Ethnicity: White & 1.12 & {$[0.94,1.34]$} & 0.209 \\
Ethnicity: Hispanic & 0.88 & {$[0.70,1.11]$} & 0.279 \\
Vintage (years) & 1.03 & {$[1.01,1.05]$} & 0.005 \\
(First) Albumin (g/dl) & 0.66 & {$[0.54,0.81]$} & $<.0001$ \\
(First) Creatinine (mg/dl) & 0.96 & {$[0.93,0.99]$} & 0.016 \\
(First) Hemoglobin (g/dL) & 0.90 & {$[0.84,0.96]$} & 0.002 \\
BMI (kg/m ${ }^{2}$ ) & 0.98 & {$[0.97,0.99]$} & 0.003 \\
$\Delta$ Physical Component Score* & 0.97 & {$[0.96,0.98]$} & $<.0001$ \\
$\Delta$ Mental Component Score* & 0.99 & {$[0.99,1.00]$} & 0.070 \\
\hline
\end{tabular}

*Hazard ratios were calculated corresponding with a 1 point increase in PCS/MCS score in 12 months BMI: body mass index; $\Delta$ : delta; $\mathrm{Cl}$ : confidence interval; LCL: lower control limit; UCL: upper control limit.

Table 7.9 Hazard Ratios for hospitalization in patients with $\geq 2$ surveys.

\begin{tabular}{llll}
\hline Parameter & Hazard Ratio & $\mathbf{9 5 \% ~ C l ~ [ L C L , ~ U C L ] ~}$ & p - value \\
\hline age & 1.00 & {$[1.00,1.01]$} & 0.010 \\
male & 0.89 & {$[0.83,0.95]$} & 0.000 \\
Ethnicity: White & 0.99 & {$[0.92,1.07]$} & 0.812 \\
Ethnicity: Hispanic & 0.91 & {$[0.83,1.01]$} & 0.078 \\
Vintage (years) & 1.00 & {$[0.99,1.01]$} & 0.572 \\
(First) albumin (g/dI) & 0.77 & {$[0.70,0.84]$} & $<.0001$ \\
(First) creatinine (mg/dl) & 0.99 & {$[0.97,1.00]$} & 0.081 \\
(First) Physical Component Score & 0.98 & {$[0.98,0.98]$} & $<.0001$ \\
(First) Mental Component Score & 1.00 & {$[0.99,1.00]$} & 0.015 \\
$\Delta$ Physical Component Score* & 0.99 & {$[0.98,0.99]$} & $<.0001$ \\
$\Delta$ Mental Component Score* & 1.00 & {$[0.99,1.00]$} & 0.007 \\
\hline
\end{tabular}

*Hazard ratios were calculated corresponding with a 1 point increase in PCS/MCS score in 12 months $\Delta$ : delta; $\mathrm{Cl}$ : confidence interval; LCL: lower control limit; UCL: upper control limit.

\section{DISCUSSION}

This study assessed the relation between changes in HRQOL domains, hospitalization and mortality, as well as important clinical and laboratory parameters in the same patients over a well-defined time period in a large cohort of patients.

In addition to studying the dynamics of $\mathrm{HRQOL}$, we also studied the associations of $\mathrm{HRQOL}$ in a cross-sectional analysis. In agreement to the existing literature ${ }^{2,7}$, predominantly nutritional parameters were related to $\mathrm{HRQOL}$, especially to PCS scores. We observed that 
NLR as a marker of inflammation was related to PCS scores, whereas in the meta-analysis of Spiegel et al. the relation between inflammatory markers and PCS scores were relatively small ${ }^{8}$. Subdividing patients by age groups showed that MCS scores tended to be higher in older patients as compared to younger patients, which was in agreement with previous literature ${ }^{3,26}$. Possibly this can be explained by different life expectations, and a different acceptance of the illness role in elderly as compared to younger patients. As expected, PCS scores were significantly higher in younger patients ( $<50$ years) as compared to patients over 50 years of age, with a significant decline of PCS scores by different age categories. In general, correlates between biochemical and clinical parameters and MCS scores, as well as other domains were less strong as compared to PCS scores ${ }^{27-29}$.

Changes in HRQOL over time were not significant for the whole patient group, although additional analyses showed that when divided into subgroups, relatively large changes in PCS and MCS scores could be observed. Earlier studies using the Short Form-36 HRQOL questionnaires suggested that changes in PCS and MCS scores between 2 and 3 points were clinically meaningful ${ }^{19,24}$. Despite the lack of significant changes in PCS and MCS scores over time for the whole group, a minimum of a 2-point change $(<-2$ or $>2)$ in both PCS as well as MCS scores was observed in almost $80 \%$ of the patients, suggesting strong dynamics in HD patients' HRQOL over time, which average out in the entire group.

Changes in HRQOL were mainly associated with changes in nutritional parameters, such as serum creatinine and enPCR. The strength of the association between changes in biochemical and clinical parameters and HRQOL was however relatively small. The parameter that showed the strongest correlation with changes in PCS scores in HD patients over time was serum albumin. Whereas serum albumin was influenced by inflammation and malnutrition ${ }^{30-32}$, serum creatinine, which was not only affected by dialysis dose ${ }^{33}$ and residual renal function ${ }^{34}$, was also strongly related to lean body mass (LBM) ${ }^{35}$. Moreover, LBM has a strong association with muscle strength, and indirectly with exercise capacity ${ }^{36}$. A low exercise capacity and physical performance were associated with a reduced $\mathrm{HRQOL}^{37}$. Thus, one could hypothesize that a positive relation between changes HRQOL and nutritional parameters reflects an improved overall health status as well as an increased physical performance. Future studies are needed to address there relations in more detail.

In contrast to the strong association between changes in nutritional parameters and changes in $\mathrm{HRQOL}$, the relation with changes in NLR as a parameter of inflammation was less strong in the cross-sectional analysis. Although conjectural, one explanation might be that changes in inflammatory status, above its background level, are more likely to be associated with acute events that have a less long-standing impact on HRQOL.

A novel observation is the relation between changes in serum sodium concentration and changes in PCS scores. Previous studies already showed that low sodium concentrations were related to increased mortality in chronic conditions like congestive heart failure ${ }^{3,38,39}$. Some of the speculative mechanisms behind the inverse relation between changes in serum 
sodium levels are concomitant congestive heart failure, overhydration, inflammation or the sick cell syndrome, in which low sodium levels are associated with malnutrition ${ }^{40,41}$.

As for outcome, changes in PCS scores were independent predictors for hospitalization and mortality after adjustment for clinical and demographic parameters. Even minor changes in the PCS scores showed to be associated with risk of hospitalization, where time to first hospitalization was prolonged with 1.4 percent when PCS scores are increased with only 1 point in 12 months. Additionally, mortality risk seemed to be reduced by 2.3 percent when PCS scores increased only by 1 point in 12 months. Our findings indicate that a repeated assessment of HRQOL presents, next to its role as an indicator of the patients' wellbeing, important multidimensional information to the conventional focus on biochemical parameters or dialysis efficacy.

This study had several limitations. One of the drawbacks of the study was its retrospective design. Also, the study was conducted only in HD patients regardless of the underlying causes for ESRD. Also, there might be a selection bias of slightly 'healthier' patients who survived for at least 12 months and who consented to have repeated surveys done. Although both changes in HRQOL as well as changes in biochemical parameters over time were studied, no data regarding C-reactive protein were present, although recent evidence suggests that NLR can be used as a surrogate marker of inflammation ${ }^{42}$.

\section{CONCLUSIONS}

Our findings stressed the importance of changes in HRQOL, as well as the clinical assessment of HRQOL in dialysis patients. Changes in HRQOL, especially changes in PCS scores, are related to changes in nutritional parameters but are also an independent predictor of outcome. In addition to its role in reflecting the patients' well-being, repeated assessment of HRQOL adds to a multidimensional view of the patient in a simple and noninvasive way. Future studies should address whether therapeutic interventions based on HRQOL measurements may lead to improved patient outcomes. 


\section{REFERENCES}

1. Mazairac AH, de Wit GA, Penne EL, van der Weerd NC, de Jong B, Grooteman MP, et al. Changes in quality of life over time--Dutch haemodialysis patients and general population compared. Nephrol Dial Transplant 2011;26:1984-1989.

2. Walters BA, Hays RD, Spritzer KL, Fridman M,Carter WB. Health-related quality of life, depressive symptoms, anemia, and malnutrition at hemodialysis initiation. Am J Kidney Dis 2002;40:1185-1194.

3. DeOreo PB. Hemodialysis patient-assessed functional health status predicts continued survival, hospitalization, and dialysis-attendance compliance. Am J Kidney Dis 1997;30:204-212.

4. Mapes DL, Bragg-Gresham JL, Bommer J, Fukuhara S, McKevitt P, Wikstrom B, et al. Healthrelated quality of life in the Dialysis Outcomes and Practice Patterns Study (DOPPS). Am J Kidney Dis 2004;44:54-60.

5. Lowrie EG, Curtin RB, LePain N,Schatell D. Medical outcomes study short form-36: a consistent and powerful predictor of morbidity and mortality in dialysis patients. Am J Kidney Dis 2003;41:1286-1292.

6. Lopes AA, Bragg-Gresham JL, Satayathum S, McCullough K, Pifer T, Goodkin DA, et al. Healthrelated quality of life and associated outcomes among hemodialysis patients of different ethnicities in the United States: the Dialysis Outcomes and Practice Patterns Study (DOPPS). Am J Kidney Dis 2003;41:605-615.

7. Kalantar-Zadeh K, Kopple JD, Block G,Humphreys MH. Association among SF36 quality of life measures and nutrition, hospitalization, and mortality in hemodialysis. J Am Soc Nephrol 2001;12:2797-2806.

8. Spiegel BM, Melmed G, Robbins S,Esrailian E. Biomarkers and health-related quality of life in end-stage renal disease: a systematic review. Clin J Am Soc Nephrol 2008;3:1759-1768.

9. Avramovic M,Stefanovic V. Health-related quality of life in different stages of renal failure. Artif Organs 2012;36:581-589.

10. Singh AK, Szczech L, Tang KL, Barnhart H, Sapp S, Wolfson M, et al. Correction of anemia with epoetin alfa in chronic kidney disease. N Engl J Med 2006;355:2085-2098.

11. Drueke TB, Locatelli F, Clyne N, Eckardt KU, Macdougall IC, Tsakiris D, et al. Normalization of hemoglobin level in patients with chronic kidney disease and anemia. N Engl J Med 2006;355:2071-2084.

12. Pfeffer MA, Burdmann EA, Chen CY, Cooper ME, de Zeeuw D, Eckardt KU, et al. A trial of darbepoetin alfa in type 2 diabetes and chronic kidney disease. N Engl J Med 2009;361:20192032.

13. Locatelli F,Del Vecchio L. Haemoglobin levels and health-related quality of life: a neglected hard end point. Nephrol Dial Transplant 2014;29:1272-1274.

14. Lacson E, Jr., Xu J, Lin SF, Dean SG, Lazarus JM,Hakim R. Association between achievement of hemodialysis quality-of-care indicators and quality-of-life scores. Am J Kidney Dis 2009;54:1098-1107. 
15. Cruz MC, Andrade C, Urrutia M, Draibe S, Nogueira-Martins LA,Sesso Rde C. Quality of life in patients with chronic kidney disease. Clinics (Sao Paulo) 2011;66:991-995.

16. Usvyat LA, Barth C, Bayh I, Etter M, von Gersdorff GD, Grassmann A, et al. Interdialytic weight gain, systolic blood pressure, serum albumin, and C-reactive protein levels change in chronic dialysis patients prior to death. Kidney Int 2013;

17. Gabbay E, Meyer KB, Griffith JL, Richardson MM,Miskulin DC. Temporal trends in healthrelated quality of life among hemodialysis patients in the United States. Clin J Am Soc Nephrol 2010;5:261-267.

18. Merkus MP, Jager KJ, Dekker FW, De Haan RJ, Boeschoten EW,Krediet RT. Quality of life over time in dialysis: the Netherlands Cooperative Study on the Adequacy of Dialysis. NECOSAD Study Group. Kidney Int 1999;56:720-728.

19. Wu AW, Fink NE, Marsh-Manzi JV, Meyer KB, Finkelstein FO, Chapman MM, et al. Changes in quality of life during hemodialysis and peritoneal dialysis treatment: generic and disease specific measures. J Am Soc Nephrol 2004;15:743-753.

20. Hays RD, Kallich JD, Mapes DL, Coons SJ,Carter WB. Development of the kidney disease quality of life (KDQOL) instrument. Qual Life Res 1994;3:329-338.

21. Feeny D, Furlong W, Boyle M,Torrance GW. Multi-attribute health status classification systems. Health Utilities Index. Pharmacoeconomics 1995;7:490-502.

22. Lacson E, Jr., Xu J, Lin SF, Dean SG, Lazarus JM,Hakim RM. A comparison of SF-36 and SF-12 composite scores and subsequent hospitalization and mortality risks in long-term dialysis patients. Clin J Am Soc Nephrol 2010;5:252-260.

23. Ware JE, Snow SK, Kosinski M, Gandek B. SF-36 Health Survey Manual and Interpretation Guide, Boston, The Health Institute, New England Medical Center. 1993

24. Ware JE, Kosinski M, Keller SD. SF-36 Physical and Mental Health Summary Scales: A User's Manual, 2nd Ed., Boston, The Health Institute, New England Medical Center. 1994

25. Fukuhara S, Lopes AA, Bragg-Gresham JL, Kurokawa K, Mapes DL, Akizawa T, et al. Healthrelated quality of life among dialysis patients on three continents: the Dialysis Outcomes and Practice Patterns Study. Kidney Int 2003;64:1903-1910.

26. Mittal SK, Ahern L, Flaster E, Maesaka JK,Fishbane S. Self-assessed physical and mental function of haemodialysis patients. Nephrol Dial Transplant 2001;16:1387-1394.

27. Allen KL, Miskulin D, Yan G, Dwyer JT, Frydrych A, Leung J, et al. Association of nutritional markers with physical and mental health status in prevalent hemodialysis patients from the HEMO study. J Ren Nutr 2002;12:160-169.

28. Tanaka M, Yamazaki S, Hayashino Y, Fukuhara S, Akiba T, Saito A, et al. Hypercalcaemia is associated with poor mental health in haemodialysis patients: results from Japan DOPPS. Nephrol Dial Transplant 2007;22:1658-1664.

29. Kusek JW, Greene P, Wang SR, Beck G, West D, Jamerson K, et al. Cross-sectional study of health-related quality of life in African Americans with chronic renal insufficiency: the African American Study of Kidney Disease and Hypertension Trial. Am J Kidney Dis 2002;39:513-524. 
30. Yeun JY,Kaysen GA. Factors influencing serum albumin in dialysis patients. Am J Kidney Dis 1998;32:S118-125.

31. Odamaki M, Kato A, Takita T, Furuhashi M, Maruyama Y, Yonemura K, et al. Role of soluble receptors for tumor necrosis factor alpha in the development of hypoalbuminemia in hemodialysis patients. Am J Nephrol 2002;22:73-80.

32. Kopple JD. McCollum Award Lecture, 1996: protein-energy malnutrition in maintenance dialysis patients. Am J Clin Nutr 1997;65:1544-1557.

33. Kaysen GA, Chertow GM, Adhikarla R, Young B, Ronco C, Levin NW. Inflammation and dietary protein intake exert competing effects on serum albumin and creatinine in hemodialysis patients. Kidney Int 2001;60:333-340.

34. Fouque D, Vennegoor M, ter Wee P, Wanner C, Basci A, Canaud B, et al. EBPG guideline on nutrition. Nephrol Dial Transplant 2007;22 Suppl 2:ii45-87.

35. Baxmann AC, Ahmed MS, Marques NC, Menon VB, Pereira AB, Kirsztajn GM, et al. Influence of muscle mass and physical activity on serum and urinary creatinine and serum cystatin $C$. Clin J Am Soc Nephrol 2008;3:348-354.

36. van den Ham EC, Kooman JP, Schols AM, Nieman FH, Does JD, Franssen FM, et al. Similarities in skeletal muscle strength and exercise capacity between renal transplant and hemodialysis patients. Am J Transplant 2005;5:1957-1965.

37. Brenner I. Exercise performance by hemodialysis patients: a review of the literature. Phys Sportsmed 2009;37:84-96.

38. Levy WC, Mozaffarian D, Linker DT, Sutradhar SC, Anker SD, Cropp AB, et al. The Seattle Heart Failure Model: prediction of survival in heart failure. Circulation 2006;113:1424-1433.

39. Balling L, Schou M, Videbaek L, Hildebrandt P, Wiggers H,Gustafsson F. Prevalence and prognostic significance of hyponatraemia in outpatients with chronic heart failure. Eur J Heart Fail 2011;13:968-973.

40. Flear $\mathrm{CT}$,Singh $\mathrm{CM}$. The sick cell concept and hyponatremia in congestive heart failure and liver disease. Lancet 1982;2:101-102.

41. Flear CT, Gill GV,Burn J. Hyponatraemia: mechanisms and management. Lancet 1981;2:26-31.

42. Okyay GU, Inal S, Onec K, Er RE, Pasaoglu O, Pasaoglu H, et al. Neutrophil to lymphocyte ratio in evaluation of inflammation in patients with chronic kidney disease. Ren Fail 2013;35:29-36. 



\section{CHAPTER 8}

GENERAL DISCUSSION AND SUMMARY 


\section{GENERAL DISCUSSION}

This thesis focused on body composition (BC), physical activity (PA) and health-related quality of life (HRQOL) in stage 5 chronic kidney disease (CKD-5) non-dialysis and dialysis patients. Moreover, the transition period between the CKD-5 non-dialysis phase and the first six months of starting dialysis were studied. This in contrast with previous studies, which mainly studied the above mentioned parameters from three months after the start of dialysis, due to the fact that at that point in time the patient is believed to have achieved a stable clinical situation. However, the less well studied transition period from the CKD-5 non-dialysis phase to the initiation of dialysis is one of the most critical periods for end-stage renal disease (ESRD) patients ${ }^{1,2}$. On one hand, dialysis will partly reverse uremic symptomatology, on the other hand, the patient becomes dependent on medical technology in order to maintain life, with the help of a treatment that may have pronounced physiological and psychological effects. Moreover, previous research showed that the first 90-120 days after starting hemodialysis (HD) therapy is associated with increased risk of mortality ${ }^{3-5}$, and that approximately 35 percent of the mortality during the first year occurs in the first 90 days after the start of dialysis ${ }^{3}$. Therefore, it is important to get more insight in the time course of various clinically relevant parameters early after the start of HD, in order to provide a better understanding of the risk associated with the early transition period following initiation of dialysis treatment. CHAPTER 2 provides a general literature overview on phenotypic changes, with special attention for cardiovascular and nutritional parameters during the first year of dialysis treatment.

The first topic of the thesis, discussed in CHAPTER 3, relates to the assessment of BC. Protein energy wasting (PEW), defined as "the state of decreased body stores of protein and energy fuels", is very common in dialysis patients ${ }^{6}$. The diagnosis of PEW is based on criteria such as low body weight, low protein and energy levels, and loss of muscle mass ${ }^{6}$. As such, there is a need for an objective assessment of $\mathrm{BC}$. Whereas various technologies are available to assess $\mathrm{BC}$, such as computed tomography (CT), dual-energy x-ray absorptiometry (DEXA), and multi resonance imaging (MRI), none of these are practical to use in a busy clinical environment. Bioimpedance analysis, however, is operator independent and easy to use on a bedside setting, and has been used for nutritional assessment and for BC assessment in studies in dialysis patients ${ }^{7}$. Multi-frequency (MF) bioimpedance analysis is, in theory, able to distinguish between extracellular (ECW) and intracellular water (ICW), and estimates BC as a 2-compartment (2-C) model by calculating fat free mass (FFM) and fat mass (FM) ${ }^{8}$. Nevertheless, variations in a patient's hydration state may have a strong influence on the prediction of $\mathrm{FFM}^{9,10}$. A more recent prediction model was validated by Chamney et al. in which also fluid overload (overhydration: $\mathrm{OH}$ ) is estimated next to $\mathrm{FFM}$ and $\mathrm{FM}^{9}$. This 3-compartment (3-C) model is used by the body composition monitor ( $\mathrm{BCM}$ ) and divides the body into the following compartments; and a separate component for $\mathrm{OH}$. In this model, ATM is assumed to consist of adipose tissue and adipose water, both hydrated and non- 
hydrated tissue, in contrast with the $2-\mathrm{C}$ model, were FM consists only of adipose tissue (figure 8.1).

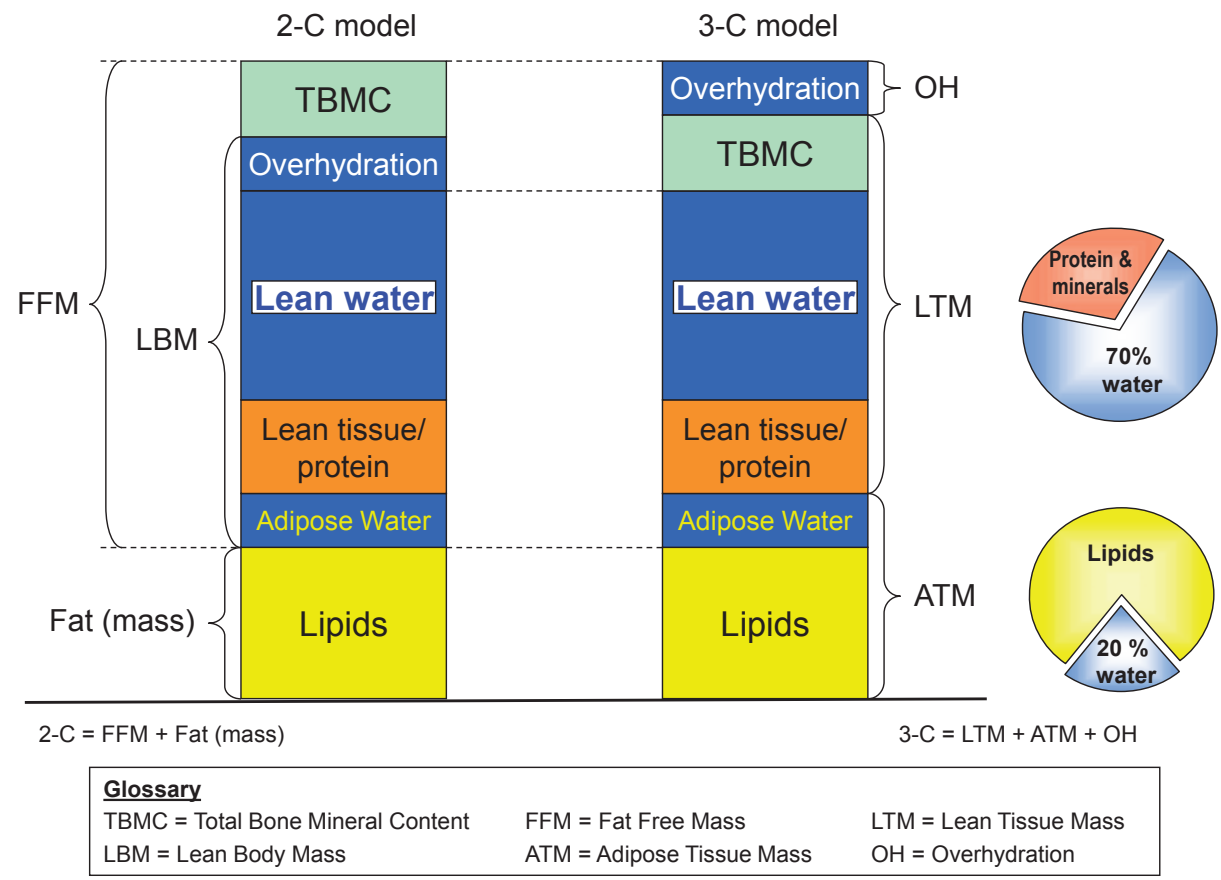

Figure 8.1 Distribution of body composition compartments ${ }^{11}$.

Thus, in the 3-C model the hydration component of ATM is considered, this in contrast with FM of the 2-C model, were this hydration component is not included. In the LTM compartment no excess $\mathrm{ECW}(\mathrm{OH})$ is included, in contrast with FFM of the $2-\mathrm{C}$ model were $\mathrm{OH}$ is included in this component ${ }^{9}$. When comparing $\mathrm{BC}$ estimated by the 2-C and 3-C model significant differences between both models were observed, which could partly be explained by the presence of $\mathrm{OH}$ in our patient group, since measurements were performed before dialysis. Also the consideration of body mass index (BMI) in the estimation of body compartments might account for some remaining difference between the 2-C and 3-C models ${ }^{12}$.

The differences between the $2-\mathrm{C}$ and $3-\mathrm{C}$ model stress out the need for population-based reference values for the $3-\mathrm{C}$ model. Therefore, reference values from Wieskotten et al., which were specifically developed for the 3-C model, were used ${ }^{13}$. These values showed that a large percentage of our patient group had a lean tissue index (LTI) (LTM corrected for height) below age-matched reference values, despite the fact that BMI was in general not decreased in the studied population. In contrast, fat tissue index (FTI) (ATM corrected for height) was above reference values in a substantial percentage of patients, suggesting the presence of sarcopenic obesity ${ }^{14}$ in a significant percentage of this patient group. In recent literature, the term sarcopenic obesity has been used to define the loss of LTM while FM 
is preserved or even increased ${ }^{14}$. In chapter 3 , it was shown that FTI was above reference values in a substantial percentage of dialysis patients, as compared with reference ranges for age-matched healthy controls.

The question is whether the increase in FM observed in prevalent dialysis patients is actually detrimental or protective. A recent study of Marcelli et al. showed that a low LTI and FTI, and specifically a combination of both, was associated with poorer survival as compared with a LTI and FTI within reference ranges ${ }^{15}$. Whereas this is not a proof for a protective effect of higher FM, the results clearly show that a reduced FM is associated with adverse outcomes.

Next to the assessment of $\mathrm{BC}$, it is important to include functional tests in the assessment of dialysis patients, as these also provide important information for clinical decision making, and because of their relation to outcome ${ }^{16}$. Functional tests, such as hand-grip strength (HGS) and the four meter walking test, are commonly used tests which are respectively used in the assessment of sarcopenia ${ }^{17,18}$ (loss of skeletal muscle mass and strength ${ }^{14}$ ), physical performance, or frailty (syndrome characterized by multiple pathologies associated with aging, such as weight loss, fatigue, weakness, low activity, slow motor performance, and balance and gait abnormalities ${ }^{19}$ ). Since HGS was strongly associated with $\mathrm{BC}$, assessed by bioimpedance (in both the 2-C and 3-C model), and significant associations were observed between HGS and results of the four meter walking test, it is clear that BC and physical function are related. Moreover, it should be emphasized that these simple, noninvasive and non-time consuming techniques may be of value in the early diagnosis of sarcopenia and/ or reduced physical performance in dialysis patients. This could facilitate interventions at an earlier point in time before the development of clinical symptoms.

CHAPTER 4 mainly focused on PA, BC and physical performance in CKD-5 patients, in relation to the stage of renal failure and the effects of starting dialysis. Previous studies showed associations between the sedentary lifestyle of dialysis patients and an increased risk of hospitalization and mortality ${ }^{20,21}$. Both PA and physical performance are low in dialysis patients leading to a sedentary lifestyle ${ }^{22,23}$. Other reports suggest that PA is already low in the CKD-5 non-dialysis phase, possibly due to the fatigue associated with advanced renal failure and the presence of comorbid disease, but possibly also to pre-existent lifestyle factors ${ }^{24}$. A study in elderly nursing home patients showed a sharp decline in functional status following the start of dialysis ${ }^{25}$.

The aim of this chapter was to compare PA and BC between CKD-5 non-dialysis patients, dialysis patients and healthy controls, and to assess the effects of the start of dialysis on $\mathrm{PA}$ and BC. Moreover, the relation between PA and BC was assessed, which is of special relevance given the relation between both physical inactivity as well as low LTI with mortality in ESRD patients ${ }^{15,20,21}$. This chapter showed that PA, measured by the Sensewear device, which is a field test instead of the more commonly used self-reported questionnaires, was already lower in the CKD-5 non-dialysis phase as compared with healthy age-matched 
controls, and not different from dialysis patients. With regard to BC, LTI was lower and FTI was higher in dialysis patients as compared with CKD-5 non-dialysis patients as well as with healthy controls. However, BC was not different between CKD-5 non-dialysis patients and healthy controls. To study the effect of starting dialysis, CKD-5 non-dialysis patients were followed into the first six months of dialysis therapy. The results of this chapter showed modest improvements for PA and physical performance. These findings are in some contrast with findings of Kurella Tamura et al. who described a 'substantial and sustained decline in functional status' ${ }^{25}$. Nevertheless, the study population of Kurella Tamura et al. consisted mostly of frail elderly people in a nursing home environment instead of relatively young and possibly less frail patients as were included in our study. Moreover, physical performance and functional status are to some degree different constructs. In addition, no changes were observed in BC over the six month time period after the start of dialysis. However, a two year follow-up study of Marcelli et al. did found increases in FTI accompanied with decreases in LTI after the initiation of dialysis treatment ${ }^{26}$, suggesting a longer follow-up period is needed to get more insight on the effects of dialysis initiation on $\mathrm{BC}$.

Regarding the associations between PA and $\mathrm{BC}$, the main finding was that PA was inversely related to FTI, which is of relevance given the high prevalence of FTI levels above the $90^{\text {th }}$ percentile in dialysis patients, as shown in chapter 2. Contrastingly, despite a tending $(p=0.064)$, LTI was not significantly associated with parameters of PA. The relation between PA and BC may also be of relevance given the recent findings of Marcelli et al. , who showed that in the first two years of dialysis, $\mathrm{FTI}$, assessed by bioimpedance, increased by $0.95 \mathrm{~kg} / \mathrm{m}^{2}$ whereas LTI decreased by $0.4 \mathrm{~kg} / \mathrm{m}^{226}$. Whether physical inactivity is indeed the major driver for "sarcopenic obesity" in dialysis patients should be investigated in future longitudinal studies. Overall, the findings of this study underscore the importance for introducing PA programs, which should be introduced to patients in the CKD-5 non-dialysis phase already.

Next to physical inactivity, there are various other factors that influence BC in dialysis patients. One under recognized factor may be seasonality. Biological rhythms play an important role in human physiology. Whereas by far the most emphasis in the literature is paid to circadian rhythms, also seasonal variations may be highly relevant. For example, it is known that dietary intake, PA, immune function, BC and even mortality follow seasonal rhythms in the general population ${ }^{27,28}$. Usvyat et al. later showed seasonal variations in blood pressure, inter-dialytic weight gain (IDWG) and mortality in a large cohort of dialysis patients $^{29}$. In CHAPTER 5 seasonal variations in BC in dialysis patients were studied. The results of this chapter showed significant seasonal variations in $\mathrm{BC}$, with higher FM during winter and higher LTM during the summer period. Paradoxically, ECW and $\mathrm{OH}$ were actually highest during summer, which is in contrast to lower IDWG and pre-dialysis systolic blood pressure during this season. The determinants and clinical relevance of these variations should be addressed in future studies. 
In CHAPTER 6, HRQOL was studied. Next to the previously discussed parameters such as PA and BC, which affect outcome, also low HRQOL is associated with increased risk of hospitalization and mortality in dialysis patients ${ }^{30-35}$. Previous studies showed that HRQOL is low in dialysis patients as compared with the general population ${ }^{30,36,37}$. Also in CKD5 non-dialysis patients a reduction in HRQOL is observed as compared with the general population ${ }^{38-40}$. However, it is not known if HRQOL is different between dialysis patients and CKD-5 non-dialysis patients. Due to the invasiveness of starting dialysis treatment HRQOL may decrease, whereas it might improve due to the partial resolution of uremic symptoms. Nevertheless, a comparative study between CKD-5 non-dialysis and dialysis patients, or a longitudinal study following the start of dialysis before dialysis initiation has not been performed yet.

Firstly, HRQOL was compared between CKD-5 non-dialysis and dialysis patients and healthy controls. The results of this chapter showed that physical component summary (PCS), and mental component summary (MCS) scores, as measures for HRQOL, are already significantly lower in the CKD-5 non-dialysis phase as compared with healthy controls, but not different from dialysis patients. Secondly, when studying longitudinal changes from the CKD-5 nondialysis phase until six months after the start of dialysis, no significant changes in HRQOL over a six month period of time were found. The results of this chapter suggest that the start of dialysis had no major effects on HRQOL, at least not when assessed by the present methodology, and that reduced quality of life appears to be primarily related to the severe renal disease per se.

Since a large international cohort study observed a significant relation between PA and $\mathrm{HRQOL}$ in maintenance dialysis patients ${ }^{41}$ also the association between HRQOL and PA was studied. However, instead of self-reported PA, objective methods were used to assess PA. Results in this chapter showed an association between the physical domain of health (PCS) and PA, further underscoring the importance of PA programs in both CKD-5 non-dialysis and dialysis patients.

In CHAPTER 7, the prognostic value and potential determinants of HRQOL were further investigated. To interpret alterations in HRQOL it is important to identify potentially modifiable factors, such as nutritional parameters. Previous studies showed strong relations between nutritional biomarkers like albumin and creatinine and $\mathrm{HRQOL}{ }^{42,43}$. However, also in this field of work most studies have cross-sectional study designs, or studied trends in HRQOL at different time periods with varying patient cohorts ${ }^{36,44}$. Only few studies followed HRQOL in HD patients over time in the same patients ${ }^{45,46}$.

In this chapter, the dynamics of HRQOL over time, as well as determinants of changes in HRQOL were assessed in in a large US patient cohort. Firstly, a cross-sectional analysis in 77.848 HD patients showed that MCS scores seemed to be higher in older patients ( $>50$ years) as compared to younger patients ( $<50$ years), which is possibly due to the fact that older patients might have different life expectations and/or a different acceptance of 
the illness role in elderly as compared to younger patients. In contrast, PCS scores were significantly higher in younger patients. Secondly, changes in HRQOL were assessed in 8.339 of these HD patients over a one-year time period. MCS and PCS scores did not change significantly over this time period. However, when taking the clinically meaningful 2-point change in HRQOL scores in consideration, changes were observed in almost 80 percent of the patients, suggesting strong dynamics in HRQOL over time. Thirdly, the relation between changes in HRQOL and both hospitalization and mortality was assessed. These findings showed that changes in HRQOL, and especially changes in PCS scores, are related to changes in nutritional parameters, such as albumin and creatinine, but are also independent predictors of outcome. In conclusion, these outcomes showed that repeated assessment of HRQOL add a multidimensional view in reflecting the patient' well-being in a simple and noninvasive way.

\section{CONCLUSIONS}

Physical inactivity is evidently present before the start of dialysis. A recent study showed that lower PA is associated with microalbuminuria, even without a decline in kidney function ${ }^{47}$. These findings suggest that the influence of CKD on physical inactivity starts very early. In contrast with our expectations, the start of dialysis itself did only lead to modest changes in PA in this patient group, regardless of the partial reversal in the uremic state.

Whereas we did not observe changes in $\mathrm{BC}$ in the first six months after the start of dialysis, LTI was shown to be significantly lower, and FTI to be significantly higher in dialysis patients as compared with CKD-5 non-dialysis patients. Our findings, and those of Marcelli et al., suggest that alterations in $\mathrm{BC}$ take place over a longer period of time after the start of dialysis, which might eventually lead to a phenomenon called 'sarcopenic obesity' in dialysis patients. It is likely that low PA is involved in this phenomenon, given the inverse association between PA and FTI. Nevertheless, it should be recognized that the longitudinal findings are based on data of an ongoing study. For this thesis only the first six months after the start of dialysis were included. Nonetheless, the transition period from CKD-5 non-dialysis phase into the first months after the start of dialysis is critical in terms of excess mortality, and given the fact that this period is characterized by critical pathophysiological and psychological consequences. Nevertheless, follow up over more prolonged periods of time, as is planned in follow up studies, is necessary to study the effects of starting dialysis in more detail. Regarding to clinical considerations, it should be emphasized that PA programs for CKD patients should be routinely implemented in patient care, as has also been advocated in previous studies ${ }^{48,49}$. This does not only hold true for the dialysis phase, but also in the earlier stages of $C K D^{50}$. Nevertheless, such programs are expensive and not easy to realize for larger patient groups. Therefore, in the future, individual trainings possibilities for patients should be stimulated, such as cycle-ergometry during dialysis sessions, or exercise in the patients' home-based situation, as has been shown to improve cardiopulmonary fitness and $B C$ in other patient groups ${ }^{51}$. Nevertheless, there is yet limited experience in renal patients 
with these home centered programs. Modern technology, such as activity trackers, could facilitate exercise programs for patients on a personal level to remind patients to move and stay active. So, despite the fact that the Sensewear armband uses input from multiple sensors, which increases the risk of measurement errors ${ }^{52}$, it recently has been shown that multidimensional PA feedback using graphics and visualizations may be very motivational, and support behavioral changes in patients with increased risk of chronic diseases ${ }^{53}$. Therefore, such interventions providing multidimensional feedback might be a very important future possibility to increase PA in CKD patients, and possibly lower the risk for physical disability, frailty and their associated complications. Moreover, such interventions also carry the potential for improving the low HRQOL in this patient group, adverse changes in $\mathrm{BC}$ and subsequently the risk for hospitalization and mortality. This stresses out the need for future (intervention) studies to investigate these options. 


\section{REFERENCES}

1. Mclntyre CW, Rosansky SJ. Starting dialysis is dangerous: how do we balance the risk? Kidney Int 2012;82:382-387.

2. Kooman JP, Usvyat L, van der Sande FM, Thijssen S, Levin N, Leunissen KM, et al. 'Time and time again': oscillatory and longitudinal time patterns in dialysis patients. Kidney Blood Press Res 2012;35:534-548.

3. Noordzij M,Jager KJ. Increased mortality early after dialysis initiation: a universal phenomenon. Kidney Int 2014;85:12-14.

4. Robinson BM, Zhang J, Morgenstern H, Bradbury BD, Ng LJ, McCullough KP, et al. Worldwide, mortality risk is high soon after initiation of hemodialysis. Kidney Int 2014;85:158-165.

5. de Jager DJ, Grootendorst DC, Jager KJ, van Dijk PC, Tomas LM, Ansell D, et al. Cardiovascular and noncardiovascular mortality among patients starting dialysis. Jama 2009;302:1782-1789.

6. Fouque D, Kalantar-Zadeh K, Kopple J, Cano N, Chauveau P, Cuppari L, et al. A proposed nomenclature and diagnostic criteria for protein-energy wasting in acute and chronic kidney disease. Kidney Int 2008;73:391-398.

7. Yuste C, Abad S, Vega A, Barraca D, Bucalo L, Perez-de Jose A, et al. Assessment of nutritional status in haemodialysis patients. Nefrologia 2013;33:243-249.

8. Kyle UG, Bosaeus I, De Lorenzo AD, Deurenberg P, Elia M, Manuel Gomez J, et al. Bioelectrical impedance analysis-part II: utilization in clinical practice. Clin Nutr 2004;23:1430-1453.

9. Chamney PW, Wabel P, MoissI UM, Muller MJ, Bosy-Westphal A, Korth O, et al. A whole-body model to distinguish excess fluid from the hydration of major body tissues. Am J Clin Nutr 2007;85:80-89.

10. Konings CJ, Kooman JP, Schonck M, van Kreel B, Heidendal GA, Cheriex EC, et al. Influence of fluid status on techniques used to assess body composition in peritoneal dialysis patients. Perit Dial Int 2003;23:184-190.

11. Wabel P. Fresenius Medical Care D GmbH, Bad Homburg, Germany.

12. Moissl UM, Wabel P, Chamney PW, Bosaeus I, Levin NW, Bosy-Westphal A, et al. Body fluid volume determination via body composition spectroscopy in health and disease. Physiol Meas 2006;27:921-933.

13. Wieskotten S MU, Chamney P, Wabel P. Reference Ranges for Human Body Composition and Fluid Overload. Fresenius Medical Care D GmbH, Bad Homburg, Germany. 2013; Available from: http://www.bcm-fresenius.com/mediafiles/information_on_reference_ranges.pdf.

14. Cruz-Jentoft AJ, Baeyens JP, Bauer JM, Boirie Y, Cederholm T, Landi F, et al. Sarcopenia: European consensus on definition and diagnosis: Report of the European Working Group on Sarcopenia in Older People. Age Ageing 2010;39:412-423.

15. Marcelli D, Usvyat LA, Kotanko P, Bayh I, Canaud B, Etter M, et al. Body composition and survival in dialysis patients: results from an international cohort study. Clin J Am Soc Nephrol 2015;10:1192-1200. 
16. Johansen KL, Chertow GM, Jin C,Kutner NG. Significance of frailty among dialysis patients. J Am Soc Nephrol 2007;18:2960-2967.

17. Lauretani F, Russo CR, Bandinelli S, Bartali B, Cavazzini C, Di lorio A, et al. Age-associated changes in skeletal muscles and their effect on mobility: an operational diagnosis of sarcopenia. J Appl Physiol 2003;95:1851-1860.

18. Santilli V, Bernetti A, Mangone M,Paoloni M. Clinical definition of sarcopenia. Clin Cases Miner Bone Metab 2014;11:177-180.

19. Fried LP, Tangen CM, Walston J, Newman AB, Hirsch C, Gottdiener J, et al. Frailty in older adults: evidence for a phenotype. J Gerontol A Biol Sci Med Sci 2001;56:M146-156.

20. Stack AG, Molony DA, Rives T, Tyson J,Murthy BV. Association of physical activity with mortality in the US dialysis population. Am J Kidney Dis 2005;45:690-701.

21. Tentori F, Elder SJ, Thumma J, Pisoni RL, Bommer J, Fissell RB, et al. Physical exercise among participants in the Dialysis Outcomes and Practice Patterns Study (DOPPS): correlates and associated outcomes. Nephrol Dial Transplant 2010;25:3050-3062.

22. Painter P. Physical functioning in end-stage renal disease patients: update 2005. Hemodial Int 2005;9:218-235.

23. Avesani CM, Trolonge S, Deleaval P, Baria F, Mafra D, Faxen-Irving G, et al. Physical activity and energy expenditure in haemodialysis patients: an international survey. Nephrol Dial Transplant 2012;27:2430-2434.

24. Gould DW, Graham-Brown MP, Watson EL, Viana JL,Smith AC. Physiological benefits of exercise in pre-dialysis chronic kidney disease. Nephrology (Carlton) 2014;19:519-527.

25. Kurella Tamura M, Covinsky KE, Chertow GM, Yaffe K, Landefeld CS,McCulloch CE. Functional status of elderly adults before and after initiation of dialysis. N Engl J Med 2009;361:1539-1547.

26. Marcelli D, Brand K, Ponce P, Milkowski A, Marelli C, Ok E, et al. Longitudinal Changes in Body Composition in Patients After Initiation of Hemodialysis Therapy: Results From an International Cohort. J Ren Nutr 2015;

27. Shephard RJ,Aoyagi Y. Seasonal variations in physical activity and implications for human health. Eur J Appl Physiol 2009;107:251-271.

28. Cold exposure and winter mortality from ischaemic heart disease, cerebrovascular disease, respiratory disease, and all causes in warm and cold regions of Europe. The Eurowinter Group. Lancet 1997;349:1341-1346.

29. Usvyat LA, Carter M, Thijssen S, Kooman JP, van der Sande FM, Zabetakis P, et al. Seasonal variations in mortality, clinical, and laboratory parameters in hemodialysis patients: a 5-year cohort study. Clin J Am Soc Nephrol 2012;7:108-115.

30. DeOreo PB. Hemodialysis patient-assessed functional health status predicts continued survival, hospitalization, and dialysis-attendance compliance. Am J Kidney Dis 1997;30:204-212.

31. Mapes DL, Lopes AA, Satayathum S, McCullough KP, Goodkin DA, Locatelli F, et al. Healthrelated quality of life as a predictor of mortality and hospitalization: the Dialysis Outcomes and Practice Patterns Study (DOPPS). Kidney Int 2003;64:339-349. 
32. Mapes DL, Bragg-Gresham JL, Bommer J, Fukuhara S, McKevitt P, Wikstrom B, et al. Healthrelated quality of life in the Dialysis Outcomes and Practice Patterns Study (DOPPS). Am J Kidney Dis 2004;44:54-60.

33. Lowrie EG, Curtin RB, LePain N,Schatell D. Medical outcomes study short form-36: a consistent and powerful predictor of morbidity and mortality in dialysis patients. Am J Kidney Dis 2003;41:1286-1292.

34. Lopes AA, Bragg-Gresham JL, Satayathum S, McCullough K, Pifer T, Goodkin DA, et al. Healthrelated quality of life and associated outcomes among hemodialysis patients of different ethnicities in the United States: the Dialysis Outcomes and Practice Patterns Study (DOPPS). Am J Kidney Dis 2003;41:605-615.

35. Kalantar-Zadeh K, Kopple JD, Block G,Humphreys MH. Association among SF36 quality of life measures and nutrition, hospitalization, and mortality in hemodialysis. J Am Soc Nephrol 2001;12:2797-2806.

36. Mazairac AH, de Wit GA, Penne EL, van der Weerd NC, de Jong B, Grooteman MP, et al. Changes in quality of life over time--Dutch haemodialysis patients and general population compared. Nephrol Dial Transplant 2011;26:1984-1989.

37. Walters BA, Hays RD, Spritzer KL, Fridman M,Carter WB. Health-related quality of life, depressive symptoms, anemia, and malnutrition at hemodialysis initiation. Am J Kidney Dis 2002;40:1185-1194.

38. Korevaar JC, Jansen MA, Merkus MP, Dekker FW, Boeschoten EW,Krediet RT. Quality of life in predialysis end-stage renal disease patients at the initiation of dialysis therapy. The NECOSAD Study Group. Perit Dial Int 2000;20:69-75.

39. Loos C, Briancon S, Frimat L, Hanesse B,Kessler M. Effect of end-stage renal disease on the quality of life of older patients. J Am Geriatr Soc 2003;51:229-233.

40. Gorodetskaya I, Zenios S, McCulloch CE, Bostrom A, Hsu CY, Bindman AB, et al. Healthrelated quality of life and estimates of utility in chronic kidney disease. Kidney Int 2005;68:2801-2808.

41. Lopes AA, Lantz B, Morgenstern H, Wang M, Bieber BA, Gillespie BW, et al. Associations of self-reported physical activity types and levels with quality of life, depression symptoms, and mortality in hemodialysis patients: the DOPPS. Clin J Am Soc Nephrol 2014;9:1702-1712.

42. Spiegel BM, Melmed G, Robbins S,Esrailian E. Biomarkers and health-related quality of life in end-stage renal disease: a systematic review. Clin J Am Soc Nephrol 2008;3:1759-1768.

43. Lacson E, Jr., Xu J, Lin SF, Dean SG, Lazarus JM,Hakim R. Association between achievement of hemodialysis quality-of-care indicators and quality-of-life scores. Am J Kidney Dis 2009;54:1098-1107.

44. Gabbay E, Meyer KB, Griffith JL, Richardson MM,Miskulin DC. Temporal trends in healthrelated quality of life among hemodialysis patients in the United States. Clin J Am Soc Nephrol 2010;5:261-267. 
45. Merkus MP, Jager KJ, Dekker FW, De Haan RJ, Boeschoten EW, Krediet RT. Quality of life over time in dialysis: the Netherlands Cooperative Study on the Adequacy of Dialysis. NECOSAD Study Group. Kidney Int 1999;56:720-728.

46. Wu AW, Fink NE, Marsh-Manzi JV, Meyer KB, Finkelstein FO, Chapman MM, et al. Changes in quality of life during hemodialysis and peritoneal dialysis treatment: generic and disease specific measures. J Am Soc Nephrol 2004;15:743-753.

47. Martens RJ, Henry RM, Houben AJ, van der Kallen CJ, Kroon AA, Schalkwijk CG, et al. Capillary Rarefaction Associates with Albuminuria: The Maastricht Study. J Am Soc Nephrol 2016;

48. Kouidi E, Grekas D, Deligiannis A,Tourkantonis A. Outcomes of long-term exercise training in dialysis patients: comparison of two training programs. Clin Nephrol 2004;61 Suppl 1:S31-38.

49. Johansen KL. Exercise in the end-stage renal disease population. J Am Soc Nephrol 2007;18:1845-1854.

50. Johansen KL,Painter P. Exercise in individuals with CKD. Am J Kidney Dis 2012;59:126-134.

51. Slaman J, Roebroeck M, van der Slot W, Twisk J, Wensink A, Stam H, et al. Can a lifestyle intervention improve physical fitness in adolescents and young adults with spastic cerebral palsy? A randomized controlled trial. Arch Phys Med Rehabil 2014;95:1646-1655.

52. Plasqui G, Bonomi AG,Westerterp KR. Daily physical activity assessment with accelerometers: new insights and validation studies. Obes Rev 2013;14:451-462.

53. Western MJ, Peacock OJ, Stathi A,Thompson D. The understanding and interpretation of innovative technology-enabled multidimensional physical activity feedback in patients at risk of future chronic disease. PLoS One 2015;10:e0126156 



\section{SAMENVATTING}




\section{NEDERLANDSE SAMENVATTING}

In deze thesis staan lichaamssamenstelling, fysieke activiteit en gezondheids-gerelateerde kwaliteit van leven bij predialyse patiënten met stadium 5 chronisch nierfalen (CKD-5) en dialyse patiënten centraal. Tevens werden de overgangsfase van predialyse naar dialyse en de eerste zes maanden na het starten van dialyse bestudeerd. Dit in tegenstelling tot eerdere studies, welke voornamelijk bovenstaande parameters bestudeerd hebben vanaf drie maanden na de start van dialyse, omdat gesuggereerd wordt dit het punt is vanaf waar patiënten klinisch stabiel zijn. Echter, de minder goed bestudeerde overgangsperiode van de predialyse fase naar de start van dialyse, is een van de meest kritieke periodes in het leven van een patiënt met eindstadium nierfalen (ESRD). Hoewel dialyse uremische klachten zal verminderen, zal de patiënt ook afhankelijk worden van medische technologie om in leven te blijven, wat zowel leidt tot psychische als fysiologische veranderingen. Eerdere studies hebben namelijk aangetoond dat in de eerste 90 tot 120 dagen na de start van hemodialyse (HD) een verhoogd risico tot overlijden bestaat, en dat ruwweg 35 procent van deze sterftegevallen in het eerste jaar na de start van dialyse al in de eerste 90 dagen plaatsvinden.

Deze bevindingen geven duidelijk weer dat het belangrijk is om meer inzicht te krijgen in de veranderingen die het eerste jaar na de start van HD plaatsvinden met betrekking tot verschillende klinisch relevante parameters, om zo meer duidelijkheid te scheppen in het risico dat starten van HD met zich meebrengt. HOOFDSTUK 2 geeft een algemeen literatuuroverzicht met betrekking tot fenotypische veranderingen na de start van HD, vooral gericht op cardiovasculaire- en voedingsparameters in het eerste jaar na de start van HD.

Het eerste onderwerp van deze thesis, welke besproken werd in HOOFDSTUK 3, heeft betrekking op het meten van lichaamssamenstelling. Protein energy wasting (PEW), welke gedefinieerd is als "een staat waarin lichaamsvoorraad van eiwitten en andere energiebronnen verminderd zijn", komt vaak voor bij dialyse patiënten. Het stellen van de diagnose 'PEW' is gebaseerd op verschillende criteria, namelijk: een laag lichaamsgewicht, lage waarden van eiwitten en andere energiebronnen en verlies van spiermassa. Om dit vast te stellen is het belangrijk om een objectieve manier te hebben om lichaamssamenstelling te meten. Er zijn verscheidene technieken welke gebruikt worden om lichaamssamenstelling te meten zoals, computed tomography (CT), dual-energy x-ray absorptiometry (DEXA), and multi resonance imaging (MRI), echter zijn deze technieken niet toepasbaar in een drukke klinische omgeving. Bio-impedantie metingen daarentegen, zijn makkelijk bedienbaar en goed toepasbaar aan het bed van de patiënt. Daarnaast werd aangetoond dat deze methode gebruikt kan worden voor de analyse van voedingsstatus en lichaamssamenstelling bij dialyse patiënten. Multi-frequency bio-impedantie analyse kan, in theorie, een verschil maken tussen extracellulair en intracellulair water en schat lichaamssamenstelling aan de hand van het twee compartimenten (2-C) model door vetvrije massa (FFM) en vet massa 
(FM) te berekenen. Echter, variatie in de hydratiestatus van een patiënt kan van grote invloed zijn op de berekening van FFM. Dit heeft er toe geleid dat Chamney et al. een nieuw model gevalideerd hebben waarbij naast FFM en FM ook overhydratie $(\mathrm{OH})$ wordt berekend. Dit drie compartimenten (3-C) model wordt gebruikt door de body composition monitor (BCM) en verdeelt het lichaam in de volgende compartimenten: vetweefsel massa (ATM), lean tissue massa (LTM) en $\mathrm{OH}$. In dit model wordt er vanuit gegaan dat ATM uit zowel vetweefsel massa en water bestaat, dit in tegenstelling tot het 2-C model, waar FM alleen uit vetweefsel bestaat (zie CHAPTER 8, figuur 8.1). Dus, in het 3-C model is er rekening gehouden met de hydratie component van ATM, welke niet meegenomen is in het 2-C model. Daarnaast is $\mathrm{OH}$ niet meegenomen in het LTM compartiment, welke in het 2-C model juist wel in het LTM compartiment zit.

Wanneer lichaamssamenstelling volgens het 2-C en 3-C model met elkaar vergeleken worden zijn significante verschillen waar te nemen tussen beide modellen. Dit kan dus gedeeltelijk verklaard worden door $\mathrm{OH}$ in de gemeten patiëntengroep, gezien deze groep gemeten is voorafgaande aan de dialyse behandeling. Ook wordt er in het 3-C model gecorrigeerd voor body mass index (BMI) bij het schatten van de verschillende compartimenten, ook dit kan leiden tot verschillen tussen het 2-C en 3-C model.

De verschillen tussen deze twee modellen hebben ertoe geleid dat Wieksotten et al. specifieke referentiewaarden ontwikkeld hebben voor het 3-C model. Deze referentiewaarden laten zien dat een hoog percentage van de gemeten patiëntengroep een lean tissue index (LTI) (LTM gecorrigeerd voor lengte) onder de normaalwaarden had vergeleken met een leeftijdsgematchte gezonde studiepopulatie, ondanks dat de BMI gelijk was. De vet tissue index (FTI) (ATM gecorrigeerd voor lengte) daarentegen, bleek hoger te zijn in een groot deel van de patiëntengroep. Dit suggereert dat een substantieel deel van deze patiëntengroep te maken heeft met 'sarcopene obesitas'. In recente literatuur wordt sarcopene obesitas gebruikt om het verlies van spiermassa met daarbij het behoud of zelfs de toename van FM aan te duiden.

De vraag is echter of een toename in FM in prevalente dialyse patiënten juist een schadelijk of een beschermend effect heeft. Een studie van Marcelli et al. heeft aangetoond dat een lage LTI of FTI, en specifiek de combinatie van beide, sterk geassocieerd is met het risico op overlijden, vergeleken met een LTI en FTI binnen de referentiewaarden. Hoewel dit geen bewijs is voor een beschermend effect van een hogere FM, laat dit wel zien dat lage waarden van FM geassocieerd zijn met een slechtere prognose.

Ook is het belangrijk gebruik te maken van functionele testen bij het beoordelen van de gezondheid van dialyse patiënten. Deze testen kunnen helpen bij het klinisch redeneren rondom de patiënt, zeker gezien de relatie met mortaliteit en morbiditeit. Testen zoals handknijpkracht en de vier meter looptest, zijn gevalideerde en vaak gebruikte methoden die gebruikt worden bij het diagnosticeren van sarcopenie (verlies van spiermassa en spierkracht), physical performance en frailty (syndroom geassocieerd met veroudering met kenmerken als: gewichtsverlies, vermoeidheid, spierzwakte, verminderde fysieke 
activiteit, lage loopsnelheid en afwijkingen in balans en looppatroon). Gezien het feit dat handknijpkracht sterk geassocieerd is met lichaamssamenstelling (gemeten met bioimpedantie (in zowel het 2-C als 3-C model)), en dat er ook significante associaties zijn gevonden tussen handknijpkracht en de vier meter looptest, geeft duidelijk weer dat er een relatie is tussen lichaamssamenstelling en physical functioning. Mede hierdoor moeten we benadrukken dat eenvoudige, tijdbesparende technieken, zoals het meten van handknijpkracht en de vier meter looptest, van grote waarde kunnen zijn bij het vroeg vaststellen van sarcopenie en een verminderde phyiscal performance bij dialyse patiënten, waardoor er dus op een eerder moment interventies kunnen worden toegepast voordat de eerste symptomen zich voordoen.

In HOOFDSTUK 4 ligt de nadruk op fysieke activiteit, lichaamssamenstelling en physical performance bij patiënten met CKD-5. Hierin wordt de relatie tussen deze parameters en het stadium van nierfalen waarin patiënten zich bevinden bestudeerd, en wordt er gekeken naar het effect van de start van dialyse. Eerdere studies hebben associaties laten zien tussen een sedentaire levensstijl en een verhoogd risico op hospitalisatie en overlijden. Zowel fysieke activiteit als physical performance is vaak laag bij dialyse patiënten, hetgeen leidt tot een sedentaire levensstijl. Andere studies laten zien dat de fysieke activiteit vaak ook al laag is in de predialyse fase. Dit kan wellicht verklaard worden door toegenomen vermoeidheid bij een verslechterde nierfunctie en het bestaan van comorbiditeit in deze patiëntengroep, maar kan daarnaast ook verklaard worden door aangeleerde leefstijlfactoren. Daarbij laat een studie bij oudere patiënten in verzorgingstehuizen een sterke afname in functionele status zien na de start van dialyse.

Dit hoofdstuk had als doel om de fysieke activiteit en lichaamssamenstelling te vergelijken tussen predialyse patiënten, dialyse patiënten en een gezonde controlegroep, en het effect van start dialyse te bestuderen op fysieke activiteit en lichaamssamenstelling. Daarnaast werd ook de relatie tussen fysieke activiteit en lichaamssamenstelling bestudeerd, dit gezien de relatie tussen mortaliteit en zowel fysieke inactiviteit en LTI bij patiënten met ESRD.

In dit hoofdstuk is fysieke activiteit gemeten met behulp van de sensewear armband. Het voordeel van dit apparaat is dat het een objectieve test is in plaats van de vaak gebruikte zelfmonitoring vragenlijsten. Hiermee werd aangetoond dat de fysieke activiteit al lager was in de predialyse fase in vergelijking met gezonde controles van dezelfde leeftijd, en dat er geen verschillen zijn met dialyse patiënten.

Wat betreft lichaamssamenstelling; LTI was lager en FTI was hoger bij dialyse patiënten vergeleken met predialyse patiënten en gezonde controles. Echter, er was geen verschil in lichaamssamenstelling tussen predialyse patiënten en gezonde controles.

Om het effect van start dialyse te bestuderen, werden predialyse patiënten bestudeerd in de eerste zes maanden na start dialyse. Na start dialyse werden bescheiden verbeteringen in fysieke activiteit en physical performance waargenomen. Deze bevindingen zijn enigszins contrasterend met bevindingen van Kurella Tamura et al., welke 'substantiële en blijvende 
vermindering in functionele status' waarnam. Echter zou dit verklaard kunnen worden door verschillen in de studie populatie. Waar in de studie van Kurella Tamura et al. voornamelijk ouderen met tekenen van frailty geïncludeerd werden die in een verzorgingstehuis verbleven, bestond onze studie populatie uit jongere mogelijk minder 'fraile' patiënten. Daarnaast zijn physical performance en functionele status twee verschillende begrippen.

Naast bovengenoemde bevindingen zijn er geen veranderingen in lichaamssamenstelling gevonden in de eerste zes maanden na start dialyse. Echter, een twee jaar follow-up studie van Marcelli et al. beschreef een toegenomen FTI met daarbij een afname in LTI na de start van dialyse, wat suggereert dat een langere follow-up periode nodig is om meer inzicht te krijgen in de effecten van start dialyse op veranderingen in lichaamssamenstelling.

Wat betreft de associatie tussen fysieke activiteit en lichaamssamenstelling; hogere mate van fysieke activiteit gaat gepaard met een lagere FTI. Dit is relevant gezien de hoge prevalentie van FTI waarden boven het $90^{\circ}$ percentiel bij dialyse patiënten, zoals aangetoond in hoofdstuk 2. Echter, ondanks een neiging, werd LTI niet significant geassocieerd met fysieke activiteit. Deze relatie is ook relevant gezien recente bevindingen in een studie van Marcelli et al. aangetoond hebben dat FTI $0.95 \mathrm{~kg} / \mathrm{m}^{2}$ stijgt, en LTI $0.4 \mathrm{~kg} / \mathrm{m}^{2}$ daalt (gemeten middels bio-impedantie) in de eerste twee jaar na start dialyse. Of fysieke inactiviteit inderdaad een van de hoofdoorzaken is van 'sarcopene obesitas' bij dialyse patiënten moet blijken uit toekomstige longitudinale studies. Desalniettemin, laten de bevindingen van deze studie zien dat het implementeren van bewegingsprogramma's voor CKD-patiënten al vroeg in het predialyse traject van groot belang kunnen zijn.

Naast fysieke activiteit zijn er ook nog andere factoren die van invloed zijn op de lichaamssamenstelling van dialyse patiënten. Seizoensverandering is een factor waar relatief weinig aandacht naar uit gaat. Biologische ritmes spelen een belangrijke rol in de menselijke fysiologie. In de literatuur gaat verreweg de meeste aandacht uit naar het circadiaan ritme, terwijl seizoenen waarschijnlijk ook een zeer relevante rol spelen. Het is bijvoorbeeld duidelijk dat voedingsinname, fysieke activiteit, immuun functie, lichaamssamenstelling en zelfs mortaliteit een seizoensgebonden ritme volgen in de algemene bevolking. Usvyat et al. hebben aangetoond dat bij dialyse patiënten ook bloeddruk, inter-dialytische gewichtstoename en mortaliteit een seizoensgebonden patroon volgen.

In HOOFDSTUK $\mathbf{5}$ werd seizoensgebonden variatie in lichaamssamenstelling bij dialyse patiënten bestudeerd. Resultaten in dit hoofdstuk hebben laten zien dat lichaamssamenstelling ook bij dialyse patiënten varieert per seizoen. Waarbij FM hoger is in de winter en LTM in de zomer. ECW en $\mathrm{OH}$ waren het hoogst in de zomer, wat echter niet te verklaren is door inter-dialytische gewichtstoename en predialyse systolische bloeddruk tijdens dit seizoen. Deze determinanten en de klinische relevantie hiervan moeten verder worden bestudeerd in toekomstige studies. 
In HOOFDSTUK 6 werd de gezondheidsgerelateerde kwaliteit van leven (HRQOL) bestudeerd. Naast bovengenoemde parameters, zoals fysieke activiteit en lichaamssamenstelling, welke gerelateerd zijn aan morbiditeit en mortaliteit, is ook een lage HRQOL geassocieerd met een verhoogd risico op hospitalisatie en mortaliteit bij dialyse patiënten. Eerdere studies hebben laten zien dat HRQOL bij zowel predialyse als dialyse patiënten laag is vergeleken met de algemene bevolking. Het is echter niet bekend of er verschillen zijn in HRQOL tussen predialyse en dialyse patiënten. Gezien de ingrijpende effecten die het starten van dialyse met zich meebrengt is het voor de hand liggend dat HRQOL verder achteruit zal gaan, echter door het verminderen van uremische klachten zou HRQOL ook kunnen verbeteren. Toch zijn er geen studies die HRQOL vergelijken tussen predialyse en dialyse patiënten, en ook de effecten van het starten van dialyse op HRQOL zijn nog niet eerder bestudeerd.

Daarom werd HRQOL in deze studie vergeleken tussen predialyse en dialyse patiënten en gezonde controles. Resultaten lieten zien dat physical component summary (PCS) en mental component summary (MCS) scores, als maat voor HRQOL, significant lager zijn bij predialyse patiënten vergeleken met gezonde controles, maar niet bij dialyse patiënten. De longitudinale analyse laat zien dat er over een periode van zes maanden na start dialyse geen significante veranderingen optreden in HRQOL. Dit suggereert dat de start van dialyse geen nadelig effect heeft op HRQOL, in ieder geval niet wanneer HRQOL gemeten wordt via de huidige methoden, maar dat een verminderde kwaliteit van leven primair gerelateerd kan worden aan de ernst van nierfalen zelf.

Gezien een grote internationale cohort studie een significante relatie heeft aangetoond tussen fysieke activiteit en HRQOL in chronische HD patiënten, is er ook in deze studie gekeken naar de associatie tussen HRQOL en fysieke activiteit. Het verschil met deze voorgaande studie is dat er in de huidige studie gebruik is gemaakt van een objectieve methode om fysieke activiteit te meten in plaats van zelf gerapporteerde fysieke activiteit door de patiënt. Resultaten wijzen uit dat er een associatie is tussen het fysieke domein van HRQOL (PCS) en fysieke activiteit. Dit benadrukt het belang van beweegprogramma's voor zowel predialyse als dialyse patiënten.

In HOOFDSTUK 7 werd de prognostische waarde en potentiële determinanten van HRQOL verder uitgediept. Om veranderingen in HRQOL beter te kunnen begrijpen is het belangrijk om factoren die beïnvloedbaar zijn, zoals voedingsparameters, te identificeren. Eerdere studies hebben sterke relaties laten zien tussen voedingsgerelateerde biomarkers, zoals albumine en kreatinine, en HRQOL. Echter zijn de meeste studies cross-sectioneel van aard, of zijn er wel op verschillende tijdstippen trends in HRQOL bestudeert, maar met verschillende cohorten. Er zijn maar enkele studies welke HRQOL over tijd opgevolgd hebben in dezelfde groep HD patiënten.

In dit hoofdstuk is de verandering van HRQOL over tijd bestudeerd in een groot patiënten cohort met patiënten uit de Verenigde Staten. Daarnaast is er gekeken welke determinanten van invloed kunnen zijn op eventuele veranderingen in HRQOL. In een cross-sectionele 
analyse van 77.848 HD patiënten werd duidelijk dat MCS scores hoger lijken te zijn bij oudere patiënten ( $>50$ jaar) vergeleken met jongere patiënten ( $<50$ jaar). Dit is mogelijk te verklaren doordat oudere patiënten beter om kunnen gaan met hun ziekte. Acceptie rondom ziekte en de daarbij horende levensverwachtingen zijn wellicht anders bij oudere patiënten vergeleken met jongere patiënten. PCS scores zijn, in tegenstelling tot MCS scores, hoger bij jongere patiënten in vergelijking met oudere patiënten.

Veranderingen gedurende één jaar in HRQOL zijn bestudeerd bij 8.339 HD patiënten uit bovengenoemd cohort. Er werden geen significante veranderingen opgemerkt in MCS en PCS scores. Wanneer er echter rekening werd gehouden met een klinisch relevante verandering van 2 punten op de HRQOL schaal, werden er in bijna 80 procent van de patiënten veranderingen opgemerkt. Dit suggereert sterke veranderingen in HRQOL over tijd.

Als laatste werden ook relaties tussen veranderingen in HRQOL en hospitalisatie en mortaliteit bestudeerd. Resultaten laten zien dat veranderingen in HRQOL, en voornamelijk veranderingen in PCS scores, gerelateerd zijn aan veranderingen in voedingsparameters, zoals albumine en kreatinine. Opmerkelijk is daarbij dat HRQOL daarnaast ook een onafhankelijke voorspeller is van hospitalisatie en mortaliteit. Hieruit kunnen we concluderen dat het herhaaldelijk meten van HRQOL een belangrijke, maar vooral ook eenvoudige en nietinvasieve manier is om het welzijn van de patiënten te beoordelen.

\section{CONCLUSIE}

Het is duidelijk dat er al sprake is van fysieke inactiviteit voor de start van dialyse. Een recente studie heeft laten zien dat fysieke activiteit geassocieerd is met microalbuminurie, zelfs wanneer er nog geen sprake is van achteruitgang van nierfunctie. Dit suggereert dat de invloed van CKD op fysieke inactiviteit al vroeg start. In tegenstelling tot onze verwachtingen, leidt de start van dialyse enkel tot een geringe toename van fysieke activiteit, ongeachte de afname van uremische klachten.

Daar waar we geen veranderingen in lichaamssamenstelling zagen in de eerste zes maanden na de start van dialyse, was LTI significant lager en FTI significant hoger bij dialyse patiënten vergeleken met predialyse patiënten. Zowel onze bevindingen, als die van Marcelli et al., suggereren dat veranderingen in lichaamssamenstelling pas optreden na een langere periode na de start van dialyse. Dit zou uiteindelijk kunnen leiden tot het fenomeen 'sarcopene obesitas' bij dialyse patiënten. Het is waarschijnlijk dat een verminderende fysieke activiteit een rol speelt in dit fenomeen, gezien de associaties tussen fysieke activiteit en FTI. Echter, longitudinale studies naar deze bevindingen zijn nog altijd lopende. Voor deze thesis zijn alleen de eerste zes maanden na start dialyse geïncludeerd in de analyses. Echter, de overgangsperiode van predialyse naar de eerste zes maanden van de dialyse behandeling is kritiek met betrekking tot een verhoogd risico op mortaliteit. Ook wordt deze periode gekenmerkt door pathofysiologische en psychologische veranderingen. Dit maakt het 
belangrijk om de start van dialyse te blijven opvolgen in de toekomst en om dit te doen voor langere periodes, zoals gepland in toekomstige follow-up studies.

Wat betreft klinische aanbevelingen; het belang van beweegprogramma's voor CKD patiënten zou meer benadrukt moeten worden. Deze zouden op een routinematige basis moeten worden geïmplementeerd in de huidige patiëntenzorg, zoals dit ook al lange tijd wordt aanbevolen in eerdere studies. Beweegprogramma's zijn niet enkel van belang voor dialyse patiënten, ook in eerdere stadia van CKD zijn deze zeer belangrijk. Echter, zulke programma's zijn duur en vaak lastig te realiseren bij grote groepen patiënten. Daarom zouden individuele trainingsmogelijkheden meer gestimuleerd moeten worden, zoals het gebruik van dialysefietsen tijdens een dialysesessie, of oefeningen doen in de thuisomgeving, gezien eerdere studies bij chronisch zieke patiënten uitgewezen hebben de cardiopulmonale fitheid en lichaamssamenstelling te verbeteren. $\mathrm{Er}$ is echter nog maar weinig informatie beschikbaar over zelfstandig trainen in de thuissituatie. Moderne technologie, zoals activiteiten trackers, zouden patiënten wellicht op persoonlijk niveau kunnen motiveren en stimuleren om actief te blijven. Ondanks het feit dat de Sensewear armband gebruikt maakt van meerdere sensoren om fysieke activiteit te monitoren, met het gevaar voor meetfouten, is recent aangetoond dat multidimensionale feedback in de vorm van grafieken en het visualiseren van de fysieke activiteit juist motiverend is voor patiënten met een verhoogd risico op chronische aandoeningen. Dit soort feedback kan dan ook een positief effect hebben op gedrag. Dit geeft het belang weer van interventies voor CKD patiënten met betrekking tot fysieke activiteit. Multidimensionale feedback bij fysieke activiteit zou mogelijk het risico op lichamelijke beperkingen, frailty en de hierbij horende complicaties kunnen verminderen. Bovendien zouden dit soort interventies HRQOL en lichaamssamenstelling kunnen verbeteren bij deze patiëntengroep, en daaropvolgend het risico op hospitalisatie en mortaliteit verlagen. Al deze bevindingen benadrukken de noodzaak om deze mogelijke interventies in toekomstige studies te onderzoeken. 

VALORISATION ADDENDUM 


\section{VALORISATION ADDENDUM}

Reports showed that at the end of 2013 approximately 3.200 .000 patients were treated for ESRD worldwide. More or less than 2.522.000 of these patients were undergoing dialysis. Thereby it was suggested that these numbers will annually increase by 6 to 7 percent $^{1}$. In 2010 chronic kidney disease (CKD) was the $18^{\text {th }}$ cause of total number of deaths worldwide, as compared with the $27^{\text {th }}$ cause in $1990^{2}$. These numbers clearly show the rapid increase of CKD worldwide. Additionally, not only the risk of mortality is high in ESRD patients, also the risk of comorbidity is very high in this patient group and has been shown to have a negatively associated with survival ${ }^{3,4}$.

Costs for hemodialysis were $\$ 87.945$ and peritoneal dialysis were $\$ 71.630$ per patient per year respectively in $2011^{5}$, and it is known that these cost per patient will rise every year. Therefore, dialysis treatment is a high economic burden.

Next to high treatment costs, the burden of disease is high in dialysis patients. Numerous studies showed impaired health-related quality of life (HRQOL) scores in dialysis patients in both physical as well as mental health ${ }^{6-9}$, which are also directly related to physical activity $(\mathrm{PA})^{10,11}$ and body composition $(\mathrm{BC})^{12}$. In addition, results showed strong associations between regular exercise and better HRQOL scores and survival ${ }^{10}$, and higher muscle mass and better physical functioning and $\mathrm{QOL}^{12}$ in dialysis patients. Regardless of these findings, HRQOL is consistently shown to be lower in ESRD patients as compared with the general population ${ }^{6,8}$, showing the undesirable effects of ESRD in these patients. Thus, even though dialysis is a life-saving treatment, and despite continuous technical developments in dialysis therapy, the burden of kidney disease remains high.

Both these economic and social effects of ESRD stress out the need for interventions that can slow down the progression of CKD and its complications. The current approach for treatment of CKD in the out-patient clinic is mainly based on delaying or halting the progression of renal dysfunction, as well as cardiovascular and metabolic complications. This treatment often consists of blood pressure control, lipid-lowering therapy, dietary advice on salt and protein intake, as well as phosphate control and vitamin D treatment ${ }^{13}$. Additionally, it is well known that exercise on a regular basis is beneficial in relation with outcome in CKD patients ${ }^{14-16}$. The guideline for diagnostics and treatment for CKD patients by the Dutch federation of nephrology recommend PA as an intervention goal for CKD patients with mild to moderate loss of kidney function, to reduce the risk of progression of kidney failure and/or cardiovascular complications ${ }^{17}$. Also the 'K/DOQI Clinical Practice Guidelines for Cardiovascular Disease in Dialysis Patients', state that PA should be encouraged by nephrologist and dialysis staff to increase PA levels. Next to that, PA and physical functioning should be evaluated every six months ${ }^{18}$. Nevertheless, in the current nephrology practice not much attention is addressed to self-management with regard to $\mathrm{PA}^{14}$, despite the recommendations. So, not implementing stimulation of PA into routine 
patient care by nephrologists/dialysis staff, may contribute to low levels of PA and poor physical functioning ${ }^{14}$. Furthermore, low levels of PA and poor physical functioning are proven to affect HRQOL and survival ${ }^{14}$. All of this is already suggested since 1994, when the Life Options Rehabilitation Advisory Council (LORAC) promoted exercise in their renal rehabilitation report ${ }^{19}$. Still, PA programs are not overall implemented in the daily dialysis care, underscoring the need for awareness of this issue in the current renal care.

The lack regarding the promotion of PA is not only a pitfall of the current CKD care. On the one hand, making patients aware, and stimulating them to exercise, is a major advantage for successful rehabilitation of ESRD patients. On the other hand, high costs for PA programs make it difficult to keep patients exercise with the help of professionals. Therefore, one of the important concerns is the support of health insurance to make such programs easier accessible for patients, since ESRD is already a burden for the patient's economic status, due to loss of income and high costs of health care.

Ongoing research already focuses on the long term outcomes of PA programs for dialysisand transplantation patients and the cost-effectiveness of group rehabilitation. Still, not many interventional studies focus on the earlier stages of CKD. This gives us the opportunity to investigate the effects of PA on parameters such as HRQOL, in CKD patients who are not on dialysis yet. Next to that it would be of great importance to study if the start of dialysis can be delayed by slowing down the progression of CKD in the early stages by stimulating PA.

New technologies, such as activity trackers could facilitate reminders to stay physically active, which may be the future for stimulating PA in patients with chronic diseases. As a recent study already showed, multidimensional PA feedback using graphics and visualizations may be very motivational, and support behavioral changes in patients with increased risk of chronic diseases ${ }^{20}$.

Knowing that every postponement of starting dialysis, but also the prevention of comorbid diseases is cost effective, and as this thesis showed, what the importance is of PA in ESRD patients, and in line with that its relations with $\mathrm{HRQOL}$, above mentioned interventions may provide beneficial outcomes of PA in CKD patient care, and a decline in the economic burden of kidney disease on the long term. This makes it very important to support research concerning PA, BC and HRQOL in the early CKD stages, but also during the dialysis phase. 


\section{REFERENCES}

1. Fresenius Medical Care. ESRD Patients in 2013: A Global Perspective. 2013 [cited $201603-$ 02-2016]; Available from: http://www.vision-fmc.com/files/ESRD_Patients_in_2013.pdf.

2. Lozano R, Naghavi M, Foreman K, Lim S, Shibuya K, Aboyans V, et al. Global and regional mortality from 235 causes of death for 20 age groups in 1990 and 2010: a systematic analysis for the Global Burden of Disease Study 2010. Lancet 2012;380:2095-2128.

3. Khan IH, Catto GR, Edward N, Fleming LW, Henderson IS, MacLeod AM. Influence of coexisting disease on survival on renal-replacement therapy. Lancet 1993;341:415-418.

4. Gomez AT, Kiberd BA, Royston JP, Alfaadhel T, Soroka SD, Hemmelgarn BR, et al. Comorbidity burden at dialysis initiation and mortality: A cohort study. Can J Kidney Health Dis 2015;2:34.

5. US Renal Data System. USRDS 2013 Annual Data Report. Cost of ESRD. . 2013 12-04-2016]; Available from: http://www.usrds.org/2013/pdf/v2_ch11_13.pdf.

6. Mazairac AH, de Wit GA, Penne EL, van der Weerd NC, de Jong B, Grooteman MP, et al. Changes in quality of life over time--Dutch haemodialysis patients and general population compared. Nephrol Dial Transplant 2011;26:1984-1989.

7. Walters BA, Hays RD, Spritzer KL, Fridman M,Carter WB. Health-related quality of life, depressive symptoms, anemia, and malnutrition at hemodialysis initiation. Am J Kidney Dis 2002;40:1185-1194.

8. DeOreo PB. Hemodialysis patient-assessed functional health status predicts continued survival, hospitalization, and dialysis-attendance compliance. Am J Kidney Dis 1997;30:204-212.

9. Broers NJ, Usvyat LA, Kooman JP, van der Sande FM, Lacson E, Jr., Kotanko P, et al. Quality of Life in Dialysis Patients: A Retrospective Cohort Study. Nephron 2015;130:105-112.

10. Tentori F, Elder SJ, Thumma J, Pisoni RL, Bommer J, Fissell RB, et al. Physical exercise among participants in the Dialysis Outcomes and Practice Patterns Study (DOPPS): correlates and associated outcomes. Nephrol Dial Transplant 2010;25:3050-3062.

11. Lopes AA, Lantz B, Morgenstern H, Wang M, Bieber BA, Gillespie BW, et al. Associations of self-reported physical activity types and levels with quality of life, depression symptoms, and mortality in hemodialysis patients: the DOPPS. Clin J Am Soc Nephrol 2014;9:1702-1712.

12. Martinson M, Ikizler TA, Morrell G, Wei G, Almeida N, Marcus RL, et al. Associations of body size and body composition with functional ability and quality of life in hemodialysis patients. Clin J Am Soc Nephrol 2014;9:1082-1090.

13. Jha V, Garcia-Garcia G, Iseki K, Li Z, Naicker S, Plattner B, et al. Chronic kidney disease: global dimension and perspectives. Lancet 2013;382:260-272.

14. Painter P,Roshanravan B. The association of physical activity and physical function with clinical outcomes in adults with chronic kidney disease. Curr Opin Nephrol Hypertens 2013;22:615-623.

15. Johansen KL,Painter P. Exercise in individuals with CKD. Am J Kidney Dis 2012;59:126-134.

16. Painter P. Physical functioning in end-stage renal disease patients: update 2005. Hemodial Int 2005;9:218-235. 
17. Nederlandse federatie voor Nefrologie. Richtlijn Diagnostiek en Behandeling van Patiënten met Chronische Nierschade. 2015 20-06-2016]; Available from: http://www.nefro.nl/uploads/_I/Mi/_IMi1CJhguCZucn976lhyA/Concept-NfN-richtlijnDiagnostiek-en Behandeling-chronische-nierschade-2015.pdf.

18. K/DOQI clinical practice guidelines for cardiovascular disease in dialysis patients. Am J Kidney Dis 2005;45:S1-153.

19. Life Options Rehabilitation Advisory Council: Renal Rehabilitation: Bridging the Barriers. Madison, WI:Medical Education Institute 1994;

20. Western MJ, Peacock OJ, Stathi A,Thompson D. The understanding and interpretation of innovative technology-enabled multidimensional physical activity feedback in patients at risk of future chronic disease. PLoS One 2015;10:e0126156. 



\section{DANKWOORD}




\section{DANKWOORD}

Bij het tot stand komen van dit proefschrift zijn er velen die ik moet bedanken voor hun bijdrage. Zoveel zelfs dat ik vast mensen ga vergeten, sorry daarvoor.

Ik begin met het bedanken van alle lieve patiënten die deelgenomen hebben aan al onze studies. Bedankt dat jullie telkens weer vol enthousiasme en geduld al onze metingen hebben ondergaan. Jullie levensverhalen, dankbaarheid, maar vooral ook positiviteit hebben mij enorm geïnspireerd.

Professor dr. Kooman, beste Jeroen, ik ben ontzettend dankbaar en trots dat ik in 2011 de kans kreeg om als promovenda bij de nefrologie te starten. Ons eerste gesprek was motiverend, gezellig, maar ik voelde me vooral heel welkom. Dat is in de voorbijgaande jaren nooit veranderd. Je weet als geen ander te motiveren en te enthousiasmeren en je deur staat altijd open. Ook je interesse en openheid op persoonlijk vlak maakt het werken met jou zeer aangenaam. Ik had geen betere promotor kunnen treffen. Bedankt voor je vertrouwen in mij.

Professor dr. Leunissen, beste Karel, ik moet beginnen met u alsnog gelijk te geven; de 4 jaar zijn inderdaad sneller voorbij gegaan dan ik had gedacht (helaas). Bedankt voor deze mooie kans en het vertrouwen.

Dr. Van der Sande, beste Frank, bedankt voor de fijne samenwerking. Ook bij jou kon ik met elk verzoek binnenwandelen. Je stiptheid en oog voor detail hebben me geholpen om de puntjes op de i te zetten.

Leden van de beoordelingscommissie, voorzitter prof. dr. Bekers, prof. dr. Van Loon, prof. dr. Gaillard (UMCG), prof. dr. Ter Wee (VUmc) en dr. Plasqui, hartelijk dank voor jullie tijd en moeite welke jullie genomen hebben bij het beoordelen van mijn proefschrift.

Lieve Nanda (Diederen), bedankt dat je zo een fijne collega en vriendin bent. Vanaf je eerste dag stond je voor me klaar en hielp je uit waar nodig. Ik kijk met veel plezier terug op hilarische, gezellige en zeker ook hele mooie momenten samen. Onze vele roadtripjes zal ik nooit vergeten, jij (én het busje) vast en zeker ook niet. ;) Het betekent dan ook veel voor me dat je straks als mijn paranimf naast me staat als afsluiting van mijn promotietraject.

Beste Remy (Martens), als mijn collega, kamergenoot en paranimf wil ik je bedanken voor al je hulp, maar zeker ook alle gezelligheid de afgelopen jaren. Ik kan je niet genoeg bedanken voor je statistisch significante bijdrage aan mijn analyses $(p<0.001)$. Ook onze vele reisjes naar congressen en symposia staan in mijn geheugen gegrift, maar gelukkig hebben we ook de foto's nog! 
Beste Tom (Cornelis), bedankt voor de samenwerking op de dialyseafdeling. Ik heb dit als prettig ervaren en wie weet komen we elkaar in de toekomst nog een keer tegen bij het doen van onderzoek.

Piet (Claessens) en Thijs (de Graaf), heel erg bedankt voor het oplossen van alle technische problemen. Jullie stonden op elk moment met oplossingen klaar en zonder jullie had ik beslist aanzienlijk minder data gehad om mee te werken.

Collega's van de dialyseafdeling, Gertie (Brepoels), hartelijk dank voor jullie hulp bij het plannen en mogelijk maken van onze onderzoeken. Bryan (Franssen), heel erg bedankt dat ik af en toe (best wel vaak) gebruik mocht maken van je computervaardigheden.

Alle behulpzame collega's van de externe centra die mee hebben gewerkt aan het mogelijk maken van de 'Transitie' studie. Marc (Hermans), Ans (Verstappen), Suzan (Jeuken) en Ellen (Goertz) van het Viecuri Ziekenhuis Venlo. Stijn (Konings) en Elise (Ponse) van het Catharina Ziekenhuis Eindhoven. Joris (Wirtz), Marieke (Emmen), Fatma (Unal) en Natasja (Bonaparte) van het Laurentius Ziekenhuis Roermond. Frank (Stifft) en Karen (op de Beek) van het Zuyderland Medisch Centrum Sittard. Tom (Dejagere) van het Jessa Ziekenhuis Hasselt. Daarnaast wil ik ook alle artsen en verpleegkundigen van deze centra bedanken die zo enthousiast hebben meegedacht om de studie zo goed mogelijk te laten verlopen. Bedankt voor jullie inzet, zonder jullie was dit niet gelukt.

Collega's bij de nefrologie, Maarten (Christiaans), Elizabeth (Litjens), Mariëlle (Gelens), Elly (van Duijnhoven), John (Dackus) en Philip (Ulrichts). Hartelijk dank voor jullie inzet en hulp bij alle lopende studies. Onderzoek doen is altijd het werk van velen en ook zonder jullie was het nooit gelukt.

Collega's van verpleegafdeling D5, en in het bijzonder Mildred en Simone, bedankt voor jullie hulp bij de transplantatie studie.

Lilian, Anke, Tiny, Etiënne, Marleen en Naomi, bedankt dat ik jullie met allerlei vragen mocht lastig vallen. Er was niets teveel moeite voor jullie.

Beste Loe (Donselaar), Steven (Meex), Vincent (Kleijnen), Alma (Mingels) en Eline (Cardinaels) van het centraal diagnostisch laboratorium. Joris (Vanderlocht) en Marjolijn (van Tuijl) van laboratorium weefseltypering. Claudia (Bosma) en collega's van de Biobank Maastricht. Heel erg bedankt voor al jullie hulp met de verzamelde bloedmonsters. 
Many thanks to Fresenius Medical Care for supporting our research, we would not be able to do as much research as needed without your support. Also Prof. Canaud, Dr. Wabel and others, thank you for your support, great insights and your valuable comments on my work.

Dear colleagues from the renal research institute (RRI), Dr. Peter Kotanko, Len (Usvyat), thank you for your hospitality and your help and expertise during my visit in 2012. I've had a wonderful time and was able to publish two great manuscripts with your help and support.

Mijn ouders, lieve papa en mama, jullie verdienen een bijzonder woord van dank. Ik sta hier omdat jullie altijd het beste uit mij hebben gehaald. Zonder jullie inzicht, vastberadenheid en geloof in mij had ik dit nooit bereikt. Ik wil jullie bedanken voor jullie onvoorwaardelijke liefde, steun en raad. Maar vooral bedankt dat ik de vrijheid heb gekregen om mijn eigen keuzes te maken. Jullie zijn de beste!

Broertje, lieve Roy, bedankt dat ik je grote zus mag zijn. Ik kan me voorstellen dat het niet altijd gemakkelijk is geweest om een grote zus te hebben die altijd gelijk heeft, ook als dat niet zo is. ;) Dat ook al jouw dromen mogen uitkomen.

Lieve vrienden, bedankt dat jullie zoveel interesse tonen in mijn werk. Maar vooral bedankt voor alle fijne tijd die ik met jullie mag doorbrengen. Mijn 'Maudjes', mede dankzij al jullie 'juffenverhalen' ben ik dankbaar voor mijn vak. Promoveren was soms zwaar, maar driftige kleuters en beginnende pubers onder controle houden lijkt me zoveel zwaarder. Aniek, Bjel, Denise, Eefje en Frederique, dit hele avontuur is zo'n 11 jaar geleden samen met jullie begonnen. Studeren aan de UM was niet half zo leuk geweest zonder jullie en ondanks dat we na ons afstuderen allemaal ons eigen pad gevolgd hebben zijn jullie nog steeds mijn vriendinnen. Eefs, bedankt voor alle nuttige 'Bandito'breaks, soms kon een koffietje en een babbeltje tot verhelderende oplossingen leiden. Ik wens jou ook heel veel succes met je naderende promotie, we drinken er snel weer een koffietje op!

Liefste Joey, lief, bedankt dat je nooit moppert als ik mijn werk (en soms de daarbij behorende frustraties) mee naar huis neem. Bedankt voor je hulp bij dit proefschrift, maar vooral bedankt dat je me laat zien dat er naast werk nog zoveel meer is. Ik hou van je. xo 



\section{CURRICULUM VITAE}




\section{CURRICULUM VITAE}

Natascha Juliana Hendrika Broers werd geboren op 2 december 1986 te Maastricht. In 2005 behaalde zij haar VWO diploma aan het Stella Maris College te Meerssen. Daarna begon zij aan de studie gezondheidswetenschappen aan de Universiteit van Maastricht, waar zij in 2009 haar BSc diploma behaalde met als afstudeerrichtingen 'Bioregulatie en Gezondheid' en 'Bewegingswetenschappen'. Hierop volgend startte zij, wederom aan de Universiteit Maastricht, aan de European Master of Metabolism and Nutrition waarvan zij in 2010 haar MSc diploma in 'Physical Activity and Health' ontving. Na haar afstuderen heeft zij kort als onderzoeksassistente bij 'De Maastricht Studie' gewerkt, waarna zij in 2011 startte als promovenda bij de vakgroep Interne Geneeskunde, onderafdeling Nefrologie. 



\section{LIST OF PUBLICATIONS}




\section{LIST OF PUBLICATIONS}

Mingels AMA, Cardinaels EPM, Broers NJH, van Sleeuwen A, Streng AS, van Dieijen-Visser MP, Jeroen P Kooman JP, Bekers O. Cardiac troponin T: smaller molecules in patients with end-stage renal disease than after onset of acute myocardial infarction. Clinical Chemistry, accepted for publication.

Broers NJH, Martens RJH, Cornelis T, van der Sande FM, Diederen NMP, Hermans MMH, Wirtz JJJM, Stifft F, Konings CJAM, Dejagere T, Canaud B, Wabel P, Leunissen KML, Kooman JP. Physical activity in end-stage renal disease patients, a study in CKD-5 non-dialysis and dialysis patients including the transition period. Submitted for publication.

Broers NJH, Usvyat LA, Kooman JP, van der Sande FM, Lacson E Jr, Kotanko P, Maddux FW. Quality of life in dialysis patients: a retrospective cohort study. Nephron. (2015) 130:105-12

Broers NJH, Cuijpers ACM, van der Sande FM, Leunissen KML, Kooman JP. The first year on haemodialysis: a critical transition. Clin Kidney J. (2015) 8:271-7

Broers NJH, Usvyat LA, Marcelli D, Bayh I, Scatizzi L, Canaud B, van der Sande FM, Kotanko P, MoissI U, Kooman JP; on behalf the MONitoring Dialysis Outcomes (MONDO) Consortium. Season affects body composition and estimation of fluid overload in haemodialysis patients: variations in body composition; a survey from the European MONDO database. Nephrol Dial Transplant. (2015) 30:676-81

Broers NJH, Martens RJH, Cornelis T, Diederen NMP, Wabel P, Sande van der FM, Leunissen KML, Kooman JP. Body composition in dialysis patients: a functional assessment of bioimpedance using different prediction models. J Ren Nutr. (2015) 25:121-8

Cornelis T, Broers NJH, Titulaer DCLM, Henskens YM, van Oerle R, van der Sande FM, Spronk HM, Vink H, Leunissen KM, ten Cate H, Kooman JP. Effects of ultrapure hemodialysis and low molecular weight heparin on the endothelial surface layer. Blood Purif. (2014) 38:203-210

Kooman JP, Broers NJH, Usvyat L, Thyssen S, van der Sande FM, Cornelis T, Levin NW, Leunissen KM, Kotanko P. Out of control: accelerated aging in uremia. Nephrol Dial Transplant (2013) 28: 48-54 
